\title{
Integrating stimulation practices with geo-mechanical properties in liquid-rich plays of Eagle Ford Shale
}

\author{
Ahmed Yusuf
}

Follow this and additional works at: https://researchrepository.wvu.edu/etd

\section{Recommended Citation}

Yusuf, Ahmed, "Integrating stimulation practices with geo-mechanical properties in liquid-rich plays of Eagle Ford Shale" (2016). Graduate Theses, Dissertations, and Problem Reports. 7019.

https://researchrepository.wvu.edu/etd/7019

This Dissertation is protected by copyright and/or related rights. It has been brought to you by the The Research Repository @ WVU with permission from the rights-holder(s). You are free to use this Dissertation in any way that is permitted by the copyright and related rights legislation that applies to your use. For other uses you must obtain permission from the rights-holder(s) directly, unless additional rights are indicated by a Creative Commons license in the record and/ or on the work itself. This Dissertation has been accepted for inclusion in WVU Graduate Theses, Dissertations, and Problem Reports collection by an authorized administrator of The Research Repository @ WVU.

For more information, please contact researchrepository@mail.wvu.edu. 


\title{
INTEGRATING STIMULATION PRACTICES WITH GEO- MECHANICAL PROPERTIES IN LIQUID-RICH PLAYS OF EAGLE FORD SHALE
}

\author{
Ahmed Yusuf \\ Dissertation submitted to the \\ College of Engineering and Mineral Resources \\ at West Virginia University \\ in partial fulfilment of the requirements for the degree of \\ Doctor of Philosophy in \\ Petroleum and Natural Gas Engineering \\ H. Ilkin Bilgesu, Ph.D., Chair \\ Samuel Ameri, M.S. \\ Kashy Aminian, Ph.D. \\ Timothy Carr, Ph.D. \\ Brain Anderson, Ph.D. \\ West Virginia University \\ Petroleum \& Natural Gas Engineering \\ Morgantown, West Virginia \\ 2016
}

Keywords: Hydraulic fracture, reservoir modeling, Eagle Ford Shale, Well spacing

Copyright 2016 Ahmed Yusuf 


\begin{abstract}
Eagle Ford Frac Modeling: Integrating Proppant Transport with Geomechanical Properties for Long-Term Results in Liquids-Rich Plays
\end{abstract}

Ahmed Yusuf

Many of the techniques for hydraulically fracturing design were attempted in the liquidrich Eagle Ford developments. This study shows why different results were observed due to the variation of geomechanical stresses of the rock across a play and related reservoir properties. An optimum treatment for a liquids-rich objective is much different than that for a gas shale due primarily to the multiphase flow and higher viscosities encountered.

This study presents a new treatment workflow for liquids-rich window of Eagle Ford Shale. Review and integration of data from multiple sets across the play are used as input to a 3D hydraulic fracture simulator to model key fracture parameters which control production enhancement. These results are then used within a production analysis and forecast, well optimization, and economic model to compare treatment designs with the best placement of proppant to deliver both high initial production and long term ultimate recoveries.

A key focus for this workflow is to maximize proppant transport to achieve a continuous - optimum conductive - fracture half length. Often, due to the complexity of unconventional deposition, it is difficult to maintain complete connectivity of a proppant pack back to the wellbore. As a result, much of the potential of the fracture network is lost. Understanding the interaction of a hydraulic fracture and the rock fabric helps with designing this behavior to achieve the best results. These results are used to determine optimum well spacing to effectively develop within a selected reservoir acreage.

Currently, numerous wells exist with over two years of production history in much of the Eagle Ford shale formation. Results from this study are used to compare values from field production to demonstrate the importance of employing a diligent workflow in integrating reservoir and operational parameters to the fracture design. A proper understanding and application of hydraulic fracturing modeling is achieved using the methodology presented in this study. 


\section{ACKNOWLEDGEMENT}

This dissertation was initiated by Dr. H. Ilkin Bilgesu, to integrate proppant transport with geomechanical properties for long term result in liquid rich plays. To fully understand this project, some technical knowledge of unconventional reservoir modeling is helpful.

During the project, I have been very fortunate to have Dr. Bilgesu as my adviser and committee chair. I appreciate his guidance, where the entire aspect of Petroleum Engineering is included.

I am very grateful to Prof. Samuel Ameri for his help and encouragement during my study at WVU. I would like to thank Dr. Aminian, Dr. Carr, and Dr. Anderson for serving as committee members.

I would also like to mention Beverly Matheny, our Administrative Assistant, for her help and support during this research. 


\section{TABLE OF CONTENTS}

ABSTRACT

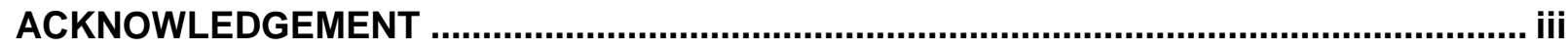

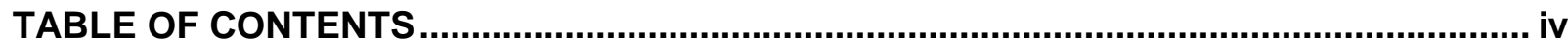

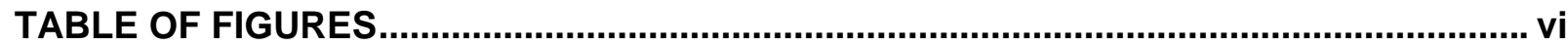

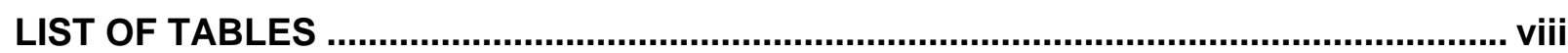

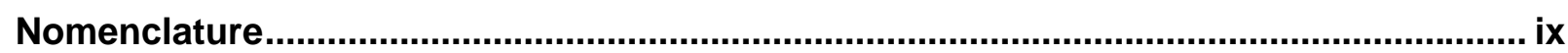

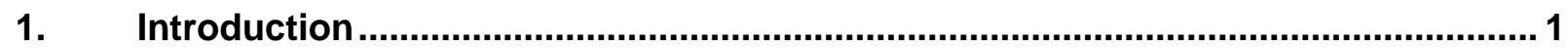

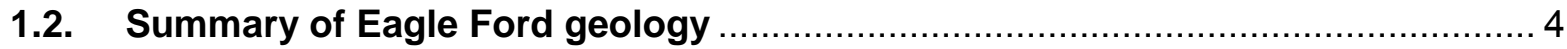

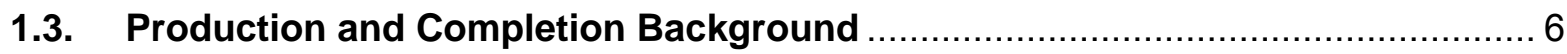

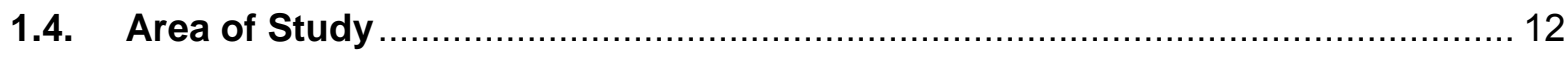

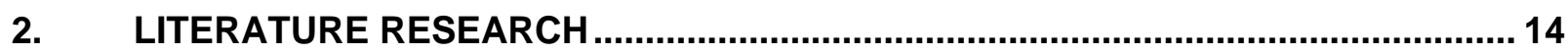

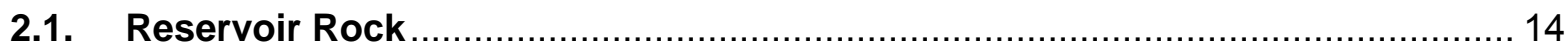

2.2. Rock and Reservoir Properties of Eagle Ford ……...................................... 15

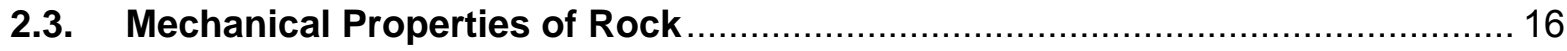

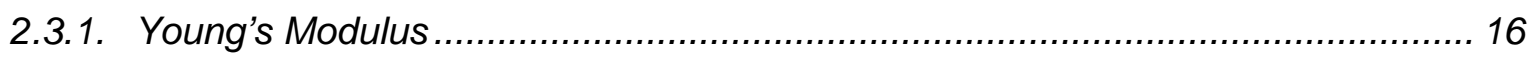

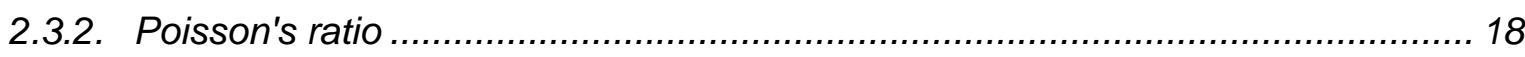

2.3.3. Three Principle Stresses ...................................................................... 18

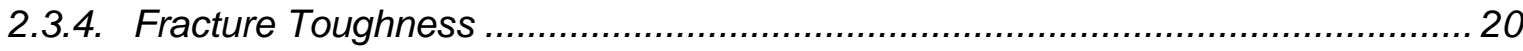

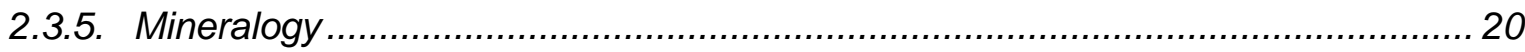

2.4. Eagle Ford Shale Hydraulic Fracturing Treatment Techniques....................... 23

2.4.1. Surface Area Fracture Treatment .............................................................. 24

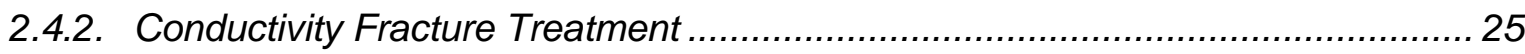

2.4.3. Hybrid Fracture Treatment ..................................................................... 26

2.5. Assessment of Eagle Ford Shale Reservoir Properties …........................... 27

2.6. Fluid Behavior in the Eagle Ford Shale

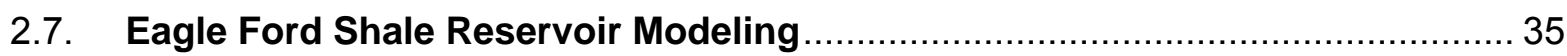

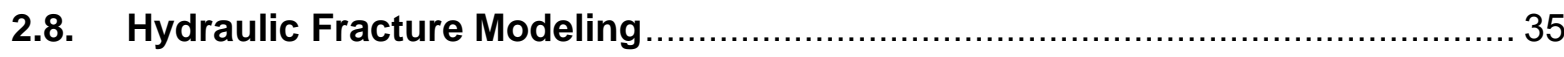

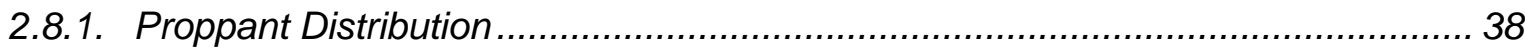

2.8.2. Uniform Proppant Distribution ................................................................... 40

2.8.3. Dominant Fracture Proppant Distribution ..................................................... 40

2.8.4. User Specified Proppant Distribution ............................................................. 40

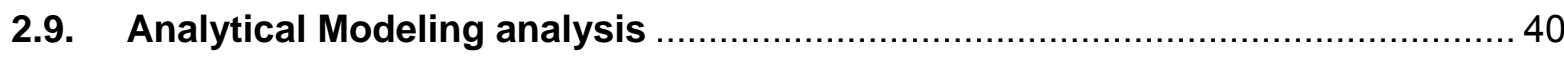

2.9.1. Horizontal Multi-stage Enhanced Fracture Model ........................................ 42

2.10. Numerical Model Analysis ........................................................................... 43

2.10.1. Reservoir Description ............................................................................... 44

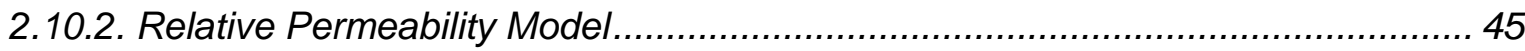


2.11. Previous Work Done With Eagle Ford Shale ........................................ 46

2.12. Eagle Ford Shale Treatment Design Procedure ...................................... 49

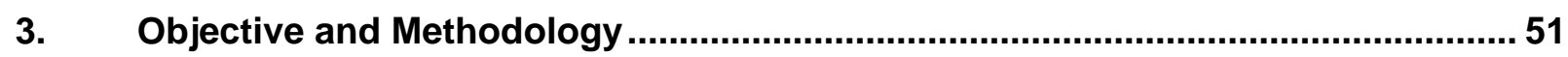

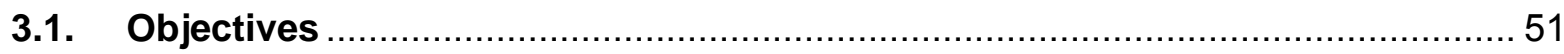

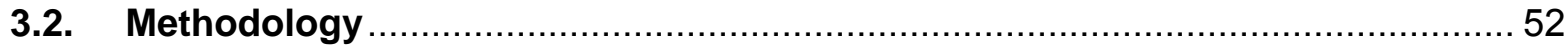

3.2.1 First Generation Stimulation Treatment Design (Base Model) ........................... 53

3.2.2 Parametric Studies ............................................................................ 62

3.2.3 Second Generation Stimulation Design: Optimization ..................................... 63

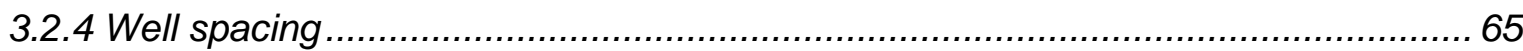

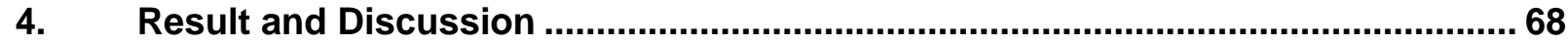

4.1. Base Model Stimulation Treatment Design (First Generation Treatment Design)

4.1.1. Impact of Fluid System and Proppant on Fracture Properties.......................... 68

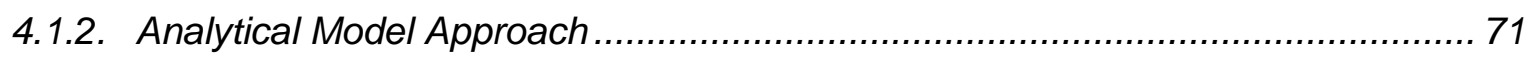

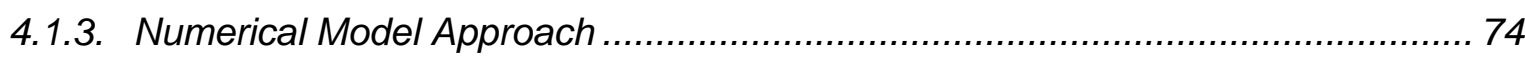

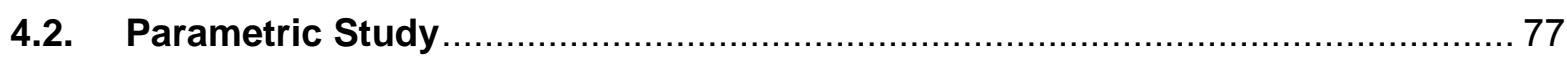

4.2.1. Hydraulic Fracture Treatment Design................................................ 77

4.2.2. Reservoir Simulation .......................................................................... 81

4.3. Second Generation Stimulation Treatment Design (Optimization) .................. 88

4.3.1. Impact of Fluid system and Proppant into Fracture Properties.................. 90

4.3.2. Eagle Ford Field Data Analysis .................................................... 95

4.3.3. Completion and Production Analysis............................................. 98

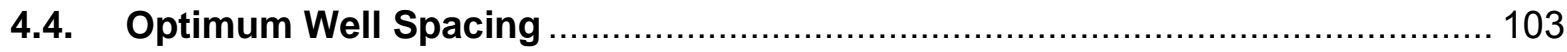

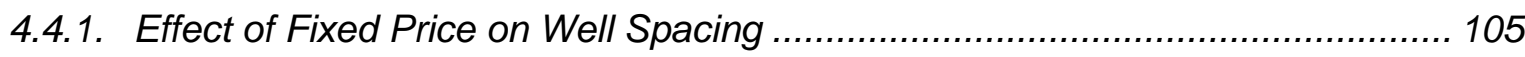

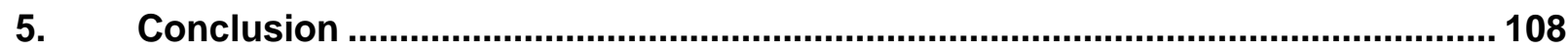

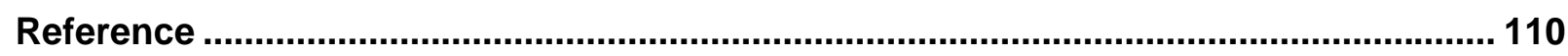

Appendix A: A Discrete Fracture Network Model....................................................... 115

Appendix B: Analytical Method ............................................................................ 119 


\section{TABLE OF FIGURES}

Figure 1: Eagle Ford shale play map (Energy Information Administration and Drillinginfo, Inc.)

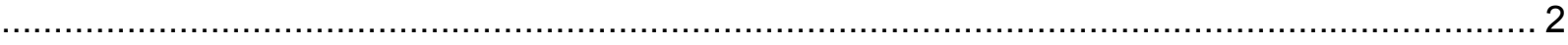

Figure 2: Structural and tectonic features (Hertz, et al, 2011) …................................... 5

Figure 3: Initial GOR ratios of Eagle Ford wells-January 2000 - June 2014 (EIA and drilling

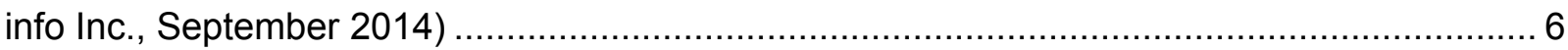

Figure 4: Eagle Ford drilling permits issued (Railroad Commission of Texas) ……................. 7

Figure 5: Life cycle of unconventional plays (IHS Energy Eagle Ford Regional Play

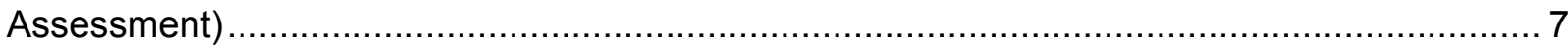

Figure 6: Counties with Production from Eagle Ford Shale (Data Source: IHS Energy) ........... 8

Figure 7: Average First Year oil production (BBLS) quartile (Data Source: IHS Energy) .......... 9

Figure 8: Top 25\% wells and Bottom 25\% wells (Data Source: IHS Energy) ......................... 10

Figure 9: Area of Study- La Salle County (Drilling info) ................................................... 12

Figure 10: Relative abundance of major sediment rocks (Schlumberger 2007) ................... 15

Figure 11: Rock mechanical Properties of Well \#1 ....................................................... 16

Figure 12: The Effect of YM on Fracture Length (well \#1 log data) ……........................... 17

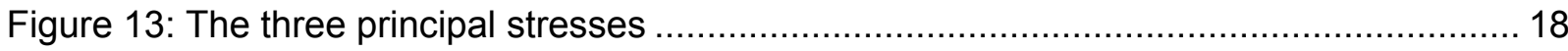

Figure 14: A cross plot of Young's Module \& Poisson's Ratio showing brittleness percentage increase to the southwest corner of the plot (Rickman et al. 2008)................................... 22

Figure 15: Rate, fluid, and proppant concentration selection based on brittleness and ductility.

(Adopted and modified from Chong et al, 2010)........................................................ 22

Figure 16: Seven offset wells Reservoir thickness (ft.), Upper \& Lower (Organic) Eagle Ford 28

Figure 17: Seven offset wells TOC (\%.), Upper \& Lower (Organic) Eagle Ford ....................... 29

Figure 18: Seven offset wells Porosity (\%), Upper \& Lower (Organic) Eagle Ford ................. 29

Figure 19: Well Log Data from Eagle Ford Shale (Driskill, et al 2012) .................................. 30

Figure 20: Maturity variation within the Eagle Ford (Wan, el at 2013)................................ 31

Figure 21: Hydrocarbon Generation Fundamentals and recovery Impact (Wan, el at 2013) .. 32

Figure 22: Three-Dimensional Fracture Geometry (Meyers \& Associate 2014) ..................... 35

Figure 23: Warren and Root (1963) Idealization of the heterogeneous porous media (Meyers,

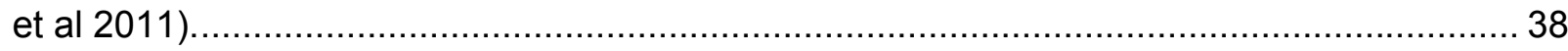

Figure 24: Proppant transport scenarios (Cipolla et al. 2008) ............................................. 39

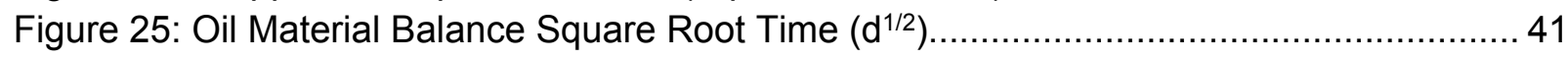

Figure 26: Enhanced Hydraulic fracture model (Stalgorova, et al 2012)............................ 43

Figure 27: Cartesian grid represented by grid blocs and spacing (CMG, Imex 2015)............. 44

Figure 28: Relative permeability curve (CMG, Imex 2015)............................................... 45

Figure 29: Proppant embedment simulation for various YM vs. closure stress (Cipolla et al.

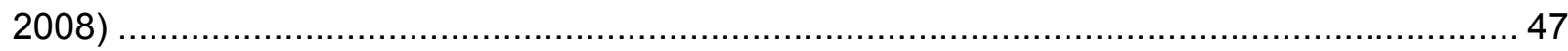

Figure 30: Hydraulic Fracture treatment design procedure based rock brittleness ................ 49

Figure 31: Well \# 1 Micro-Seismic Fracture Geometry for all Stage ....................................... 55

Figure 32: Well \# 1 Lateral side view for all Stage ……….............................................. 56

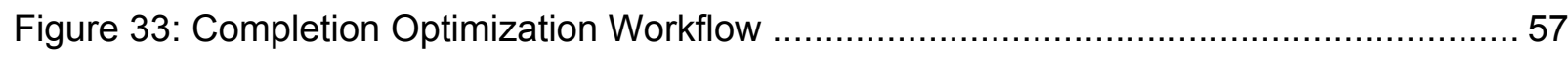

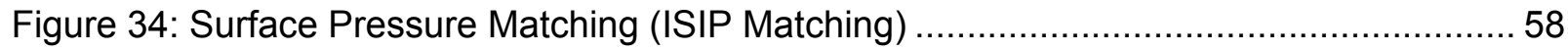

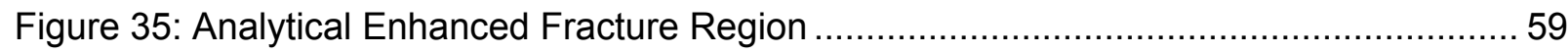

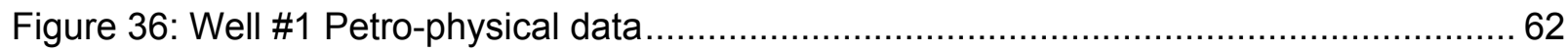

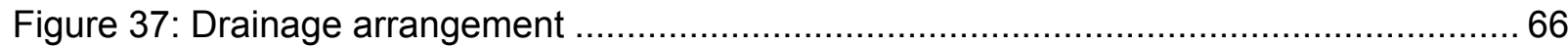




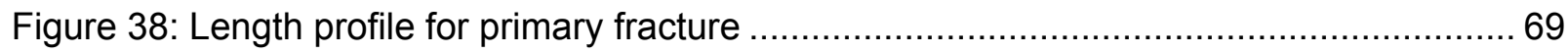

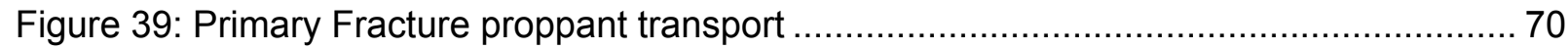

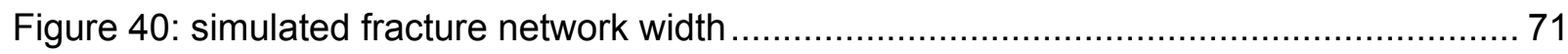

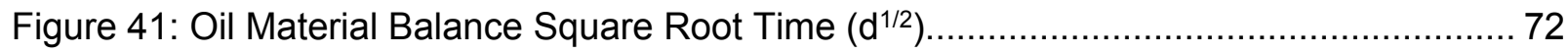

Figure 42: Base Model Analytical Pressure match ....................................................... 73

Figure 43: Base model for oil production forecasting .............................................. 74

Figure 44: Base case Cumulative Oil Forecast and history Match .................................... 75

Figure 45: Base Case Cumulative Gas Forecast and history Match ............................... 76

Figure 46: Relationship between treatment volume and fracture geometry ....................... 78

Figure 47: Effect of Aspect ratio on fracture length ................................................. 78

Figure 48: Discrete Fracture Network with different Aspect ratio .................................... 79

Figure 49: Sensitivity analysis for PAD volume selection ........................................ 80

Figure 50: Effect of Aspect ratio on Fracture conductivity ............................................ 81

Figure 51: Relationship between Fracture Half-length and Cumulative Oil .......................... 82

Figure 52: Relationship between Fracture Permeability and Cumulative Oil........................ 83

Figure 53: Sensitivity analysis of Cumulative Oil ..................................................... 83

Figure 54: Sensitivity analysis of Cumulative Gas....................................................... 84

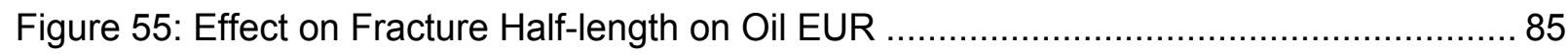

Figure 56: Effect on Fracture Half-length on Gas EUR ............................................ 86

Figure 57: Effect on Fracture Permeability on Cumulative Oil......................................... 87

Figure 58: Effect on Fracture Permeability on Cumulative Gas ..................................... 87

Figure 59: Brindell hardness number of various shale reservoir in North America................. 88

Figure 60: Well \#1 and adjacent well Brindell hardness value ......................................... 89

Figure 61: Effect of Fluid Viscosity on Penetration and conductivity ............................... 91

Figure 62: Effect of proppant concentration on proppant transport and penetration ............. 91

Figure 63: Second generation cumulative oil and history match ...................................... 93

Figure 64: Second generation cumulative gas and history match ................................... 93

Figure 65: Cumulative gas production with First and Second generation designs ................ 94

Figure 66: Cumulative oil production with First and Second generation designs ................... 94

Figure 67: Effect on fluid and proppant volume into Cumulative Oil................................... 99

Figure 68: First Generation and Second Generation Production comparison ..................... 100

Figure 69: Effect of 100 mesh ratio in cumulative oil production ..................................... 101

Figure 70: First and Second generation average cumulative oil (bbl. /stage) comparison .... 102

Figure 71: Number of wells per section vs cumulative oil production .............................. 104

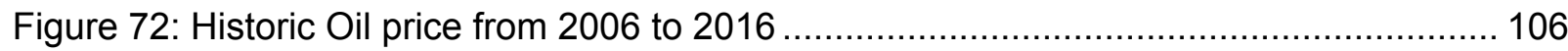




\section{LIST OF TABLES}

Table 1: Summary of first year production in Eagle Ford Shale (Data Source: IHS Energy) .. 10 Table 2: Summary of first year production in Eagle Ford Shale by County (Data source: IHS

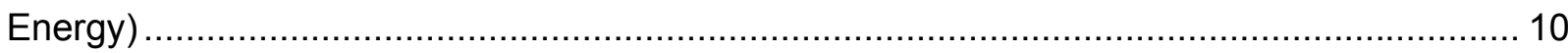

Table 3: Summary of Treatment Data in Eagle Ford Shale (Data source: IHS Energy)......... 11 Table 4: Summary of Treatment Data in Eagle Ford Shale by County (Data source: IHS Energy) .......................................................................................................... 11

Table 5: Ranges of Young's Module for different rocks (Meyers \& Associate 2014)............. 17

Table 6: Fracture Toughness Ranges (Meyers \& Associate 2014) .................................. 20

Table 7: Minerals identified in the Eagle Ford Shale (Sondhi, 2011).............................. 20

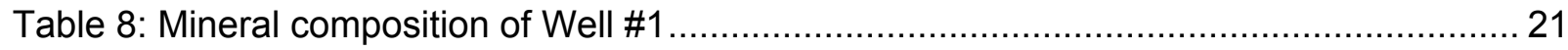

Table 9: Surface Area -Type of Fracture Treatment Design (Barree, et al. 2011)............... 25

Table 10: Conductivity-Type of Fracture Treatment Design (Barree, et al. 2011) ................ 26

Table 11: Hybrid-Type of Fracture Treatment Design (Barree, et al. 2011) ....................... 27

Table 12: Eagle Ford offset well Core Data............................................................. 30

Table 13: Molar composition of synthetic Eagle Ford oil (Orangi et al. 2011) ...................... 33

Table 14: Molar composition of synthetic Eagle Ford gas condensates (Orangi et al. 2011).. 33

Table 15: Black oil PVT properties for the Eagle Ford oil window (Chaudhary et al. 2011)... 34

Table 16: The Characteristics of discrete fracture network (DFN) (Meyers \& Associate 2014)

Table 17: Summary of Well 1 Casing Design ................................................................ 54

Table 18: Summary of Well 1 Stimulation Design ............................................................... 54

Table 19: Analytical Model Input Parameters .............................................................. 60

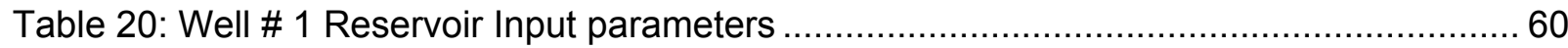

Table 21: Numerical Model Input parameters ............................................................. 61

Table 22: Comparison of First and Second generation treatment designs......................... 64

Table 23: Different scenario of number of wells per section.............................................. 65

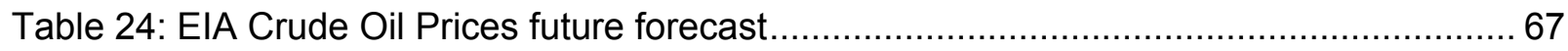

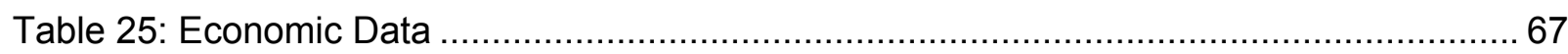

Table 26: Base Model Results for Hydraulic Fracturing Properties ................................. 69

Table 27: Summary of fracture treatment design and reservoir properties ......................... 73

Table 28: History match parameters (First generation) ................................................. 75

Table 29: Summary of the results of fracture treatment design and reservoir properties........ 76

Table 30: Impact of aspect ratio on fracture properties ............................................... 79

Table 31: Summary of result of sensitivity analysis .................................................... 85

Table 32: First and Second Generation Hydraulic Fracture Properties and production forecast

烈

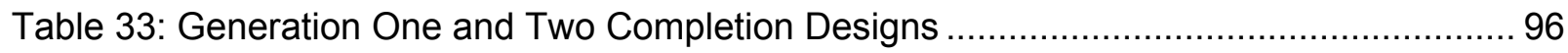

Table 34: Generation One Pump Schedule ................................................................. 96

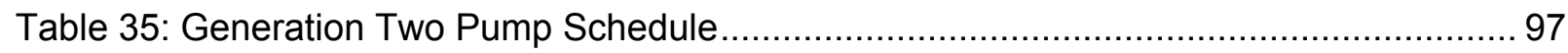

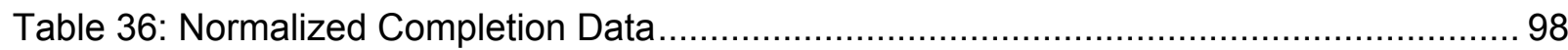

Table 37: After 180 days First Generation and Second Generation Production comparison 102

Table 38: Results of optimum well spacing with EIA future oil price forecast..................... 106

Table 39: Results of optimum well spacing with reduced EIA future oil price forecast......... 107

Table 40: Effect on oil price for well spacing ................................................................ 107 


\section{Nomenclature}

$a=$ Ellipse major axis

$A=$ Area, $\mathrm{ft}^{2}$.

$b=$ Ellipse minor axis

$C=$ Leakoff coefficient, $\mathrm{ft} / \mathrm{min}^{\wedge 1 / 2}$.

$C_{f D}=$ Dimensionless fracture conductivity

$d_{h}=$ Hydraulic diameter, in

$d_{i j}=$ Spacing between discrete fractures

$E=$ Young's modulus, Psi.

$E^{\prime}=$ Effective Young's modulus, psi.

$f=$ Darcy friction factor

$G(\theta)=$ Nolte $\mathrm{G}$ function, Fluid loss function

$h=$ Fracture height, $\mathrm{ft}$.

$H_{\zeta}=$ Characteristic fracture half - dimension

$H_{p}=$ Pay zone height, $\mathrm{ft}$

$H_{w}=$ Total wellbore height, $\mathrm{ft}$

$k^{\prime}=$ Consistency index

$L=$ Fracture half - length, $\mathrm{ft}$.

$n^{\prime}=$ Flow behavior index

$N=$ Total number of transverse fractures

$p=$ Pressure, $\mathrm{psi}$

$P=\mathrm{G}-$ function pressure, ISIP $-\mathrm{p}(\mathrm{t})$

$p_{i}=$ Reservoir pressure, $\mathrm{psi}$

$\mathrm{q}=$ Injection or flow rate, $\mathrm{bpm}$

$r=$ Radial coordinate

$S_{p}=$ Spurt loss coefficient

$t=$ Time, $\min$

$t_{p}=$ Pump time, $\min$

$v=$ velocity, $\mathrm{ft} / \mathrm{s}$

$V_{f}=$ Fracture volume, bbl 
$V_{l}=$ Fluid loss volume (no spurt loss)

$V_{s p}=$ Volume loss by spurt

$w=$ Fracture width, in

$\alpha_{a}=$ Leakoff area parameter

$\alpha_{L}=$ Length propagation parameter

$\alpha_{p}=$ Pressure parameter

$\alpha_{w}=$ Width propagation parameter

$\beta=$ Propagation parameter

$\gamma_{c}=\mathrm{G}$ function parameter

$\Delta p=$ Net fracture pressure, $\mathrm{p}_{f}-\sigma$

$\Delta x=$ Discrete fracture network spacing, $\mathrm{y}-\mathrm{z}$ plane

$\Delta y=$ Discrete fracture network spacing, $\mathrm{x}-\mathrm{z}$ plane

$\Delta z=$ Discrete fracture network spacing, $\mathrm{x}-\mathrm{y}$ plane

$\eta=$ Fracture efficiency

$\eta_{s}=$ Efficiency excluding spurt loss

$\lambda=$ Reservoir aspect ratio

$\theta=$ Dimensionless time, $\theta=t / t_{p}$

$\theta_{c}=$ Dimensionless closure time, $\theta_{c}=t_{c} / t_{p}$

$\lambda, \zeta=$ Integration indices

$\zeta=$ Dimensionless coordinate $\zeta=x / L$

$\tau=$ Time of fracture leakoff area creation

$\Phi=$ Fluid lose fracture

$\Phi_{i j}=3 \mathrm{D}$ influence factor

$\psi=$ Dimensionless momentum parameter, Stiffness multiplier

$\sigma=$ Minimum horizontal stress

$D=$ Dimensionless

$D F N=$ Discrete fracture network

$f=$ Fracture

$l=$ Fluid loss

$p=$ Pay zone, end of pumping 
$p f=$ Primary or dominant fracture

$\mathrm{m}=$ Slope from the flow equation using material balance time (oil)

$\mathrm{b}=$ Decline exponent

$\mathrm{q}_{\mathrm{i}}=$ initial rate

$\mathrm{t}=$ Time

$\mathbf{C}_{\mathrm{t}}=$ Total compressibility, $1 / \mathrm{psi}$

$\mathrm{h}=$ Net pay, $\mathrm{ft}$.

$\mathrm{k}=$ Permeability, $\mathrm{mD}$

$\mathrm{X}_{\mathrm{f}}=$ Fracture half-length, $\mathrm{ft}$.

$\mathrm{Y}_{\mathrm{e}}=$ Reservoir width, $\mathrm{ft}$.

$\mathrm{L}_{e}=$ Effective horizontal wellbore length, $\mathrm{ft}$.

$\mathrm{n}_{\mathrm{f}}=$ Number of fractures/stages

$\mathrm{p}_{\mathrm{j}}=$ Initial reservoir pressure, $\mathrm{psi}$

$p_{\mathrm{wf}}=$ Wellbore flowing pressure, $\mathrm{psi}$

$\mathrm{p}_{\text {wff }}=$ Sandface forecast pressure, $\mathrm{psi}$

$\mathrm{p}_{\mathrm{pi}}=$ Initial pseudo-pressure, $\mathrm{psi}$

$\mathrm{T}=$ Temperature, ${ }^{\circ} \mathrm{F}$

$\mathrm{S}=$ skin

$\mathrm{F}_{\mathrm{CD}}=$ Dimensionless fracture conductivity

$\mu=$ Viscosity of primary fluid (gas/oil/water), $c p$

$\varphi=$ porosity, $\%$ 


\section{Introduction}

The Eagle Ford Shale is a hydrocarbon producing formation located in South Texas. It has become extremely important due to its ability to produce high volumes of liquidrich hydrocarbons, producing more than other traditional shale plays. The types of hydrocarbon produced vary from dry gas, condensate, and oil making it an excellent liquid-rich play. The direction of phase change from oil to gas in the Eagle Ford shale proceeds from north to south and from shallow to deep, where oil is mainly present in the shallowest northern section. Figure 1 shows the oil (green), volatile/condensate (orange) and dry gas (red) producing windows. It is one of the most active shale plays in US, with horizontal drilling and multistage completion activities beginning in 2009 . The shale play extends over an area roughly 50 miles wide and 400 miles long with an average thickness of 250 feet. Although it is perceived that it is composed of shale, the Eagle Ford shale is a hydrocarbon-bearing, Late Cretaceous formation that was deposited in a marine continental shelf environment. It is made up of organic-rich calcareous- mud rock with mineralogy varying from $40-90 \%$ carbonate minerals, 15 $30 \%$ clay, and $15-20 \%$ quartz. The total-organic-carbon content (TOC) ranges from 2 to $12 \%$, thermal maturity ( $\%$ Ro) is between $0.45 \%$ and $1.4 \%$, API gravity varies between $28^{\circ}$ and $62^{\circ}$, porosity range is $8 \%$ to $12 \%$, and pressure gradient varies between 0.5 and 0.8+ (psi/ft.) (Za Za Energy, 2013). The high carbonate content and subsequently lower clay content make the Eagle Ford more brittle and easier to stimulate through hydraulic fracturing.

The foundation of Eagle Ford Rock makes this play convincingly different than other unconventional reservoirs such as Haynesville, Barnett, and Marcellus shale. 


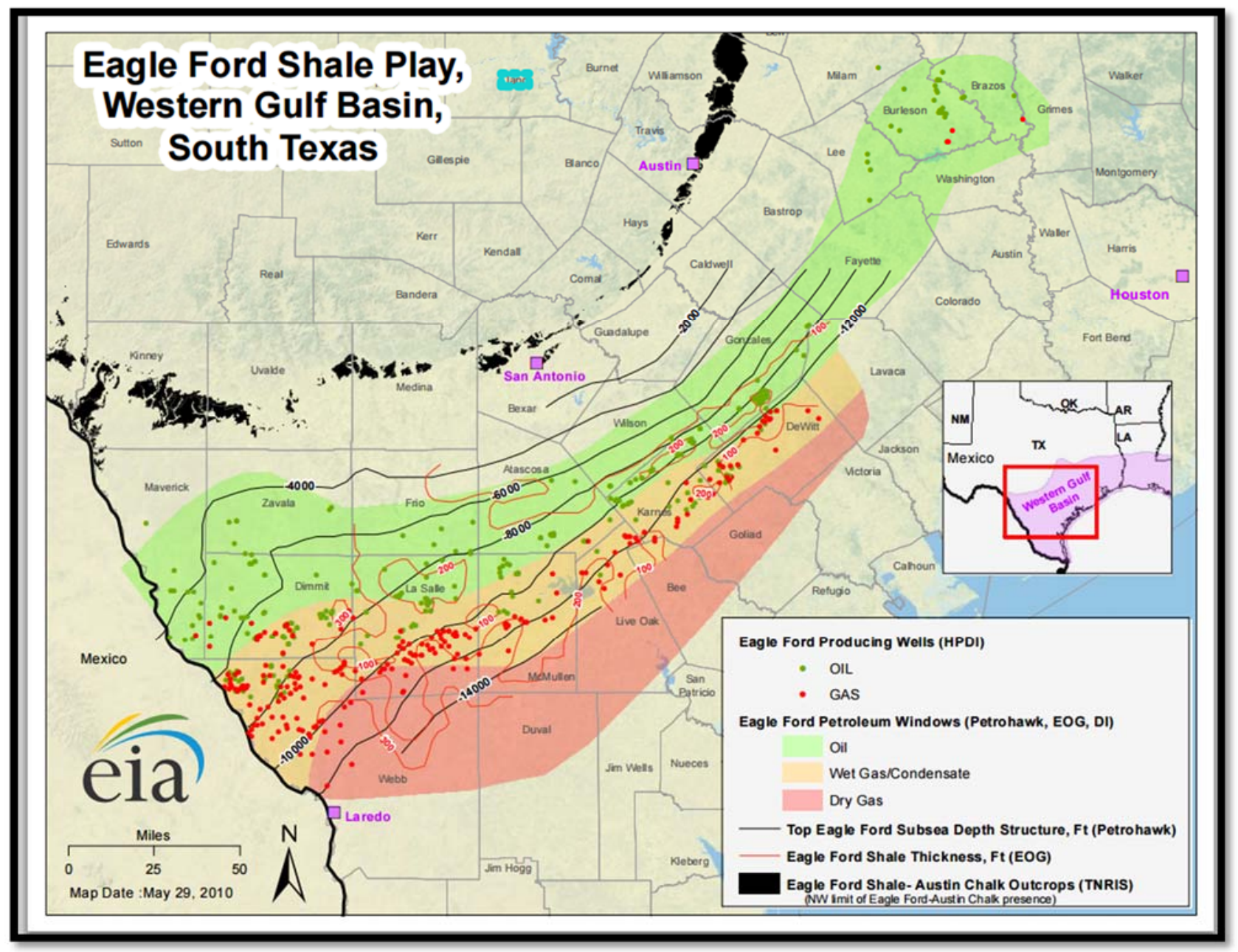

Figure 1: Eagle Ford shale play map (Energy Information Administration and Drillinginfo, Inc.)

In order to achieve an optimal development plan, it is important to evaluate the reserves and resources early on. McKinney et al. (2002) stated that suboptimal development plans can result in potential losses of more than half in regards to the asset value. The permeability in the Eagle Ford shale is normally tens or hundreds nanodarcies and can even yield long transient-flow periods, which complicate both production forecasting and reserves estimation. In addition to the extremely low matrix permeability, there are other factors that makes forecasting production from hydraulically fractured horizontal wells in Eagle Ford shale highly complicated including:

Multistage fracture treatments in Eagle Ford do not always generate conventional biwing planar, instead they generate a desecrate fracture network (DFN) that exhibits 
fracture fairways that are long and wide. Interaction between advancing hydraulic fracture and pre-existing natural fractures can generate complex fracture geometry. The history of drilling and completion in Eagle Ford is a relatively short period. Therefore, the effect of generated complex fracture geometry on production performance needs further studying and analysis.

An optimum fracture treatment for a liquids-rich objective is much different than that for a gas shale due primarily to the multiphase flow and higher viscosities encountered. Therefore, many techniques for hydraulically fracturing design were attempted early on in the liquid-rich Eagle Ford developments. Hydraulic fracturing continues to be the most important mechanism to produce hydrocarbons out of Eagle Ford formation. Different treatment method was used in Eagle Ford whether is a velocity based fluid system (slick water) or viscosity based fluid system (cross link). After an early success of gas shale stimulation design, some operators were willing to use slick water, injecting at high rate, large volume water fracture treatment with very low proppant concentration in the various shale plays including Eagle Ford Shale. The goal of this treatment was to contact large surface area of the reservoir. Considerable horizontal wells in Eagle Ford Shale wells were completed using high rate large volume slick water and the outcome had mixed result. On the other hand, crosslink fracture treatments were implemented where higher conductivity fractures were needed due to presence of clay swelling, and proppant embedment problems that can significantly reduce fracture conductivity. This method was not successful some area of Eagle Ford formation due to the variation of geomechanical stresses of the rock across a play and reservoir properties.

It is important to study and evaluate the regional or local characteristics of Eagle Ford formation before designing and implementing stimulation design. Log and core analysis, micro-seismic event, rock mineralogy analysis, Brinell hardness values, unpropped fracture conductivity, Diagnostic Fracture Injection Test (DFIT), fluid composition, and phase behavior can determine the guideline for selecting type of localized fracture treatment design. 


\subsection{Summary of Eagle Ford geology}

In conventional reservoirs, oil and gas form in shale rocks and then migrate upwards to sandstones and porous limestone where they become trapped.

However, in unconventional reservoirs such as Eagle Ford, significant amount of oil and gas remain in the shale. Without innovative and newer techniques, it's very difficult to recover great amount of hydrocarbon from the Shale formation.

The play was named Eagle Ford, a town in Dallas County where the shale outcrops. It trends across Texas from the Mexican Border in The South into East Texas, It is located in several counties stretching Giddings field in Brazos and Grimes counties down into the Maverick Basin in Maverick County [EIA]. Figure 1 shows some of the counties in which Eagle Ford Shale is located.

The Eagle Ford formation is divided into two parts, an upper and a lower part of Eagle Ford. The upper part is characterized by interlayered light and dark gray calcareous mud rock deposited during a regressive interval. The lower part which has higher organic content is mostly dark gray mudstone deposited during a transgressive interval. The lower Eagle Ford Shale consists of discontinuous low-permeability sandstone layers which are the primary target for drilling and completion. It is organically rich and produces more hydrocarbons than the upper Eagle Ford, which can be attributed to the fact that the oxygenated environment as the depth decrease (Bazan, L.W., et al 2010).

The Eagle Ford sits above the Buda Limestone and below the Austin Chalk (Parra et al., 2013). The Austin Chalk has been naturally fractured and hydrocarbons produced within it were the sourced Eagle Ford formation. The extent of the Eagle Ford formation and difference in its thickness and stratigraphy are in large part restricted by regional tectonic features. Figure 2 shows the structural and tectonic features that influenced the depositional extent, depth, and thickness of the productive and prospective regions of the Eagle Ford formation (Hertz, et al, 2011). 


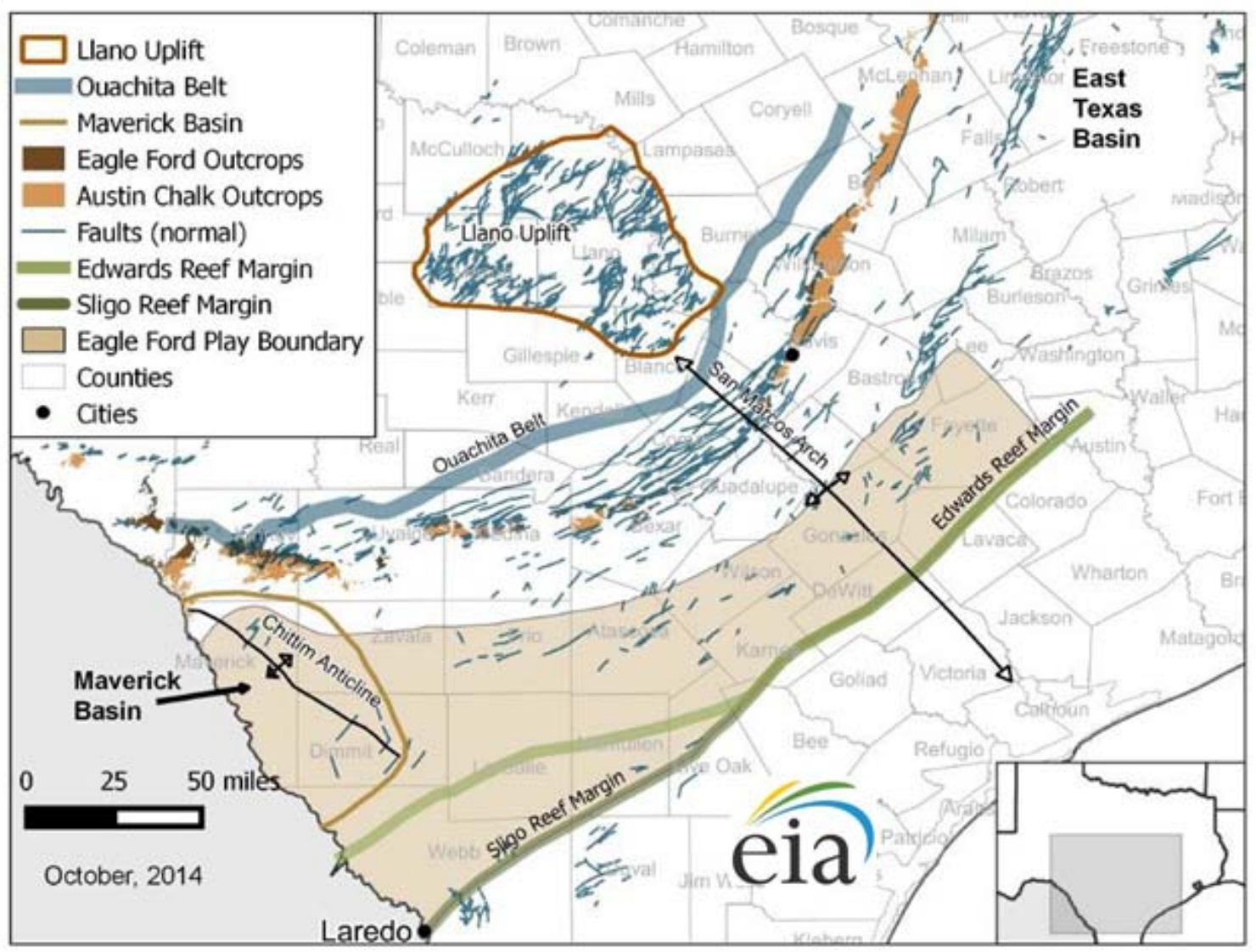

Figure 2: Structural and tectonic features (Hertz, et al, 2011)

The depth of the Eagle Ford reservoir determined the initial GOR content. Deeper wells to the southeast of the play have higher initial GORs and called gas window which produce greater share of natural gas, while the shallower wells to the northwest of the play have lower initial GORs called oil window and produce greater share of oil. In the eastern half of the play, the wells that intersect the reservoir between shallow and deep levels have initial GORs of $6000 \mathrm{cf} / \mathrm{bbl}$. and called volatile/condensate window and producing more oil relative to gas (Condon and Dyman, 2006). The western half of the play includes a wider depth distribution of wells, intersecting the formation from deeper to a shallow depth and has initial GORs of up to $6000 \mathrm{cf} / \mathrm{bbl}$. and producing more gas relative to oil.

Figure 3 shows production across the Eagle Ford based of initial Gas-to-Oil Ratios (GORs). Most wells now being drilled for hydrocarbons produce a mixture of oil and natural gas. Figure 1 in the Eagle Ford map defined the oil, condensate, and gas "windows" of the play 


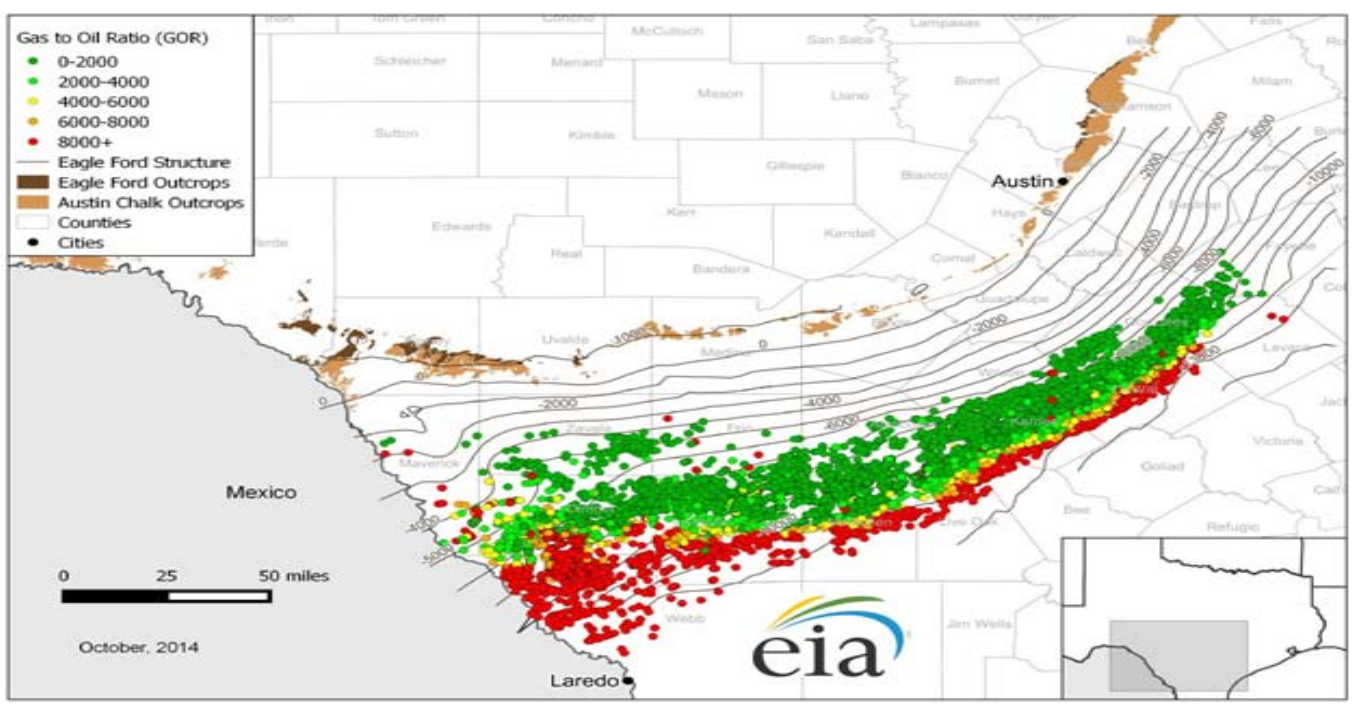

Figure 3: Initial GOR ratios of Eagle Ford wells-January 2000 - June 2014 (EIA and drilling info Inc., September 2014)

\subsection{Production and Completion Background}

In the fall of 2008, the discovery well was drilled in La Salle County, Texas. That first year, there were few wells that were permitted and drilled, and ultimately targeting the Eagle Ford Formation in South Texas (Drilling-Info, 2012). Today the Eagle Ford Shale has become one of the most drilled shale formations in the United States. Many operators have started investing, using both horizontal drilling and hydraulic fracturing techniques to reach and extract oil and gas from the shale formation. As shown in Figure 4, drilling permits in the Eagle Ford Shale began to drastically increase in 2010, which led to more than 1,000 permits being issued. By 2014, more than 5,000 permits were issued during the year. 


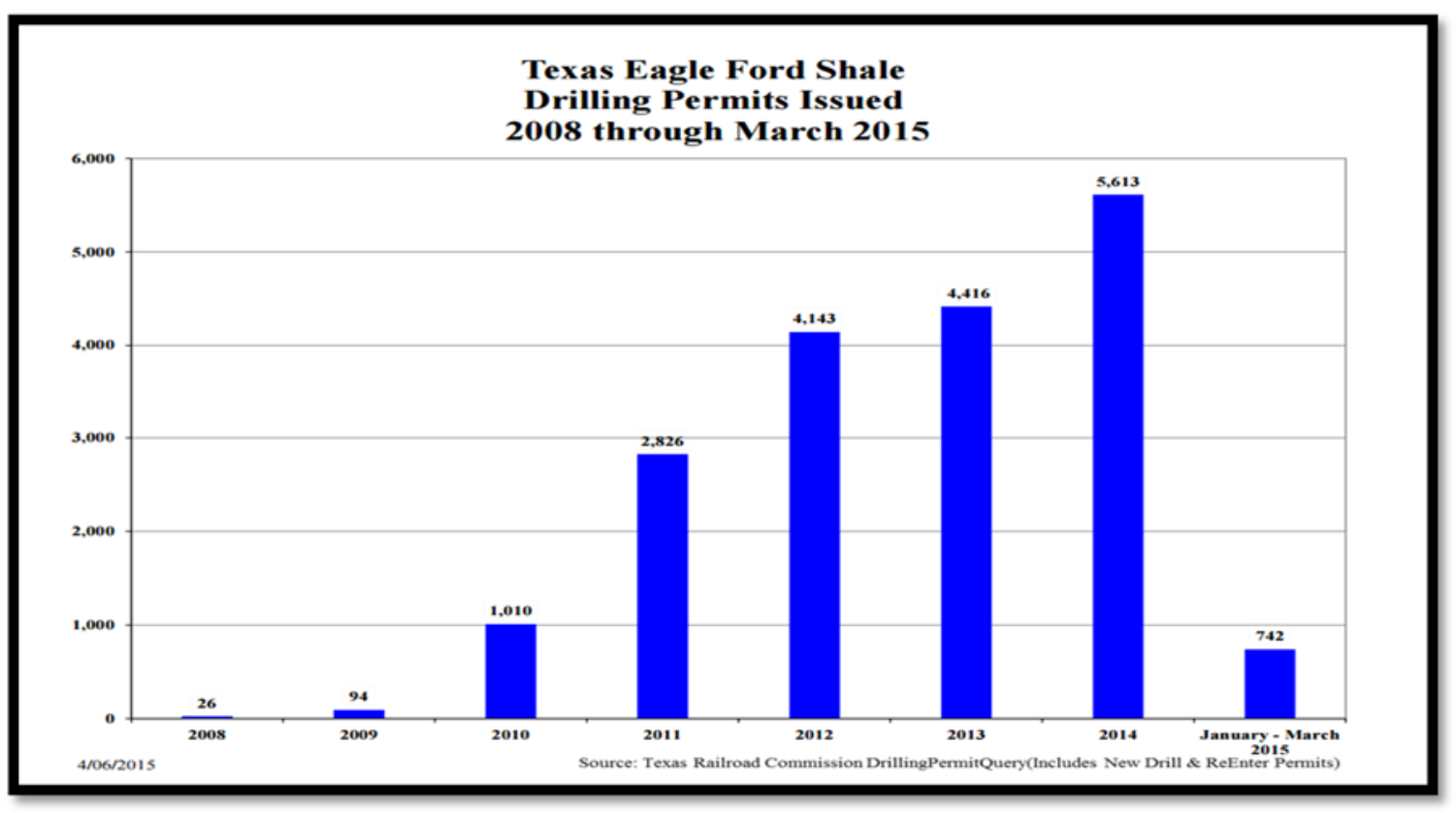

Figure 4: Eagle Ford drilling permits issued (Railroad Commission of Texas)

Currently, the Eagle Ford producing well count and over 11,000 ft. drilling activity are increasing rapidly compared to other shale plays. In summer of 2014, the oil and gas production from the Eagle Ford was 1.2 million barrels per day and 5 billion cubic feet per day, respectively. This amounted to a total of 2 million barrels of oil equivalent per day. In contrast with summer 2013 , gas production grew by $22 \%$, oil by $28 \%$, and the barrels of oil equivalent by $26 \%$ [2015 IHS Energy Eagle Ford Regional Play Assessment] Companies' target change to infill drilling hinted the play had entered the adulthood phase as indicated in Figure 5.

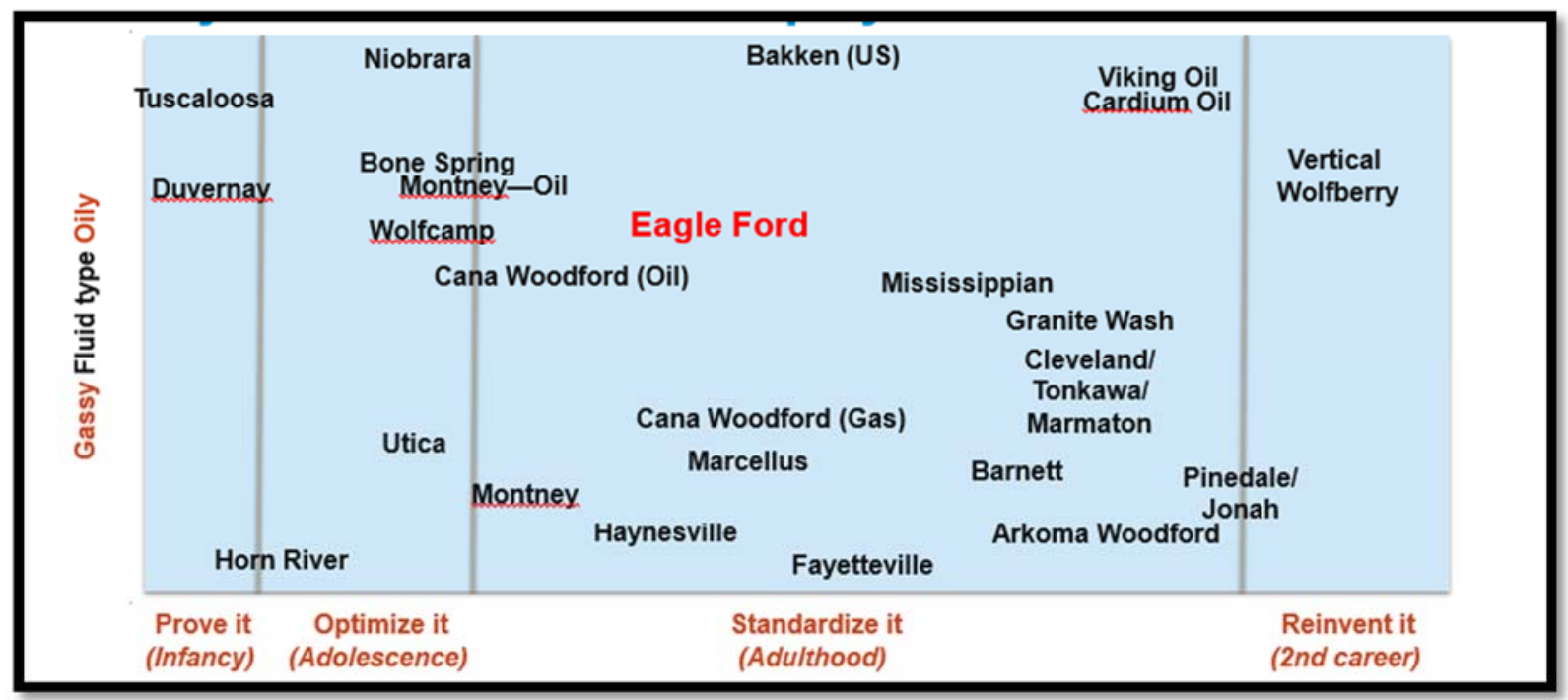

Figure 5: Life cycle of unconventional plays (IHS Energy Eagle Ford Regional Play Assessment) 
Originally, there were over 30 fields. However, due to field consolidations, the number of fields have been reduced to currently 22 as active (with 17 in active) located within the Railroad Commission Districts 1 thru 5 and the fields cover 26 counties. Figure 6 presents most active counties in Eagle Ford such as Atascosa, DeWitt, Dimmit, Frio, Gonzales, Karnes, La Salle, Lavaca, Live oak, Mc Mullen, Webb, Wilson, and Zavala County.

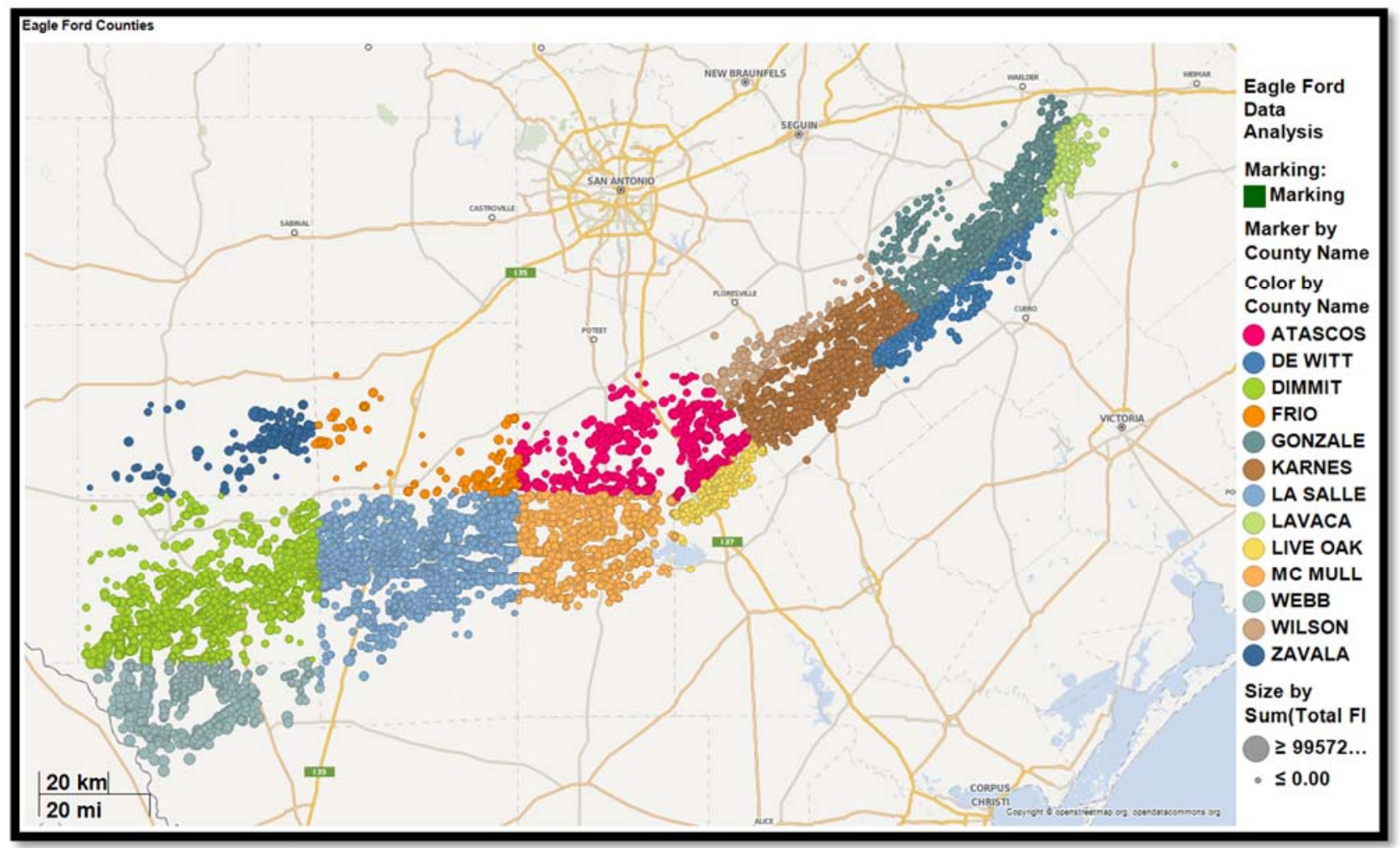

Figure 6: Counties with Production from Eagle Ford Shale (Data Source: IHS Energy)

Data mining study of Eagle Ford wells production and completion design were conducted. Production data and multistage hydraulic fracture treatment in different county were gathered, leading to the development of a criteria or standard by which wells can be evaluated, such as all wells must have:

- Eagle Ford play (reservoir)

- Horizontal (hole direction)

- Active (production status)

- Has production/ completion data (production and treatment volume)

Since 2010 more than 10,000 horizontal wells have been drilled and all have been hydraulically fractured. Statistical analysis was conducted to understand historical 
production and completion trends. Production volume, completion types, lateral length, total proppant mass, and efficiency were analyzed. The highest yielding wells were located northeast part of Eagle Ford. Figures 7 and 8 and Table 1 show that Eagle Ford has sweet spot with higher initial and first year cumulative production.

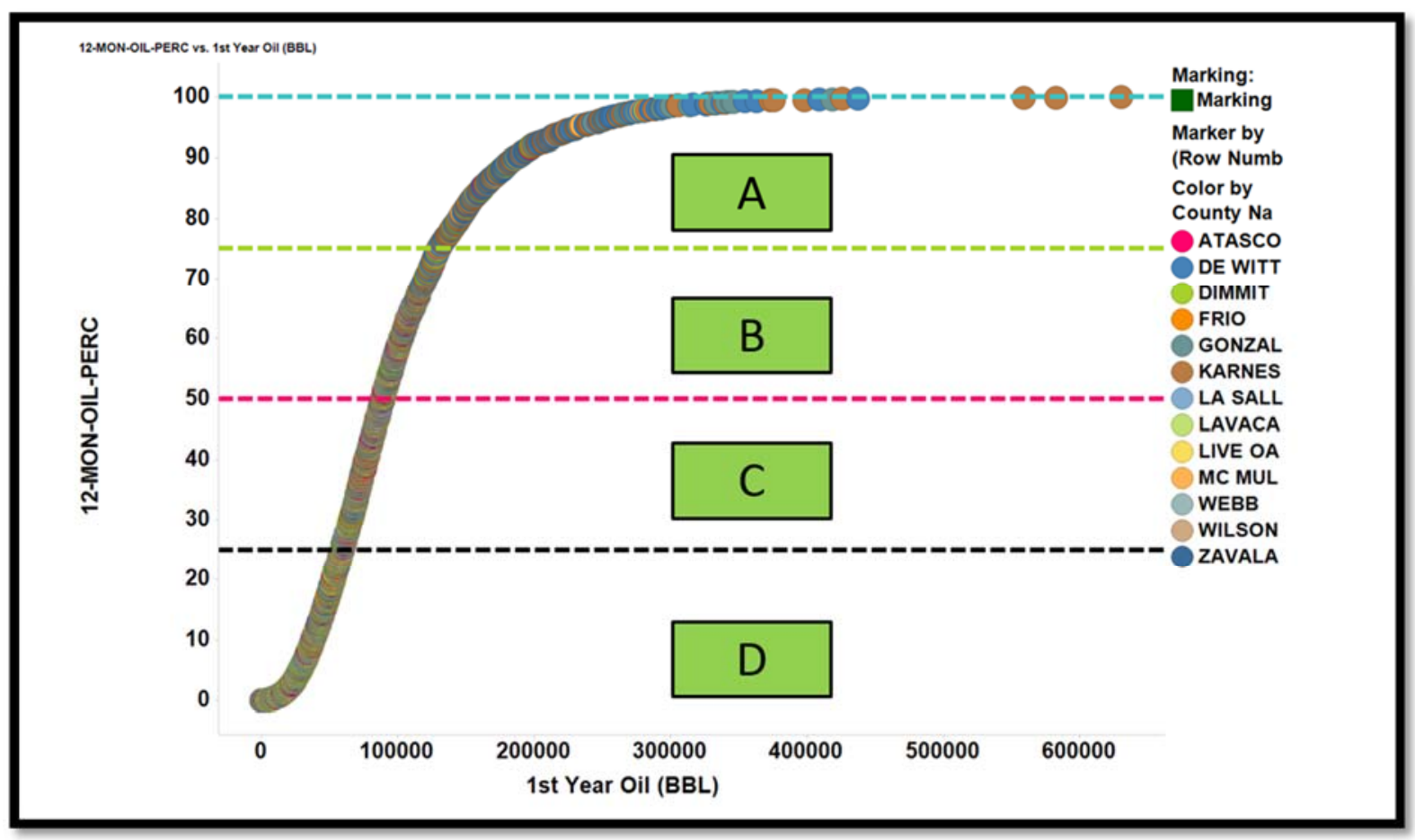

Figure 7: Average First Year oil production (BBLS) quartile (Data Source: IHS Energy)

Cumulative frequency map of the best and worst $25 \%$ of producing wells showed distinct sweet spots in Karnes, Gonzalez, and DeWitt counties. By contrast, poorer wells were spread throughout the play. There may be many reasons a well can perform poorly including reservoir properties, rock properties, and poor completion practices.

Table 1 lists average initial production and first year cumulative oil and gas production quartile. Group A and B wells which were the best producing groups that are deeper than the other groups. Production and completion development were supported by considering geologic and reservoir trends. Several properties increase in the southwest direction across the play, including depth, thickness, oil API, gas content, and pressure. Table 2 presents average cumulative production in first year in each county. 


\begin{tabular}{||l|r|c|c|r|r|r||}
\hline \hline Group & WC & \multicolumn{1}{l|}{$\begin{array}{l}\text { Avg_1st_Year_Oil } \\
\text { (BBL) }\end{array}$} & $\begin{array}{l}\text { Avg_1st_Year_Gas } \\
\text { (MCF) }\end{array}$ & \multicolumn{1}{l|}{$\begin{array}{l}\text { Avg_IP_Oil } \\
\text { (BBL) }\end{array}$} & $\begin{array}{l}\text { Avg_IP_Gas } \\
\text { (MCF) }\end{array}$ & \multicolumn{2}{l|}{$\begin{array}{l}\text { Avg_TVD } \\
\text { (ft.) }\end{array}$} \\
\hline A & 990 & 181,886 & 309,430 & 25,433 & 35,154 & 11,501 \\
\hline B & 1669 & 107,701 & 175,711 & 17,089 & 21,277 & 10,274 \\
\hline C & 2431 & 74,070 & 144,676 & 12,847 & 18,313 & 9,662 \\
\hline D & 5500 & 32,710 & 192,365 & 6,650 & 27,695 & 8,857 \\
\hline
\end{tabular}

Table 1: Summary of first year production in Eagle Ford Shale (Data Source: IHS Energy)

\begin{tabular}{|c|c|c|c|c|c|c|}
\hline County & WC & Avg_1 $1^{\text {st }} Y_{-}$Oil (BBL) & $\begin{array}{c}\text { Avg_1 }{ }^{\text {st }} Y_{-} \text {Gas } \\
\text { (MSCF) }\end{array}$ & Avg(TVD) & $1^{\text {st }} Y \_C u m \_p r o d \%$ & WC \% \\
\hline DE WITT & 597 & 130,805 & 341,369 & 12,667 & $15 \%$ & $6 \%$ \\
\hline KARNES & 1438 & 97,072 & 129,773 & 11,262 & $11 \%$ & $14 \%$ \\
\hline GONZALES & 1033 & 85,129 & 105,652 & 10,534 & $10 \%$ & $10 \%$ \\
\hline LIVE OAK & 291 & 68,324 & 159,373 & 11,651 & $8 \%$ & $3 \%$ \\
\hline MC MULLEN & 1005 & 65,517 & 105,705 & 10,571 & $8 \%$ & $10 \%$ \\
\hline LA SALLE & 1747 & 62,690 & 122,010 & 8,789 & $7 \%$ & $17 \%$ \\
\hline LAVACA & 157 & 60,392 & 100,661 & 11,667 & $7 \%$ & $2 \%$ \\
\hline ATASCOSA & 616 & 55,104 & 43,632 & 9,762 & $6 \%$ & $6 \%$ \\
\hline WILSON & 138 & 52,053 & 20,934 & 8,508 & $6 \%$ & $1 \%$ \\
\hline FRIO & 145 & 48,839 & 53,242 & 7,533 & $6 \%$ & $1 \%$ \\
\hline DIMMIT & 1991 & 48,285 & 213,433 & 7,378 & $6 \%$ & $19 \%$ \\
\hline ZAVALA & 175 & 45,729 & 14,270 & 6,101 & $5 \%$ & $2 \%$ \\
\hline WEBB & 959 & 31,325 & 643,250 & 8,313 & $4 \%$ & $9 \%$ \\
\hline
\end{tabular}

Table 2: Summary of first year production in Eagle Ford Shale by County (Data source: IHS Energy)

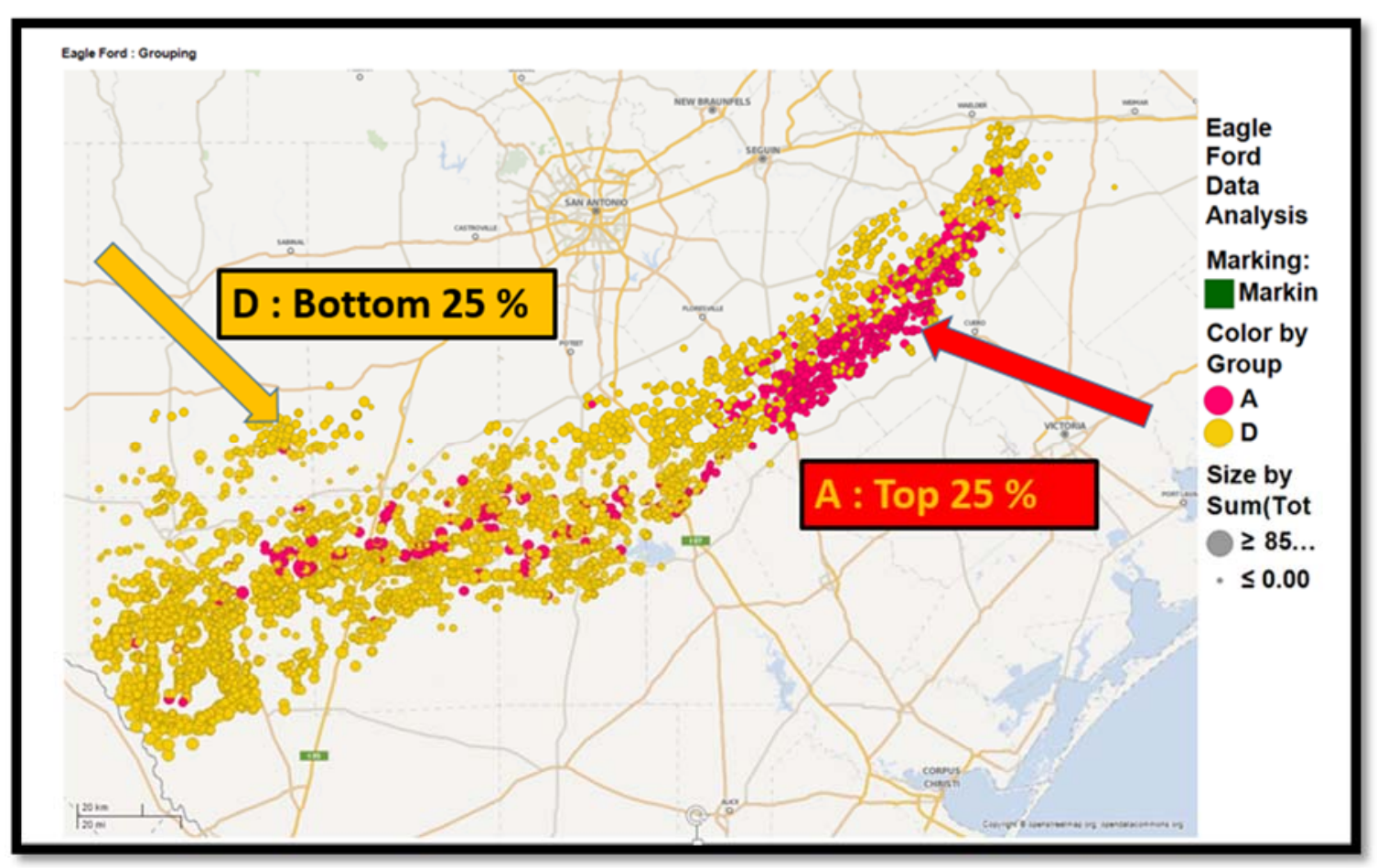

Figure 8: Top 25\% wells and Bottom 25\% wells (Data Source: IHS Energy) 
The information gathered from producing data in Eagle Ford such as initial production and first year cumulative oil and gas were compared with hydraulic fracture treatment data in order to determine the parameters that can drive overall productivity.

Breakdown of treatment design in each group is illustrated in Table 3. Average lateral length was over $5300 \mathrm{ft}$., average injected fracture fluid was 120, $000 \mathrm{BBL}$, and average proppant pumped into well was 6 million pounds.

\begin{tabular}{||l|l|l|l|l||}
\hline Group & WC & Avg_Lat Len (ft.)) & Avg_Fluid (BBL) & Avg_Prop (lbs) \\
\hline A & 990 & 5,334 & 122,630 & $6,698,184$ \\
\hline B & 1,669 & 5,477 & 119,820 & $6,317,219$ \\
\hline C & 2,431 & 5,454 & 120,913 & $6,006,244$ \\
\hline D & 5,500 & 5,086 & 116,681 & $5,304,841$ \\
\hline Average & & 5337 & 120,011 & $6,081,622$ \\
\hline
\end{tabular}

Table 3: Summary of Treatment Data in Eagle Ford Shale (Data source: IHS Energy)

Finally, summary treatment design in each county is illustrated in Table 4. Average lateral length is over $5300 \mathrm{ft}$., average well count per county is 815 wells, average injected fracture fluid of $113,000 \mathrm{BBL}$, and average proppant pumped into well was 6 million pounds.

\begin{tabular}{||c|c|c|c|c|c|c||}
\hline \hline County & WC & $\begin{array}{c}\text { Avg_1st } \\
\text { Year_Oil(BBL) }\end{array}$ & $\begin{array}{c}\text { Avg_Lat } \\
\text { Len(ft.) }\end{array}$ & $\begin{array}{c}\text { Avg_Fluid } \\
\text { (BBL) }\end{array}$ & $\begin{array}{c}\text { Avg_Prop } \\
\text { (Ibs)) }\end{array}$ & $\begin{array}{c}\text { Avg_TVD(ft } \\
\text {.) }\end{array}$ \\
\hline DE WITT & 625 & 135,308 & 4,738 & 87,843 & $4,953,747$ & 12,672 \\
\hline KARNES & 1,484 & 98,807 & 4,852 & 101,490 & $5,382,335$ & 11,251 \\
\hline GONZALES & 1,063 & 85,516 & 4,701 & 99,697 & $5,790,168$ & 10,532 \\
\hline LIVE OAK & 290 & 73,546 & 4,827 & 79,590 & $4,006,895$ & 11,648 \\
\hline \hline MC MULLEN & 1,034 & 65,769 & 5,594 & 128,182 & $6,397,838$ & 10,563 \\
\hline LA SALLE & 1,801 & 62,789 & 5,566 & 125,870 & $6,483,670$ & 8,802 \\
\hline LAVACA & 165 & 61,097 & 5,091 & 110,091 & $5,192,870$ & 11,674 \\
\hline ATASCOSA & 650 & 54,586 & 5,653 & 132,596 & $6,580,547$ & 9,745 \\
\hline WILSON & 138 & 52,609 & 5,598 & 100,415 & $5,267,378$ & 8,508 \\
\hline FRIO & 156 & 48,174 & 5,617 & 116,112 & $6,837,469$ & 7,550 \\
\hline DIMMIT & 2,043 & 47,187 & 5,373 & 133,382 & $5,032,718$ & 7,378 \\
\hline ZAVALA & 182 & 46,630 & 6,721 & 121,230 & $7,705,901$ & 6,109 \\
\hline WEBB & 959 & 31,329 & 5,133 & 137,883 & $5,912,277$ & 8,313 \\
\hline Average & $\mathbf{8 1 5}$ & $\mathbf{6 6 , 4 1 1}$ & $\mathbf{5 , 3 4 3}$ & $\mathbf{1 1 3 , 4 1 4}$ & $\mathbf{5 , 8 1 1 , 0 6 3}$ & $\mathbf{9 5 9 6}$ \\
\hline
\end{tabular}

Table 4: Summary of Treatment Data in Eagle Ford Shale by County (Data source: IHS Energy) 


\subsection{Area of Study}

This study focuses on localized optimization design in Eagle Ford shale, particularly in La Salle County, where a cookie cutter treatment design was used. The goal was to replicate the treatment design utilized in the best producing area in Eagle Ford such as Dewitt, Gonzales, and Karnes counties.

La Salle County is located in south Texas and it is one of the development areas of the Eagle Ford Shale. Geology varies and production includes fluctuating amounts of oil, gas-condensate, wet gas, and dry gas. The northern half (shallow) of the county produces more liquids and gas production increases as one moves towards south (deeper). Figure 9 shows the location of La Salle county.

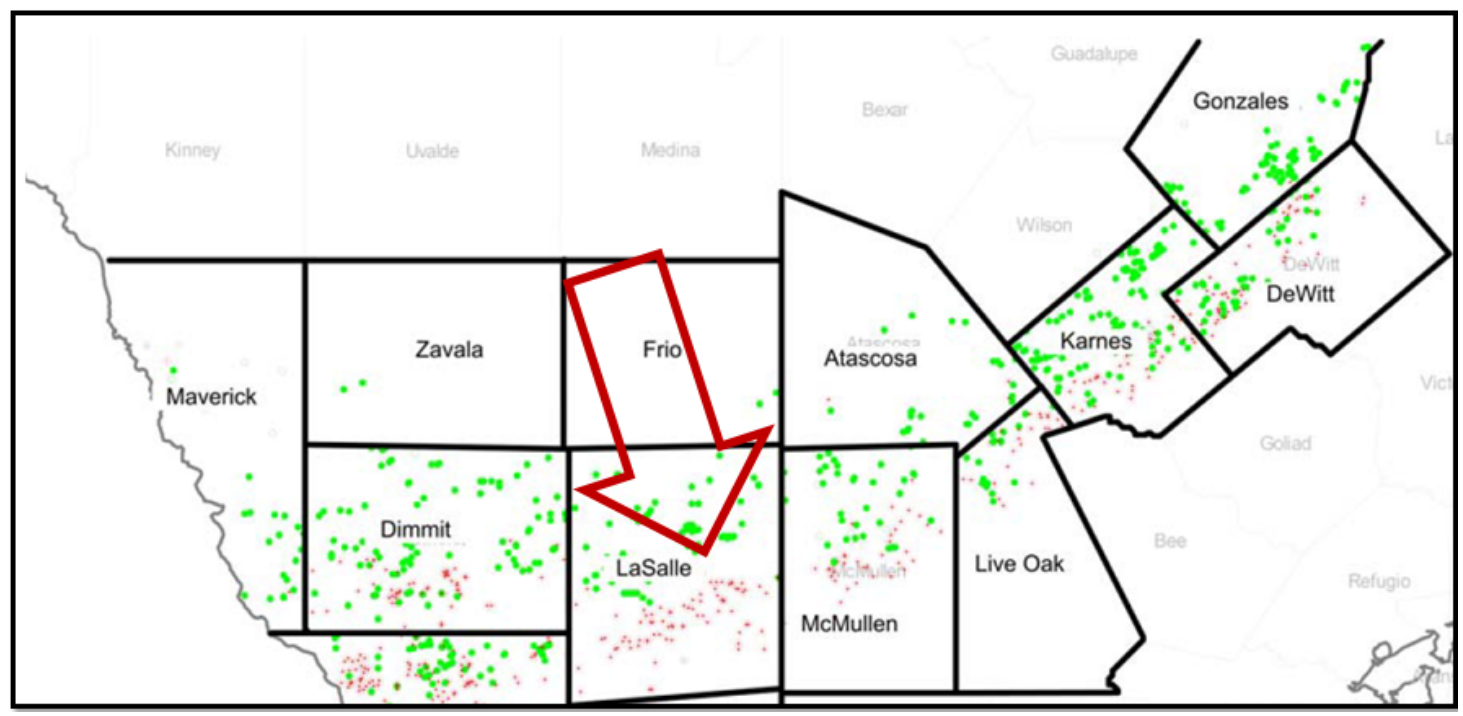

Figure 9: Area of Study- La Salle County (Drilling info)

Optimization of Eagle Ford stimulation techniques became the most important

objectives for completion and production engineers over the last four years. Fracturing fluid systems, treatment rates, proppant types and concentration, and completion details such as number of stages, number of clusters, and perforation intervals in horizontal laterals generated large number of variables impacting production for any company.

Integrating data from multiple sets across the play such as geology, rock mechanics, reservoir, and fluid properties data are used as input for a 3D hydraulic fracture simulator to model key fracture parameters which control production enhancement. 
These results are then used with a Production analysis, Forecast and Economic Model to compare which treatment designs will result in the best placement of fluid and proppant to deliver both high initial production and long term ultimate recoveries. This study investigates some of the questions frequently asked in field development planning such as:

1. What is the optimum hydraulic fracturing design?

- What is the optimum fracture geometry?

- What is optimum well spacing per section?

2. What is the optimum hydraulic fracturing treatment to achieve target design?

- What is the optimum type of fracturing fluid?

- What is the optimum volume of fracturing fluid and proppant?

- What is the optimum proppant transport method? 


\section{LITERATURE RESEARCH}

\subsection{Reservoir Rock}

A rock is defined as a collection of one or more minerals. Minerals are the fundamental building blocks of all rocks. The types of minerals present in a rock effect its behavior, and thus, its suitability as a reservoir. The classification of rocks is based on their origins. There are three major rocks, Sedimentary, Igneous, and Metamorphic Rocks. Figure 10 presents relative abundant of major sedimentary rock (Schlumberger Training Manual, 2007).

Sedimentary rocks are formed by deposition of particles derived from igneous, metamorphic or other sedimentary rocks by weathering and erosion or deposition of marine life. These are most important for oil and gas industry Sedimentary rocks provide the hydrocarbon source rocks and cap rock majority of reservoir. There are different types of Sedimentary rock such as Sandstone, limestone, and dolomite. Igneous rocks are formed from molten material which is either ejected from the earth during volcanic activity (e.g., lava flows, and ash falls), or crystallizes from a magma that is injected into existing rock and cools slowly, giving rise rocks such as granites. Igneous rocks are of minor importance for oil exploration. Rarely, hydrocarbon is produced from fractured igneous rocks. A granite has no porosity or permeability of its own, however tectonic forces may fracture the rock. Into these fractures hydrocarbons can flow to create a reservoir.

Metamorphic rocks are formed by action of temperature and/or pressure on sedimentary or igneous rocks that alter the character of the existing rock. The effect of heat and pressure is to transform the rock into a new form. In doing this it destroys all porosity and any hydrocarbons. Metamorphic rocks do not have hydrocarbon reservoirs. 


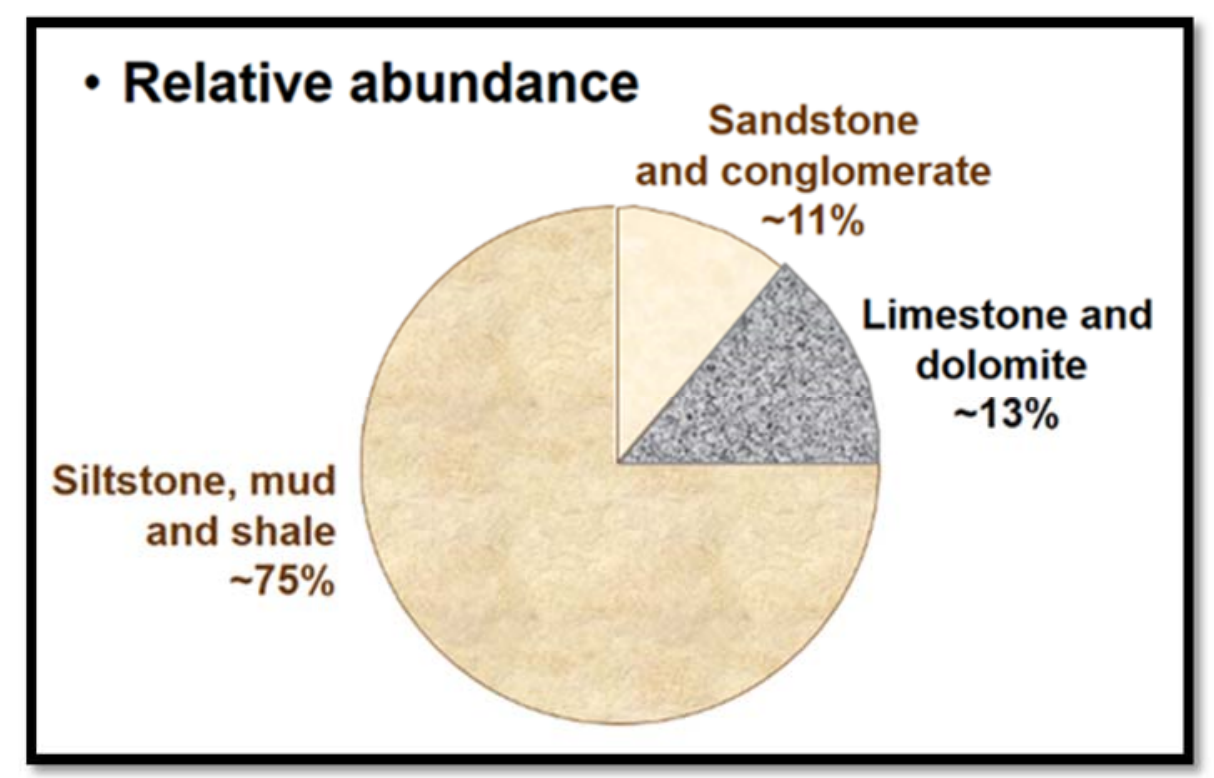

Figure 10: Relative abundance of major sediment rocks (Schlumberger 2007)

\subsection{Rock and Reservoir Properties of Eagle Ford}

Reservoir quality $(R Q)$ of shale formations is largely determined by the extent to which solid organic material has been converted to pore space by thermal maturation. Completion quality $(C Q)$ is determined by rock mechanical parameters that are essential to stimulate organic shale (Sayers et al 2015). Each shale play is unique with respect to production mechanism and geomechanical and petrophysical properties. In Eagle Ford shale, success is dependent on understanding the rock and reservoir properties. Once these parameters are understood, it is important to improve well performance.

Petrophysical and geomechanical parameters are based on core and logging measurements and utilized as an input for completion and reservoir modelling. It is vital to investigate the effect of petrophysical parameters that controls reservoir quality $(R Q)$ such as effective porosity, pore pressure, and total organic content (TOC). Also important are the geomechanical parameters that influence completion quality (CQ) such as stress, natural fractures, and mineralogy (Denney, 2012).

It's important to understand rock mechanical properties and mineralogy as a guideline to determine the completion of shale reservoirs. Figure 11 shows profile of the rock 
properties collected for well $1 \mathrm{H}$ in Eagle Ford, such as Young's modulus, Poison ratio, and stress gradient. The behavior of the rocks affects the quality of the reservoir and its interaction with the fluids, which flow through them. Therefore, understanding reservoir rock and its effect on fluid transport properties is the key to enhance ultimate recovery.

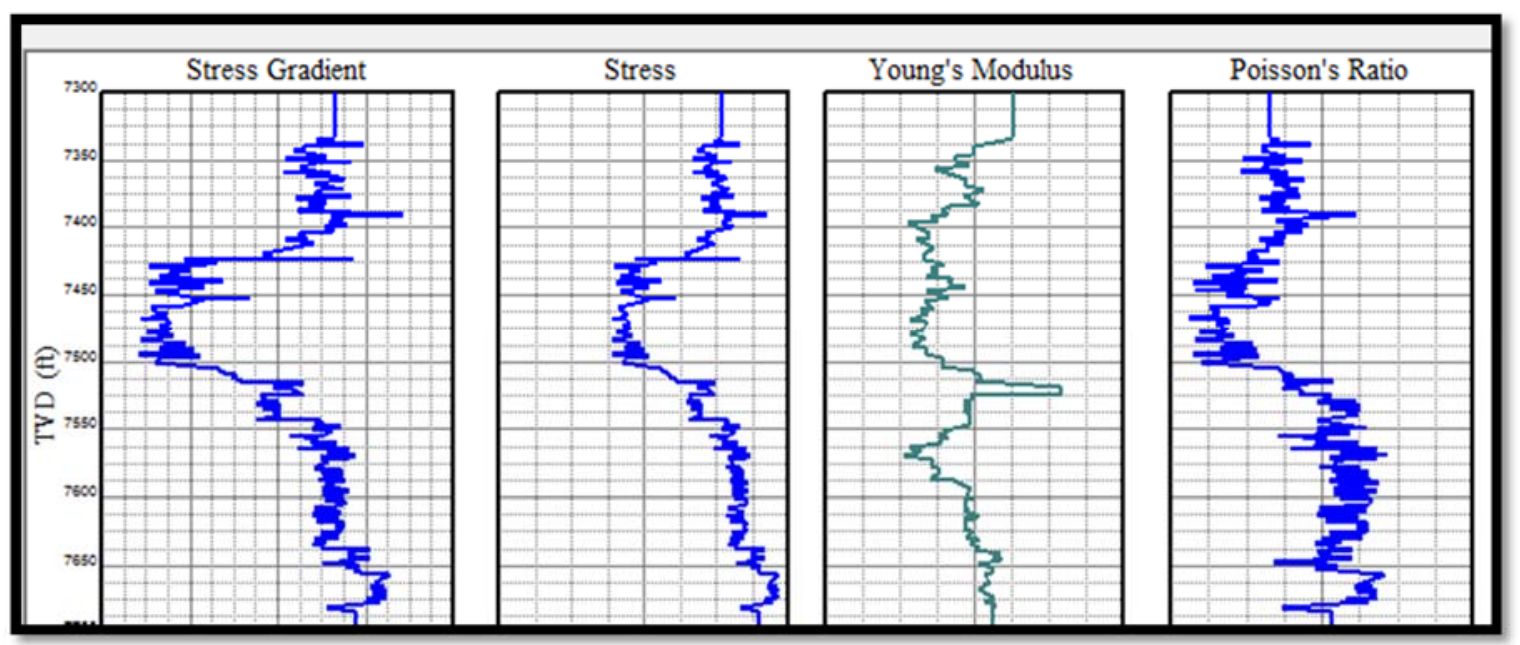

Figure 11: Rock mechanical Properties of Well \#1

\subsection{Mechanical Properties of Rock}

Rock mechanical properties are very important for designing of hydraulic fracture treatment. Each shale play is unique and treatment design method should be determined based on individual quality and characteristics. Knowledge of rock mechanical properties is essential to understand how Eagle Ford shale wells are drilled and completed. The effect of various parameters on the fracture geometry and propagation are examined.

\subsubsection{Young's Modulus}

Young's modulus is the ratio of stress over strain. For linear-elastic deformation, Young's modulus is a constant with a unique value for a particular rock and in-situ conditions. The module constitutes the ability of a rock to resists deformation under load. Therefore, it measures of rocks stiffness. As stiffness of the rock increase, the fracture width will decrease and the length will increase for given set of input 
parameters as illustrated in Figure 12. The YM value of different rocks is presented in Table 5. (Meyers 2014).

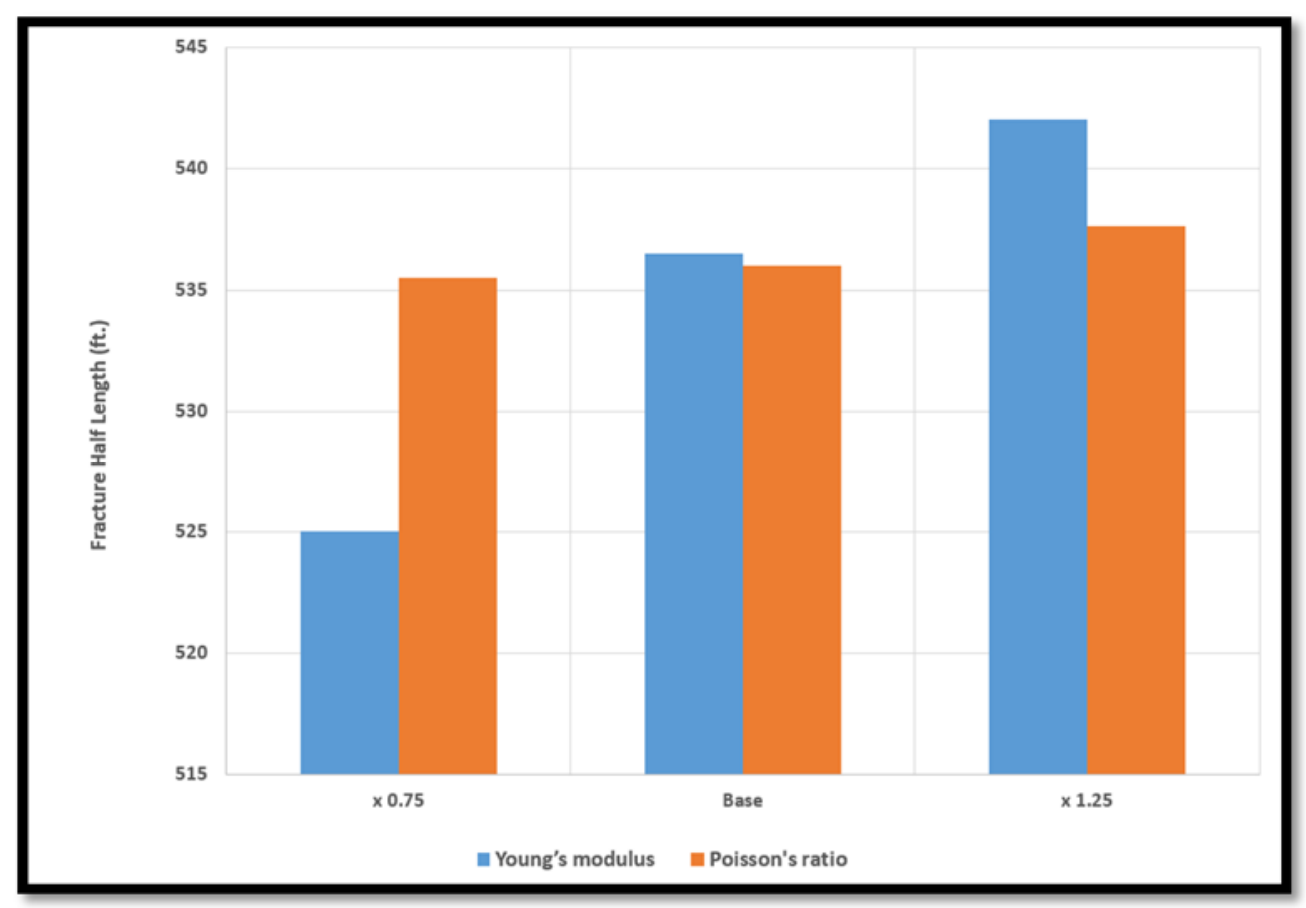

Figure 12: The Effect of YM on Fracture Length (well \#1 log data)

Young's Module is expressed in Equation-1 where: $E$ is Young's in psi, $\sigma$ is stress (psi) and $\varepsilon$ is strain in (psi).

$$
E=\frac{\sigma}{\varepsilon}=\frac{F / A}{\Delta L / L}
$$

\begin{tabular}{||l|c|}
\hline Rock Type & Range (10 \\
& $\mathbf{p s i})$ \\
\hline Limestone-Reef Breccia & $1-5$ \\
\hline Limestone-Porous & $2-7$ \\
\hline Limestone-Med. to Fine Grained & $4-11$ \\
\hline Dolomite & $6-13$ \\
\hline Hard Dense Sandstone & $4-7$ \\
\hline Medium Hard Sandstone & $2-4$ \\
\hline Porous unconsolidated to poorly consolidated & $0.1-2$ \\
\hline
\end{tabular}

Table 5: Ranges of Young's Module for different rocks (Meyers \& Associate 2014) 


\subsubsection{Poisson's ratio}

Poisson's ratio is the ratio of transverse contraction strain to the axial strain resulting from an applied stress. Estimated Poisson's ratios for rock formations are 0.25. The effects of Poisson's ratio on fracture geometry and propagation characteristics is very limited and has a minor effect. Poisson's ratio is used to determine in-situ stresses assuming rock behaves elastically and tectonic stresses are known or insignificant. It can be expressed using the equation below:

$$
v=\frac{\varepsilon_{h}}{\varepsilon_{V}}
$$

\subsubsection{Three Principle Stresses}

The fracture propagations, size, orientation, and the magnitude of the pressure needed to generate it, are controlled by the formation's in situ stress field. This stress field may be defined by three principal stresses, which are oriented perpendicular to each other. The magnitudes and orientations of these three principal stresses are determined by the tectonic regime in the area and by depth, pore pressure and rock properties, which regulate how stress is carried and distributed among formations (Bilgesu et al, 2011). In situ stresses control the orientation and propagation direction of hydraulic fractures. Hydraulic fractures are tensile fractures, and they open in the direction of least resistance stress. Stress regime is the dominant factor controlling direction and propagations of hydraulic fractures as illustrated in Figure 13.

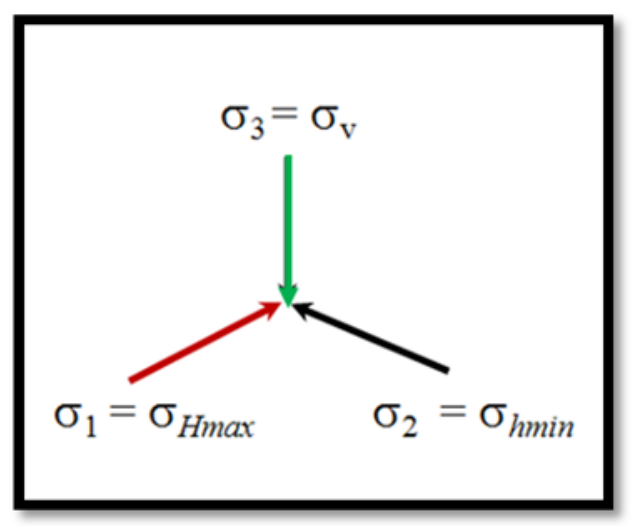

Figure 13: The three principal stresses 
The three principal stresses increase with depth. The rate of increase with depth defines the vertical gradient. The principal vertical stress or overburden stress, is caused by the weight of rock overlying a measurement point. It can be expressed as:

$$
\sigma_{v}=g \int_{0}^{H} \rho \cdot d H
$$

Where $\sigma_{v}$ is vertical stress, $\mathrm{g}$ is gravitational force, $\mathrm{H}$ is formation depth and $\rho$ is rock density.

The fracture stress gradients are correlated with vertical and pore pressure and is given by Hubbert and Wilson equation as:

$$
\sigma_{v}^{\prime}=\sigma_{v}-\alpha P_{p}
$$

Where $\mathrm{P}_{\mathrm{p}}$ is the pore pressure and $\alpha$ is the Biot poro-elastic constant The minimum horizontal stress is a function of geo-mechanical parameters such as Young's modulus $(E)$ and Poison's ratio $(v)$. The minimum horizontal stress can be determined by the following equation.

$$
\sigma_{h, \min }=\frac{v}{1-v}\left(\sigma_{v}-\alpha P_{p}\right)+\alpha P_{p}
$$

Maximum horizontal stress is related with tectonic stress in the region and can be determined by the summation of minimum horizontal stress and tectonic stress in the region. It can be determined by the following equation.

$$
\sigma_{H, \text { max }}=\sigma_{h, \text { min }}+\sigma_{\text {tect }}
$$

Where $\sigma_{\text {tect }}$ is the tectonic stress of the region. 


\subsubsection{Fracture Toughness}

The definition of fracture toughness is established from stress intensity factor, developed in linear elastic fracture mechanics (LEFM). Fracture toughness is a measure of rock resistance to fracture extension. It is proportional to the amount of energy that can be absorbed by the rock before propagation occurs. The basis for this relationship involves the assumption that pre-existing fissures exist which induce high stress concentrations in their proximity. These areas become points for crack initiation and propagation. Table 6 presents fracture toughness value for different formations (Meyers, 2014).

\begin{tabular}{|l|l|}
\hline Formation Type & psi- in ${ }^{1 / 2}$ \\
\hline Siltstone & $950-1650$ \\
\hline Sandstone & $400-1600$ \\
\hline Limestone & $400-950$ \\
\hline Shale & $300-1200$ \\
\hline
\end{tabular}

Table 6: Fracture Toughness Ranges (Meyers \& Associate 2014)

\subsubsection{Mineralogy}

Sixteen different minerals were identified in the Eagle Ford Shale that are clustered into four groups as presented in Table 7. Mineralogy has an important role for deciding the economic exploitation potential of a shale reservoir and the possibility of hydraulic fracturing success. Fractures are generated more easily in carbonate-rich shales than in clay-rich shales (Sondhi, 2011).

\begin{tabular}{||l|l|l|l|l||}
\hline \hline Total Clay & Total Carbonate & Total Feldspar & Quartz & Others \\
\hline Illite & Calcite & Orthoclase & Quartz & Pyrite \\
\hline Smectite & Dolomite & Oglioclase Feldspar & & Anhydrite \\
\hline Chlorite & Siderite & Albite & & Apatite \\
\hline Mixed Clays & Aragonite & & & \\
\hline
\end{tabular}

Table 7: Minerals identified in the Eagle Ford Shale (Sondhi, 2011) 
The composition of selected Well \#1 is mainly calcite with very low clay content as illustrated in Table 8 . The result of clay contents of less than $20 \%$ with a mixed-layer of Illite/Smectite of $10 \%$ or less can give a guideline of how to choose the best hydraulic fracture design. The rock and fluid properties of shale reservoirs display huge variation, making it difficult to implement a similar treatment design and procedure on every geological formation. Unique treatment methods and procedures must be developed for each area. Every well in Eagle Ford must be drilled and hydraulically fractured in multiple stages, which requires understanding of rock mechanical properties and mineralogy as a guideline to complete the shale reservoir.

\begin{tabular}{|l|c|}
\hline NON-CLAY FRACTION & Value (\%) \\
\hline Quartz & 11.3 \\
\hline K-Feldspar & 0.1 \\
\hline Plagioclase & 2.4 \\
\hline Organic Carbon (TOC) & 2.8 \\
\hline Apatite & 1.1 \\
\hline Pyrite & 1.2 \\
\hline Marcasite & 0.3 \\
\hline Calcite & 63.6 \\
\hline Dolomite & 0.9 \\
\hline TOTAL & 83.7 \\
CLAY FRACTION & Value (\%) \\
\hline Mixed-Layer ILLITE/SMECTITE (Includes R3) & 7.1 \\
\hline Illite + Mica & 7.3 \\
\hline Chlorite & 0.0 \\
\hline Kaolinite & 2.0 \\
\hline TOTAL & 16.3 \\
\hline GRAND TOTAL & 100.0 \\
\hline
\end{tabular}

Table 8: Mineral composition of Well \#1

Parameters such as micro-seismic monitoring results, log and core data, and DFIT related to completion must be evaluated and analyzed with a result to implement changing fracture treatment to find optimum design. One of the major design parameters is the Brittleness index. The rock brittleness integrates both Poisson's Ratio and Young's Modulus. These two parameters are combined to reflect the rocks ability to fail under stress and to keep fracture open once the rock is fractured. 
Figures 14 and 15 illustrate representation of brittleness concept. Lower the value of Poisson's Ratio, the more brittle the rock as the value of Young's Module increase. Higher the value of Poisson's Ratio, the more ductile the rock as the value of Young's Module decrease. Ductile rocks are not preferred choice for hydraulic fracturing due to sudden closure after completion of fracture treatment. However, ductile rocks make good seal for the reservoir rock. On the other hand, brittle rock is more naturally fractured and will also respond positively to hydraulic fracturing treatment. Brittleness index is a function of Young's modulus and Poisson's ratio and it is used to select treatment design.

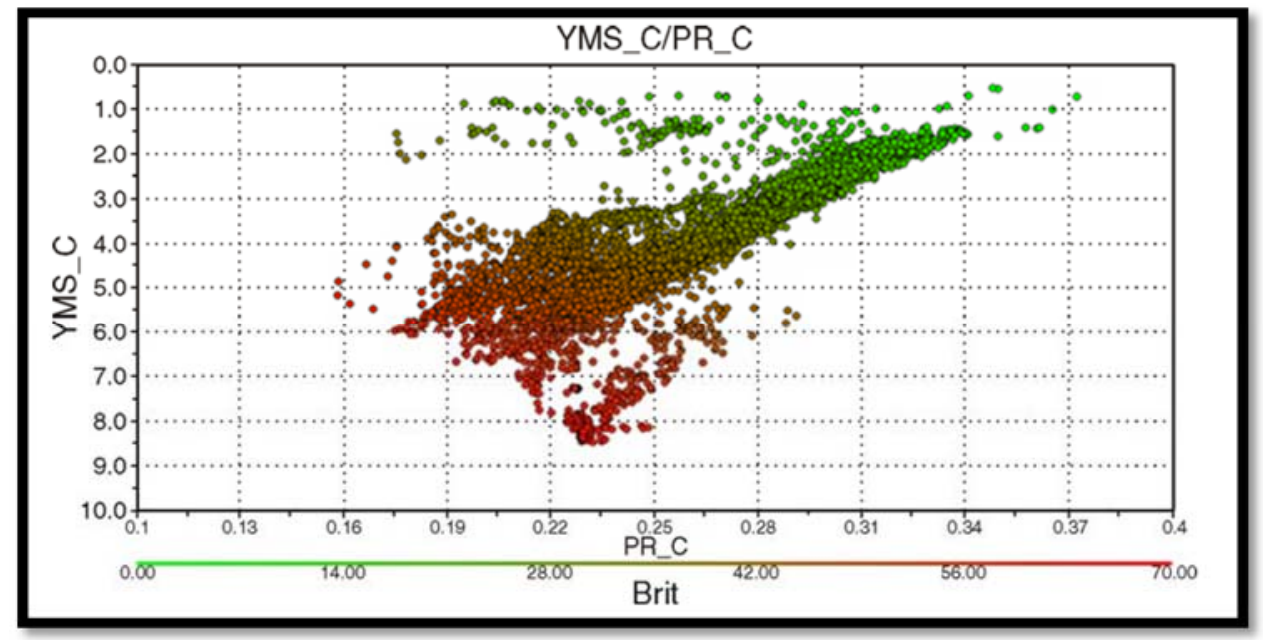

Figure 14: A cross plot of Young's Module \& Poisson's Ratio showing brittleness percentage increase to the southwest corner of the plot (Rickman et al. 2008).

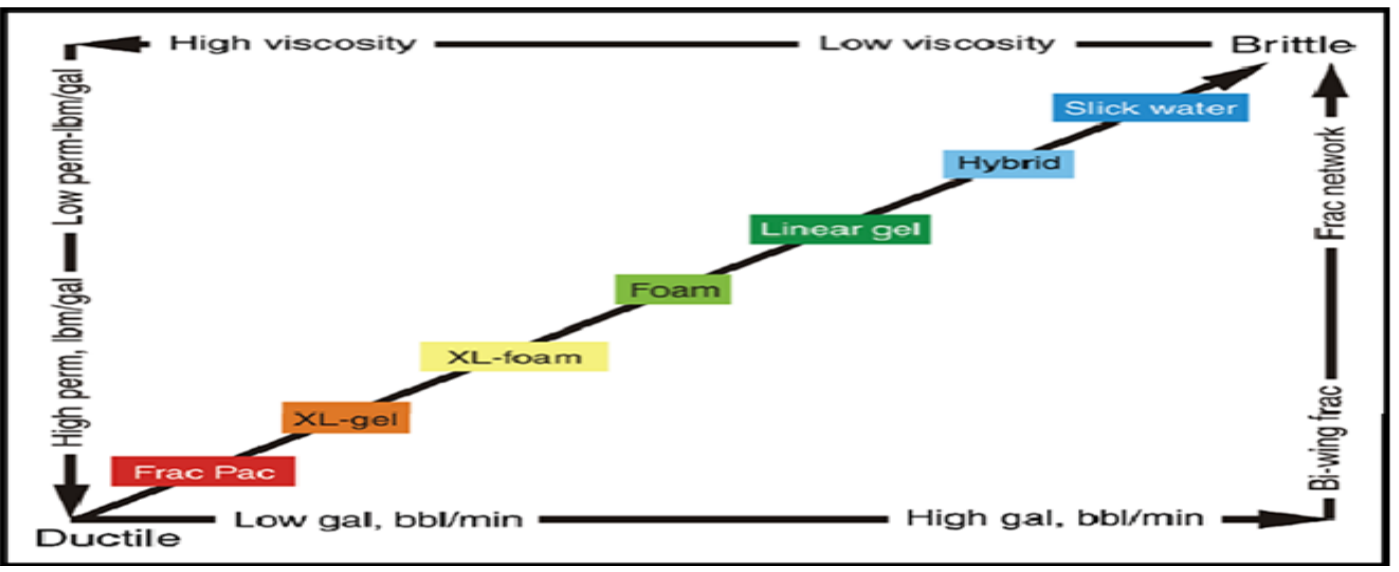

Figure 15: Rate, fluid, and proppant concentration selection based on brittleness and ductility. (Adopted and modified from Chong et al, 2010). 
Mullen et al. (2010) recommended a fluid system based on the brittleness determined for the shale. Rickman et al. (2008) explained the concept of rock brittleness which combines both Poisson's Ratio (rock ability to fail under stress) and Young's Modulus (maintain a fracture once the rock is fractured). The brittleness of the Eagle Ford shale is markedly different than other shale plays.

The application of brittleness index as a general guideline to fracture treatment design and helps to select design variables such as the type of fracture treatment which produces the desired complex fracture geometry based on the fracture intensity.

\subsection{Eagle Ford Shale Hydraulic Fracturing Treatment Techniques}

The objective of unconventional stimulation technologies is to increase the rate of oil/gas flow from the reservoir to the wellbore. It's utilized for conditions where the natural reservoir flow characteristics are not favorable and need to be improved for oil and gas recovery. Unconventional reservoir stimulation techniques require integrating design into reservoir fluids and rock properties. Each job must be designed for the target formation and its special characteristics such as pay thickness, reservoir fluids, lithology, rock stress and other characteristics to optimize development of a complex Discrete Fracture Network (DFN). There are several types of commonly used fracturing well stimulation methods such as hydraulic fracturing, acid fracturing, and matrix acidizing.

Each shale play has unique properties that need to be considered when selecting fracture treatment design, fluid and proppant types and volumes. Eagle Ford Shale presents a great variability, and for this reason no single technique for hydraulic fracturing has universally worked. The composition of fracturing fluids must be altered to meet specific reservoir and operational conditions. To modify fluid behavior, fracturing fluid additives need to be utilized such as, buffers, bactericides, clay stabilizers, fluid loss additives, friction reducers, temperature stabilizers, surfactants, and non-emulsifiers agents. There are different types of fracture treatments such as:

1. Surface area fracture treatment (water frac) 
2. Conductivity fracture treatment (cross-link frac)

3. Hybrid fracture treatment

Additional knowledge of local properties will help the selection criteria for choosing the optimum treatment.

\subsubsection{Surface Area Fracture Treatment}

Large volume of low viscosity slick-water fluid is pumped with small quantities of proppant. The majority of proppant used in such treatment is either $40 / 70$ mesh or 100 mesh size. The idea is to contact as much surface area as possible and create discrete fracture network (DFN) or complex network, improving reservoir-to-wellbore connectivity. Barree, et al. (2011) investigated slick water hydraulic fracturing. It is suited for complex reservoirs with high Young's Modules, low stress anisotropy, brittle and naturally fractured, and tolerant of large volumes of water. Table 9 presents a typical surface area fracture treatment design.

In unconventional reservoirs such as Barnet shale, there is a direct correlation between treatment size, DFN size, shape, and production response. Increasing treatment size, DFN size and complexity results in increase of stimulated reservoir volume. The main reason such treatments has been successful is due to permeability of the generated fractures with significantly higher than matrix permeability. Fracture permeability is a function of width (ft.) (Craft et al. 1991) and increasing the treatment size will increase the width of the fracture.

The disadvantage is the inherently poor proppant carrier characteristics of slick water, requiring high pump rates to achieve flow velocity necessary to overcome the tendency of proppant to settle. Additionally, narrow fracture widths and large quantities of water usage are expected. 


\begin{tabular}{|c|c|c|c|c|c|}
\hline Fluid System & $\begin{array}{c}\text { Clean } \\
\text { Volume (gal) }\end{array}$ & $\begin{array}{l}\text { Proppant } \\
\text { Conc. (ppg) }\end{array}$ & $\begin{array}{l}\text { Proppant } \\
\text { Type }\end{array}$ & Rate (bpm) & $\begin{array}{l}\text { Proppant } \\
\text { Total (lbs) }\end{array}$ \\
\hline FR water & 2000 & & & 25 & \\
\hline $15 \%$ FE acid & 1500 & & & 25 & \\
\hline FR Water & 2000 & & & 30 & \\
\hline $15 \%$ FE acid & 1500 & & & 30 & \\
\hline FR Water & 12,000 & & & 30 & \\
\hline FR Water & 2000 & & & 30 & \\
\hline $15 \%$ FE acid & 1500 & & & 25 & \\
\hline FR Water & 50,000 & & & 60 & \\
\hline FR Water & 200,000 & 0.1 & $\begin{array}{c}\text { Premium } \\
\text { White-40/70 }\end{array}$ & 60 & 20,000 \\
\hline FR Water & 50,000 & 0.2 & $\begin{array}{c}\text { Premium } \\
\text { White-40/70 }\end{array}$ & 60 & 10,000 \\
\hline FR Water & 50,000 & 0.3 & $\begin{array}{c}\text { Premium } \\
\text { White-40/70 }\end{array}$ & 60 & 15,000 \\
\hline FR Water & 50,000 & 0.4 & $\begin{array}{c}\text { Premium } \\
\text { White-40/70 }\end{array}$ & 60 & 20,000 \\
\hline FR Water & 50,000 & 0.5 & $\begin{array}{c}\text { Premium } \\
\text { White-40/70 }\end{array}$ & 60 & 25,000 \\
\hline \multirow[t]{2}{*}{ FR Water } & 13,090 & & & 60 & \\
\hline & 485,590 & & & & 90,000 \\
\hline
\end{tabular}

Table 9: Surface Area -Type of Fracture Treatment Design (Barree, et al. 2011)

\subsubsection{Conductivity Fracture Treatment}

This is a common type of fracture treatment with higher concentrations of large mesh proppant placed with a cross link fluid system to overcome embedment and multiphase flow issue. Selection criteria of such treatments include the softer, more ductile reservoirs with higher stress anisotropy where planer type fracture is expected (Barree, et al. 2011). Table 10 presents a typical conductivity type treatment design.

Cross-linked fluids have proven to be highly effective in both low and high permeability formations. They offer good proppant transport, a stable fluid rheology at temperatures as high as $300^{\circ} \mathrm{F}$, low fluid loss and good cleanup properties. 


\begin{tabular}{|c|c|c|c|c|c|}
\hline Fluid System & $\begin{array}{c}\text { Clean } \\
\text { Volume (gal) }\end{array}$ & $\begin{array}{l}\text { Proppant } \\
\text { Conc. (ppg) }\end{array}$ & $\begin{array}{l}\text { Proppant } \\
\text { Type }\end{array}$ & $\begin{array}{l}\text { Rate } \\
(\mathrm{bpm})\end{array}$ & $\begin{array}{l}\text { Proppant } \\
\text { Total (lbs) }\end{array}$ \\
\hline Reactive fluid pad & 5000 & & & 45 & \\
\hline FR water pad & 25000 & & & 45 & \\
\hline FR water pad & 50000 & 0.5 & $\begin{array}{c}\text { Premium } \\
\text { White-40/70 }\end{array}$ & 45 & 25000 \\
\hline Enhanced XI fluid pad & 3000 & & & 45 & 0 \\
\hline Enhanced XL fluid & 25000 & 0.5 & $\begin{array}{c}\text { Premium } \\
\text { White-20/40 }\end{array}$ & 45 & 12500 \\
\hline Enhanced XL fluid & 25000 & 1 & $\begin{array}{c}\text { Premium } \\
\text { White-20/40 }\end{array}$ & 45 & 25000 \\
\hline Enhanced XL fluid & 30000 & 2 & $\begin{array}{c}\text { Premium } \\
\text { White-20/40 }\end{array}$ & 45 & 60000 \\
\hline Enhanced XL fluid & 30000 & 3 & $\begin{array}{c}\text { Premium } \\
\text { White-20/40 }\end{array}$ & 45 & 90000 \\
\hline Enhanced XL fluid & 15000 & 4 & $\begin{array}{c}\text { Premium } \\
\text { White-20/40 }\end{array}$ & 45 & 60000 \\
\hline Enhanced XL fluid & 4000 & 4 & $\begin{array}{l}\text { Resin coated } \\
\text { proppant-20/40 }\end{array}$ & 45 & 16000 \\
\hline \multirow[t]{2}{*}{ FR water pad } & 4000 & & & 15 & \\
\hline & 216000 & & & & 288500 \\
\hline
\end{tabular}

Table 10: Conductivity-Type of Fracture Treatment Design (Barree, et al. 2011)

\subsubsection{Hybrid Fracture Treatment}

This treatment is a combination of surface area and conductivity treatment. High rate, low viscosity fluid (water) pad, friction reducers and breakers followed by high viscosity cross-linked fluid with continuous increasing proppant concentration stages are used. This type of treatment becomes more interesting in shale plays due to higher regained permeability than conductivity fracture treatment. Table 11 is a typical hybrid type treatment design. 


\begin{tabular}{|c|c|c|c|c|c|c|c|c|}
\hline & Stage Type & $\begin{array}{l}\text { Flow Rate } \\
\text { (bpm) }\end{array}$ & $\begin{array}{l}\text { Prop Conc. } \\
\text { (ppg) }\end{array}$ & $\begin{array}{c}\text { Clean Vol . } \\
\text { (gal) }\end{array}$ & $\begin{array}{l}\text { Stg Length } \\
\text { (mins) }\end{array}$ & $\begin{array}{c}\text { Cumul Time } \\
\text { (min:sec) }\end{array}$ & Fluid Type & Proppant Type \\
\hline & Water injection & 20.00 & 0.00 & 5,000 & 5.95 & $5: 57$ & FR66 & \\
\hline & Water injection & 15.00 & 0.00 & 2,000 & 3.17 & $9: 07$ & FR66 & \\
\hline & Main frac pad & 45.00 & 0.00 & 20,000 & 10.58 & $19: 42$ & FR66 & \\
\hline & Prop slug & 45.00 & 1.00 & 5,000 & 2.78 & $22: 29$ & FR66 & 100 mesh \\
\hline & Main frac slurry & 45.00 & 0.00 & 20,000 & 10.58 & $33: 04$ & FR66 & \\
\hline & Prop slug & 45.00 & 1.00 & 5.000 & 2.78 & $35: 51$ & FR66 & 100 mesh \\
\hline & Main frac slurry & 45.00 & 0.00 & 20.000 & 10.58 & $46: 26$ & FR66 & \\
\hline & Prop slug & 45.00 & 1.00 & 5,000 & 2.78 & $49: 13$ & FR66 & 100 mesh \\
\hline & Main frac slurry & 45.00 & 0.00 & 18.000 & 9.52 & $58: 44$ & 25\# Linear & \\
\hline & Main frac slurry & 40.00 & 0.00 & 2,000 & 1.19 & $59: 56$ & 25\# Linear & \\
\hline \multirow{7}{*}{ 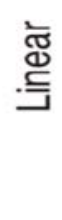 } & Main frac slurry & 40.00 & 0.25 & 5.000 & 3.01 & $62: 56$ & 25\# Linear & 30/50 Prop \\
\hline & Main frac slurry & 40.00 & 0.00 & 5,000 & 2.98 & $65: 55$ & 25\# Linear & \\
\hline & Main frac slurry & 45.00 & 0.50 & 5.000 & 2.69 & $68: 36$ & 25\# Linear & 30/50 Prop \\
\hline & Main frac slurry & 45.00 & 0.00 & 5,000 & 2.65 & 71:15 & 25\# Linear & \\
\hline & Main frac slurry & 45.00 & 0.75 & 9.000 & 4.88 & $76: 08$ & 25\# Linear & 30/50 Prop \\
\hline & Main frac slurry & 45.00 & 0.00 & 5,000 & 2.65 & $78: 47$ & 25\# Linear & \\
\hline & Main frac slurry & 45.00 & 1.00 & 9,000 & 4.92 & $83: 42$ & 25\# Linear & 30/50 Prop \\
\hline \multirow{7}{*}{ 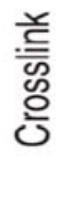 } & Main frac slurry & 25.00 & 0.00 & 20,000 & 19.05 & $102: 45$ & 35\# Xlink & \\
\hline & Main frac slurry & 30.00 & 1.00 & 15.000 & 12.47 & $115: 13$ & 35\# Xlink & 20/40 Prop \\
\hline & Main frac slurry & 30.00 & 2.00 & 20.000 & 17.37 & $132: 35$ & 35\# Xlink & 20/40 Prop \\
\hline & Main frac slurry & 35.00 & 3.00 & 25,000 & 19.41 & $152: 00$ & $30 \#$ Xlink & 20/40 Prop \\
\hline & Main frac slurry & 40.00 & 4.00 & 15,000 & 10.61 & $162: 37$ & $30 \#$ Xlink & 20/40 Prop \\
\hline & Main frac flush & 45.00 & 0.00 & 22,000 & 11.64 & $174: 15$ & FR66 & \\
\hline & Shut-in & 0.00 & 0.00 & o & 5.00 & $179: 15$ & Shut-in & \\
\hline
\end{tabular}

Table 11: Hybrid-Type of Fracture Treatment Design (Barree, et al. 2011)

\subsection{Assessment of Eagle Ford Shale Reservoir Properties}

In recent years, significant progress has been made in understanding geological, petro-physical, rock and fluid characterization of unconventional plays, as well as their impact on production. Shale reservoir performance is controlled by many of the same essential parameters as the conventional reservoir.

Like conventional reservoir, EF production of oil from organic shale reservoirs is a function of porosity, hydrocarbon saturation, pore pressure, matrix permeability, volume of hydraulic fracture and fracture conductivity. Fracture geometry, porosity, saturations and initial pressure dominate initial production rates. Matrix permeability becomes increasingly important in maintaining productivity in later stages in the life of the well. Further complexity includes predicting completion effectiveness which requires understanding of key parameters such as created fracture geometry, conductivity, proppant transport and placement. Additional challenge is understanding fluid composition and phase behavior which have strong effects on rate and recovery. 
Eagle Ford shale development has increasingly focused on liquid rich area in recent years, due to relatively low natural gas prices. In order to economically explore, appraise, develop and produce liquid rich shale reservoir, it's important to understand their key characteristics.

Eagle Ford formation depth ranges from 2,500 ft. to $14,000 \mathrm{ft}$., the thickness ranges from $50 \mathrm{ft}$. to more than $300 \mathrm{ft}$., the pressure gradients are between 0.4 and $0.8 \mathrm{psi} / \mathrm{ft}$., and TOC ranges from $2 \%$ to $9 \%$. Some area of EF core data analysis shows that the gas saturation is very high and permeability varies between $1 \mathrm{nD}$ to $800 \mathrm{nD}$ (Stegent et al., 2010).

A petro-physical analysis was conducted on Eagle Ford offset wells to evaluate reservoir characteristic and their potential in upper and lower Eagle Ford (organic). Figure 16, 17, and Table 12 show offset well data of the petro-physical analysis which characterizes the effective porosity, permeability, thickness, organic content, and estimates of net to illustrate cutoff for water saturation, permeability, resistivity, porosity, etc.

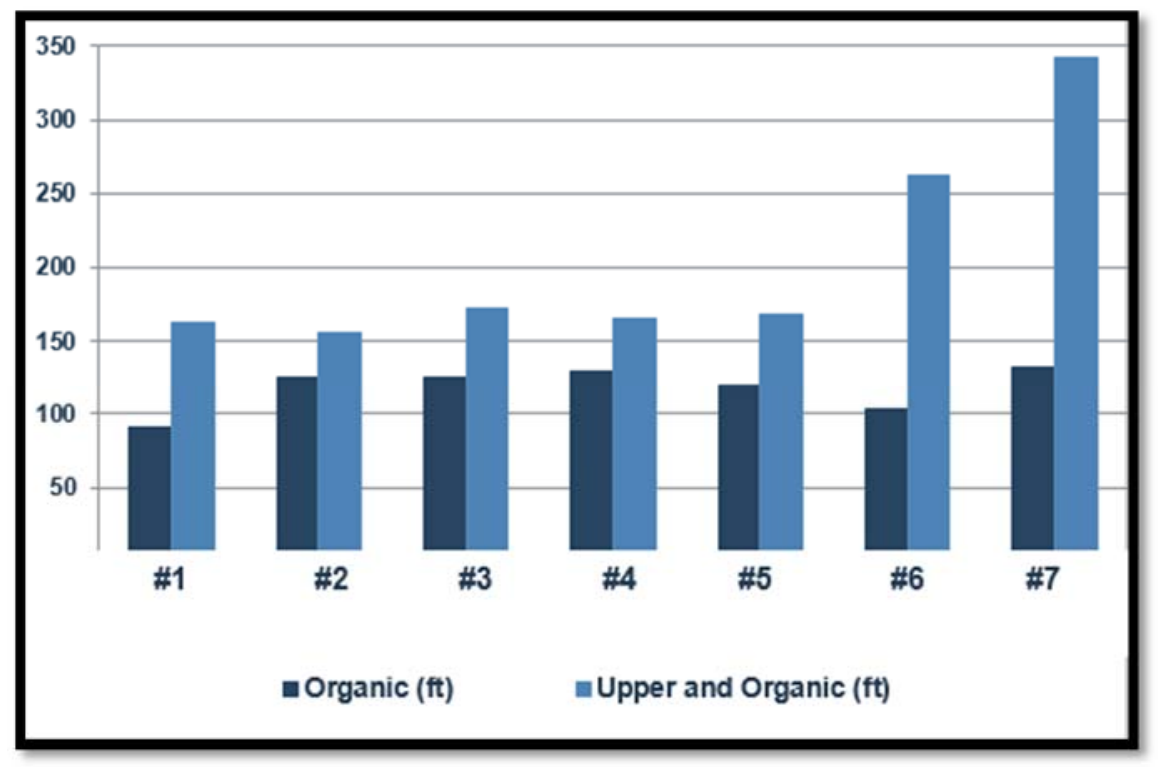

Figure 16: Seven offset wells Reservoir thickness (ft.), Upper \& Lower (Organic) Eagle Ford 


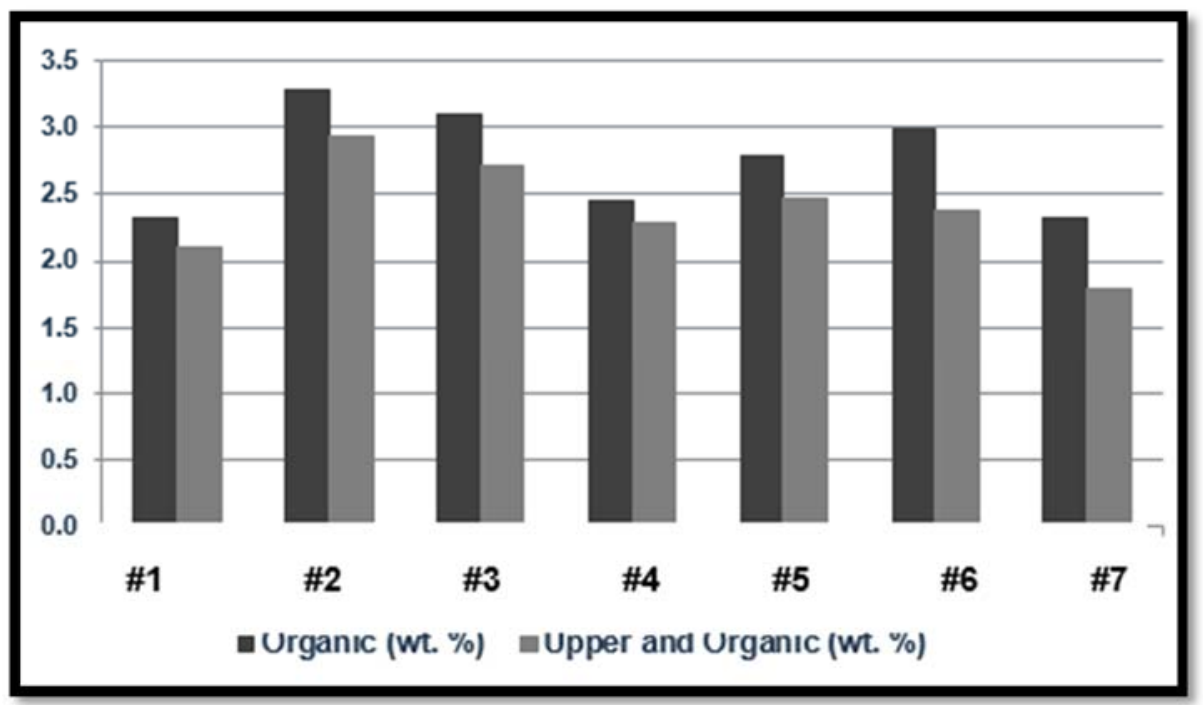

Figure 17: Seven offset wells TOC (\%.), Upper \& Lower (Organic) Eagle Ford

The Eagle Ford shows a clear-cut thickening in the Maverick Basin (Driskill, et al 2012). Figure 18 summarizes reservoir properties obtained from log data and it indicates a strong relationship between density and total organic carbons (TOC). Also reservoir properties were collected from wells with density logs in Maverick Basin. The density was used to determine porosity curves as well as hydrocarbon saturation using the density based GRI process.

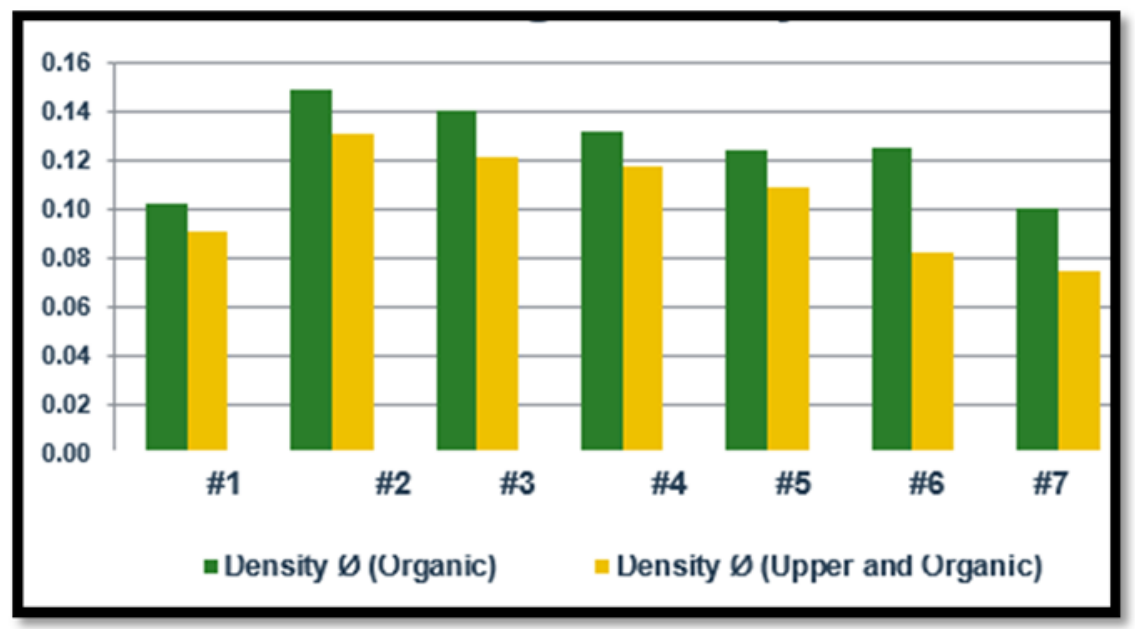

Figure 18: Seven offset wells Porosity (\%), Upper \& Lower (Organic) Eagle Ford 


\begin{tabular}{|l|r|}
\hline Parameter & Average Values \\
\hline GRI Matrix Permeability (md) & $5.40172 \mathrm{E}-05$ \\
\hline GRI Matrix Permeability - Absolute (md) & 0.000918966 \\
\hline GRI Bulk Density (gm/cm^3) & 2.469957746 \\
\hline GRI Grain Density (gm/cm³) & 2.643619718 \\
\hline GRI Total Porosity (percent) & 8.22943662 \\
\hline GRI Gas Filled Porosity (percent) & 3.868241507 \\
\hline GRI Saturations - Sg (percent) & 46.13492958 \\
\hline GRI Saturations - So (percent Vp) & 27.16887324 \\
\hline GRI Saturations - Sw (percent) & 26.69619718 \\
\hline GRI Saturations - OBM Filtrate (percent) & 5.846338028 \\
\hline GRI Saturations Total & 100 \\
\hline
\end{tabular}

Table 12: Eagle Ford offset well Core Data

Due to low porosity, shales typically have low net hydrocarbon pore thickness and resource density. Low matrix permeability limits productivity and drainage area as well as economic rates and recoveries. These geological constrains are countered with hydraulic fracturing, which is critical to achieving larger drainage area and economic rates and recovery. Liquids rich unconventional plays are also significantly impacted by large pressure gradients in the near wellbore area and by variations in rock and fluid properties. Figure 19 shows well logs illustrating degree of correlation within the lower Eagle Ford where track 1 is the Formation, track 2 is Gamma ray, track 3 Deep resistivity, track 4 Neutron porosity (green) and Density (red).

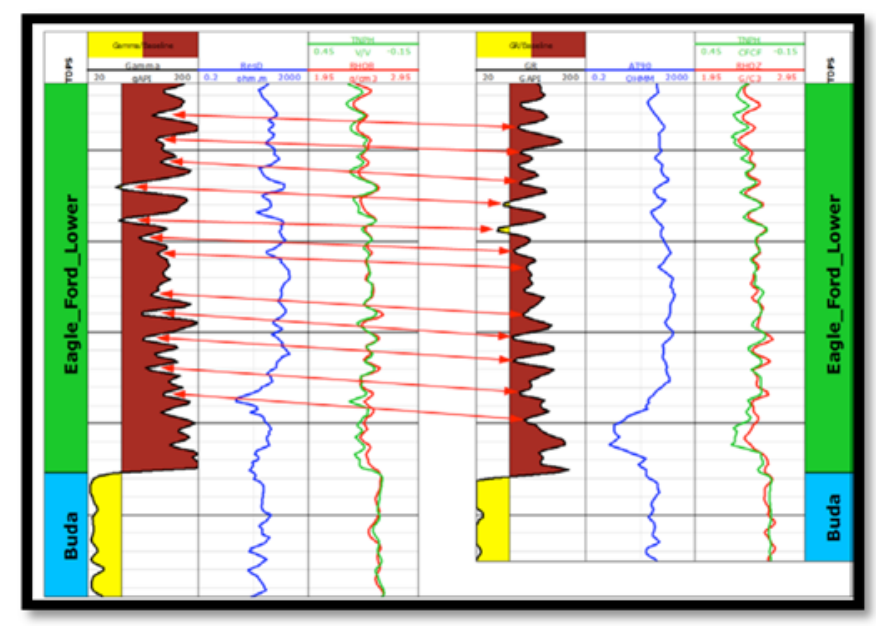

Figure 19: Well Log Data from Eagle Ford Shale (Driskill, et al 2012) 


\subsection{Fluid Behavior in the Eagle Ford Shale.}

Eagle Ford Shale display a wide range variation of maturity. Fluid maturity is a function of time and temperature and it's strongly related to depth as Kerogen changes from oil to dry gas. In Eagle Ford, Wan, el at (2013) investigated the oil window and observed it in the up dip, shallow part of the play toward the north-west, and dry gas is found in the south eastern, deeper portion of the play. Local variations can be driven by underlying deep structure and heat transport.

As illustrated in Figure 20, fluid type within the Eagle Ford differ from oil to volatile oil to condensate to wet gas and finally to dry gas. Due to the burial history, there can be huge well to well differences around this trend.

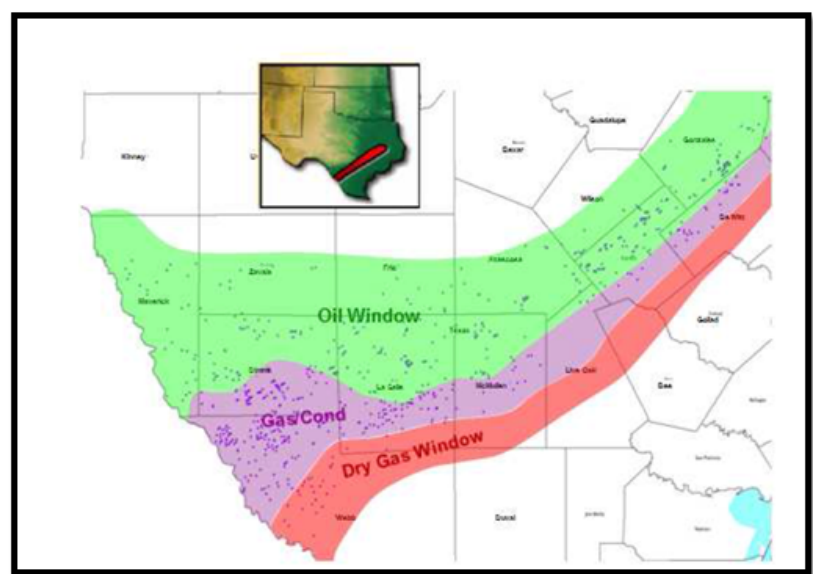

Figure 20: Maturity variation within the Eagle Ford (Wan, el at 2013)

Detailed examination of all available production data for Eagle Ford provides better understanding of the effect of liquid content on production. Also maturity of the fluid system need to be addressed as this has major implication on reservoir development. Hydrocarbon generation fundamentals can help to understand the reserve, productivity, and drive mechanism related with different fluid systems.

Figure 21 provides overview of the different products exist with different shale plays from black oil to dry gas and their impact on reservoir characteristics. These effects originate from two major factors, namely, degree of organic matter development and 
application related fluid production. The amount of organic-derived porosity and permeability have a strong effect nearly every key component of storage and flow capacity. Due to immaturity, there is less organic-derived porosity and permeability, therefore, some form of permeability enhancement such as hydraulic fracturing to produce commercial production rate is needed.

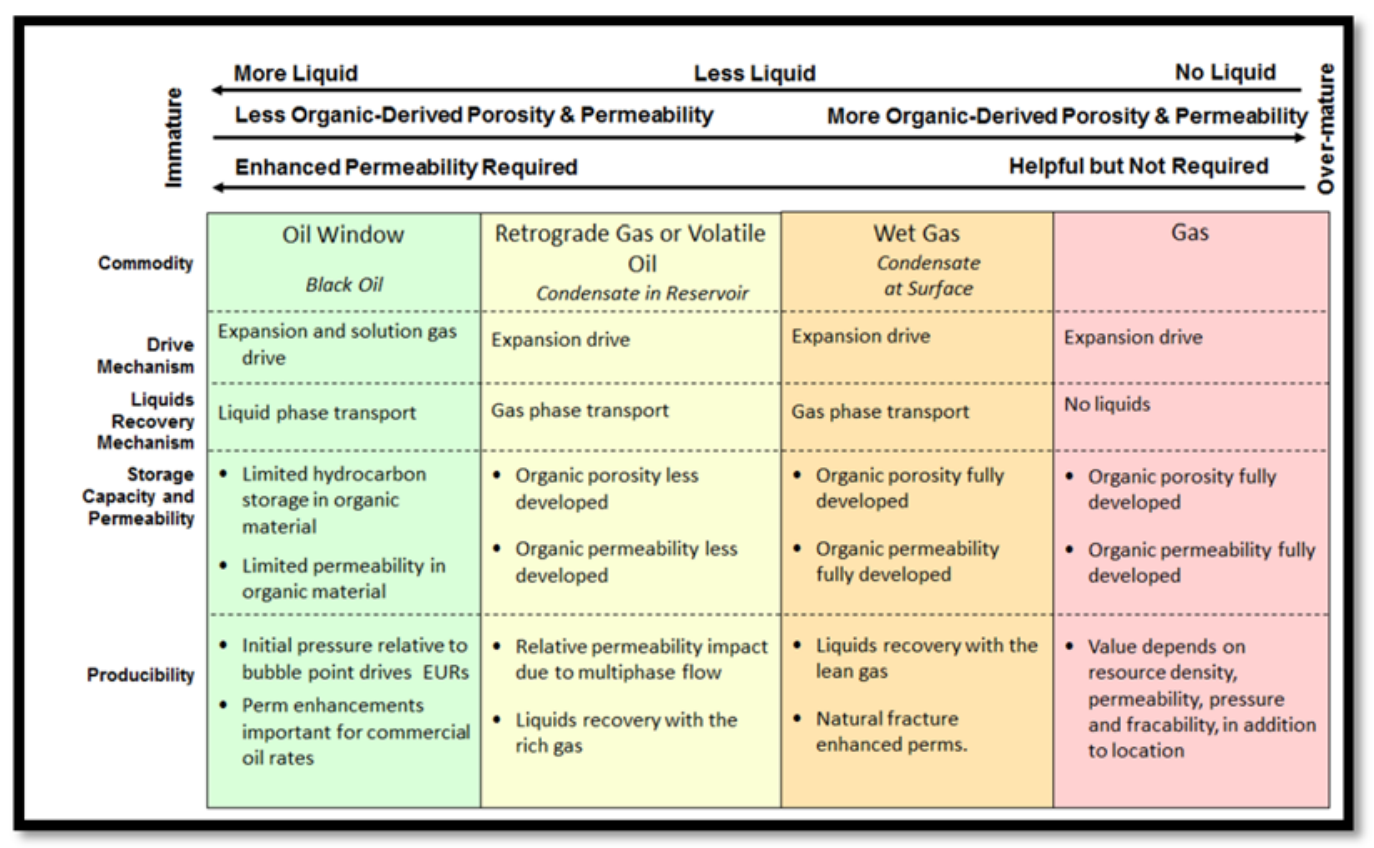

Figure 21: Hydrocarbon Generation Fundamentals and recovery Impact (Wan, el at 2013)

Bottom hole and surface fluid samples may not be good models of in-situ reservoir fluid, which can be attributed to the long transient flow time in low permeability shale reservoirs. However, the most common method for PVT analysis is still to collect produced gas and liquid samples at the surface and recombine them in a laboratory (Whitson and Sunjerga, 2012). Table 13 and 14 illustrate molar composition of synthetic oil and condensed data. Orangi et al. (2011) produced a set of synthetic Eagle Ford fluids by recombining typical stock tank oil and gas compositions. Available data for their study were stock tank oil API gravity, GasOil Ratio (GOR), Condensate-Gas Ratio (CGR), reservoir temperature, and reservoir pressure. Orangi et al. (2011) modified the recombined compositions to yield reservoir fluids with different GOR values of 500, 1000, and 2000 SCF/STB, and different CGR values of 30, 100, 150, and 200 STB/MMSCF. 
Tables 13 and 14 highlight recombined compositions for oil and gas-condensate fluids with different GOR/CGR values developed by Orangi et al. (2011), based on the Peng and Robinson (1976) equation of state.

\begin{tabular}{|c|c|c|c|c|c|c|c|}
\hline \multirow{3}{*}{ Component } & \multirow{3}{*}{$\begin{array}{c}\text { Molecular } \\
\text { Weight }\end{array}$} & \multirow{3}{*}{$\begin{array}{l}\text { Specific } \\
\text { Gravity }\end{array}$} & \multirow{3}{*}{$\mathbf{T}_{c}(\mathbf{R})$} & \multirow{3}{*}{$\begin{array}{c}\mathbf{P}_{c} \\
(p \operatorname{pia})\end{array}$} & \multirow{2}{*}{\multicolumn{3}{|c|}{$\begin{array}{c}\text { Composition (mole \%) } \\
\text { GOR (SCF/STB) }\end{array}$}} \\
\hline & & & & & & & \\
\hline & & & & & 500 & 1000 & 2000 \\
\hline C1 & 16.04 & 0.3500 & 343.3 & 673.1 & 31.23 & 44.52 & 56.45 \\
\hline N2 & 28.01 & 0.8080 & 227.2 & 492.3 & 0.07 & 0.10 & 0.13 \\
\hline $\mathrm{C} 2$ & 30.07 & 0.4800 & 549.8 & 708.4 & 4.31 & 5.88 & 7.29 \\
\hline C3 & 44.10 & 0.5077 & 665.8 & 617.4 & 4.15 & 4.51 & 4.83 \\
\hline $\mathrm{CO} 2$ & 44.01 & 0.8159 & 547.6 & 1071.3 & 1.28 & 1.82 & 2.31 \\
\hline IC4 & 58.12 & 0.5631 & 734.6 & 529.1 & 1.35 & 1.30 & 1.25 \\
\hline $\mathrm{NC4}$ & 58.12 & 0.5844 & 765.4 & 550.7 & 3.38 & 2.98 & 2.62 \\
\hline IC5 & 72.15 & 0.6248 & 828.7 & 483.5 & 1.81 & 1.51 & 1.24 \\
\hline NC5 & 72.15 & 0.6312 & 845.6 & 489.5 & 2.14 & 1.71 & 1.33 \\
\hline NC6 & 86.18 & 0.6641 & 914.2 & 439.7 & 4.62 & 3.28 & 2.08 \\
\hline $\mathrm{C} 7-\mathrm{C} 10$ & 114.40 & 0.7563 & 1060.5 & 402.8 & 16.30 & 11.56 & 7.32 \\
\hline $\mathrm{C} 11-\mathrm{C} 14$ & 166.60 & 0.8135 & 1223.6 & 307.7 & 12.00 & 8.94 & 5.92 \\
\hline C15 - C19 & 230.10 & 0.8526 & 1368.4 & 241.4 & 10.04 & 7.13 & 4.51 \\
\hline $\mathrm{C} 20+$ & 409.20 & 0.9022 & 1614.2 & 151.1 & 7.31 & 4.76 & 2.75 \\
\hline
\end{tabular}

Table 13: Molar composition of synthetic Eagle Ford oil (Orangi et al. 2011)

\begin{tabular}{|c|c|c|c|c|c|c|c|c|}
\hline \multirow{3}{*}{ Component } & \multirow{3}{*}{$\begin{array}{l}\text { Molecular } \\
\text { Weight }\end{array}$} & \multirow{3}{*}{$\begin{array}{l}\text { Specific } \\
\text { Gravity }\end{array}$} & \multirow{3}{*}{$\mathbf{T}_{\mathrm{c}}(\mathbf{R})$} & \multirow{3}{*}{$\begin{array}{c}\mathbf{P}_{c} \\
\text { (psia) }\end{array}$} & \multirow{2}{*}{\multicolumn{4}{|c|}{$\begin{array}{c}\text { Composition (mole \%) } \\
\text { CGR(STB/MMSCF) }\end{array}$}} \\
\hline & & & & & & & & \\
\hline & & & & & 30 & 100 & 150 & 250 \\
\hline C1 & 16.04 & 0.3500 & 343.3 & 673.1 & 74.73 & 70.75 & 65.88 & 63.74 \\
\hline N2 & 28.01 & 0.8080 & 227.2 & 492.3 & 0.18 & 0.17 & 0.15 & 0.15 \\
\hline $\mathrm{C} 2$ & 30.07 & 0.4800 & 549.8 & 708.4 & 9.43 & 8.94 & 8.34 & 8.07 \\
\hline C3 & 44.10 & 0.5077 & 665.8 & 617.4 & 5.24 & 4.98 & 4.67 & 4.53 \\
\hline $\mathrm{CO} 2$ & 44.01 & 0.8159 & 547.6 & 1071.3 & 3.05 & 2.89 & 2.69 & 2.60 \\
\hline IC4 & 58.12 & 0.5631 & 734.6 & 529.1 & 1.14 & 1.10 & 1.05 & 1.02 \\
\hline $\mathrm{NC4}$ & 58.12 & 0.5844 & 765.4 & 550.7 & 1.96 & 1.90 & 1.83 & 1.79 \\
\hline IC5 & 72.15 & 0.6248 & 828.7 & 483.5 & 0.79 & 0.81 & 0.83 & 0.83 \\
\hline NC5 & 72.15 & 0.6312 & 845.6 & 489.5 & 0.69 & 0.73 & 0.79 & 0.82 \\
\hline NC6 & 86.18 & 0.6641 & 914.2 & 439.7 & 0.24 & 0.67 & 1.19 & 1.42 \\
\hline $\mathrm{C} 7-\mathrm{C} 10$ & 112.00 & 0.7527 & 1051.4 & 408.6 & 1.67 & 4.28 & 7.63 & 9.10 \\
\hline C11-C14 & 175.00 & 0.8201 & 1245.9 & 296.9 & 0.81 & 2.56 & 4.55 & 5.43 \\
\hline C15-C19 & 210.00 & 0.8424 & 1327.6 & 259.0 & 0.06 & 0.16 & 0.28 & 0.33 \\
\hline $\mathrm{C} 20+$ & 250.00 & 0.8612 & 1405.8 & 226.3 & 0.03 & 0.08 & 0.14 & 0.16 \\
\hline
\end{tabular}

Table 14: Molar composition of synthetic Eagle Ford gas condensates (Orangi et al. 2011) 
A black oil simulator can be utilized in the Eagle Ford oil window, with initial reservoir pressure being well above the bubble point pressure. Therefore, reservoir fluid exists as undersaturated (single phase). It is known that using a black oil model can decrease simulation time and calculations. Table 15 outlines the black oil PVT properties for the Eagle Ford Shale in the oil window used by Chaudhary et al. (2011).

\begin{tabular}{|c|c|}
\hline Reservoir temperature, ${ }^{\circ} \mathrm{F}$ & 255 \\
\hline Bubble point pressure for oil, psi & 2398 \\
\hline Solution gas oil ratio, SCF/STB & 650 \\
\hline Oil API gravity & 42 \\
\hline 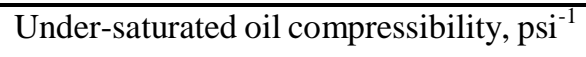 & $1 \times 10^{-5}$ \\
\hline Gas specific gravity & 0.8 \\
\hline
\end{tabular}

Table 15: Black oil PVT properties for the Eagle Ford oil window (Chaudhary et al. 2011). 


\subsection{Eagle Ford Shale Reservoir Modeling}

Modeling is performed at early stages of field development to estimate parameters such as treatment efficiency, fracture geometry, optimum well spacing, and secondary recovery at later stages. The reservoir characterization is required to define reservoir properties such as porosity and permeability for each grid block in a reservoir simulation model. It also requires description of the reservoir's rock and fluid properties, validation of completion and production history, and extensive history matching to validate and modify this input data. When history matching is complete, numerous predictions of field and well performance characteristics are calculated for various development scenarios. In general, there are two modeling solutions, analytical and numerical modeling. The analytical methods provide exact solutions to simplified problems, while numerical methods yield approximate solutions to the exact problems. One consequence of this is that the level of detail and time required to define a numerical model is more than its equivalent analytical model.

\subsection{Hydraulic Fracture Modeling}

Three-dimensional planar fracture model initiate propagation in both horizontal and vertical fracture with large length to height aspect ratios. This model produces the most realistic geometries and can be applied for generating discrete fracture network (DFN). The model assumes a bounded geometry at the leading edge (perimeter) as illustrated in Figure 22 (Meyers 2014).

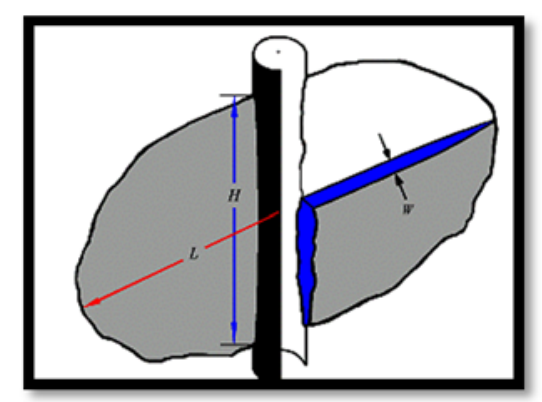

Figure 22: Three-Dimensional Fracture Geometry (Meyers \& Associate 2014) 
Conventional fracture treatment provides bi-wing fractures because it requires less energy. But the existing of low stress anisotropy and natural fractures in shale formations provide geo-mechanical conditions that cause hydraulically induced discrete fractures to start and propagate as both horizontal and vertical fractures in three principle planes (Meyers, et al 2011). The micro-seismic measurement data gathered during fracture treatment can be very helpful as a diagnostic element to calibrate fracture model forming the Discrete Fracture Network (DFN) geometry including areal extend, fracture length, fracture height and fracture width. Multiple fractures could be initiated from the wellbore. Each fracture could propagate from the wellbore originating from set of perforations and one main fracture (Dominant or Primary Fracture) may be extended from the wellbore and secondary fracture may split off, forming a fracture spray. Table 16 presents the characteristics of a discrete fracture network (DFN) (Meyers 2014).

\begin{tabular}{|l|l|l||}
\hline Name & Fracture Plane & Aperture Opening Along \\
\hline Major Vertical Fractures & $\mathrm{x}-\mathrm{z}$ & $\sigma 3$ Minor Axis \\
\hline Minor Vertical Fractures & $\mathrm{y}-\mathrm{z}$ & $\sigma 2 \quad$ Major Axis \\
\hline Horizontal Fractures & $\mathrm{x}-\mathrm{y}$ & $\sigma 1 \quad$ Vertical Axis \\
\hline
\end{tabular}

Table 16: The Characteristics of discrete fracture network (DFN) (Meyers \& Associate 2014)

The propagation of hydraulic fractures is assumed to be controlled by:

- The reservoir in situ effective stress, defined by the total stress tensor and reservoir pressure.

- The rock matrix strength, deformability, heterogeneity and anisotropy.

- The geometry and mechanical and flow properties of the natural fracture system.

- The configuration and operation of the hydraulic injection process.

The fundamental first-order discrete fracture network (DFN) equations of mass and momentum conservation are based on a similar solution methodology. The 
formulation utilizes a pseudo three-dimensional ellipsoidal approach. The major assumptions are:

1. The primary fracture or dominant fracture is in $x-z$ plane and propagates perpendicular to the minimum horizontal stress, $\sigma_{3}$. The $y-z$ and $x-y$ plane fractures propagate perpendicular to $\sigma_{2} \& \sigma_{3}$.

2. DFN may have secondary fractures in all three principles planes,

3. Fractures will only propagate in the $y-z$ and $x-y$ planes if the fracture pressure is greater than minimum horizontal stress in that plane.

4. The initial conditions with existing natural fractures in the formation can initiate multiple hydraulic fractures.

5. Fractures in the $x-z$ plane (other than the dominant fracture) are not generated unless a fracture network in the $y-z$ plane is established for the fracture to propagate (i.e., in the DFN the fractures must be connected.). These assumptions are not applicable for multiple or cluster type fractures which may be disjointed

6. The numerical solution is based on ellipsoidal type of equations. The fracture stimulated reservoir volume is ellipsoidal as well as the geometric distributions. The width and height profiles are however calculated from the governing p3D pressure-width-height relationships.

7. Fracture interaction for stiffness and fluid loss is considered.

8. The fracture height at the joints in the $x-z$, and $y-z$ planes are assumed to be the same. This summation is true for $2-D$ and penny shape fractures but may not be for well contained fractures. This assumption will not have a great effect on the solution unless there is a considerable fracture volume and/or fluid loss in the regions of high confining stress contrast at the upper and lower fracture height extensions.

9. The fracture network extension (with the exception of the dominant fracture) can be limited to a finite fracture extent in each plane.

The fracture network model is based on a similar methodology presented by Warren and Root (1963) for dual porosity natural fracture reservoir (Meyers, et al 2011). Figure 23 represents the concept of a hetrogeneous porous media. The fracture network model 
assumes dominant (primary) and secondary fractues can be initiated and propogated discreatly in pronciple planes provided conditions listed above are achieved.

Vertical fractures can be initiated in the $x-z$ plane (major axis) and $y-z$ planes (minor axis), and horizontal fracture can propogate in the $x-y$ plane (vertical axis).

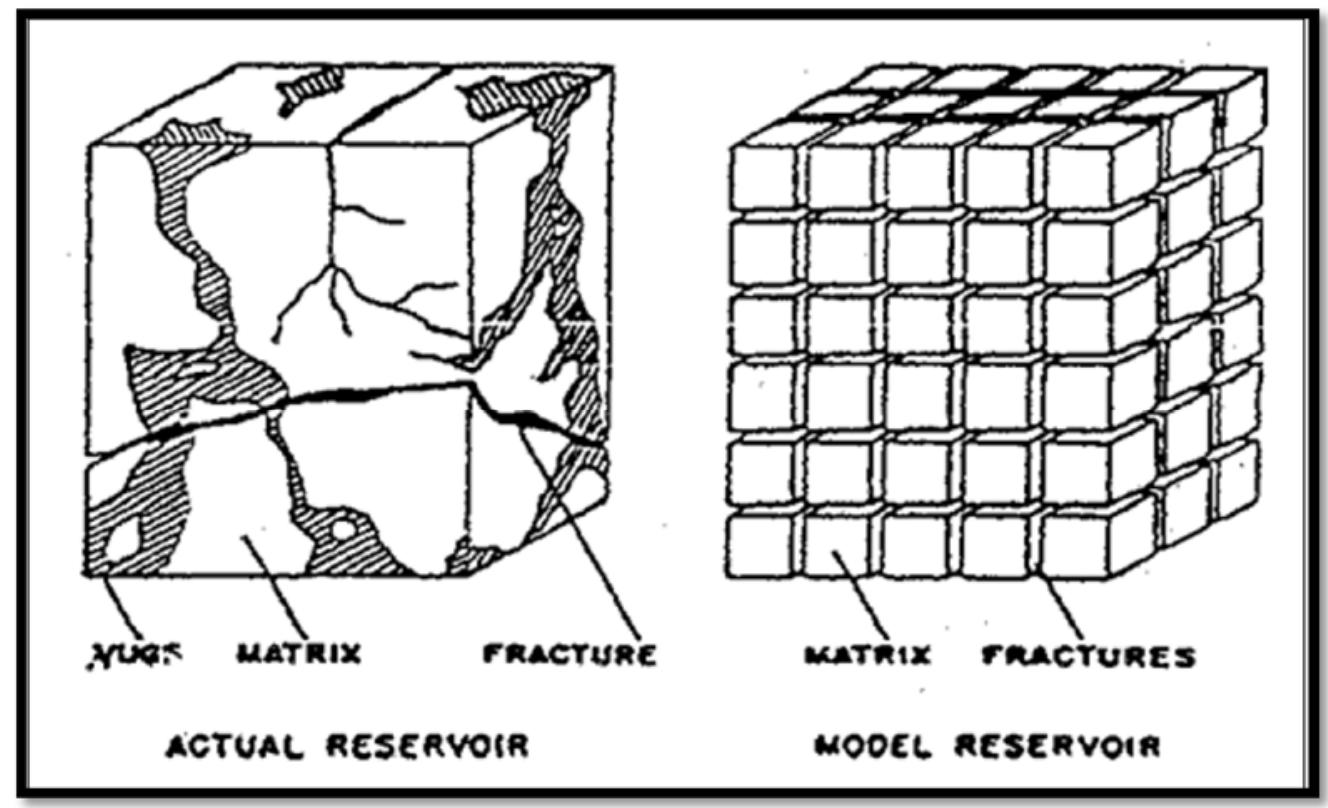

Figure 23: Warren and Root (1963) Idealization of the heterogeneous porous media (Meyers, et al 2011).

The modeling for DFN growth is based on numerical solution for the equations satisfying continuity, mass conservation, constitutive relationship and momentum equations Appendix A shows the basic equations for the discrete fracture network (DFN) model.

\subsubsection{Proppant Distribution}

Proppant distribution in a DFN is very complicated and naturally difficult to solve. There are three different scenarios for proppant distribution and transportation (Cipolla et al. 2004). Figure 24 illustrates the three different scenarios for proppant transportation.

1. "The proppant is evenly distributed throughout the complex fracture system." 
2. "The proppant is concentrated in a dominant planar fracture with un-propped complex fracture system accepting fluid only."

3. "The proppant settle and forms pillars that are evenly distributed within the complex fracture system."

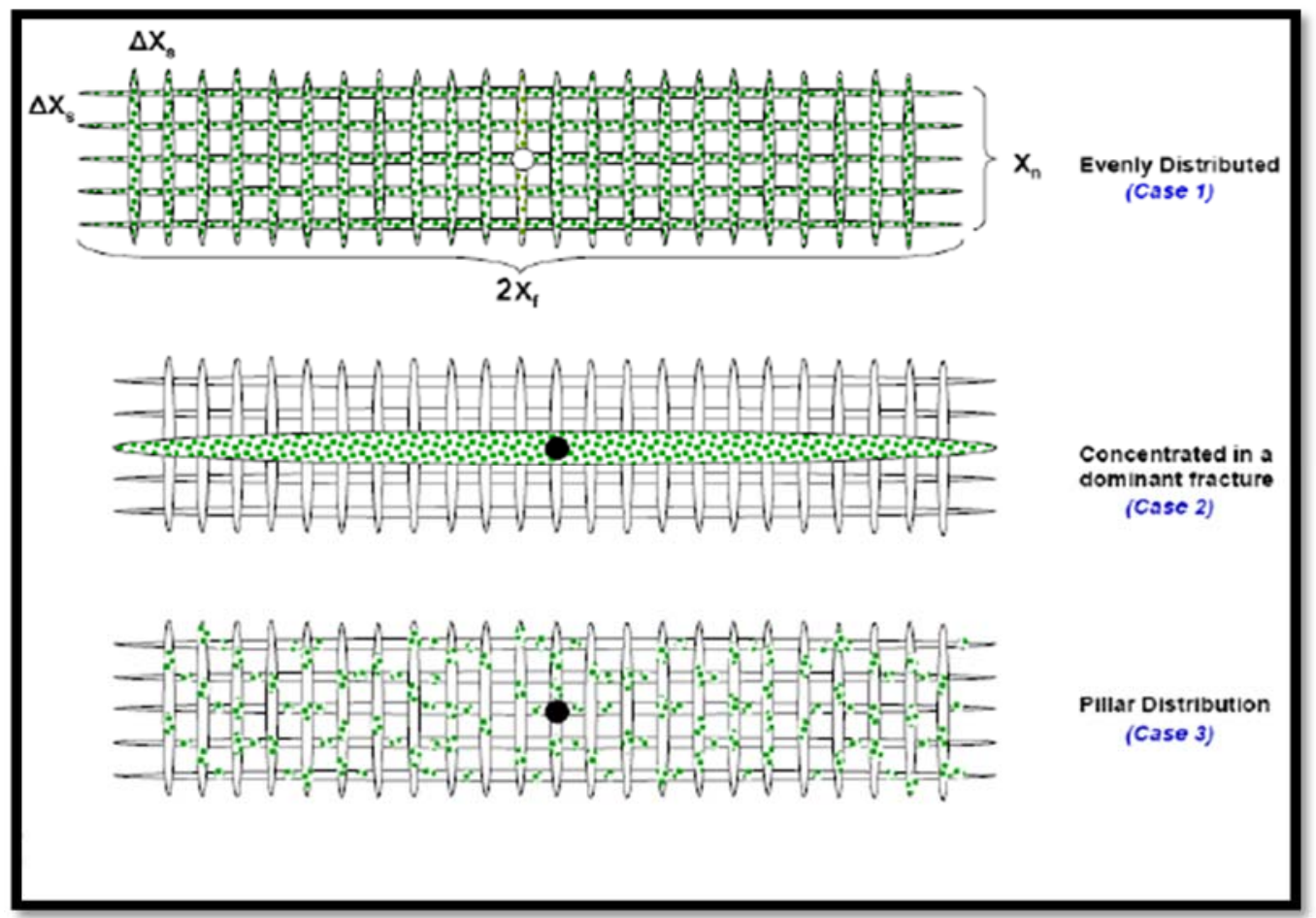

Figure 24: Proppant transport scenarios (Cipolla et al. 2008)

The dominant fracture efficiency is used to determine proppant transport and distribution. The flux is also slightly different in the primary fracture depending on the proppant distribution option and will therefore give slight deviations in the numerical solution. To simplify the theory while preserving the limiting solutions, assumptions for proppant distribution styles are

- Uniform,

- Primary Fracture (Dominant)

- User specified 


\subsubsection{Uniform Proppant Distribution}

The Uniform Proppant Distribution option assumes that the proppant can be transported uniformly (i.e., concentrating only due to fluid loss not flow dispersion in the secondary fractures or bridging at DFN interfaces.) throughout the DFN. It is transported into dominant fracture as a slurry.

\subsubsection{Dominant Fracture Proppant Distribution}

The Dominant Fracture Proppant Distribution option assumes that all the proppant remains in the primary fracture and no proppant enters the secondary DFN.

Consequently, the secondary fractures act primarily as fluid loss conduits from the primary fracture

\subsubsection{User Specified Proppant Distribution}

The User Specified Proppant Distribution option allows the user to specify the minimum proppant allocation that remains in the primary fracture with the remaining proppant entering the secondary DFN. Discrete fracture network (DFN) proppant distribution basic equations are shown in Appendix A.

\subsection{Analytical Modeling analysis}

Modeling is the process of history matching pressure and rate transient data based on a mathematical model. It is vital to evaluate the pressure and rate transient data before modeling because it defines probable reservoir configurations and provides good estimates of reservoir parameters. Models provide not unique solutions (different model types can match the same set of data), and as a result, it is recommended to choice appropriate model type. Parameter values obtained during the analysis step provide a good starting point for an appropriately chosen model type. Seeking history match, parameters can then be optimized by automatic parameter estimation. Before using the automatic parameter estimation method, corrupted parts should be cleaned from the data set to prevent the attempt to match with invalid points. (Anderson, et al 2014). 
Material balance time is a present analysis method used by the industry. Since material balance time is actually boundary-dominated flow superposition time, these analyses may appear to show boundary-dominated flow even when the reservoir is still exhibiting transient flow. The production data is analyzed using a plot and a linear flow appears as a straight line trend. Since the basic assumption is the infinite conductivity in the fracture, finite conductivity manifests as a positive intercept on the plot. The equations presented are based on the assumption of a constant flowing pressure at the well. This is a reasonable simplification for tight gas and shale production, in which wells are typically produced under high drawdown.

The flow regimes stay longer periods of time and that is a major challenge for analyzing shale reservoirs. It's very difficult to predict recoverable resources along with reservoir properties such as fracture length, fracture conductivity, permeability, and drainage area.

Figure 25 is an example of a specialized plot of a normalized pressure (y-axis) versus square root of time (x-axis). This plot can be used to determine the slope from the linear portion of Figure 25 . From the slope of the equation, fracture half-length and permeability are determined as a single product. To determine either one explicitly, the other parameter must be known. The slope is inversely proportional to stimulated reservoir volume (AsRv), flow capacity of well ( $A \sqrt{K}$ ), fracture half length, and effective half length $\left(x_{f} \sqrt{k}\right)$.

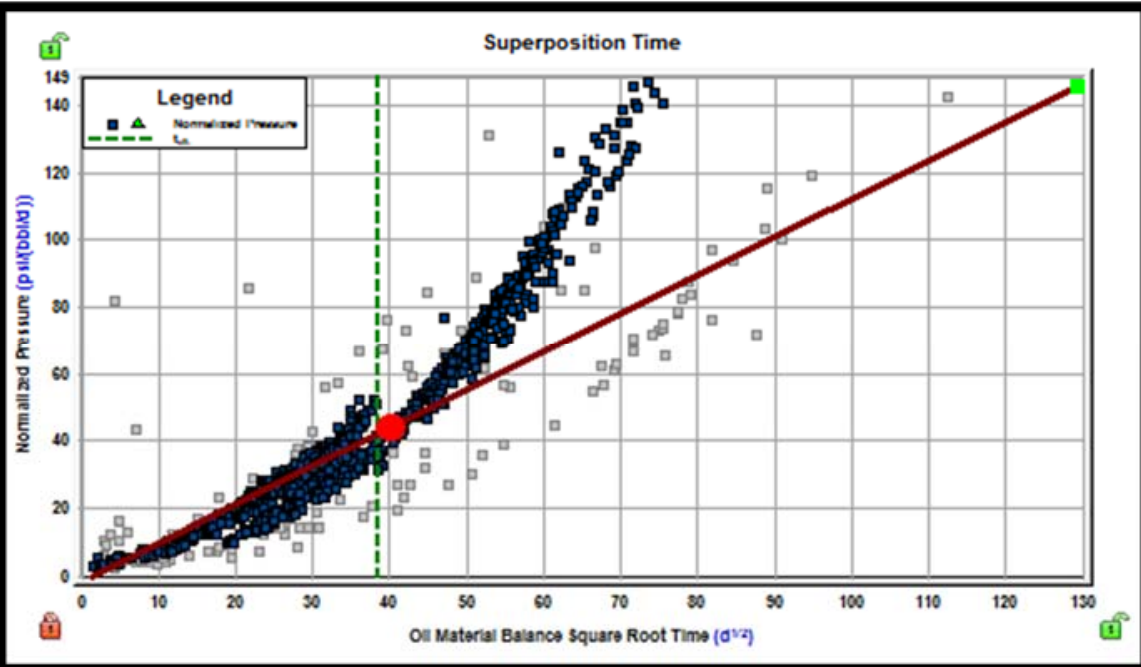

Figure 25: Oil Material Balance Square Root Time $\left(d^{1 / 2}\right)$ 
Followings are the parameters determined from the slope:

$A \sqrt{K} \quad=$ flow capacity $\left(m d^{\frac{1}{2}} f t^{2}\right)$

$x_{f} \sqrt{k}=$ flow capacity $\left(m d^{\frac{1}{2}} f t\right)$

AsRV $=$ Stimulated reservoir Area (acres)

\subsubsection{Horizontal Multi-stage Enhanced Fracture Model}

Horizontal drilling with multistage hydraulic fractures become the common way to produce hydrocarbons from shale reservoirs. Due to fractures created based on geomechanical conditions, it does not always result in bi-wing fractures but also secondary fractures or branches. For modelling purposes, secondary fractures can be represented by a high permeability region near each stage, while the bulk of space between the stages remains un-stimulated as illustrated in Figure 26 . This model is a rectangular reservoir model consisting of a non-contributing horizontal well and transverse fractures. This model assumes that all the fractures are uniformly spaced with equal half-fracture length. (The reservoir can extend beyond the fracture tips.) This model has an improved effective permeability region around each fracture, and the distance from the fracture to the permeability boundary $\left(X_{1}\right)$ can be estimated.

This model takes the following linear flow regimes into account (Stalgorova, et al 2012).

- within the fracture (at very early time)

- within the stimulated region towards the fractures

- within the non-stimulated regions towards the stimulated region

- within the non-stimulated region towards the wellbore 


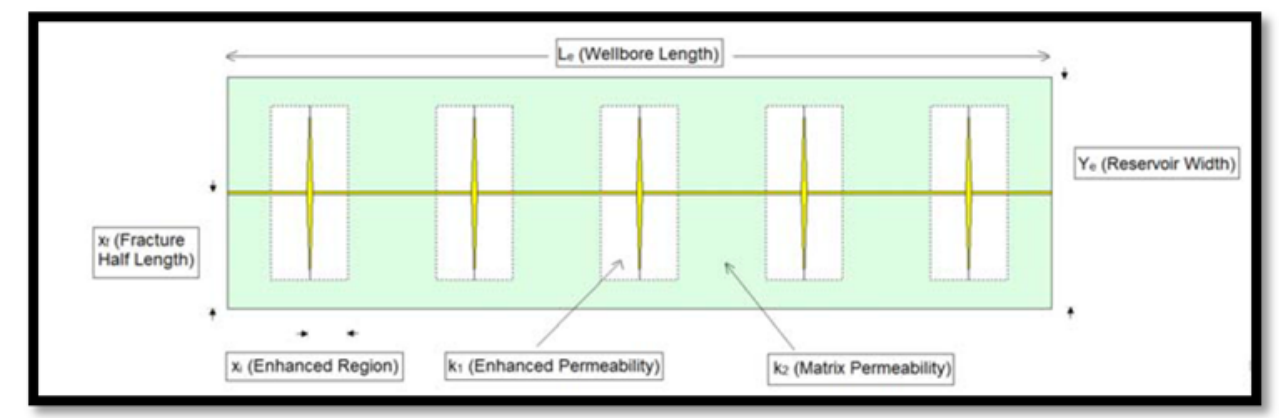

Figure 26: Enhanced Hydraulic fracture model (Stalgorova, et al 2012).

\subsection{Numerical Model Analysis}

The assumption of the analytical model for production data analysis is single-phase flow in the reservoir. In order to perform multiple flowing phases, the model must be able to handle changing fluid saturations and relative permeability functions. Since these phenomena are highly non-linear, analytical solutions are very difficult to obtain and use. Thus, numerical models are generally used to provide solutions for the multiphase flow problem. The model can be created with fewer simplifying assumptions than analytical model. Multiphase behavior and the change of rock and fluid properties with pressure can be incorporated exactly

The model solves the nonlinear partial-differential equations (PDEs) describing fluid flow through porous media with numerical methods. Method uses the process of discretizing the PDEs into algebraic equations, and solving those algebraic equations to obtain the solutions. These solutions that represent the reservoir behavior are the values of pressure and phase saturation at discrete points in the reservoir and at discrete times.

The advantage of the numerical method approach is that the reservoir heterogeneity, mass transfer between phases, and forces / mechanisms responsible for flow can be taken into consideration adequately. Multiphase flow, capillary and gravity forces, spatial variations of rock properties, fluid properties, and relative permeability characteristics can be represented accurately in a numerical model. 


\subsubsection{Reservoir Description}

The purpose of gridding reservoir simulation is to convert geological model into discrete system on which fluid flow equations can be solved. Numerical reservoir description starts with the definition of the grid. The reservoir may contain more layers and possible faults. The following are some criteria for selecting grid block size:

- Capable to identify saturations and pressures at specific locations and times.

- Adequately represent the geometry/geology and physical properties of the reservoir.

- Sufficient to describe the dynamics of pressure, fluid flow, and well behavior.

- Accurately model the reservoir fluid mechanics and comparable mathematics odd simulator.

Two types of non-radial grid geometries are accepted as industry standards rectangular Cartesian geometry (RCG) and non-rectangular corner point geometry (CPG). (CMG modeling group, 2015). Figure 27 shows Cartesian grid blocks and spacing. Standard Cartesian grids are the most common gridding schemes because they are the easiest to implement. Grids can be created from structural maps. Number of grids and grid properties describe the volume of a reservoir and we need to specify:

- Number of grid blocks for each direction (i,j or $\mathrm{x}, \mathrm{y})$

- Number of layers ( $k$ or $z)$

- Grid spacing (grid block width)

- Properties of all grid or layers (porosity, permeability, thickness and etc.)

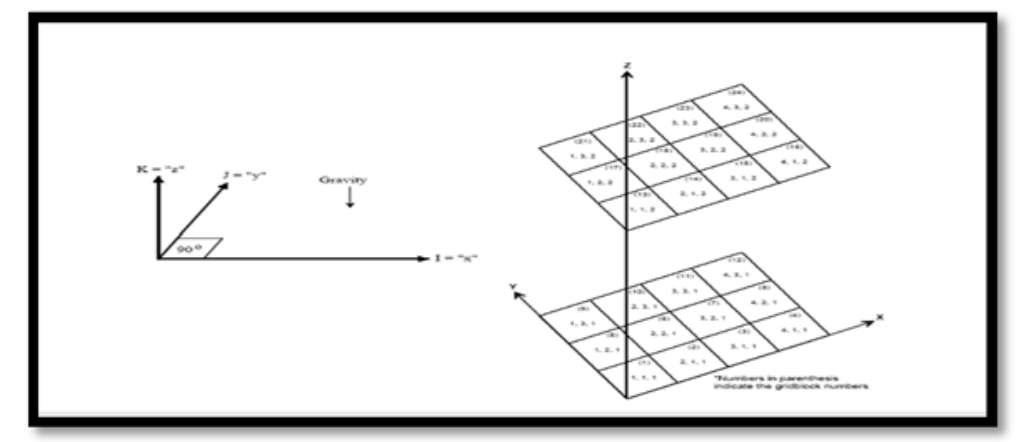

Figure 27: Cartesian grid represented by grid blocs and spacing (CMG, Imex 2015) 


\subsubsection{Relative Permeability Model}

Unconventional reservoirs are economically attractive but operationally difficult. Fluid, rock, and rock-fluid properties are critical for optimal reservoir development. Rock-fluid properties make fluid flow characterization a challenging task. Rock-type based compaction, PVT behavior such as decreased oil bubble point pressure and the resultant viscosity, GOR behavior, interfacial tension, capillary pressure, and relative permeability greatly impact the initial flow rates and ultimate recovery.

The relative permeability values for unconventional reservoirs are difficult to obtain. They cannot be accurately measure due to difficulties in obtaining a representative sample from the reservoir. The only practical method to obtain the realistic values is by history matching the production history. Absolute permeability and relative permeability are two of the most important flow properties that affect hydrocarbon production rates. Absolute permeability is a property of the porous medium and is a measure of the capacity of the medium to transmit fluids. In multiphase flow in porous media, the relative permeability of each phase at a specific saturation is the ratio of the effective permeability of the phase to the absolute permeability. Figure 28 shows a typical relative permeability curve. Relative permeability of each phase is defined by the following equation:

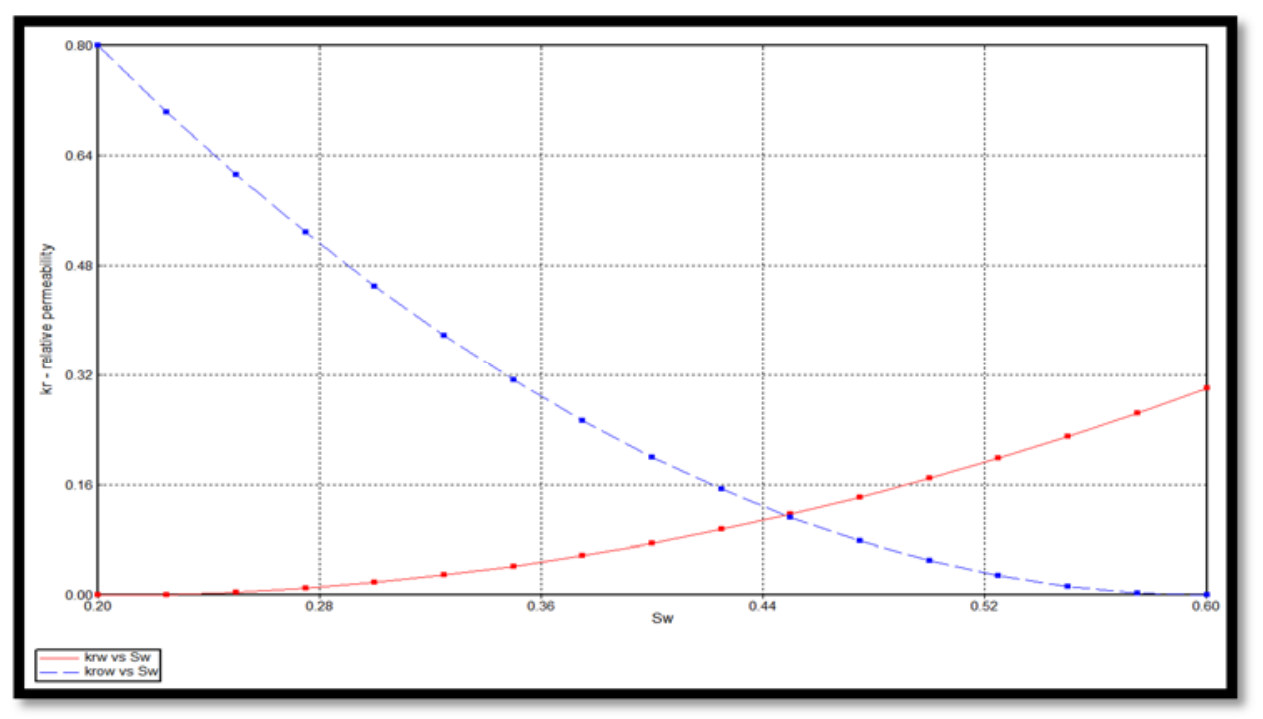

Figure 28: Relative permeability curve (CMG, Imex 2015) 
$K_{\text {ro }}=\frac{K_{o}}{K}$

$K_{r g}=\frac{K_{g}}{K}$

$K_{r w}=\frac{K_{w}}{K}$

Where,

$\mathrm{k}_{\mathrm{ro}}=$ relative permeability to oil

$\mathrm{k}_{\mathrm{rg}}=$ relative permeability to gas

$\mathrm{k}_{\mathrm{rw}}=$ relative permeability to water

$\mathrm{k}$ = absolute permeability

$\mathrm{k}_{\mathrm{o}}=$ effective permeability to oil for a given oil saturation

$\mathrm{k}_{\mathrm{g}}=$ effective permeability to gas for a given gas saturation

$\mathrm{k}_{\mathrm{w}}=$ effective permeability to water at some given water

\subsection{Previous Work Done With Eagle Ford Shale}

Stegent et. al (2010) study shows that cores of the Eagle Ford reservoir rock had low YM and high clay content. This indicates that the rock is relatively soft and prone to proppant embedment as illustrated in Figure 29. The softer, more ductile rock potentially can have more stress anisotropy (the difference between the maximum and minimum horizontal rock stress which allows for more planar-type fracture). Higher concentrations of larger- mesh proppant placed with a hybrid fluid system provides the conductivity to overcome embedment and multiphase flow. Their study also shows that Eagle Ford cores may not have a lot of visible natural fractures, meaning a balance of net pressure may be required to maintain small 
fracture offsets along weak bedding planes and fissures during stimulation. A proper design rate and fluid viscosity is required to create primary fractures at the well bore and create the necessary fracture width while remaining in the pay interval. After detailed analysis and observation, Stegent et. al. (2010) concluded that:

- Hybrid treatment out performed slick water fracture treatment in the EF shale in the area of high liquid production.

- Lower injection rate between 35 and $50 \mathrm{bbl} . / \mathrm{min}$ were sufficient to effectively stimulate EF shale with hybrid fluid and engineering design.

- Higher production occurrences correlate to higher conductive fracture that utilize higher concentrations of larger mash proppants, especially in high liquid production reservoirs.

- Fracture conductivity is important to sustain production when multiphase hydrocarbon flow is expected.

- Higher proppant concentration with 20/40 mesh size proppant can be placed in the EF formation with proper perforation scheme and a proper fracturing fluid design.

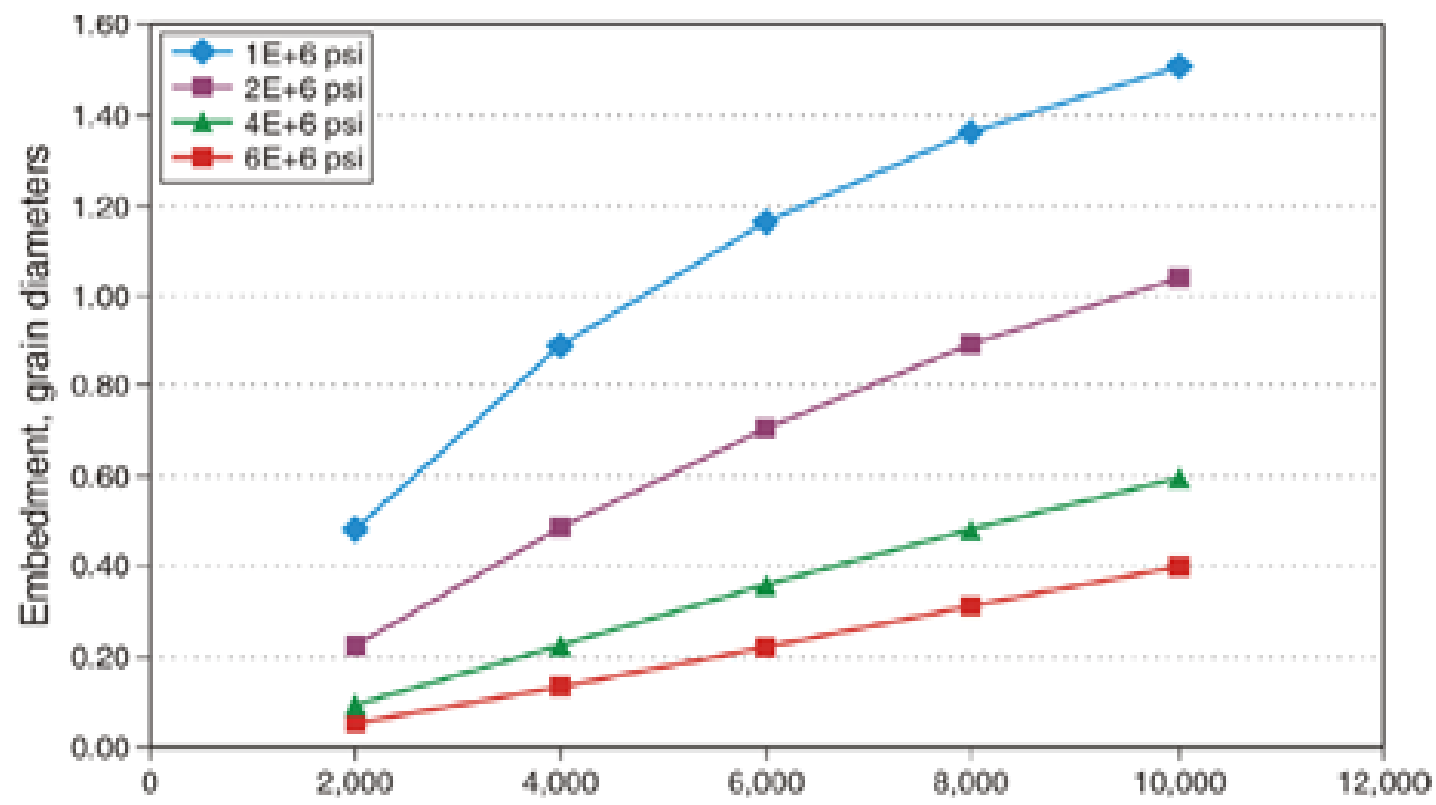

Figure 29: Proppant embedment simulation for various YM vs. closure stress (Cipolla et al. 2008) 
Bazan et. al. (2010)_presented the challenges required for a hydraulic fracture model and treatment design tailored specifically to the EF shale. Rock and fluid properties such as Young's modulus, stress, pressure dependent leak off, and complex fracture propagation limit confidence in traditional fracture models and can result early job termination and less than optimal fracture treatment.

Fracture length, fracture conductivity, cluster spacing, multi-stage completions along the horizontal wellbore are mixed to provide the effect of improved hydraulic fracture design. Utilizing DFN for hydraulic fracture design in EF shale helps to model complex fracture behaviors that may improve the fracture geometry predictions. After detailed analysis regarding DFN modeling in EF, Bazan et. al (2010) concluded that:

- DFN modeling is one option to improve a stimulation program for enhanced hydrocarbon production. Completion technologies, such as microseismic analysis are useful for calibration process for DFN fracture model.

- Increasing fracture geometry can enhance well productivity in EF. Production forecast results for different proppant types indicate a significant potential for increasing productivity for EF well by using higher quality proppant.

- Integrating DFN modeling, microseismic monitoring, production history matching, and radioactive logs with improved fracture conductivity can improve well performance.

Robin et al. (2014) conducted a study of perforation cluster contribution variation in several shale plays including EF. The main objective was to improve initial flow capacity of the well by increasing number of perforation clusters. The study also determined optimum horizontal logging program needed to characterize the rock and grouping rock with similar properties into fracture stages and the position of perforation clusters within those stages to minimize over all stress differential between different set of perforation clusters. The results show the concept of reservoir quality $(R Q)$ and completion quality (CQ). Reservoir quality is defined as the petrophysical parameters of organic shale that makes it a viable candidate for development. 


\subsection{Eagle Ford Shale Treatment Design Procedure}

The heterogeneity of shales makes well treatment more difficult without understanding reservoir and rock properties. Hydraulic fracturing treatment design required specific understanding of reservoir and rock properties.

The rock and fluid properties of shale reservoirs display huge variation, making it difficult to implement the similar treatment design and procedures on every geological formation. Every well in a shale play must be drilled and hydraulically fractured in multiple stages. Therefore, unique treatment methods, and procedures must be developed for each area. Figure 30 shows treatment design procedure based on rock properties such as rock brittleness.

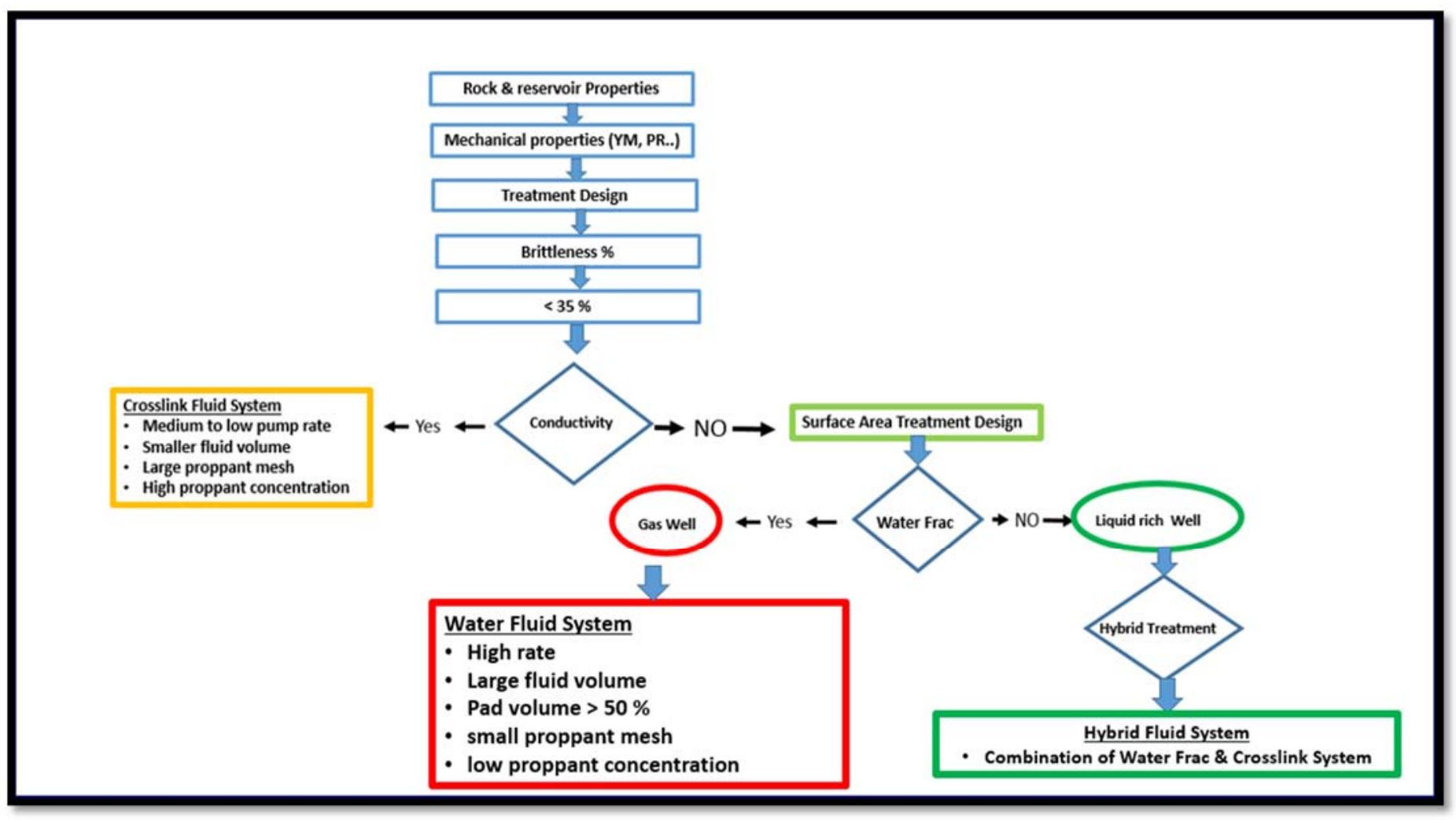

Figure 30: Hydraulic Fracture treatment design procedure based rock brittleness

Formation evaluation data can help to develop required procedure by relating the key hydraulic fracturing design parameters with productivity and ultimate recovery. Following is the summary of unconventional reservoir treatment design procedure. 
1. Determine required rock and reservoir properties.

2. Analyze and select required rock and reservoir properties.

3. Populate selected rock and reservoir data onto fracture simulator

4. Set completion parameters such as perforations, number of cluster and spacing.

5. Calibrate fracture simulator with micro seismic data.

6. Insert anisotropy stress value into fracture simulator.

7. Select fluid system based on rock and reservoir properties.

8. Implement selected treatment design including fluid volume, proppant volume and concentration, pump rate, and required additives.

9. Input created fracture properties into reservoir simulator.

10. Analyze simulated production data and history match with field data.

11. Conduct parametric study of fracture properties and its relation to productivity.

12. Select the optimum treatment design and implement it.

13. To maximize reserve booking, conduct well spacing modeling and determine related economics. 


\section{Objective and Methodology}

\subsection{Objectives}

In Eagle Ford reservoirs, the success of any prospective project is driven by stimulation design. Total well costs are dominated by the cost of hydraulic fracturing, often representing as much as $60 \%$ of the total well cost. This, as a result, requires the operator to select the best completion method that can ultimately improve hydrocarbon recovery.

This research is based on the development of Eagle Ford Formation. The focus of the proposed study is to optimize the exploitation of assets in LaSalle County, Texas.

The objectives of the study is to evaluate and make recommendations to optimize and improve the effectiveness of the fracturing treatments, effectiveness of the completions, well spacing, and production response. In summary, the objective of this study are:

1. Review and evaluate first generation treatment design: To set up workflow of completion optimization and to develop a base model for Discrete Fracture Network (DFN) model and simulating production performance of a producing horizontal well in Eagle Ford Shale.

2. Perform parametric studies: Conduct sensitivity analysis to investigate the effect of rock properties and fracturing fluid have on fracture geometry, conductivity, and ultimate EUR.

3. Develop a second generation treatment design by investigating the impact of modified hydraulic fracturing treatment design on properties of hydraulic fracture and ultimate recovery.

4. Investigate the effect of down spacing on ultimate recovery and net present value (NPV). 


\subsection{Methodology}

The production response is reviewed for a selected well to verify the impact of hydraulic fracturing modeling results. The goal is to evaluate the most effective completion method and stimulation design in relation to the optimal well productivity and spacing. Equations used for this research are presented in Appendices A and B. Available data are integrated for the purpose of understanding the effect of various treatment, completion and reservoir parameters relative to the desired study objectives. The data includes but not limited to well logs, cores, micro seismic survey results, DFIT data, completion data, stimulation data, and individual well production data. Additionally, commercial reservoir, fracturing, and economic \& decline curve simulators (CMG, Mshale, HIS, and PHDWin) are used in this study. In the implementation of the methodology, the followings task were completed:

- 3D fracture simulator (Baker Hughes / Mshale): A DFN simulator was used to provide a systematic approach for analyzing, designing, and optimizing multi stage hydraulic fracture in a horizontal well in Eagle Ford. Field treatment data, rock properties calibrated with microseismic data were used as inputs for this tool.

- Analytical Reservoir Simulator (IHS Harmony/ Rate Transient Analysis): An analytical reservoir model was used to generate type curves, estimate reservoir characteristics, and evaluate single phase analytical model utilizing history matching based on pressure and rate transient data.

- Numerical Reservoir simulator (CMG). A numerical model was used to model hydraulically fractured horizontal well with a Nano-Darcy formation to optimize fracture geometry and spacing and to increase production, EUR and NPV. It was also used to obtain history matches and production forecasts to improve oil recovery.

- Economic Simulator (PHDWin). A simulator with economic evaluation features was used to estimate an accurate economic data to justify projects, development plan, budgets, reserve report, and assess price or ownership changes. It provided comprehensive property and data management, production and reserve 
forecasting (using decline curves or other methods), and economic evaluations for field development.

\subsubsection{First Generation Stimulation Treatment Design (Base Model)}

Limited production and stimulation data were available in the area. Therefore, the best option was to either emulate other completion design or come up with a cookie-cutter design. The first stimulation design was based on a working knowledge of the northeastern part of Eagle Ford such as DeWitt, Gonzales, and Karnes County. The foundation of this stimulation design uses the following assumptions.

1. Reservoir rock is softer, more ductile, and potentially higher in stress anisotropy. Therefore, planer type fractures were expected.

2. Clay swelling and proppant embedment were considered. Therefore, larger mesh, higher concentration of proppant placement, which increases the crosslink fluid ratio. This improves near wellbore conductivity and overcomes multiphase flow and proppant embedment.

3. Conductivity type fracture treatment was selected as a stimulation choice where more viscous fluid, more proppant, and high proppant concentration is pumped into formation to obtain higher conductivity.

The horizontal well in Eagle Ford Shale was drilled transverse (perpendicular) to the expected fracture azimuth in the targeted Eagle Ford Organic Shale formation. The well was drilled using oil base mud across the lateral and completed with plug and perks system. The summary of casing design is presented in Table 17. The average lateral length is $5000 \mathrm{ft}$. with an average TVD of $7582 \mathrm{ft}$. A total of 15 stages at approximately $300 \mathrm{ft}$ stage length of hydraulic fracture treatment were successfully stimulated and mapped. Each stage had 9 to 10 perforation clusters that were $1 \mathrm{ft}$ wide and 5 shots per foot. There were 50 perforations per stage, fired at an average rate of $93 \mathrm{bpm}$, equaling $1.86 \mathrm{bpm}$ per perforation, which is considered sufficient. 


\begin{tabular}{|c|c|c|c|c|c|c|c|c|c|c|}
\hline \multicolumn{11}{|c|}{ Casing Data } \\
\hline String & $O D$ & Wgt & Grade & Thread & Depth & ID (in) & Drift & $\begin{array}{l}\text { Capacity } \\
\text { (bbls/ft) }\end{array}$ & $\begin{array}{l}80 \% \text { SF } \\
\text { Collapse }\end{array}$ & $\begin{array}{c}80 \% \text { SF } \\
\text { Burst }\end{array}$ \\
\hline Surf & $95 / 8$ & 40.00 & J-55 & LTC & $0^{\prime}-2,528^{\prime}$ & 8.835 & 8.679 & 0.0758 & 2,056 & 3,160 \\
\hline Prod & $51 / 2$ & 23.00 & T-95 & $\begin{array}{l}\text { CDC } \\
\text { HTQ }\end{array}$ & $0^{\prime}-8,108.1^{\prime}$ & 4.67 & 4.545 & 0.0211 & 10,352 & 10,032 \\
\hline Prod & $51 / 2$ & 20.00 & $\begin{array}{c}\mathrm{P}-110 \\
\mathrm{HC}\end{array}$ & LTC & $\begin{array}{c}8,108.1^{\prime}- \\
13,507 '\end{array}$ & 4.778 & 4.653 & 0.0221 & 8,864 & 10,112 \\
\hline
\end{tabular}

Table 17: Summary of Well 1 Casing Design

Treatment volumes for PRC-P $380,000 \mathrm{lbm}$ per stage was pumped. The load to recover was relatively consistent for treatment, and averaged approximately $5890 \mathrm{bbl}$. per stage. Total Injected clean fluid was 88,000 barrels with a total proppant mass of $5,700,000$ pound. An average pump rate of $93 \mathrm{Bpm}$ and average treatment pressure of 8,116 psi was recorded. High ratio of crosslink fluid with high proppant concentration was pumped to achieve high conductivity in near wellbore to lower risk of proppant embedment. A summary of first generation stimulation design volumes of well 1 is presented in Table 18.

\begin{tabular}{|l|c|}
\hline \hline Parameter & Generation 1_Value \\
\hline \hline Total Liquid Volume (BBLS) & 85,590 \\
\hline Injection Rate (BPM) & 93 \\
\hline PAD Ratio \% & 25 \\
\hline XLK Ratio \% & 69 \\
\hline 100Mesh (IBM) & 0 \\
\hline $30 / 50$ (IBM) & $5,700,000$ \\
\hline Max proppant conc. (ppg) & 5 \\
\hline Total Proppant (IBM) & $5,700,000$ \\
\hline Fluid System & Crosslink Fluid \\
\hline
\end{tabular}

Table 18: Summary of Well 1 Stimulation Design

Well 1 was successfully stimulated and mapped. Hydraulic Fracture Monitoring with Micro-Seismic examines and analyses the patterns of fluid movement, fracture development, connectivity, compaction and whether the fracture and proppant are staying in pay zone or moving out of pay zone. These important observations allow the processing of stimulation treatment plan, and provide critical understanding for long- 
term improvements for well spacing, well design, completion design, and production optimization. The objective of the fracture mapping was:

1. Estimate vertical coverage of the stimulated Eagle Ford formation.

2. Estimate degree of complexity for created fractures or fracture network.

3. Determine interaction between created fractures/stages or existing possible vaulting.

4. Estimate possible relationship between selected pump rate and fracture height growth.

5. Measure created fracture geometry (height, width, and length) and azimuth.

6. Provide direct guidance that could be used to develop future completion design.

Micro-seismic fracture mapping results for the Well 1 are summarized in Figure 31.

The spatial mapping of micro-seism is presented graphically in Figure 32.

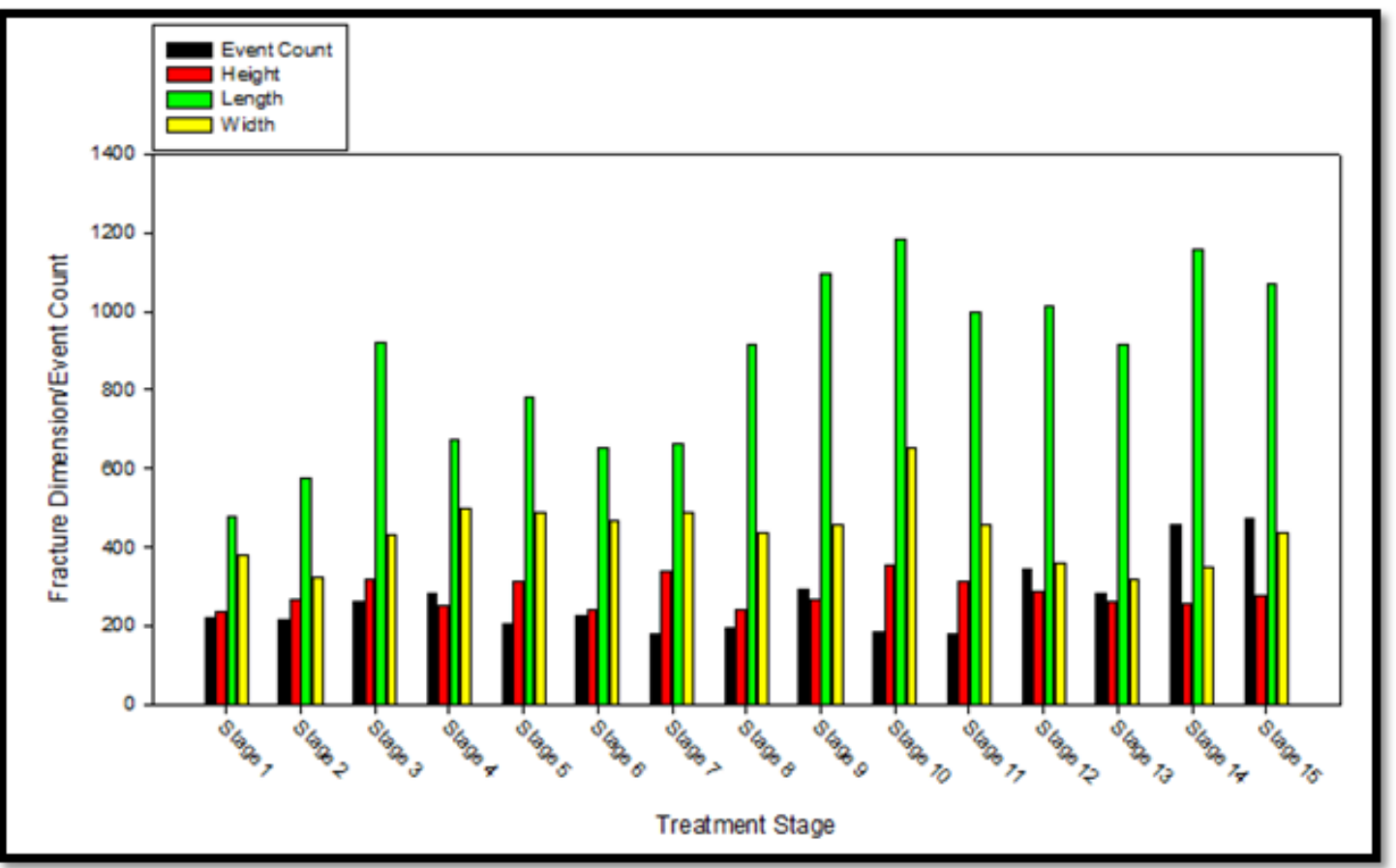

Figure 31: Well \# 1 Micro-Seismic Fracture Geometry for all Stage 
Measurements of fracture half-length on well 1 ranges from 250 to $600 \mathrm{ft}$. with average half-length of approximately $400 \mathrm{ft}$. A fracture network width ranges from 300 to $620 \mathrm{ft}$. with an average width of $394 \mathrm{ft}$. indicating some overlap between stages. The overall degree of complexity for outcome is moderate to high. The Aspect Ratio is defined as the fracture network width to fracture length $\left(2^{*} X_{f}\right)$. Calculated Aspect Ratio ranges from 0.25 to 0.80 with an average Aspect ratio ofs approximately 0.5 . Fracture network with an aspect ratio of 0.5 describes a fracture network width extension that is half of a fracture length. Fracture height for lateral is fairly constant, with an average height of approximately $245 \mathrm{ft}$. The majority of events are well-contained in the Upper Eagle Ford and the lower organic portion of the Eagle Ford, but there is some upward growth into the overlying Austin Chalk. There is also some downward growth into the underlying Buda. Proppant was likely well distributed vertically due to the use of viscous fluid and Stokes' law.

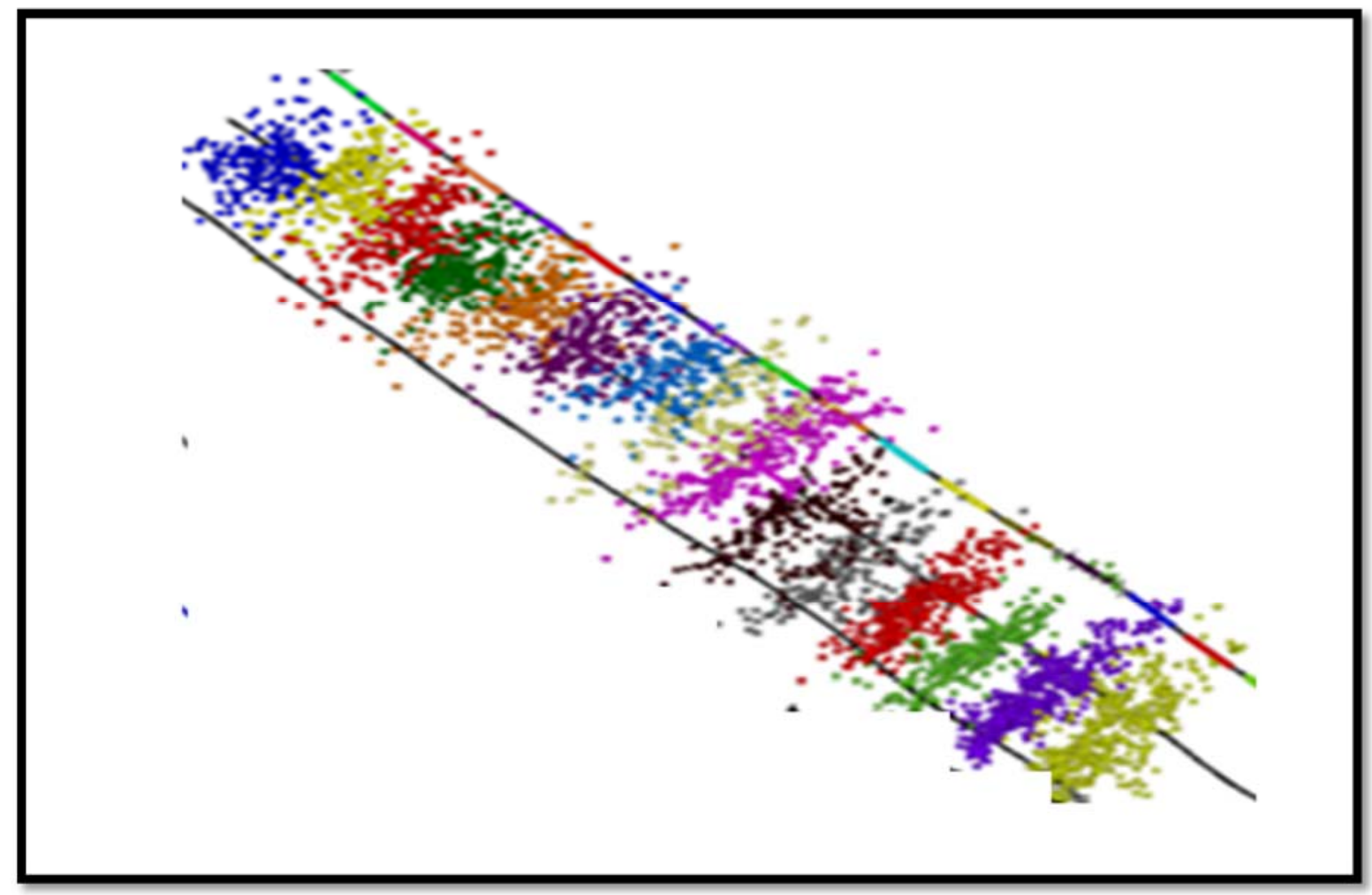

Figure 32: Well \# 1 Lateral side view for all Stage

Figure 33 presents workflow of completion optimization. One of the most challenging steps in optimizing unconventional reservoir is data gathering, validation, and proper 
use of other diagnostic tools. It is vital to integrate as many as possible different parameters in order to increase the confidence and accuracy of both fracture and reservoir simulator.

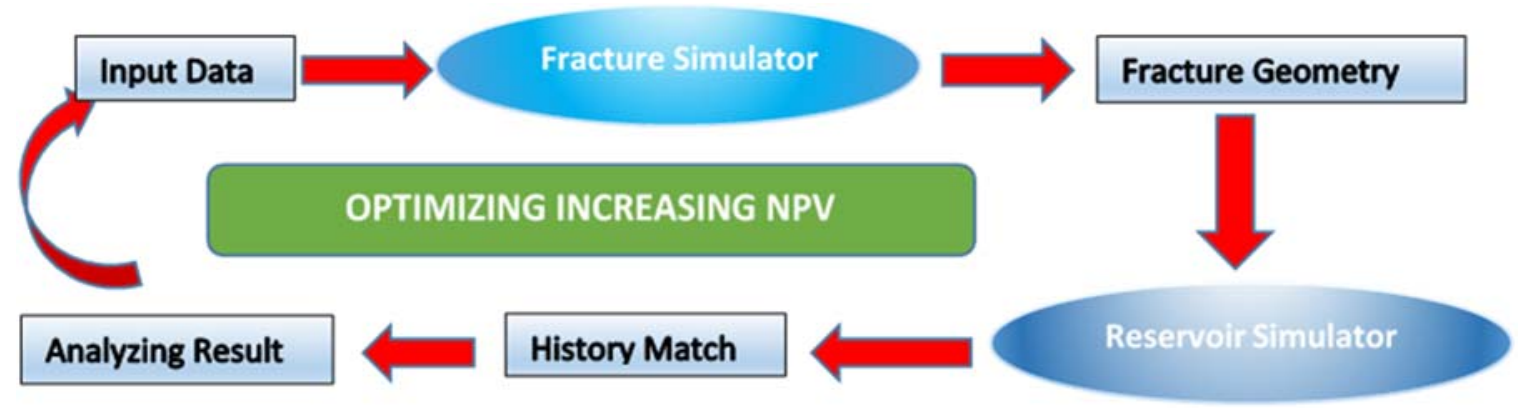

Figure 33: Completion Optimization Workflow

Conventional fracture treatment provides bi-wing fractures since it requires less energy. The presence of low stress anisotropy and natural fractures in shale formations provide geo-mechanical conditions that causes hydraulically induced discrete fractures to start and propagate in both horizontal and vertical fractures in three principle planes (Meyers, et al 2011). Generated DFN consists primary fracture (which contributes more than $90 \%$ of production) and secondary fractures (which may or may not be connected into primary fracture)

Modeling DFN requires input of the confining stress contrast in the $y-z$ and $x-y$ planes (minimum \& maximum stress) or DFN aspect ratio from micro-seismic mapping data. Based on micro-seismic data, DFN numerical simulation setup has a user specified aspect ratio of 0.5 and assumed saturated or infinite extent DFN system with numerical simulation of continuum theory. DFN fracture model setup is presented in Table 16. The stiffness interaction was modeled with empirical mechanical option. The fracture spacing in the primary $x-z$ and secondary $y-z$ planes are assumed to be equal to the spacing between clusters. First generation treatment design was implemented as illustrated in Table 18. The geometry of hydraulic fractures is assumed to be controlled by:

- The in situ effective stress, defined by the total stress and reservoir pressure. 
- The rock matrix strength, formation heterogeneity and stress anisotropy.

- The properties of the natural fracture system.

- The fracture fluid system and volumes.

Finally, surface treatment pressure was predicted to match measured ISIP value to improve confidence of the model. Figure 34 presents the surface pressure match.

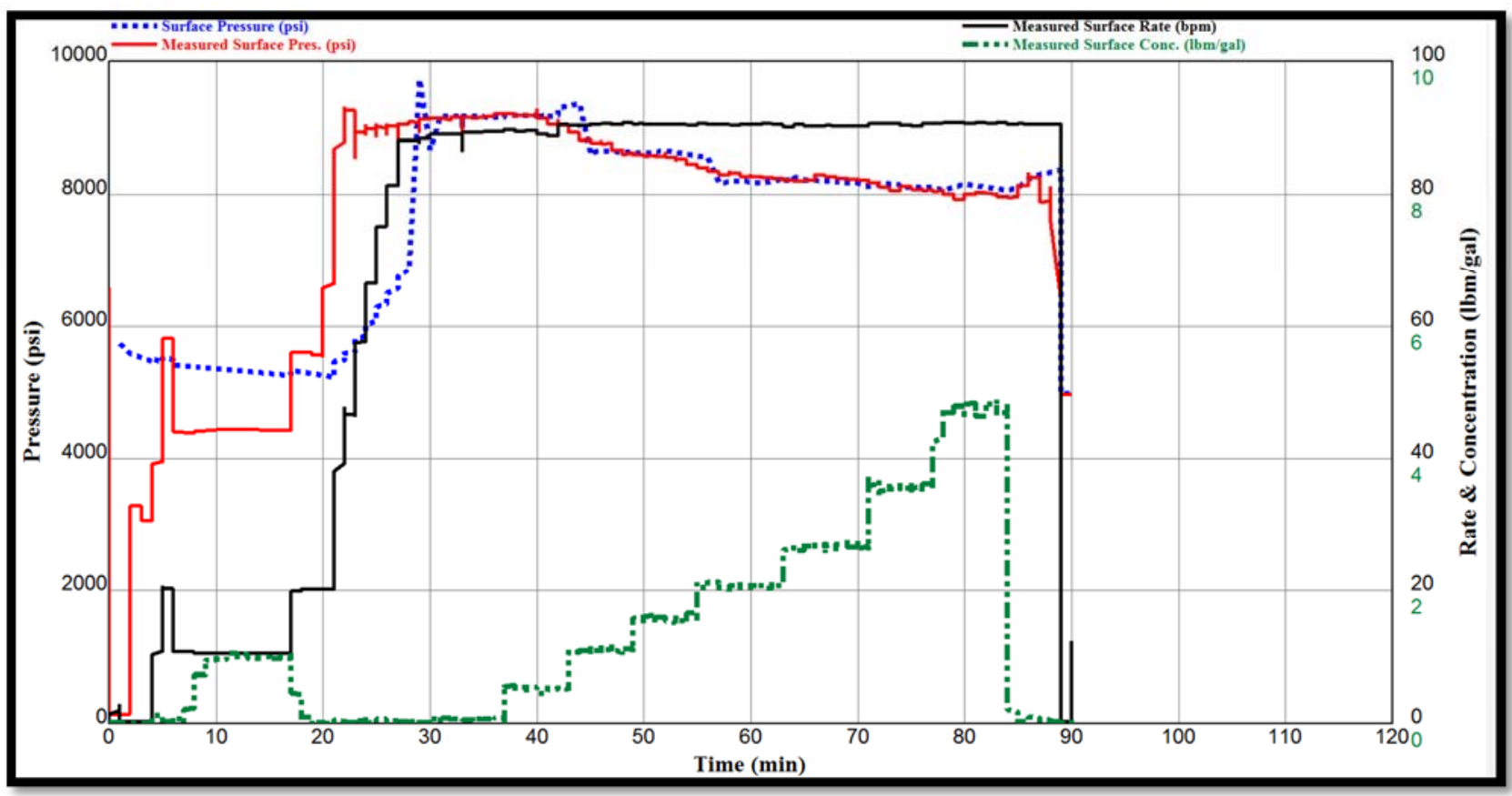

Figure 34: Surface Pressure Matching (ISIP Matching)

After successful fracture modelling, fracture properties were applied as input to reservoir simulator and analytical and numerical modelling were conducted. Rate Transient Analysis (RTA) was utilized to characterize reservoir and completion parameters. As shown in Figure 35, Enhanced Fracture Region analytical model introduced by Stalgorova and Mattar (2012) was utilized using production rate and flowing pressure. This model can demonstrate a fair physical illustration of fluid flow into multiple transverse fractures and the related improved performance of effective permeability region around each fracture. The respond of the system is typically production rates and flowing bottom hole pressures and results in the creation of appropriate reservoir description. Parameter values obtained during the analysis provide a starting point for 
model type and the distance from fracture to permeability boundary. Analytical model equations are presented in Appendix B.

Reservoir characterization and initial interpretation recorded by identification of the early transient linear flow regime as well as by time of transition to boundary or apparent boundary dominated flow ( telf). Moreover, the approach of this model requires defining volumetric parameters such as formation thickness collected from log data and reservoir fluid properties obtained from the laboratory. Completion parameters from hydraulic fracture model, such as number of stages $\left(\mathrm{n}_{\mathrm{f}}\right)$, initial reservoir pressure, lateral length ( $\left.L_{e}\right)$, and drainage width $\left(Y_{e}\right)$, which are basis of well spacing and were all inputs to the model.

Applied fracture parameters are based on the assumption of equally spaced stages, uniform transverse fractures along the lateral length of the well. The base model which is a single phase was used to simulate 50 years of oil production profile.

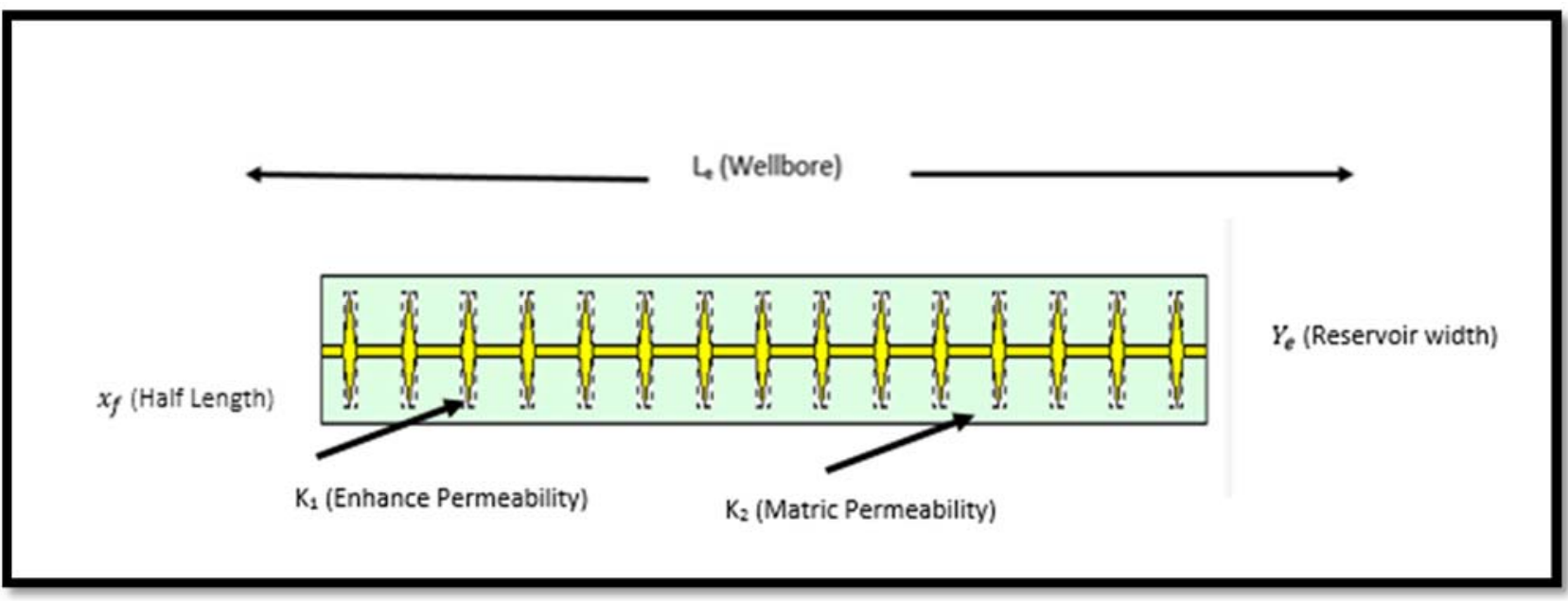

Figure 35: Analytical Enhanced Fracture Region

The completion and reservoir fluid properties of well \# 1 are presented in Table 19. Reservoir fluid data provided the saturation pressure and character of the reservoir fluid. A bubble point was observed at $2404 \mathrm{psi}$ and $224^{\circ} \mathrm{F}$ and the initial reservoir pressure (5000 psi) is higher than the observed bubble point pressure. Therefore, the reservoir fluid exists as an under saturated (single-phase) oil at static reservoir conditions. 


\begin{tabular}{|l|c|c|}
\hline \hline Parameter & Value & Unit \\
\hline \hline Initial Reservoir Pressure & 5000 & (psi) \\
\hline Bubble Point Pressure & 2404 & (psi) \\
\hline Reservoir Temperature & 246 & $\left({ }^{\circ} \mathrm{F}\right)$ \\
\hline Oil API & 38.65 & $\left({ }^{\circ} \mathrm{API}\right)$ \\
\hline Oil Specific Gravity & 0.71 & $(\mathrm{scf} / \mathrm{STB})$ \\
\hline Solution Gas-Oil Ratio & 671 & $\left({ }^{\circ} \mathrm{F}\right)$ \\
\hline Reservoir Temperature & 224 & (cp) \\
\hline Equivalent Reservoir Viscosity & 0.59 & $(\mathrm{ft})$. \\
\hline Pay Zone Thickness & 232 & \\
\hline Number of Stages & 15 & $(\mathrm{ft})$. \\
\hline Lateral Length (Le) & 5000 & \\
\hline
\end{tabular}

Table 19: Analytical Model Input Parameters

Estimated fracture properties obtained from fracture simulator were applied as input for reservoir simulator and conducted numerical modelling. These properties include laboratory PVT data and model input parameters such as estimated effective half length, propped width, and fracture permeability as shown in Table 20.

\begin{tabular}{|c|c|c|c|c|c||}
\hline Layer & Top, $\boldsymbol{f t .}$ & Thickness, ft. & $\boldsymbol{\phi}$, fraction & $\boldsymbol{S}_{\boldsymbol{w}}$, fraction & $\boldsymbol{k}, \mathbf{m d}$ \\
\hline 1 & 7424 & 35 & 0.0308 & 0.0411 & 0.000342 \\
\hline 2 & 7460 & 82 & 0.0376 & 0.1829 & 0.000148 \\
\hline 3 & 7543 & 94 & 0.0589 & 0.0749 & 0.000775 \\
\hline 4 & 7638 & 21 & 0.0322 & 0.1089 & 0.000195 \\
\hline Total/ Average & & $\mathbf{2 3 2}$ & $\mathbf{0 . 0 3 9 9}$ & $\mathbf{0 . 1 0 2}$ & $\mathbf{0 . 0 0 0 3 6 5}$ \\
\hline
\end{tabular}

Table 20: Well \# 1 Reservoir Input parameters

The simulation of a proper reservoir model was setup with Cartesian grid geometry. A planar, single porosity model for a horizontal well is used in this study. The planar model was fixed at 100 acres with multi stage hydraulic fracture using 15 stages spaced at $300 \mathrm{ft}$. per stage. The gridding of the model was done explicitly (not deploying dual porosity model) to sidestep the difficulty of having to calculate the shape factor. Four geological layers was employed in the model with $5200 \mathrm{ft}$. length and 870 feet width. Additionally, the horizontal lateral drilled was $5000 \mathrm{ft}$. and hydraulic fractures 
were placed in layer 3. Reservoir and model input parameters are presented in Table 21.

\begin{tabular}{|l|c|}
\hline \multicolumn{2}{|c|}{ Reservoir Parameters } \\
\hline Initial reservoir pressure, psia & 5000 \\
\hline Bottom hole pressure Pwf, psia & 500 \\
\hline Depth, ft. & 7450 \\
\hline Thickness, ft. & 232 \\
\hline Bubble Point Pressure, psia & 2404 \\
\hline Oil API & 38.65 \\
\hline Oil Specific Gravity & 0.71 \\
\hline Solution Gas-Oil Ratio, scf/STB & 671 \\
\hline Reservoir Temperature, ${ }^{\circ} \mathrm{F}$. Hydraulic Fracture Properties \\
\hline Equivalent Reservoir Viscosity, cp & 224 \\
\hline Drainage Area, Acre & 0.59 \\
\hline \multicolumn{2}{|c|}{100} \\
\hline Estimated Effective Fracture Half length, ft. & 206 \\
\hline Estimated propped width, ft. & 0.008 \\
\hline Estimated fracture permeability, md & 3800 \\
\hline \hline Anticipated stimulation goal & Conductivity facture \\
\hline
\end{tabular}

Table 21: Numerical Model Input parameters

The objective of this section was to perform single-well analysis of Eagle Ford Shale. The goal was to build base case and to match the performance of the Eagle Ford well for understanding the reservoir and rock properties of this well and improve the completion and stimulation design.

Petro-physics study indicates an average permeability of 365 nanodarcy (nD) over formation pay interval of $232 \mathrm{ft}$. which included both the upper and lower Eagle Ford Despite broadly known as shale, the Eagle Ford formation is actually composed of organic rich calcareous mudstone and chalks that were deposited in the upper and lower Eagle Ford. Figure 36 shows the petrophysical log data where the lower Eagle Ford is organically rich and produces more hydrocarbons than the upper Eagle Ford due to oxygenated environment as depth decrease (Bazan, L.W., et al 2010). 


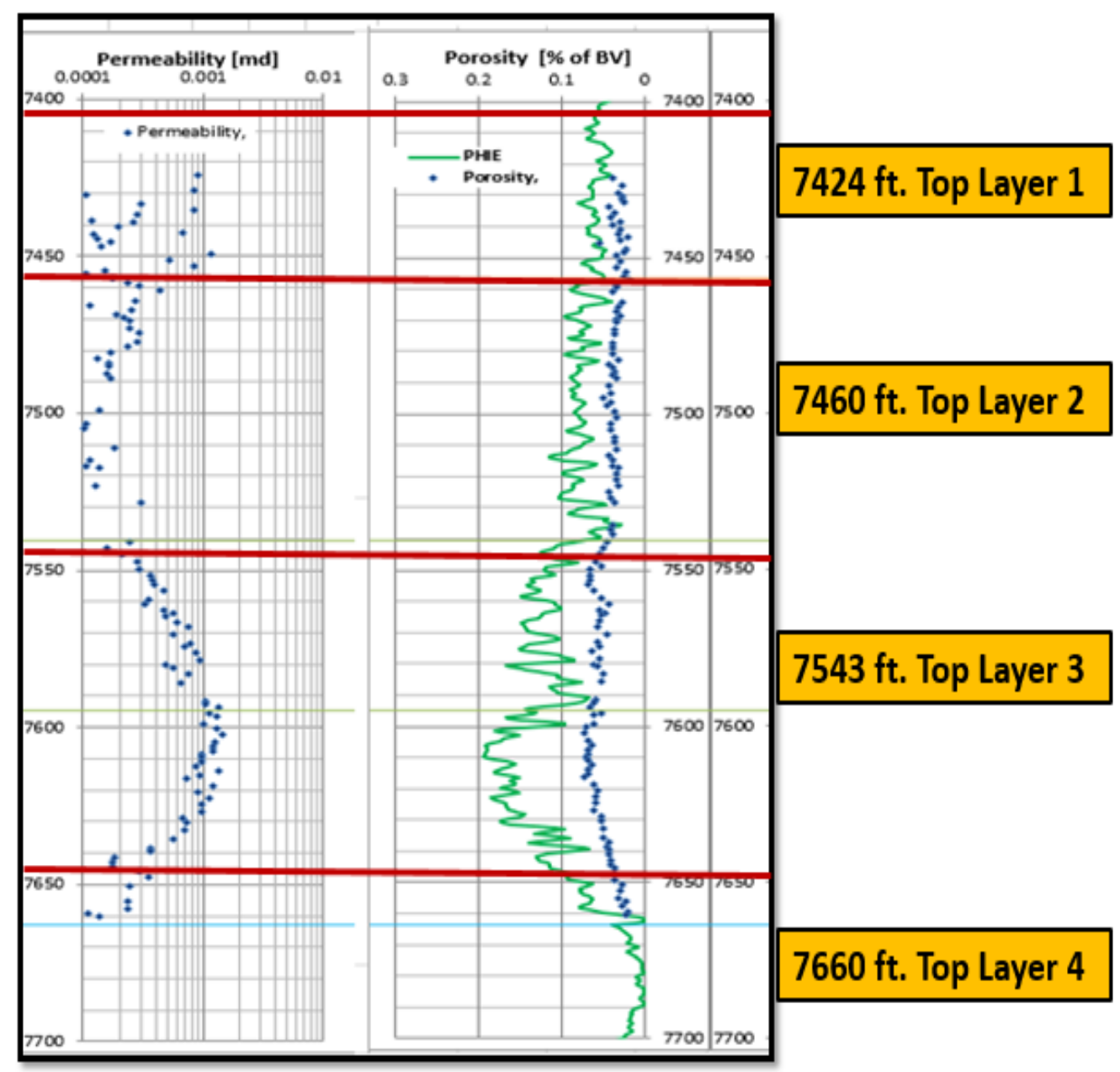

Figure 36: Well \#1 Petro-physical data

\subsubsection{Parametric Studies}

Parametric studies were conducted to illustrate the effects of various parameters on the discrete fracture network. Sensitivity model uses a micro seismic data to effectively and qualitatively calibrate the fracture model. This utilized geology, drilling survey, well log data, fracture treatment data, and a deterministic analysis of the micro seismic measurements result.

The model was setup to conduct a sensitivity study of fracture geometry. A constant slurry volume of 12, $200 \mathrm{bbl}$. /stage was injected with different aspect ratio of Eagle 
Ford shale formation. The purpose was to study the effect of stress anisotropy on fracture geometry and proppant transport, which is the main driving force of well productivity.

The results of fracture simulation (output) were used to set up reservoir simulator (input).

The main area on parametric sensitivities study was focused on the effects of rock and reservoir properties such as:

1. The effect of fluid volume and proppant concentration on dominant fracture.

2. The effect of stress anisotropy or aspect ratio from microseismic on dominant fracture.

3. The effect of stress anisotropy or aspect ratio from microseismic on fracture conductivity.

4. The effect of dominant fracture on productivity and EUR.

5. The effect of conductivity on productivity and EUR.

The result of the study was used to enhance both the completion and the fracture treatment. The key of this study was to clearly understand the different aspects of fracturing treatment such as - separating between propped and un-propped fracture length, fracture growth and geometry, fracture overlap between stages and wells, stress anisotropy effects, and treatment efficiency. This was accomplished by an approximate comparison of micro seismic events with 3D fracture simulation model.

\subsubsection{Second Generation Stimulation Design: Optimization}

The foundation of base case treatment design was the concept that hydraulic fracturing requires high viscosity to create a considerable flow path, which was needed for loading higher proppant concentrations with the achievement of optimum fracture conductivity in near wellbore. Moderate fracture complexity, which was due to the interaction of the hydraulic fracture with natural fracture and formation properties, was then subsequently observed. The flexibility of having the option to either control or 
exploit this complexity had a significant impact on fracture design and thus well performance.

In order to improve completion efficiency and increase the well productivity, a second generation treatment was designed. Optimized stimulation treatment design $\left(2^{\text {nd }}\right.$ generation) was based on the results of parametric studies and was also based on the observations of well \#1 micro-seismic evaluation of fracture mapping. The results highlighted how fracture complexity can be maximized using low viscosity fluids. Hybrid fracturing fluid system was chosen for the second generation (optimizing design treatment) and compared with first generation (base model) as listed in Table 22 with values for colored parameters showing modifications or changes. Low viscosity hybrid fluids generated fractures of minor width and therefore had greater fracture lengths. This practically increases the complexity of the created fracture network with better reservoir to wellbore connectivity.

\begin{tabular}{|l|c|c|}
\hline Parameter & Generation 1_Value & Generation 2_Value \\
\hline \hline Total Liquid Volume (BBLS) & 85,590 & 180,000 \\
\hline Injection Rate (BPM) & 93 & 90 \\
\hline PAD Ratio \% & 25 & 44 \\
\hline XLK Ratio \% & 69 & 33 \\
\hline 100 Mesh Ratio \% & & 26 \\
\hline $40 / 70$ Mesh (IBM) & $5,700,000$ & $3,429,750$ \\
30/50 (IBM) & 5 & - \\
Max proppant conc. (ppg) & $5,700,000$ & 2.5 \\
\hline Total Proppant (IBM) & 15 & $4,210,485$ \\
\hline \# of Stage & Crosslink fluid & 15 \\
\hline Fluid system & & Hybrid fluid \\
\hline
\end{tabular}

Table 22: Comparison of First and Second generation treatment designs

Once this hydraulic control was established, application of hybrid fluid system was expected to yield outstanding results in Eagle Ford formations by producing intersecting secondary fracture cracks. The basis of application of second generation treatment design was to hydraulically initiate a high pad fluid volume including 100 mesh which effectively reduces leakoff through any intersecting fractures in the formation. The 100 mesh does not restrict fluid travel down the primary fracture, and thus allows the subsequent fracturing fluid to extend the principal fracture to the desired distance into the reservoir. Low proppant concentrations were utilized to improve the effect of 
proppant distribution on fracture performance when fracture growth was complex, assuming proppant was either concentrated in a primary propped fracture or evenly distributed in a fracture network.

\subsubsection{Well spacing}

The Eagle Ford shale play was in a full-field development phase after six years of appraisal and delineation. This very often involves drilling multiple horizontal wells per section.

The objective of this task was to present sensitivity studies by varying propped fracture length and formation drainage area as a function of well spacing. Effective fracture geometry can be achieved with optimum treatment design.

Schematic diagram of typical horizontal wellbore model is shown in Figure 37. Fracture length or distance between the wells has a major effect on EUR. Applied reservoir properties were averaged value based on log and core data. A total section drainage area of 640 acres was chosen and kept constant during this study.

Group of wells with different well spacing were created for testing and the effect of down spacing are illustrated in Table 23. The wells were divided in 5 groups per section with group one for eight wells and increasing to 32 wells for group five. All groups were completed with a similar fluid system.

\begin{tabular}{|r|c|c|c|c|}
\hline Group & \# of Wells per Section & Distance between Wells & Distance from Sides & Area \\
\hline 1 & 8 & 660 & 330 & 80 \\
\hline 2 & 10 & 528 & 264 & 64 \\
\hline 3 & 13 & 406 & 203 & 49 \\
\hline 4 & 16 & 330 & 165 & 40 \\
\hline 5 & 32 & 165 & 82 & 20 \\
\hline
\end{tabular}

Table 23: Different scenario of number of wells per section 


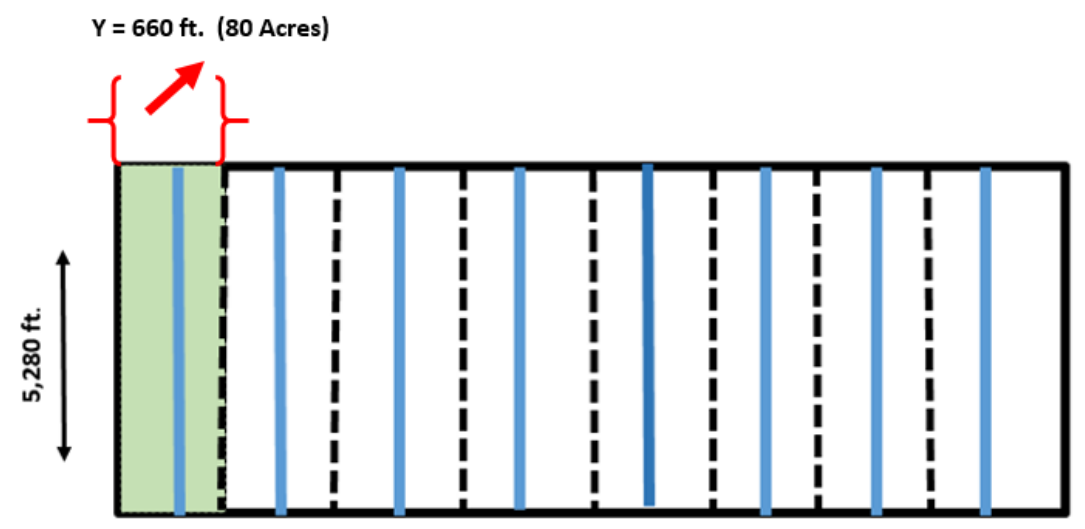

Figure 37: Drainage arrangement

The decision on how to develop the Eagle Ford shale depends on the interpretation of fracture generation, fracture propagation, proppant distance, fluid distance, and fracture geometry, which are critical for proper well spacing and draining the resource in place with each well or section. Failure to maximize stimulated area will result with portions of hydrocarbon left in a given well or section.

Down-spacing will increase well density and improve productivity from un-propped region of the Eagle Ford formation where most of the productivity originates from stimulated region. It is essential to determine the point where higher well density hardly improves production without adding necessary and incremental increase in combined volume to offset additional drilling and operating costs.

Oil prices are more volatile than before. Increased U.S. domestic oil production sent prices lower than anyone imagined. The U.S. Energy Information Administration (EIA) forecasts that WTI will average $\$ 38$ a barrel in 2016. That's significantly lower than December's forecast of $\$ 50.89$ a barrel. Supply has outstripped demand, making any predictions highly uncertain. Nevertheless, the EIA has bravely predicted that different future prices as shown in Table 24. This values was an average and utilized future development decisions especially well spacing.

Also, oil price sensitivity to well spacing were evaluated. Simulation of economic forecast were conducted with different set of constant prices for the life of the well $(\$ 80$, $\$ 60, \$ 40$, and $\$ 20)$. 


\begin{tabular}{|l|l|l|l|l||}
\hline Year & $\mathbf{2 0 1 6}$ & $\mathbf{2 0 1 7}$ & $\mathbf{2 0 1 8}$ & $\mathbf{2 0 1 9}$ \\
\hline Brent (US\$/b) & 43 & 60 & 74 & 73 \\
\hline Opec reference price (US\$/b) & 41 & 58 & 71 & 70 \\
\hline WTI (US\$/b) & 42 & 59 & 71 & 71 \\
\hline Average & $\mathbf{4 2}$ & $\mathbf{5 9}$ & $\mathbf{7 2}$ & $\mathbf{7 0}$ \\
\hline
\end{tabular}

Table 24: EIA Crude Oil Prices future forecast

The analysis in this section includes the variation of economic parameters to determine the effect of oil price and discount rate upon the optimum well spacing. Cash flow and net present value (NPV) profiles were evaluated for economic viability of well spacing.

Present cash flow and net presented value (NPV) profiles conducted in this study evaluated the economic visibility of well spacing. The values considered for investment and expenses to drill, complete, fracture, and operate a well are shown in Table 25.

The economic well spacing approach was based on Net Present Value (NPV) and Discount Return on Investment (DROI) value.

\begin{tabular}{|c|c|}
\hline Parameter & Price Deck \\
\hline Drilling Cost/Well (\$MM) & 2.30 \\
\hline Completion Cost/Well (\$ MM) & 2.65 \\
\hline Pump Cost/Well (\$ MM) & 0.24 \\
\hline P\&A Cost/Well (\$ MM) & 0.05 \\
\hline Fixed Opex (\$/month/well) & 13,800 \\
\hline Oil Variable Opex (\$/bbl.) & 3.47 \\
\hline Water Variable Opex (\$/bbl.) & 2.99 \\
\hline Working Interest & $10 \%$ \\
\hline Revenue Interest & $7.424 \%$ \\
\hline
\end{tabular}

Table 25: Economic Data 


\section{Result and Discussion}

The results of hydraulic fracturing modeling and reservoir simulation studies as well as the interpretation outcome of different treatment designs in Eagle Ford shale are presented in this section.

\subsection{Base Model Stimulation Treatment Design (First Generation Treatment Design)}

Initial treatment design was based on a working knowledge of the northeastern part of Eagle Ford where best producing wells are located. The goal was to setup workflow of stimulation optimization and develop base model for fracture and reservoir simulators and generate production profile of analytical and numerical models.

The main objective of this study was to generate conductivity type fracture treatment where more viscous fluid, more proppant, and proppant concentration is injected into formation to obtain higher conductivity (Barree, et al (2011)).

\subsubsection{Impact of Fluid System and Proppant on Fracture Properties}

A horizontal well in Eagle Ford Shale was drilled using an average lateral length of 5000 $\mathrm{ft}$. with an average TVD of $7582 \mathrm{ft}$. Total injected clean volume was 88,000 barrels with total proppant mass of 5,700,000 pounds at an average pump rate of $93 \mathrm{bpm}$. A total of 15 stages of hydraulic fracture treatment were successfully stimulated. Pad fluid volume was allocated to $25 \%$ of total fluid volume, which was first part of treatment fluid to breakdown and initiate fracture. It allowed fluid to produce sufficient penetration and generated required geometry. To overcome proppant embedment and multiphase flow, crosslinked fluid volume used was almost $70 \%$ of total fluid volume. This high viscous fluid system with higher concentration of large proppant mesh was placed into formation. Increasing viscous fluid reduced fracture complexity in near wellbore and farfield as illustrated in Figure 38. It is more difficult for high viscosity fluid to penetrate and 
intersect natural fracture or fissures. Additionally, reduction of penetration distance or effective length will diminish required stimulated area.

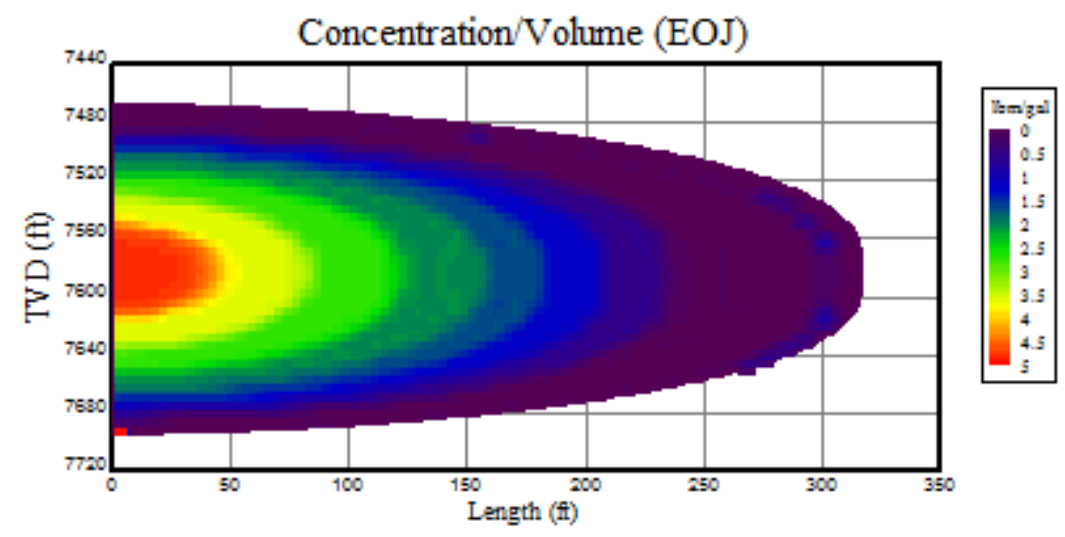

Figure 38: Length profile for primary fracture

Table 26 summarizes results for stimulation of Well \#1 and also compares micro seismic mapping results. Fracture half-length of $318 \mathrm{ft}$. was created as shown in Figure 39. This distance indicates how far fracturing fluid reached in the formation. Propped length was recorded as $237 \mathrm{ft}$. and estimated effective half-length was $208 \mathrm{ft}$.

\begin{tabular}{|l|l|l||}
\hline \hline Parameter & Primary Fracture & Unit \\
\hline \hline Fracture Half Length - Created & 318 & (ft.) \\
\hline Fracture Half Length - Propped & 237 & (ft.) \\
\hline Effective Half Length-(NW) & 208 & (ft.) \\
\hline Fracture Height & 230 & (ft.) \\
\hline Drainage Area & 100 & (Acre) \\
\hline Stimulated Area & 47 & (Acre) \\
\hline Avg. Fracture Permeability Micro-seismic Monitoring Result & (md) \\
\hline & 3200 & Unit \\
\hline \hline Parameter & Primary Fracture & (ft.) \\
\hline Average Fracture Half Length & 400 & (ft.) \\
\hline Average Fracture Height & 245 & (Acre) \\
\hline Estimated Stimulated Area & 92 & \\
\hline \hline
\end{tabular}

Table 26: Base Model Results for Hydraulic Fracturing Properties 
There was a direct correlation between rock mechanical properties, fracturing fluid system, and hydraulic fracture properties such as fracture geometry and fracture conductivity. Well \# 1 was expected to produce liquid hydrocarbons and higher concentrations of larger-mesh (30/50) proppant were used to achieve the required fracture conductivity. High fracture conductivity was a function of proppant mesh size and concentration.

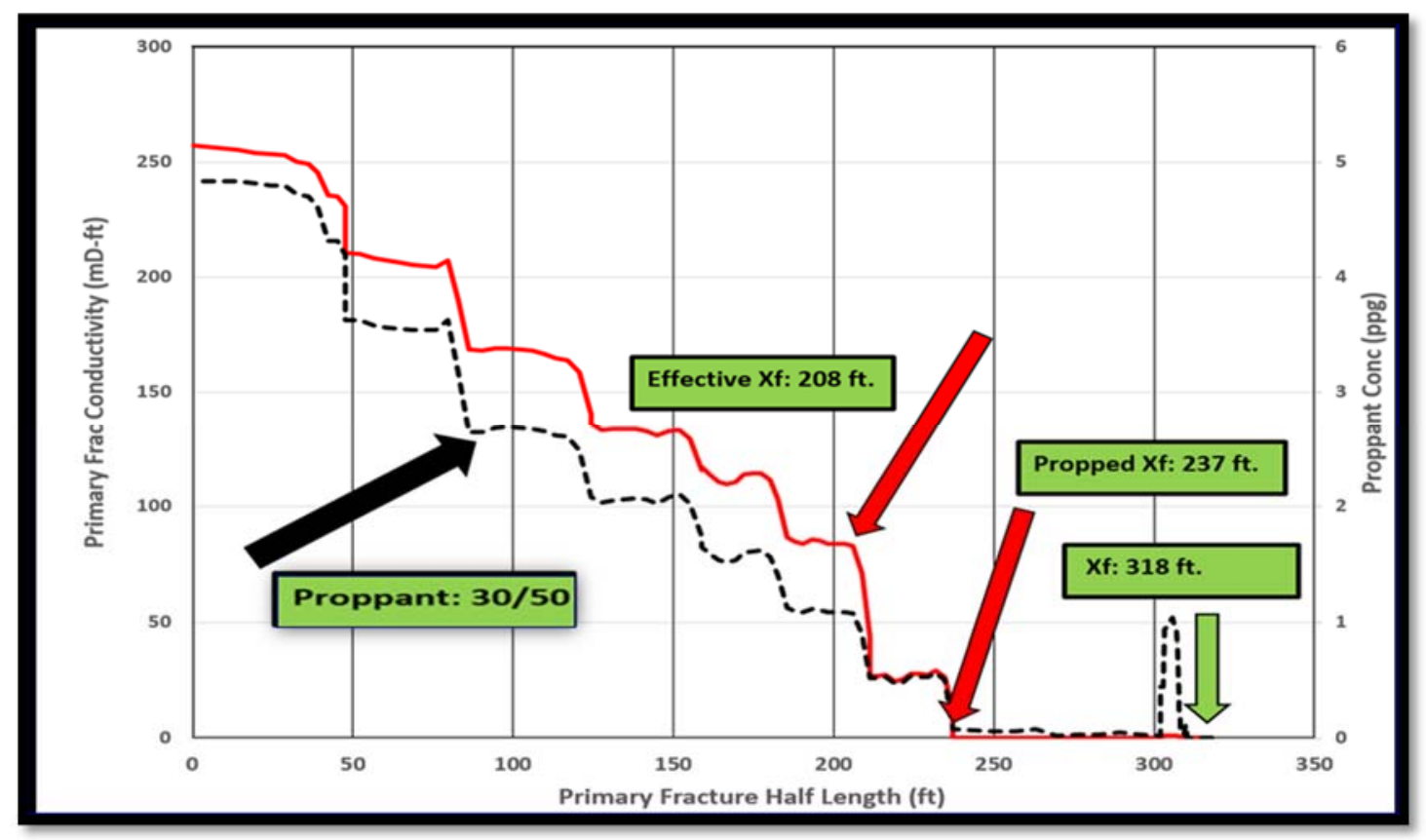

Figure 39: Primary Fracture proppant transport

Figure 40 shows simulated fracture network width of Well \#1 calibrated with micro seismic data. The results of micro seismic monitoring recorded a measured average half-length of $400 \mathrm{ft}$. and an average fracture network width of $394 \mathrm{ft}$. The Aspect Ratio is defined as the fracture network width to fracture length $\left(2^{*} X_{f}\right)$ and the calculated average Aspect ratio was approximately 0.5 . This result indicates formation is more brittle than ductile. 


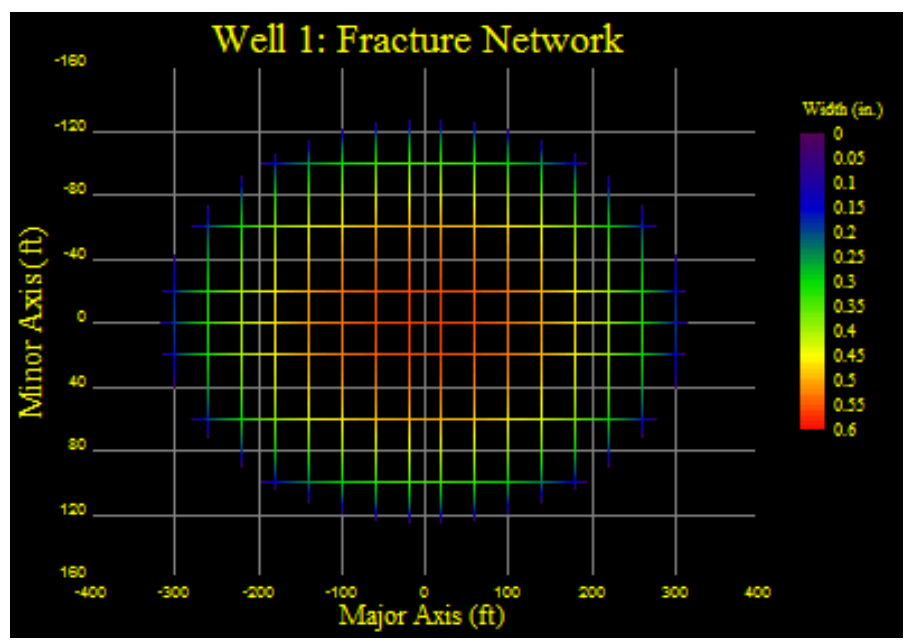

Figure 40: simulated fracture network width

Micro-seismic monitoring result implies that we are effectively stimulating and contained with the Eagle Ford without fracturing into the Austin Chalk and Buda intervals. Eagle Ford is currently spaced for 100 acres per well, fracture modeling, and micro-seismic result illustrated the apparent drainage area was not fully stimulated.

\subsubsection{Analytical Model Approach}

After successful fracture modelling, Rate Transient Analysis (RTA) was used to characterize reservoir and completion parameters. Enhanced Fracture Region analytical model introduced by Stalgorova and Mattar (2012) was utilized for the first generation well $1 \#$ with more than one year of production and pressure history.

Parameters such as formation thickness collected from log data and reservoir fluid properties obtained from the laboratory was utilized. In addition, completion parameters from hydraulic fracture model, such as number of stages $\left(\mathrm{n}_{\mathrm{f}}\right)$, initial reservoir pressure, lateral length (Le), and drainage width (Ye), which are bases of well spacing were inputted to the model. The model was based on the assumption of equally spaced 15 stages and uniform transverse fractures along the lateral length of the well. Reservoir characterization and initial interpretation was influenced by the identification of early transient linear flow regime as well as a time of transition to boundary or apparent 
boundary dominated flow ( telf) highlighted by the dashed vertical green line in Figure 41.

Figure 41 highlights transient linear flow characterized by straight line on superposition time plot where transition time was presented. As recommended by Liang et al (2011), time function used in this plot was material balance time $\left(\mathrm{t}_{\mathrm{c}}\right)$. The position of the $t_{\text {elf }}$ line, in addition to the linear flow straight-line that precedes it, were derived from the analyst's unique interpretation. Calculated parameters such as stimulated reservoir volume, dimensionless fracture conductivity had a direct correlation in the interpretation of the linear flow straight-line and $t_{\text {elf }}$. Fracture parameters were based on the assumption of equally spaced stages and uniform transverse fractures along the lateral length of the well.

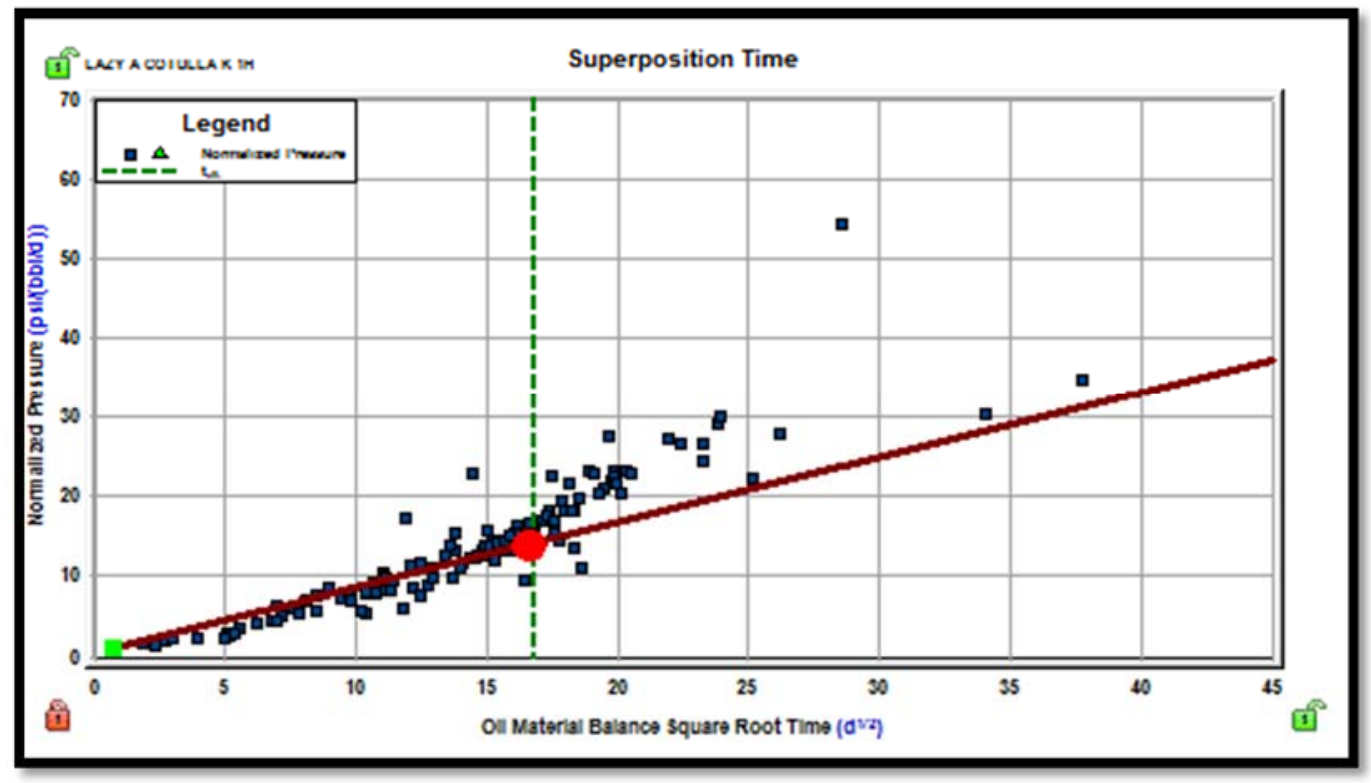

Figure 41: Oil Material Balance Square Root Time $\left(d^{1 / 2}\right)$

To justify the interpretation, adjusted parameters such as inner zone permeability $\left(k_{1}\right)$ and outer zone permeability $\left(k_{2}\right)$ were estimated and analytical model matching was applied resulting with $6 \%$ of average error as shown in Figure 42 . Matched parameters generated by fracture model was utilized in future EUR forcasts. 


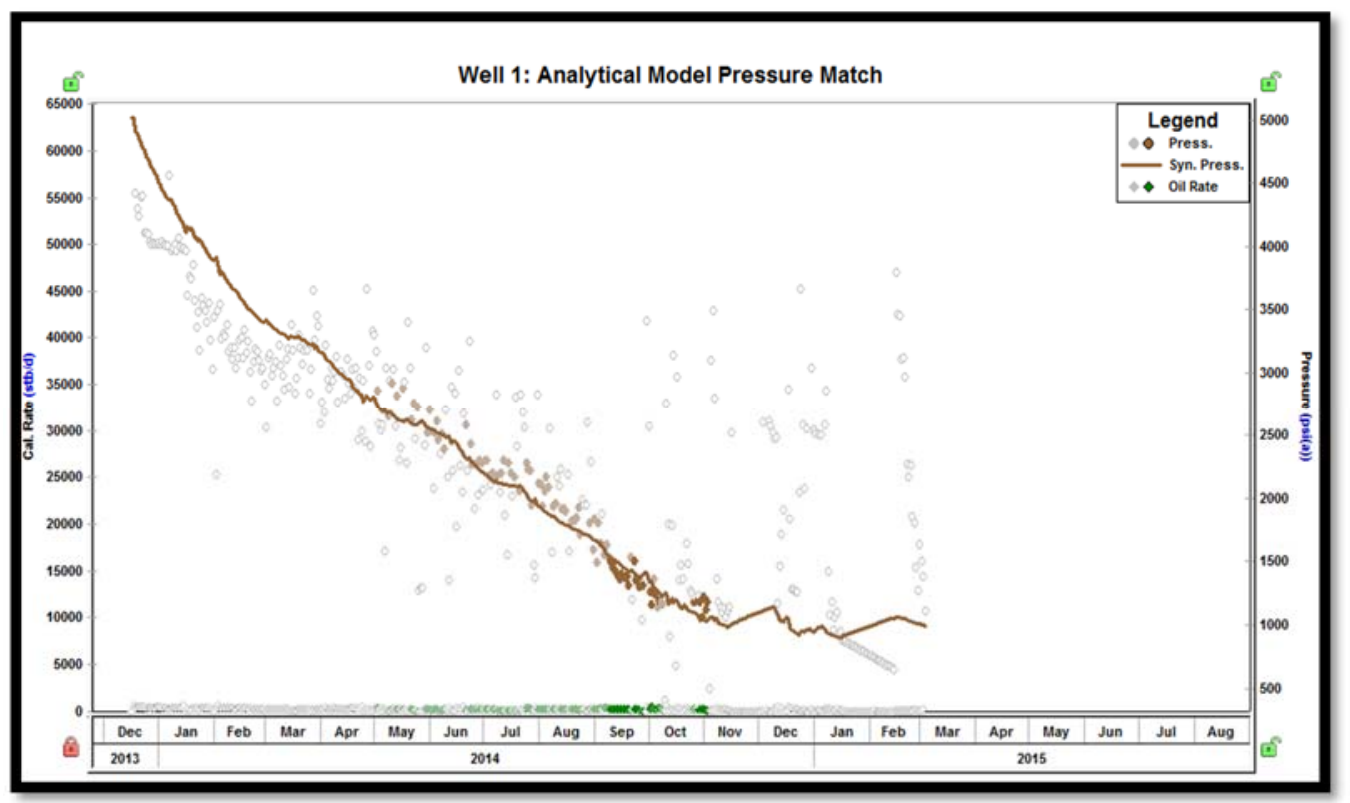

Figure 42: Base Model Analytical Pressure match

After caliberation of analytical model, base model was used to simulate for 50 years of oil production profile. The forecasted cumulative oil was $467 \mathrm{MBBL}$ while maintaining the constant bottom hole pressure as shown in Figure 43. Table 27 lists analytical model matched values and their comparison with fracture simulator results.

\begin{tabular}{|l|c|c|c||}
\hline Parameter & Frac Simulator & Analytical Model & Units \\
\hline Fracture Permeability & 3200 & 2850 & $\mathrm{md}-\mathrm{ft}$. \\
\hline Matrix Permeability & 550 & 540 & $\mathrm{nD}$ \\
\hline Drainage Area & 100 & 100 & Acres \\
\hline Stimulated Area & 47 & 51 & Acres \\
\hline Half Length & 237 & 257 & $\mathrm{ft}$. \\
\hline Stages & 15 & 15 & $\mathrm{ft}$. \\
\hline Lateral Length & 5000 & 5000 & Mstb \\
\hline EUR (Oil) & & 467 & \\
\hline
\end{tabular}

Table 27: Summary of fracture treatment design and reservoir properties 


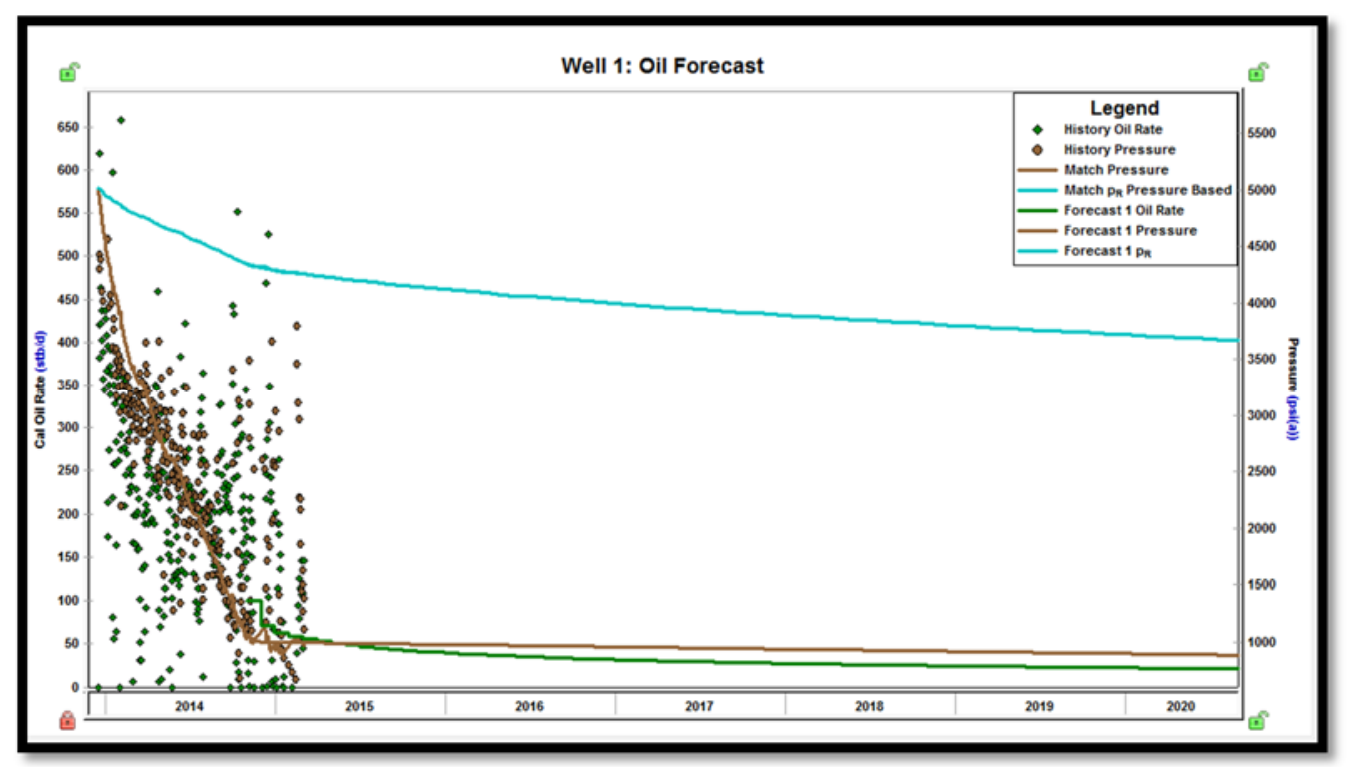

Figure 43: Base model for oil production forecasting

\subsubsection{Numerical Model Approach}

After successful fracture modelling, fracture properties were used as input to reservoir simulator. Numerical simulation was employed to validate the matched results of hydraulic fracture properties. A single porosity model was developed with a horizontal well containig 15 fracture stages.

To improve the predictions from simulation model, the base model was fine tuned to match the measured (historical) production results. The measured data used in the match were the produced oil and gas of Well \#1. Selected matching parameters were properties (porosity and permeability) of layers 1 through 4 and created hydraulic fracture properties including fracture half length, fracture permeability, and fracture width. Matching was successfully completed with an average error of $7 \%$.

To overcome proppant embedment and generate multiphase flow path, required conductivity was achieved by sacrificing formation penetration and ultimately reducing stimulated area. The best match result was recorded and matching parameters are reported in Table 28. 


\begin{tabular}{|l|l|l||}
\hline Parameter & Value & Unit \\
\hline Perm_L1 & 339 & $\mathrm{nD}$ \\
\hline Perm_L2 & 140 & $\mathrm{nD}$ \\
\hline Perm_L3 & 882 & $\mathrm{nD}$ \\
\hline Perm_L4 & 308 & $\mathrm{nD}$ \\
\hline Por_L1 & 3.02 & $\%$ \\
\hline Por_L2 & 4.67 & $\%$ \\
\hline Por_L3 & 4.67 & $\%$ \\
\hline Por_L4 & 4.01 & $\%$ \\
\hline Prim_frac_width & 0.00882 & (ft.) \\
\hline Frac_Half_length & 236.925 & (ft.) \\
\hline Prim_frac_perm & 4322.5 & (mD) \\
\hline EUR Oil (50 years) & 457 & (MBBL) \\
\hline EUR Gas (50 years) & 369 & (MMcf) \\
\hline
\end{tabular}

Table 28: History match parameters (First generation)

Matched results presented in Figures 44 and 45 were used for future production forecasting. Forecasted cumulative productions were $633 \mathrm{MBBL}$ of oil and $529 \mathrm{MMcf}$ of gas in 50 years. Table 29 summarizes the result of fracture treatment design and reservoir simulations.

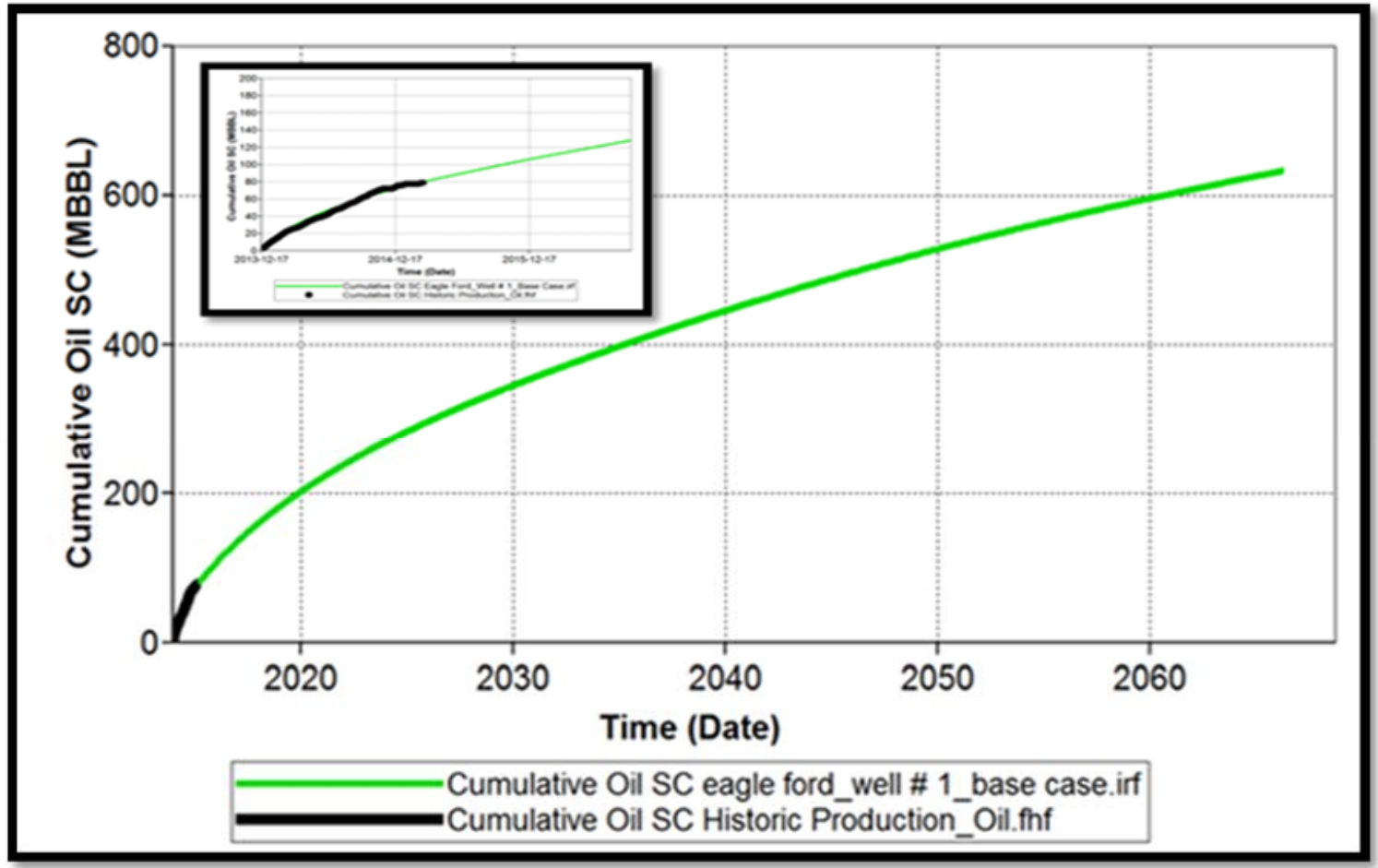

Figure 44: Base case Cumulative Oil Forecast and history Match 


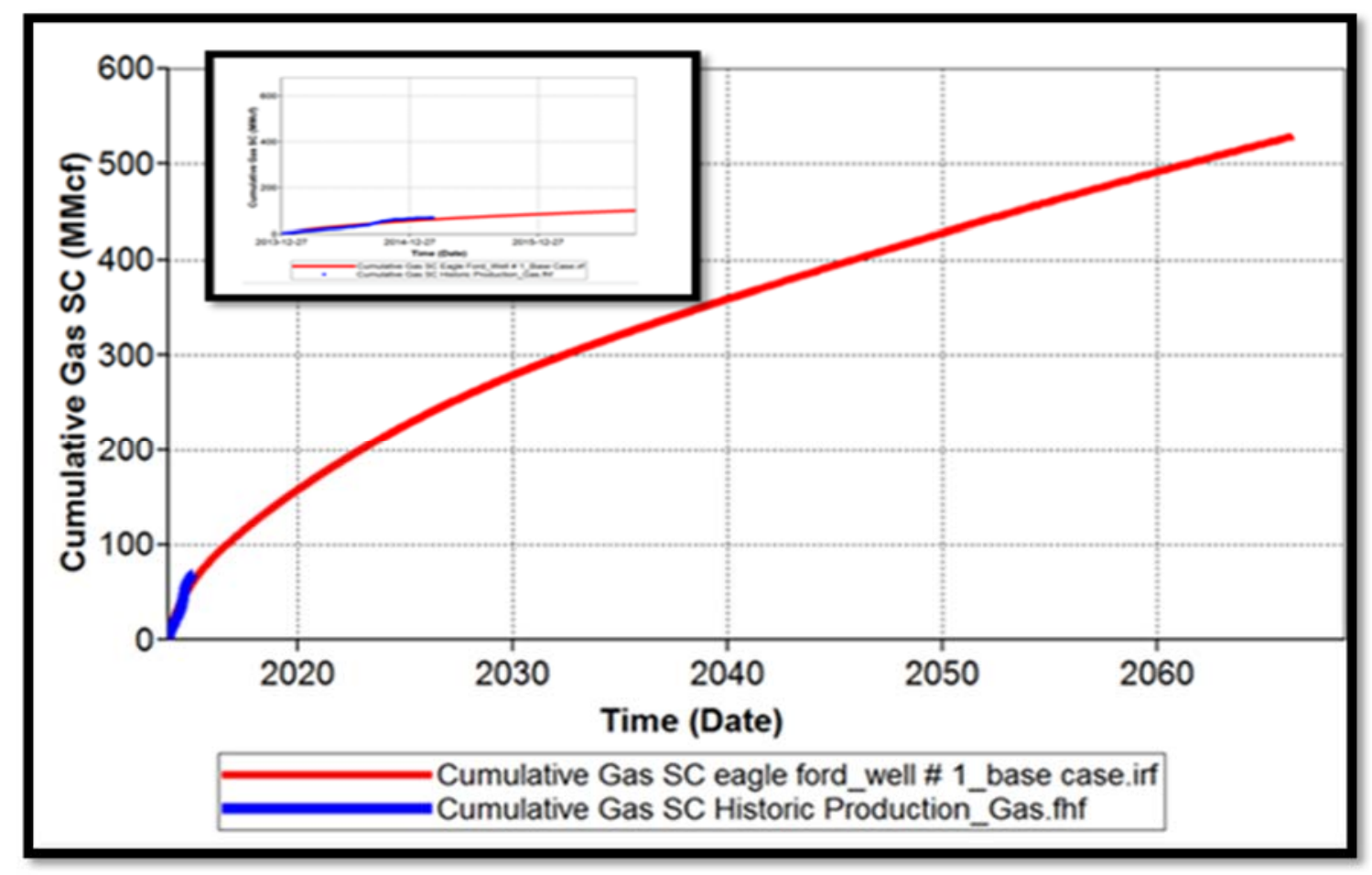

Figure 45: Base Case Cumulative Gas Forecast and history Match

\begin{tabular}{|l|c|c|c|c||}
\hline Parameter & Frac Simulator & Analytical Model & Numerical Model & Units \\
\hline Fracture Permeability & 3200 & 2850 & 4142 & $\mathrm{md}$ \\
\hline Matrix Permeability & 550 & 626 & 370 & $\mathrm{nD}$ \\
\hline Drainage Area & 100 & 100 & 100 & Acres \\
\hline Stimulated Area & 47 & 51 & 54 & Acres \\
\hline Half Length & 237 & 226 & 237 & $\mathrm{ft}$. \\
\hline Stages & 15 & 15 & 15 & $\mathrm{ft}$. \\
\hline Lateral Length & 5000 & 5000 & 5000 & $\mathrm{MBBL}$ \\
\hline EUR (Oil) & 467 & 633 & $\mathrm{MMcf}$ \\
\hline EUR (Gas) & & 529 & & \\
\hline
\end{tabular}

Table 29: Summary of the results of fracture treatment design and reservoir properties 
At the completion of study and analysis of hydraulic fracturing, analytical approach, and numerical approach modeling, it was determined that there was a need to prioritize the most important parameters such as the stimulated area. It was desirable to conduct a parametric study or sensitivity analysis to improve overall completion design and improve ultimate recovery and find answers to the following questions:

1. What is the optimum fracture design that can increase the contact between reservoir and wellbore?

2. What is optimum fluid and proppant type?

3. What are the optimum fluid volume, proppant volumes and concentrations?

4. What is the optimum drainage area per well / or how many wells per section (640 acre) is needed?

\subsection{Parametric Study}

In this section, a comprehensive reservoir simulation model used to study the impact of hydraulic fracturing parameters and it's impact on production performance of an Eagle Ford Shale are presented. The purpose of this study was to improve first generation treatment design by quantifying the influence of hydraulic fracture parameters (fracture length, fracture permeability, and propped width) and reservoir parameters (porosity and matric permeability).

\subsubsection{Hydraulic Fracture Treatment Design}

The purpose of this task was to study the effect of stress anisotropy or aspect ratio on formation of fracture geometry and proppant transport. The results showed the relationship between treatment size, formation properties, network size, and production response. Figures 46 through 48 show the relationship between treatment volume, rock properties and fracture geometry. Also observed were the fracture network size and complexity increase and the stimulated reservoir volume increases. Fluid volume was the driving force in generating fracture geometry. 


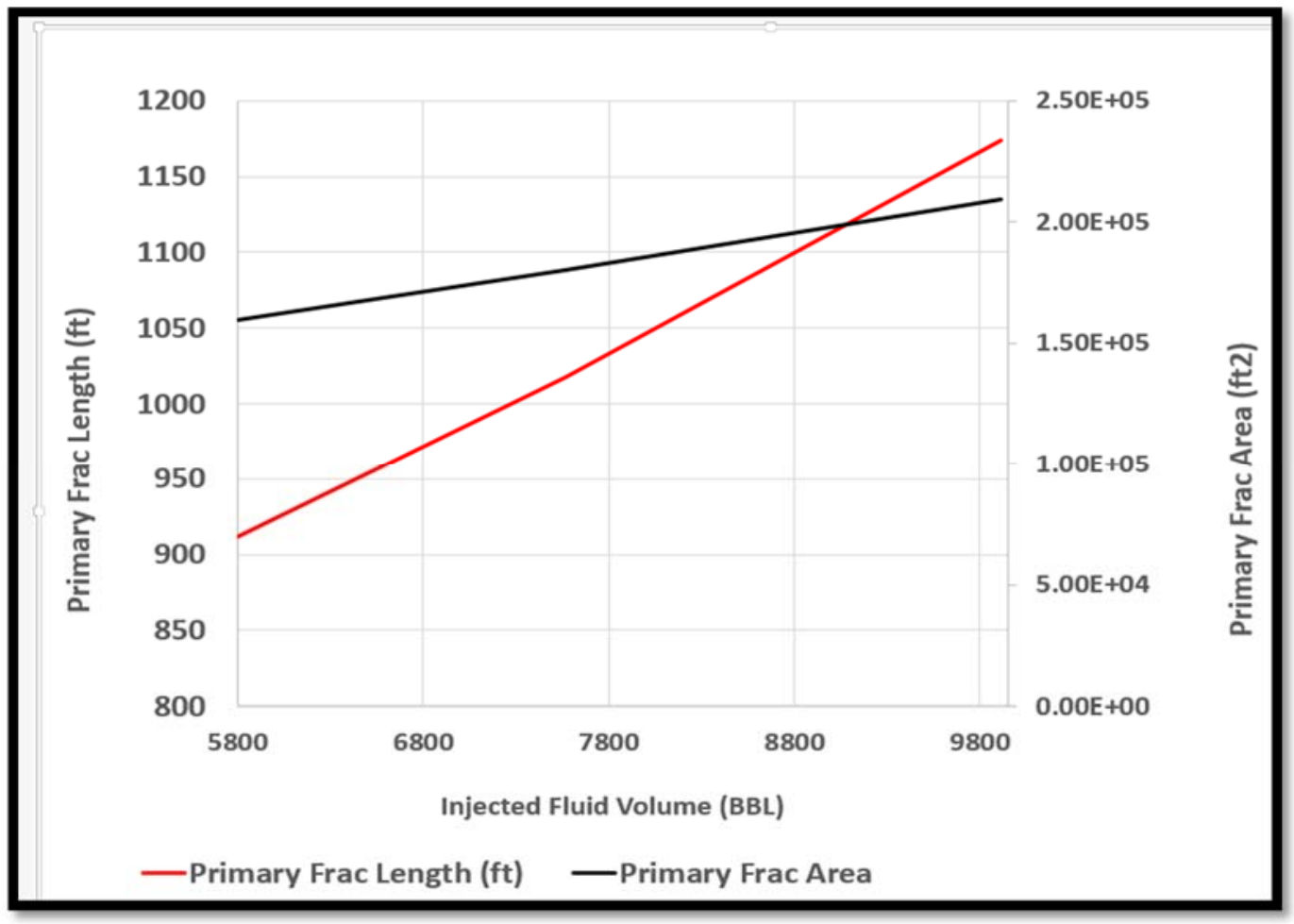

Figure 46: Relationship between treatment volume and fracture geometry

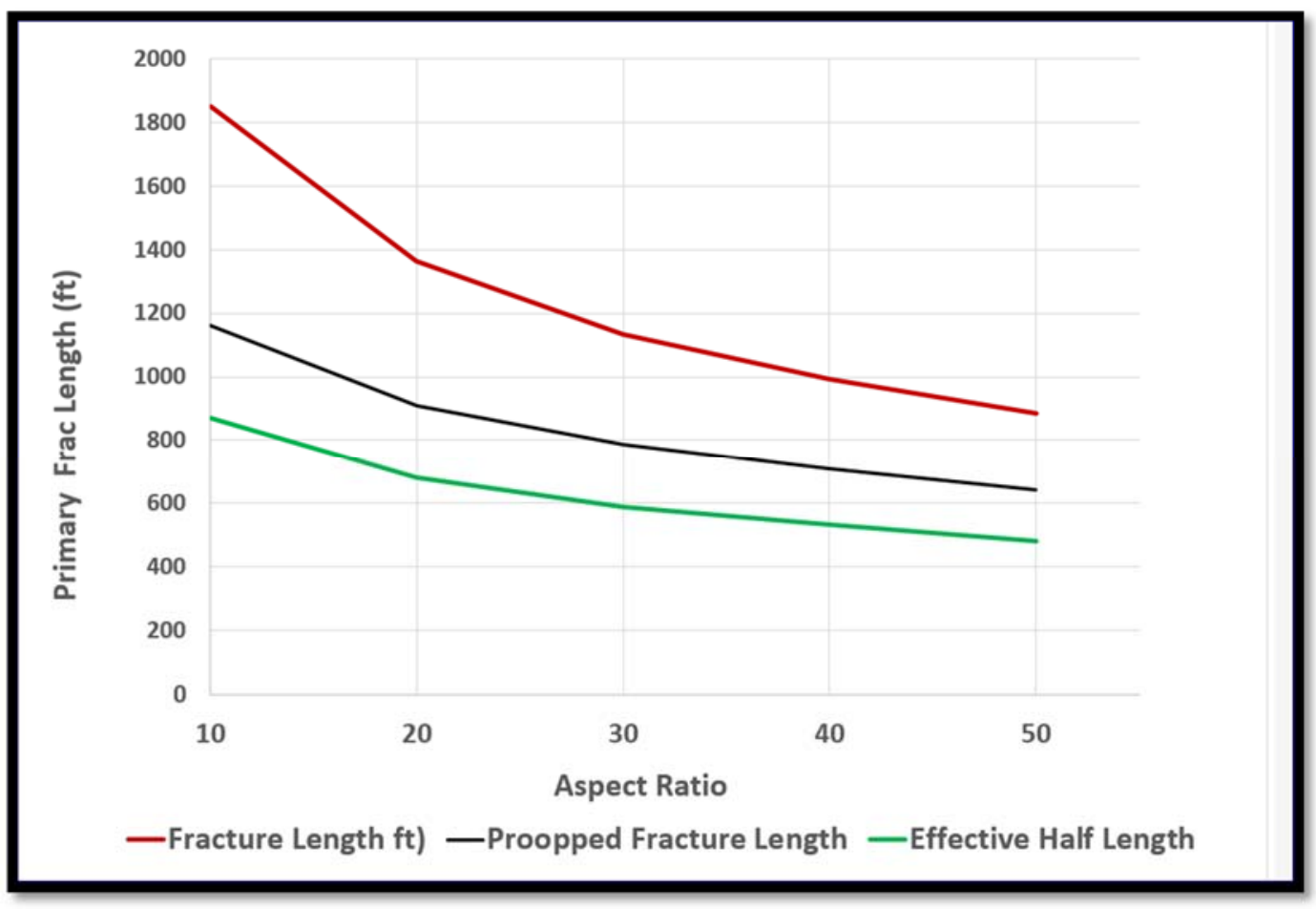

Figure 47: Effect of Aspect ratio on fracture length 


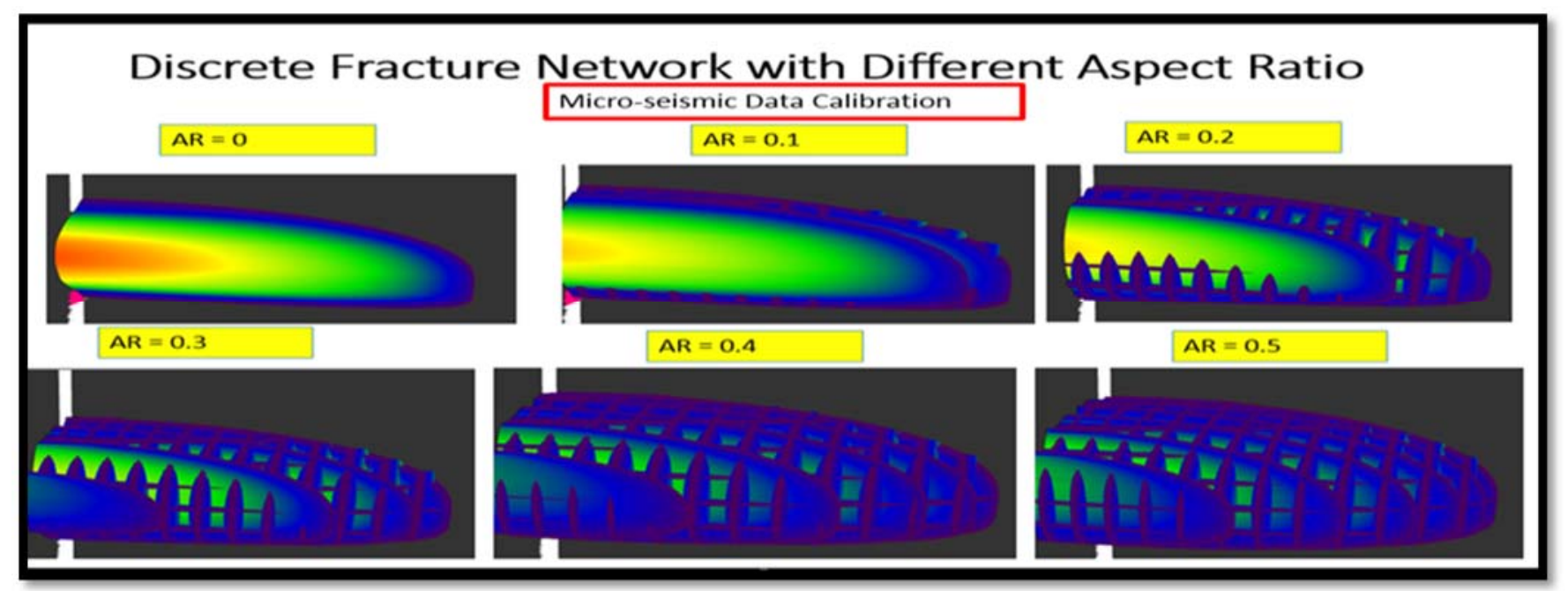

Figure 48: Discrete Fracture Network with different Aspect ratio

The model was setup for sensitivity study of fracture geometry and a constant slurry volume of $12200 \mathrm{bbl}$. was injected with different aspect ratio of Eagle Ford shale formation.

Table 30 shows the negative impact of increasing aspect ratio on fracture efficiency and length and the positive impact on stimulated reservoir volume. Additionally, Table 30 illustrates the relationship between aspect ratio and properties of hydraulic fracture. Therefore, understanding rock properties can help to select the optimum fluid volume to create desire fracture length.

\begin{tabular}{|c|c|c|c|c|c|}
\hline DFN Aspect Ratio (injected volume of 1220 bbl.) & 10 & 20 & 30 & 40 & 50 \\
\hline Fracture Efficiency, \% & 0.658 & 0.635 & 0.621 & 0.613 & 0.616 \\
\hline Length, ft. & 1848 & 1364 & 1133 & 993 & 886 \\
\hline Frac Height - Avg, ft. & 189.22 & 186.44 & 185.24 & 184.1 & 183.03 \\
\hline Primary Frac Area, $10^{5}\left(\mathrm{ft}^{2}\right)$ & 3.50 & 2.54 & 2.10 & 1.83 & 1.62 \\
\hline Max. Frac Width, in. & 0.4162 & 0.3918 & 0.3773 & 0.3686 & 0.3753 \\
\hline Avg. Wellbore Width, in & 0.3117 & 0.2957 & 0.2858 & 0.2803 & 0.2865 \\
\hline Avg. Hydraulic Frac Width, in. & 0.23655 & 0.22607 & 0.21999 & 0.21695 & 0.22302 \\
\hline DFN Area, $10^{6}\left(\mathrm{ft}^{2}\right)$ & 2.57 & 2.61 & 2.64 & 2.66 & 2.69 \\
\hline DFN SRV, $10^{6}\left(\mathrm{ft}^{3}\right)$ & 9.04 & 9.70 & 9.98 & 10.16 & 10.10 \\
\hline
\end{tabular}

Table 30: Impact of aspect ratio on fracture properties 
The connection between reservoir and wellbore with different proppant distributions were investigated. A sensitivity analysis was conducted and the required portion of fluid volumes to generate fracture length and other portions to transport proppant into the created fracture was studied. Figure 49 illustrates the relationship between injected pad volume and generated proppant half length.

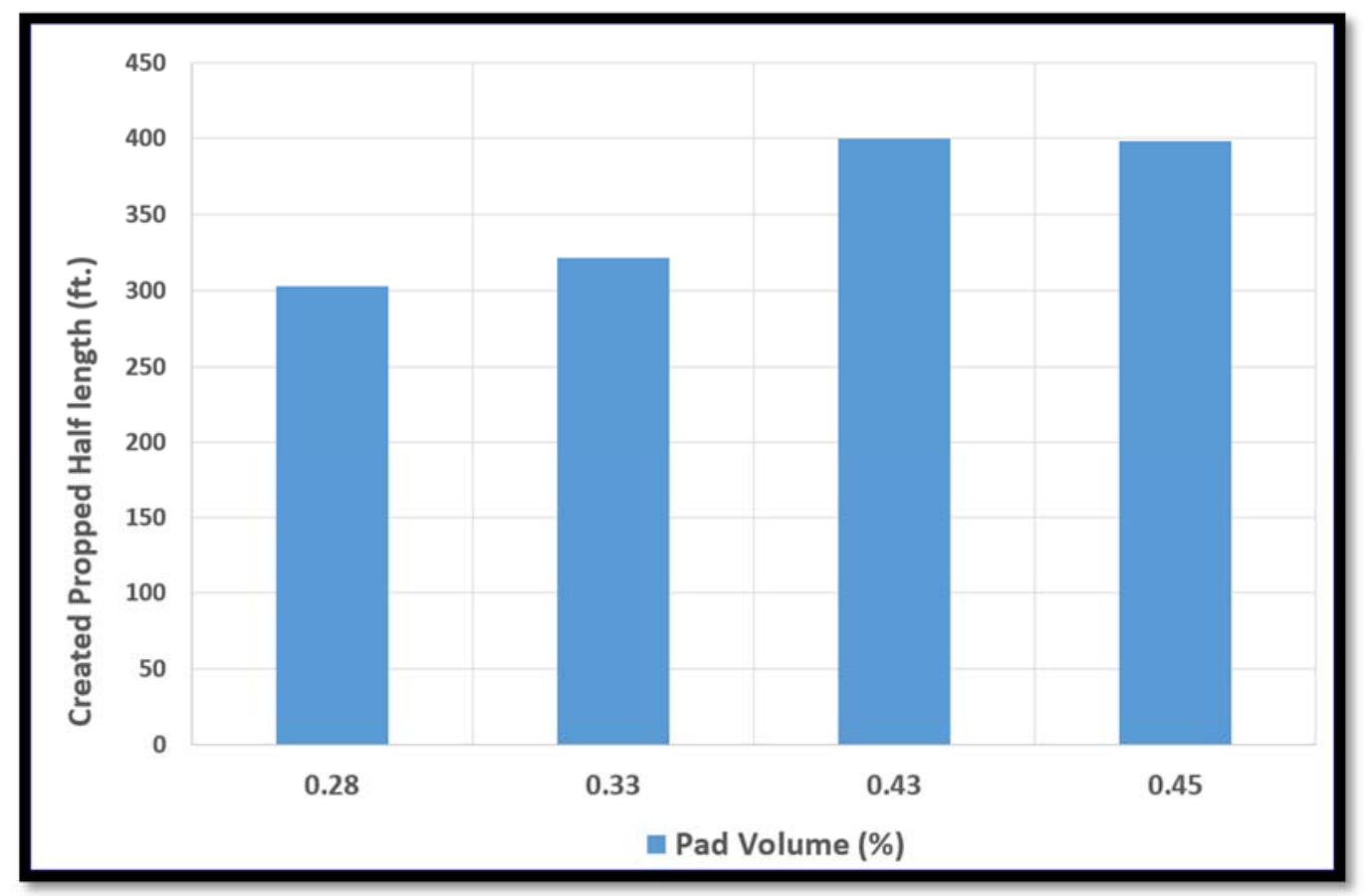

Figure 49: Sensitivity analysis for PAD volume selection

This study also investigates required conductivity in DFN, including the effect of fracture fluid viscosity on fracture complexity and proppant distribution in complex fractures.

Figure 50 shows increasing fracture complexity will result with greater loss of conductivity and diminishes the effect of fracture conductivity on productivity. The conductive fracture half-length was much shorter than estimated based on micro seismic records or generated from fracture model. 


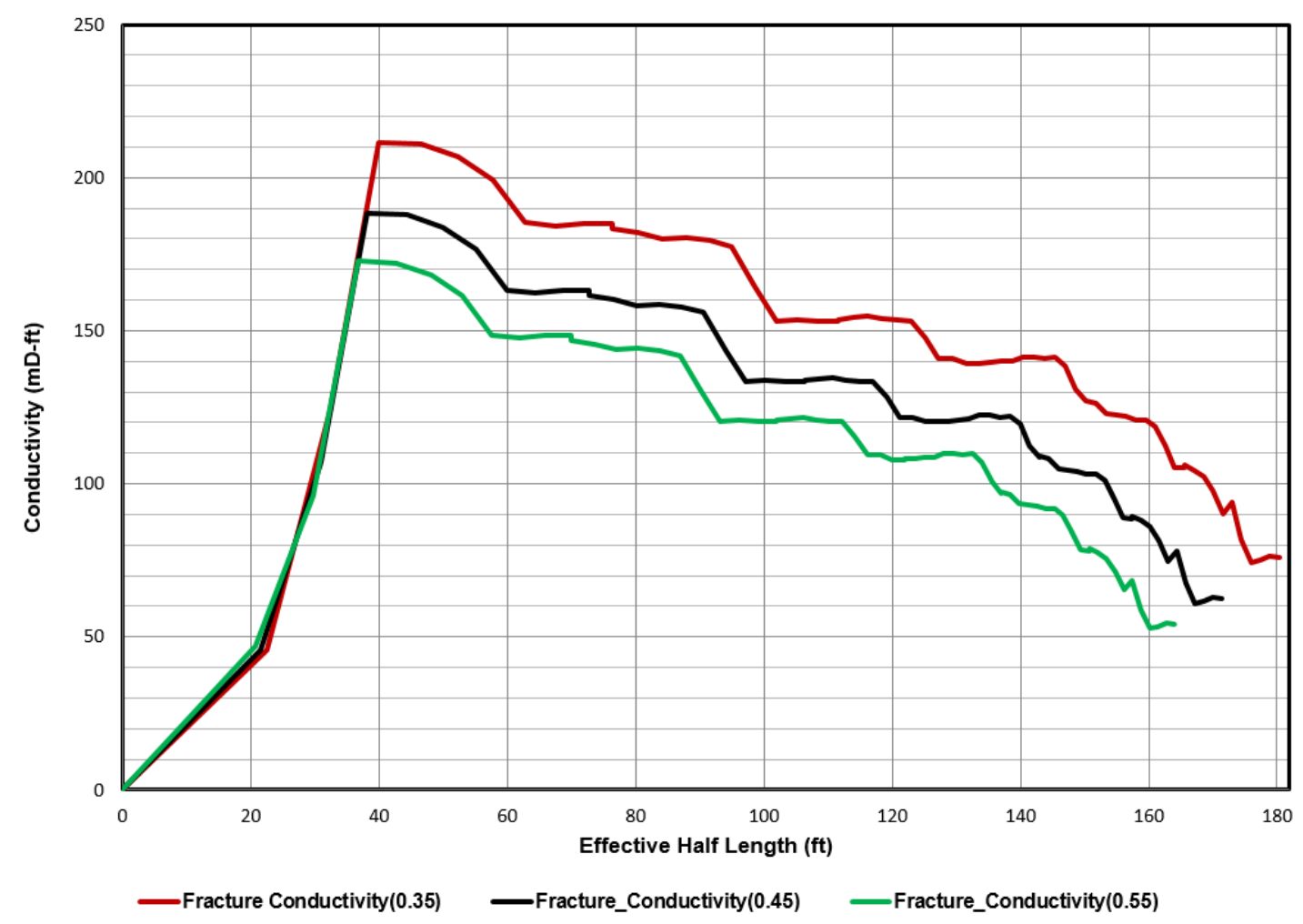

Figure 50: Effect of Aspect ratio on Fracture conductivity

\subsubsection{Reservoir Simulation}

A base model was prepared and used to evaluate sensitivity of hydraulic fracture parameters and predict its production for 30 years. The horizontal well had 15 stages with total lateral length of $5000 \mathrm{ft}$. To evaluate the impact of properties of hydraulic fracture and reservoir parameters on well production performance, sensitivity analysis were performed on some key parameters, including porosity, matrix permeability, fracture permeability, and effective half length. Sensitivity analysis can help to focus on inputs whose uncertainties have an impact on the model output, which allows reducing the complexity of the model.

Sobol sensitivity analysis used to determine how sensitive particular parameters and their effect in ultimate recovery (EUR). As illustrated in Figures 51 through 54, fracture half-length was the only parameter which had major effect on cumulative oil and gas production. 
Fracture half-length had an $81 \%$ effect on cumulative oil and $84 \%$ on cumulative gas, followed by porosity of layer 3 which was considered as organic portion of formation imposing the second highest impact on well performance. Other parameters such as fracture permeability, width, matrix permeability, and porosity had minimum effects on EUR.

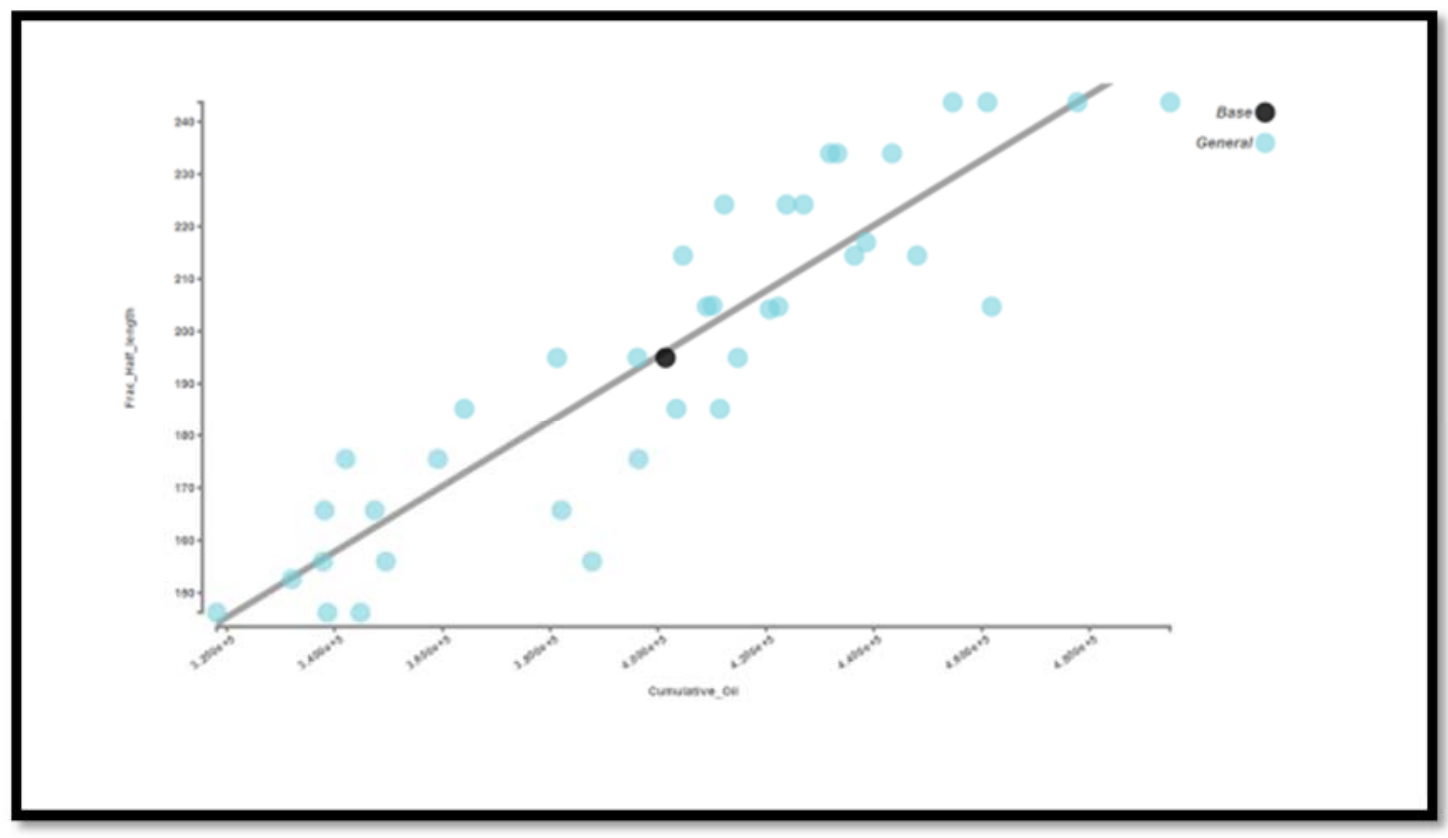

Figure 51: Relationship between Fracture Half-length and Cumulative Oil 


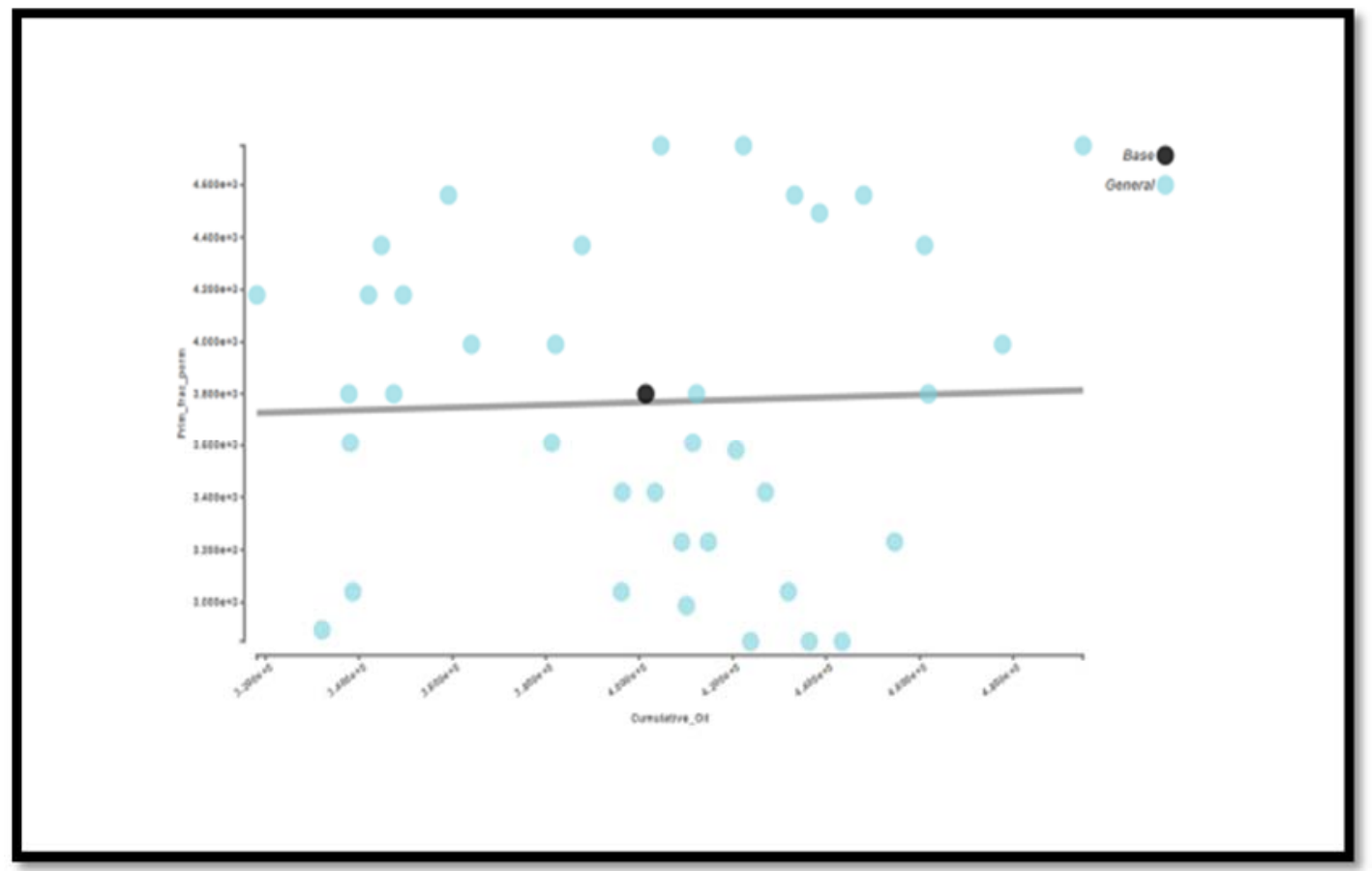

Figure 52: Relationship between Fracture Permeability and Cumulative Oil

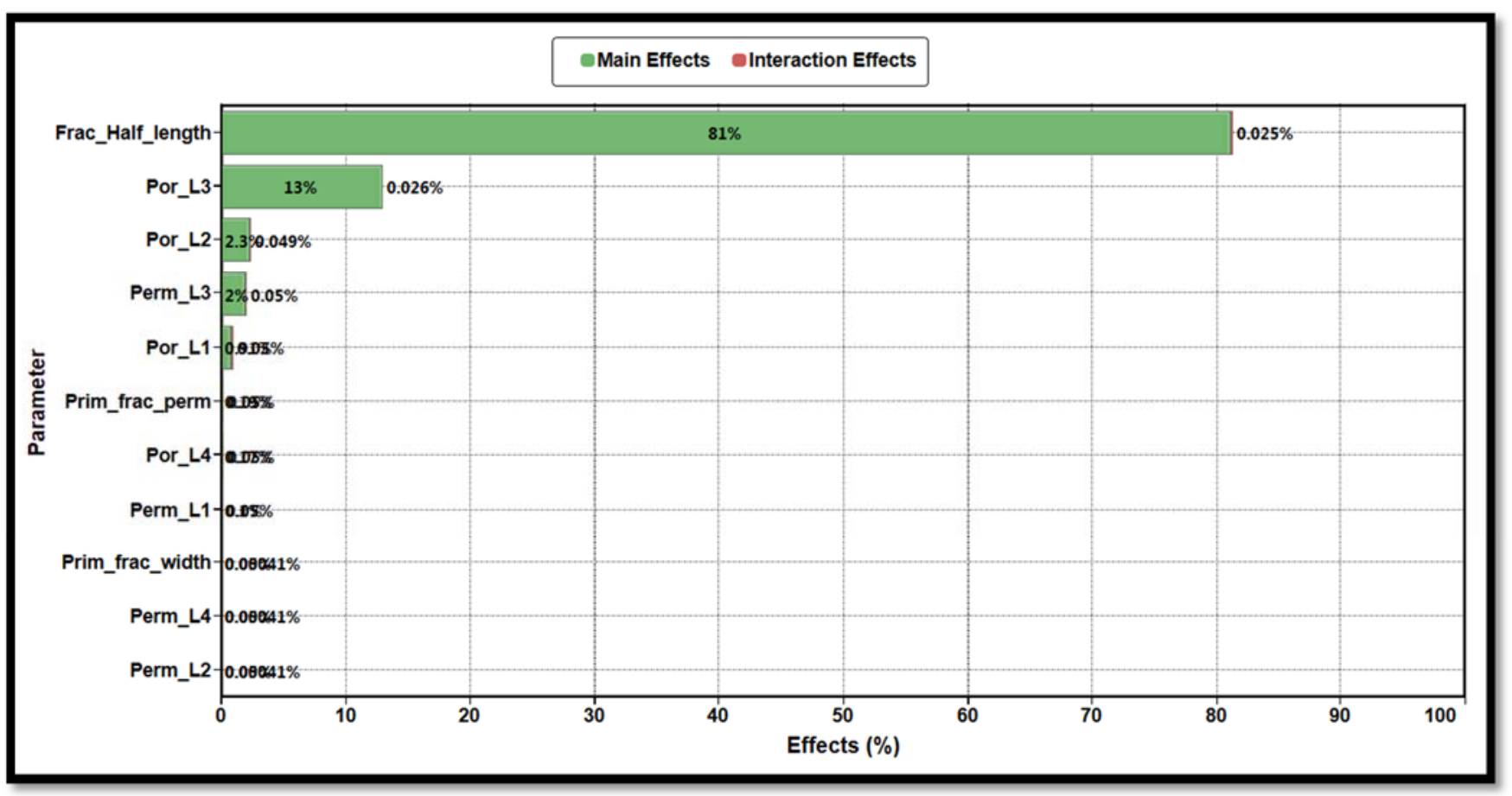

Figure 53: Sensitivity analysis of Cumulative Oil 


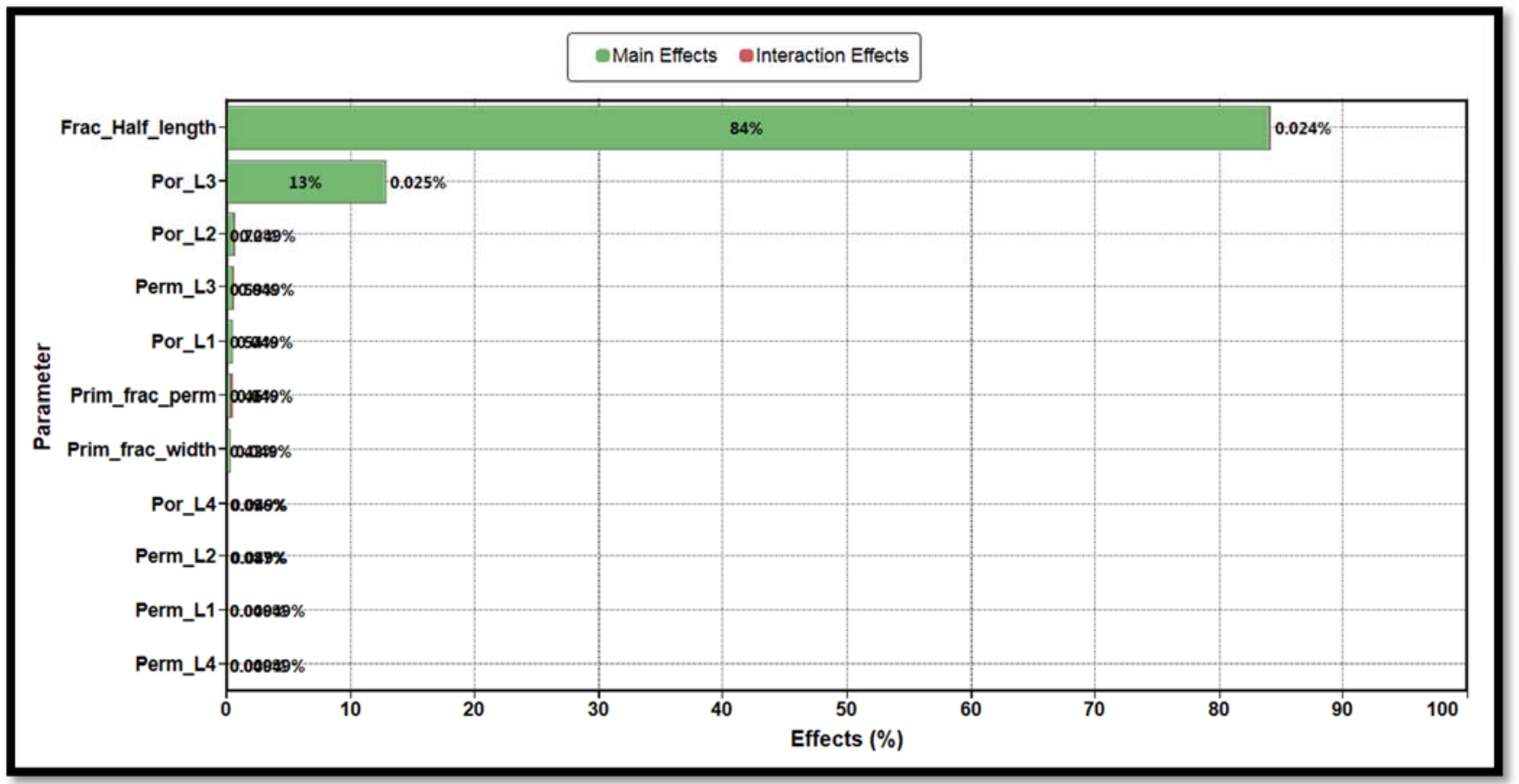

Figure 54: Sensitivity analysis of Cumulative Gas

To assess the impact of properties of hydraulic fracture such as fracture half-length and permeability, sensitivity runs were performed with following assumptions.

- The fracture half-length ranging from $200 \mathrm{ft}$. to $300 \mathrm{ft}$. with constant fracture permeability of $3800 \mathrm{md}$.

- Fracture permeability ranging $2000 \mathrm{md}$ to $4000 \mathrm{md}$ with constant half-length of $250 \mathrm{ft}$.

Sensitivity runs and their results are presented in Table 31. The results are also presented in Figures 55 and 56 indicating that the fracture half-length had the biggest impact on well performance. Increasing half-length from $200 \mathrm{ft}$. to $250 \mathrm{ft}$. provides additional $76 \mathrm{MBBL}$ of oil and increasing from $250 \mathrm{ft}$. to $300 \mathrm{ft}$. produces extra 137 MBBL of oil. 


\begin{tabular}{|c|l|l|l|l||}
\hline \multicolumn{6}{|c||}{ Effect on fracture half-length on EUR } \\
\hline Run \# & Half Length (ft.) & Frac-Perm (md) & Oil EUR (MBBL) & Gas EUR \\
\hline 1 & 200 & 3800 & 407 & 330 \\
\hline 2 & 250 & 3800 & 483 & 379 \\
\hline 3 & 300 & 3800 & 545 & 458 \\
\hline & \multicolumn{2}{|c|}{ Effect on fracture permeability on EUR } \\
\hline 1 & 250 & 2000 & 471 & 373 \\
\hline 2 & 250 & 3000 & 479 & 390 \\
\hline 3 & 250 & 4000 & 484 & 399 \\
\hline
\end{tabular}

Table 31: Summary of result of sensitivity analysis

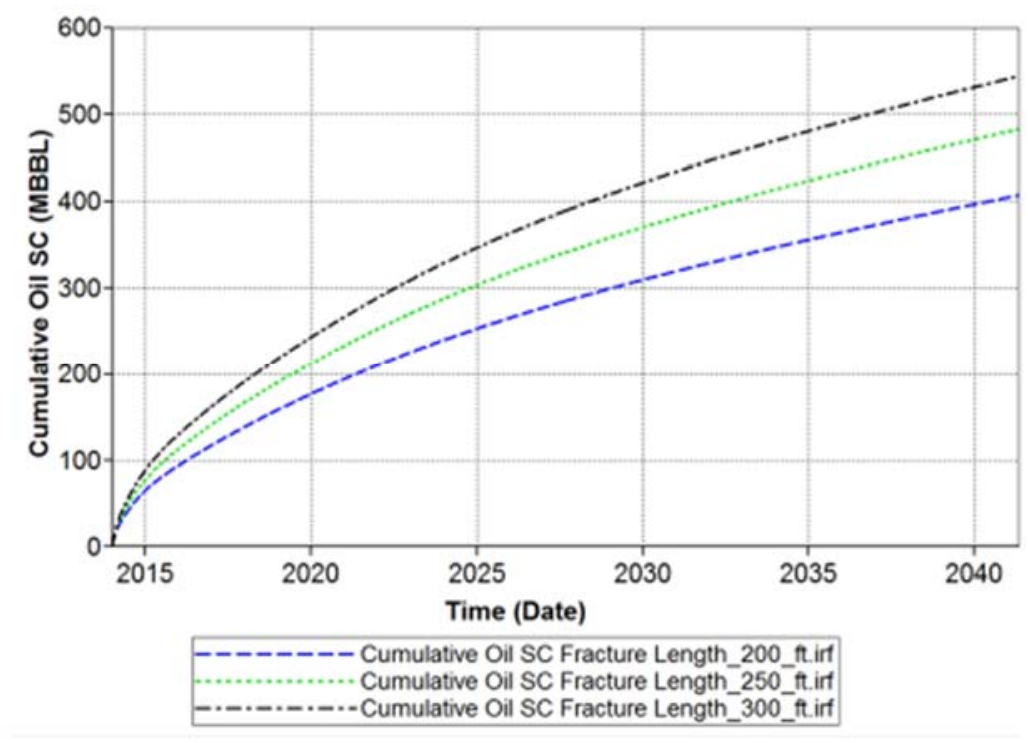

Figure 55: Effect on Fracture Half-length on Oil EUR 


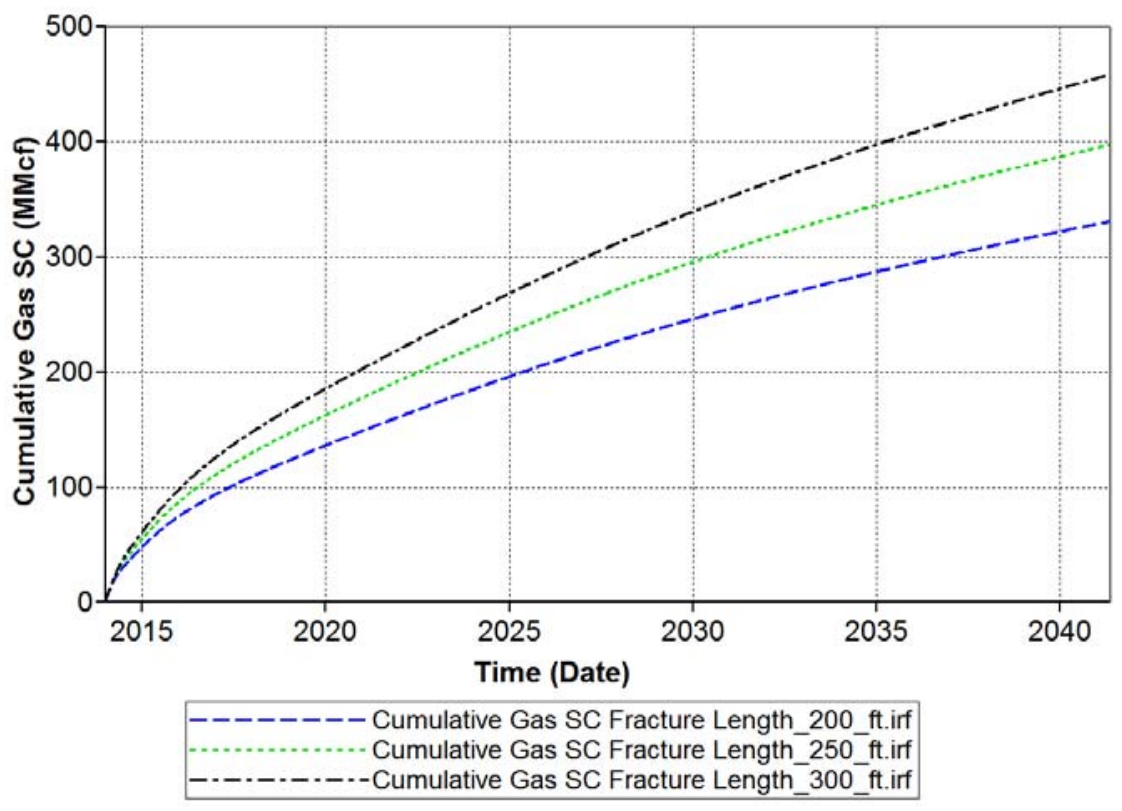

Figure 56: Effect on Fracture Half-length on Gas EUR

The fracture permeability had the lowest and insignificant impact on well performance as illustrated in Figures 57 and 58. Increase in fracture permeability from $2000 \mathrm{md}$ to 4000 required high viscous fluid and high proppant concentration and resulted with an average oil production increase of $20 \mathrm{MBBL}$. 


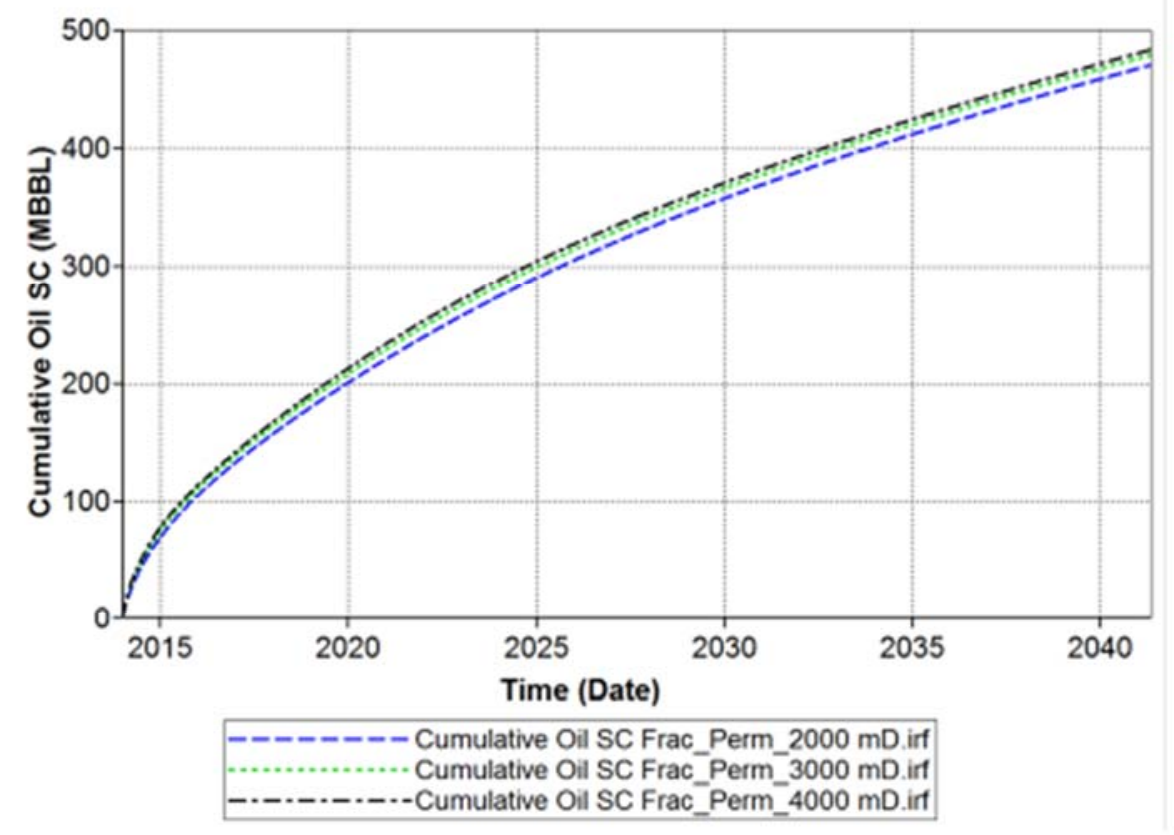

Figure 57: Effect on Fracture Permeability on Cumulative Oil

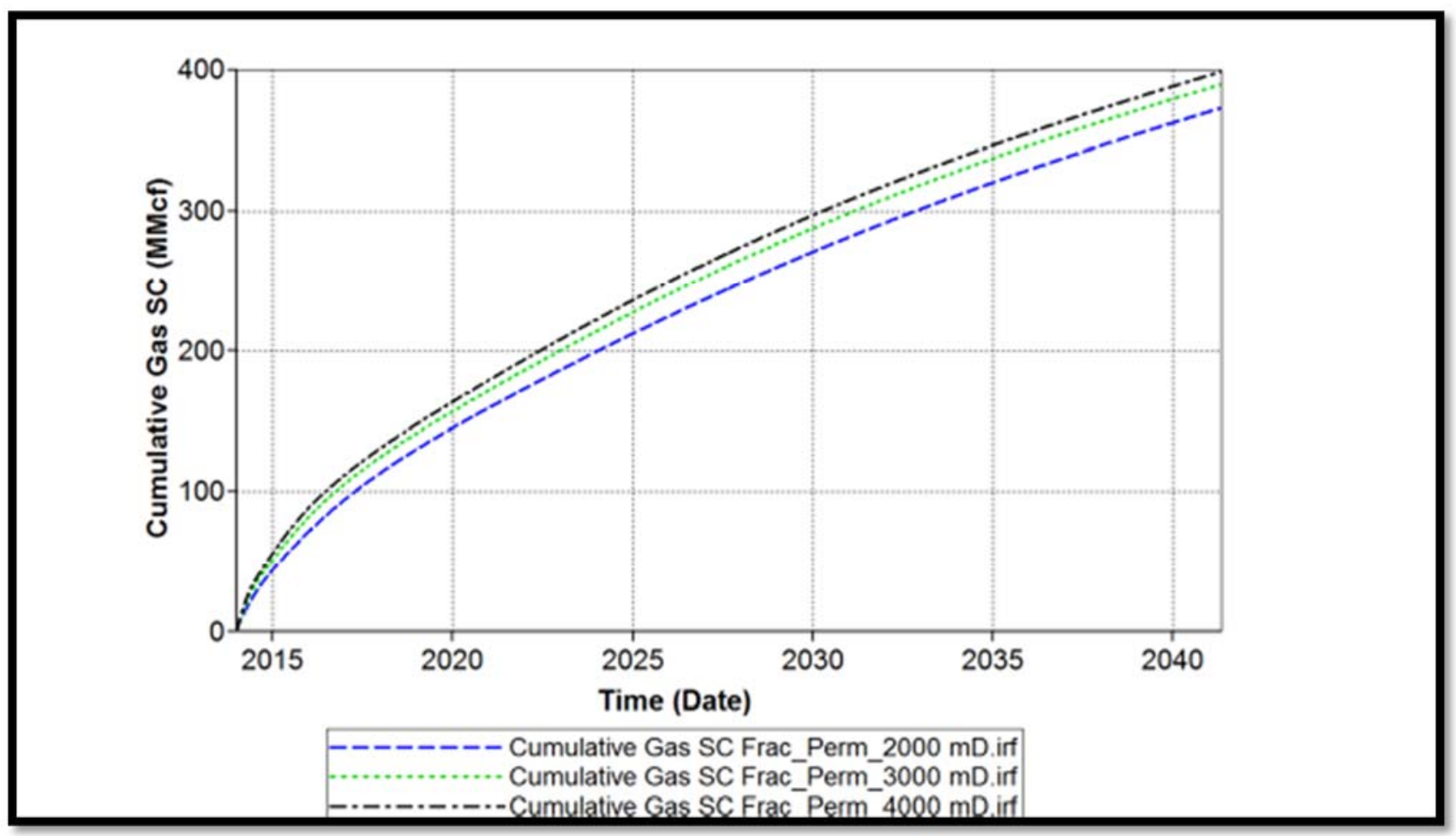

Figure 58: Effect on Fracture Permeability on Cumulative Gas 


\subsection{Second Generation Stimulation Treatment Design (Optimization)}

The first generation treatment design was based on the production of best yielding wells in Eagle Ford. The outcome of a fracture treatment depends on the Brindell hardness number (BHN NO.) Values of this property based on core test results from various shale reservoirs (Stegent, et al (2010)) are shown in Figure 59. Eagle Ford has a low BHN which indicates that the rock is relatively soft or more ductile and also prone to proppant embedment. To overcome this, a conductivity design option was implemented. The basis of this treatment design was the concept that hydraulic fracturing requires high viscosity to create a considerable flow path, followed by a loading with higher proppant concentration to achieve optimum fracture conductivity in near wellbore. Fracture complexity is typically reduced when fluid viscosity is increased. Also, penetration distance or length significantly reduces as viscosity increases. As a result of this approach production respond of first treatment design was less than expected.

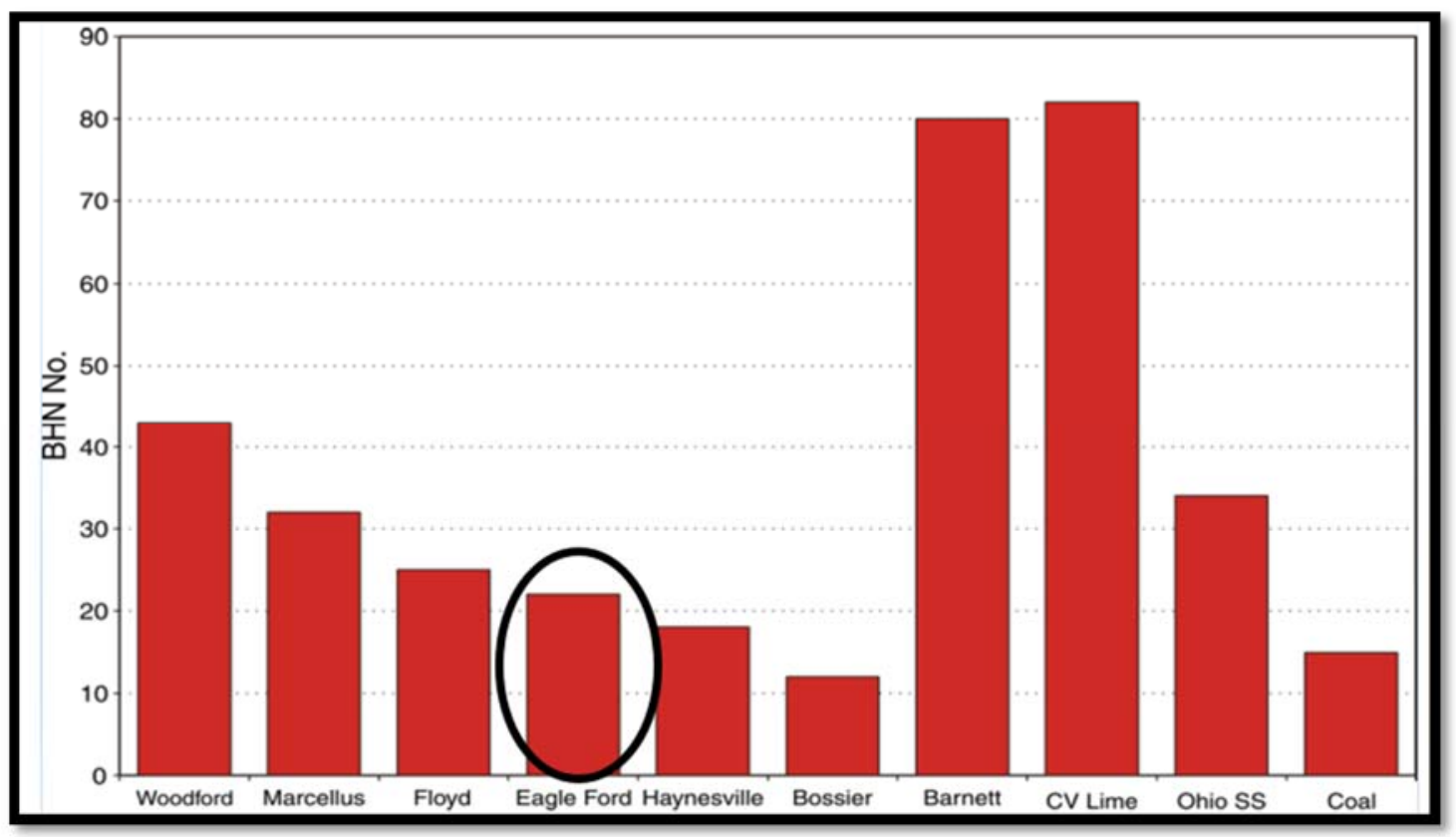

Figure 59: Brindell hardness number of various shale reservoir in North America

Treatment design can vary from area to area due to the varying geomechanical properties observed across the Eagle Ford. After detailed analysis of parametric study 
presented earlier with based local rock and fluid properties, a new treatment was designed $\left(2^{\text {nd }}\right.$ generation $)$.

Second generation stimulation treatment was based on local rock properties of well \#1 and its offsite well, including micro-seismic fracture mapping data and Brindell hardness values. Figure 60 shows that the formation in study area is more brittle with $\mathrm{YM}$ of $4.5 \mathrm{x}$ 10E6 psi. This means that there is no risk of proppant embedment. As a result, hybrid fracturing fluid system was chosen for second generation treatment design. High fluid volume with low viscosity hybrid fluid system generates fractures of minor width and therefore had greater fracture length, practically increasing the complexity of the created fracture network for a better reservoir-to-wellbore connectivity. Moderate fracture complexity was expected due to the interaction of the hydraulic fracture with natural fracture based on observed formation properties. Options to control or exploit this complexity can have a significant impact on fracture design and well performance.

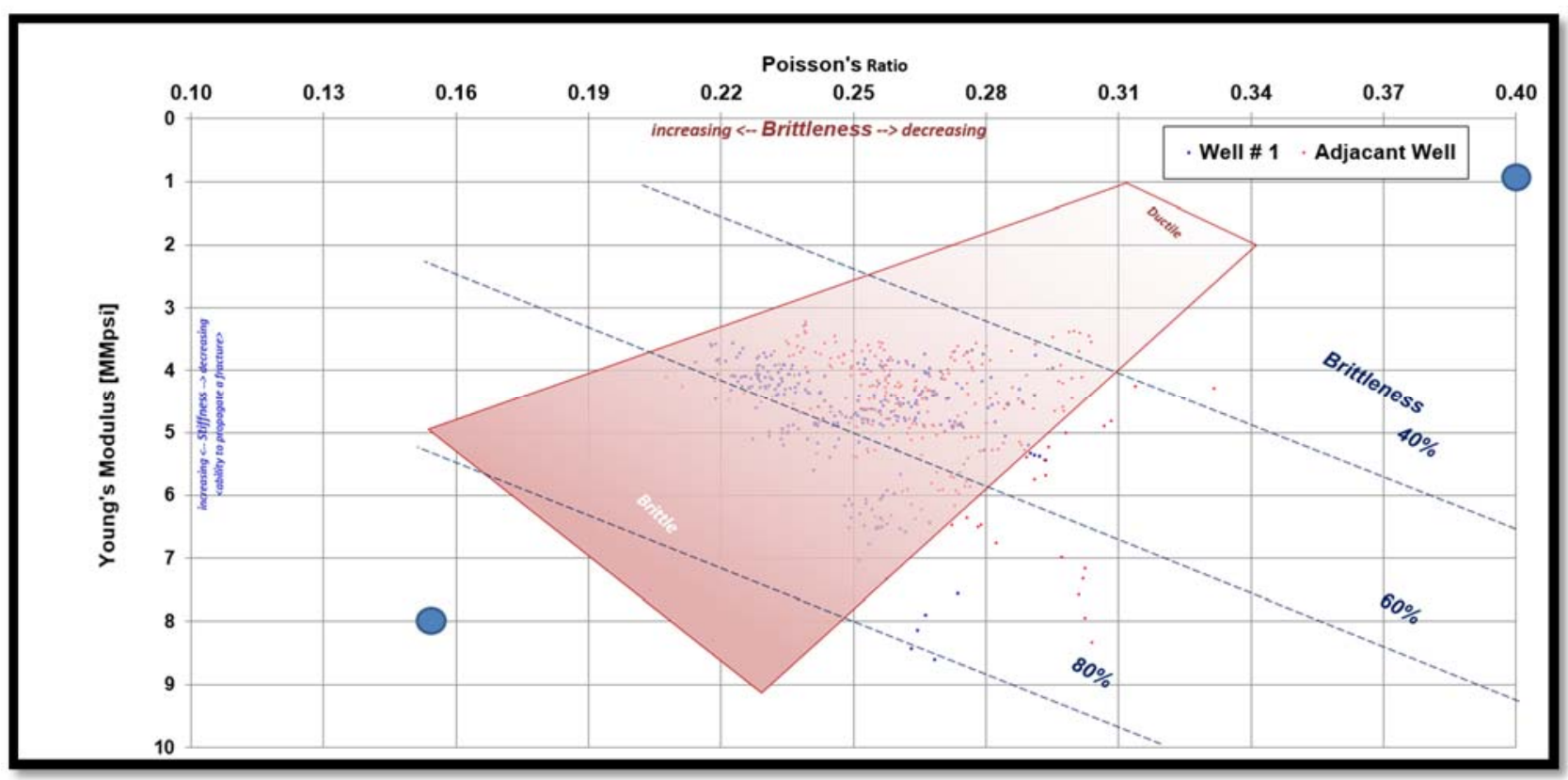

Figure 60: Well \#1 and adjacent well Brindell hardness value Application of hybrid fluid system provides outstanding results in Eagle Ford formations with intersecting secondary fracture cracks which are encountered once this hydraulic control is established. 


\subsubsection{Impact of Fluid system and Proppant into Fracture Properties}

The application of second generation was hydraulically initiated into the formation with a high pad fluid volume to create a large surface area based on parametric study values shown in Figure 49. The treatment design included a ramp of fine-grained, low density proppant (100 mesh) and high rates early in the stage to achieve secondary and farfield proppant placement. Towards the end of the stage, low medium density (40/70) proppants were pumped to fill the primary fracture up to the perforations. Improved initial and long-term recoveries were achieved by expanding fracture surface area while also maintaining fracture connectivity.

It was observed that the grain of larger mesh proppants such as 30/50 and 20/40 mesh was difficult to transport beyond the primary fracture. High density proppant cannot transport sand properly in the primary fracture because it requires a higher viscosity fluid system that significantly reduces fracture surface area. Therefore, smaller mesh size proppants such as 100 mesh and 40/70 were selected for second generation treatment design. These proppants can pass through the complex fracture network into the secondary fractures, while simultaneously propping the primary fracture. Figures 61 and 62 present relationship between proppant transport, conductivity and formation penetration for both designs. 100 mesh effectively reduced leak-off through any intersecting fractures. It did not restrict fluid travel down the primary fracture, and thus allowed the subsequent fracturing fluid to extend to the principal fracture with desired distance into the reservoir.

In addition, low proppant concentration was utilized to improve the effect on proppant distribution on primary and secondary fractures with the assumption that proppant was either concentrated in a primary propped fracture or evenly distributed in a fracture network. After effective proppant transport, expected range of un-propped fracture was reduced. 


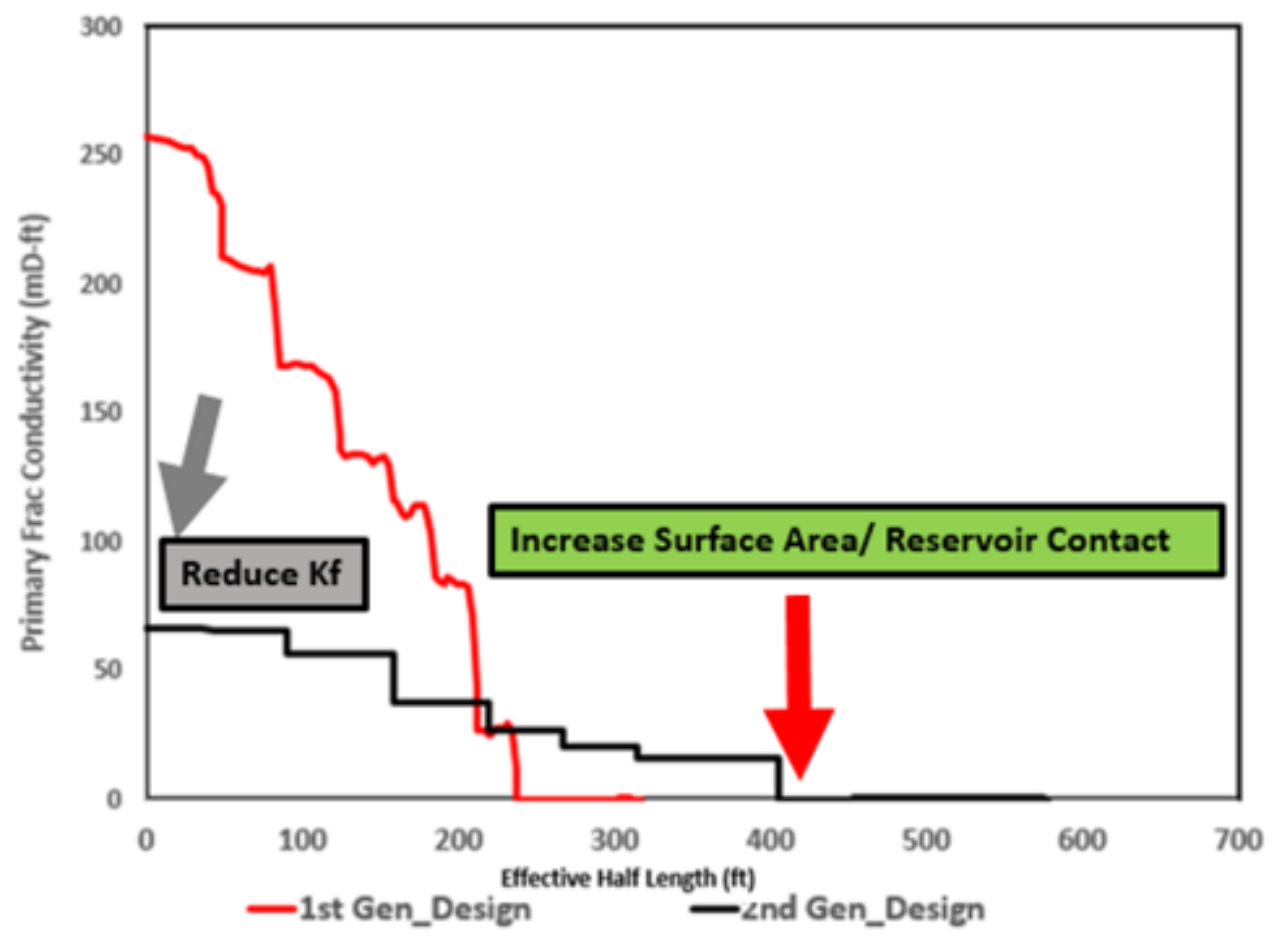

Figure 61: Effect of Fluid Viscosity on Penetration and conductivity

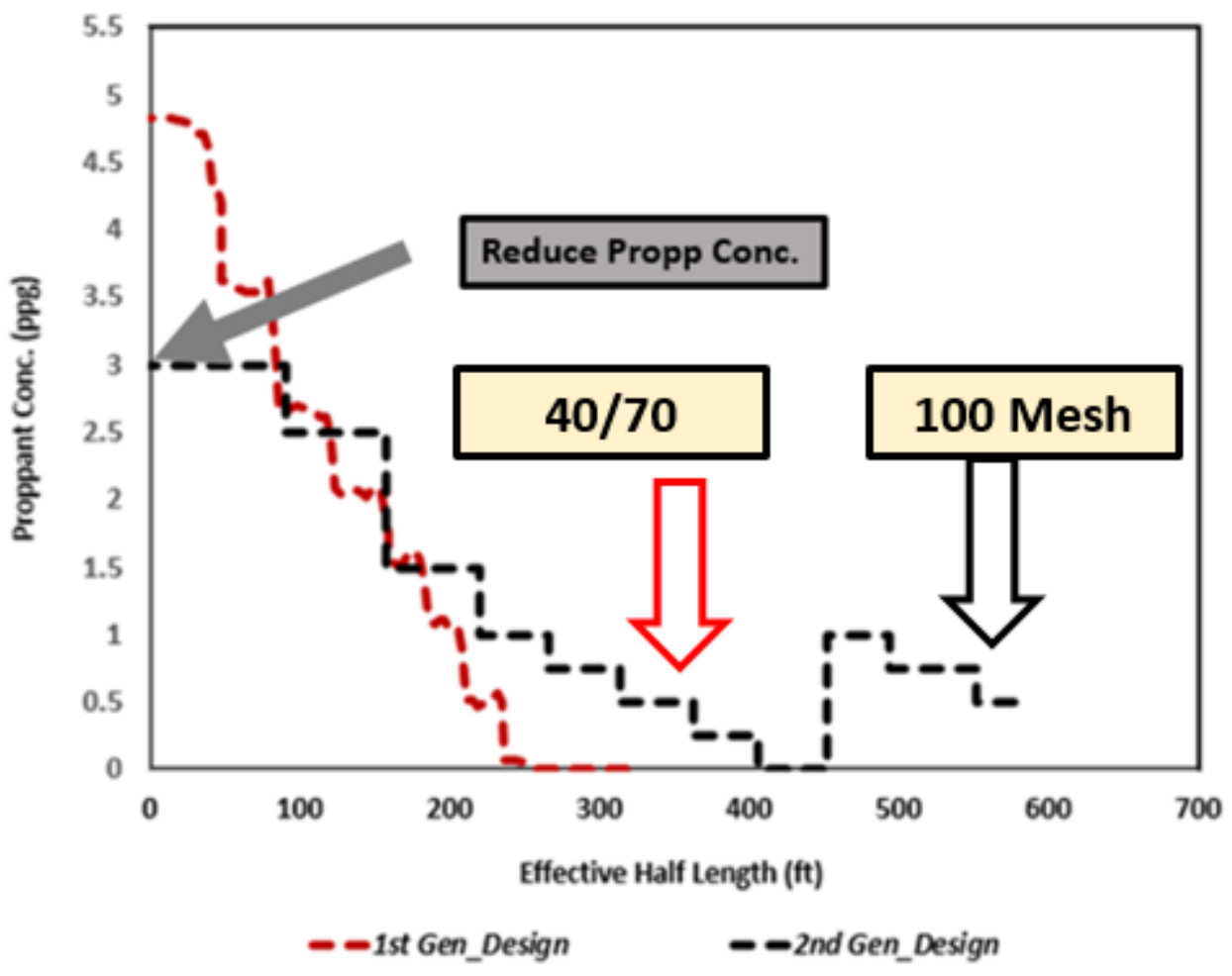

Figure 62: Effect of proppant concentration on proppant transport and penetration 
Table 32 summarizes and compares first and second generation simulation results. Injected fluid was increased as a result of expanding surface area. Lower proppant concentration and smaller mesh size was utilized with reduced conductivity and increased connectivity and proppant distribution. A fracture half-length of $575 \mathrm{ft}$. was created and propped length was recorded at $395 \mathrm{ft}$. with estimated effective half-length of $320 \mathrm{ft}$. This was a value close to near wellbore (NW) conductive half-length or contributing length.

\begin{tabular}{|c|c|c|c|}
\hline Parameter & First Generation & Second Generation & Unit \\
\hline \multicolumn{4}{|c|}{ Result of Hydraulic Fracture Modeling } \\
\hline Fracture Half Length - Created & 318 & 575 & (ft.) \\
\hline Fracture Half Length - Propped & 237 & 395 & (ft.) \\
\hline Effective Half Length-(NW) & 208 & 320 & (ft.) \\
\hline Fracture Permeability & 4142 & 2000 & (md) \\
\hline Fracture Height & 230 & 225 & (ft.) \\
\hline Drainage Area & 100 & 100 & (Acre) \\
\hline Matrix Permeability & 370 & 370 & (nD) \\
\hline Stages & 15 & 15 & \\
\hline Lateral Length & 5000 & 5000 & (ft.) \\
\hline Stimulated Area & 47 & 73 & (Acre) \\
\hline \multicolumn{4}{|c|}{ History Match Parameters and Cumulative Production Forecast } \\
\hline Lateral Length & 5000 & 5000 & (ft.) \\
\hline Avg. Fracture Permeability & 3200 & 1800 & (md) \\
\hline Half Length & 237 & 347 & (ft.) \\
\hline Stimulated Area & 54 & 80 & (Acre) \\
\hline EUR (Oil) & 633 & 855 & (MBBL) \\
\hline EUR (Gas & 529 & 735 & (MMcf) \\
\hline
\end{tabular}

Table 32: First and Second Generation Hydraulic Fracture Properties and production forecast

After successful fracture modelling, fracture properties were applied as input to reservoir simulator. In the next step, simulated production was matched with second generation well's historical production data. Selected matching parameters were porosity and permeability of layer 1 through layer 4 , hydraulic fracture properties including fracture half length, fracture permeability, and fracture width. Matching was successfully completed with an average error of $6.8 \%$. The results indicated that the cumulative oil was increased by $26 \%$ compared to first generation design, with a cumulative gas increase of $28 \%$. Stimulated surface area was increased by $32 \%$. The production 
forecast profiles are presented in Figures 63 and 64 . Figures 65 and 66 show the expected increase in cumulative oil and gas production at the end of 50 years when the new second generation design is used.

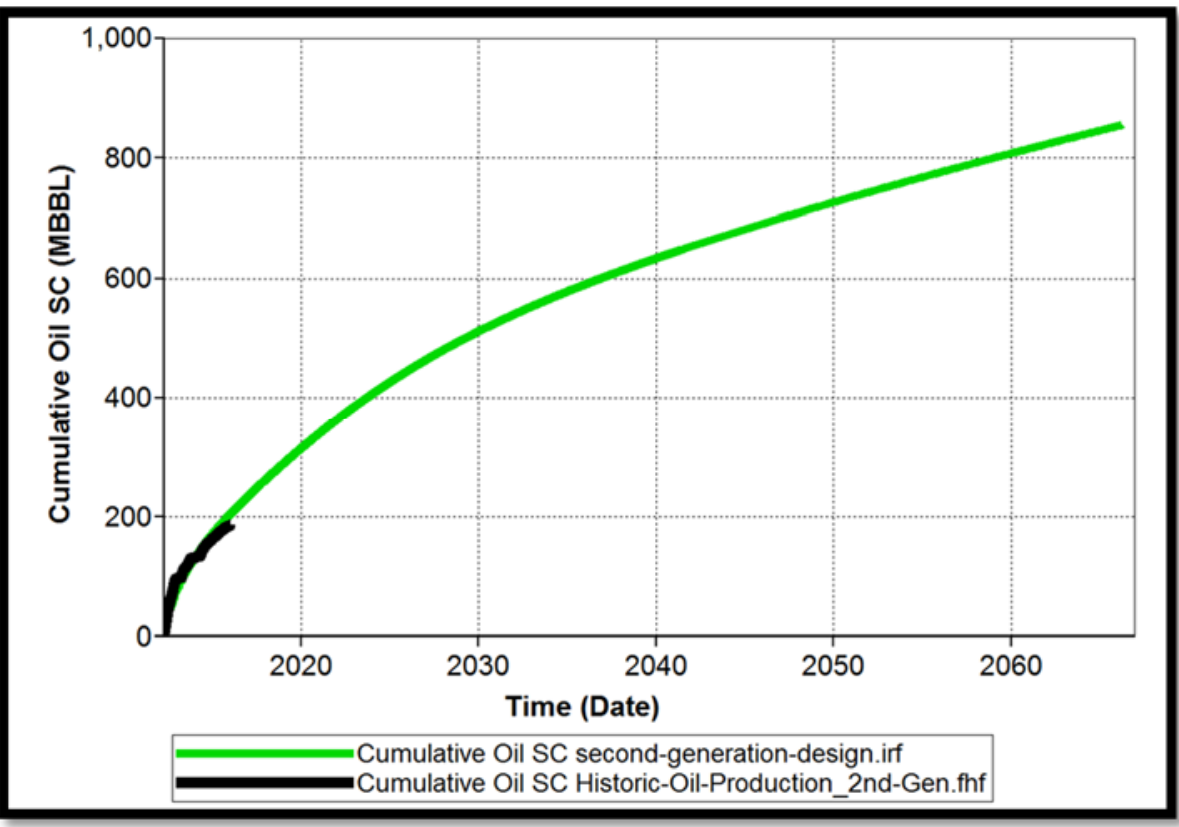

Figure 63: Second generation cumulative oil and history match

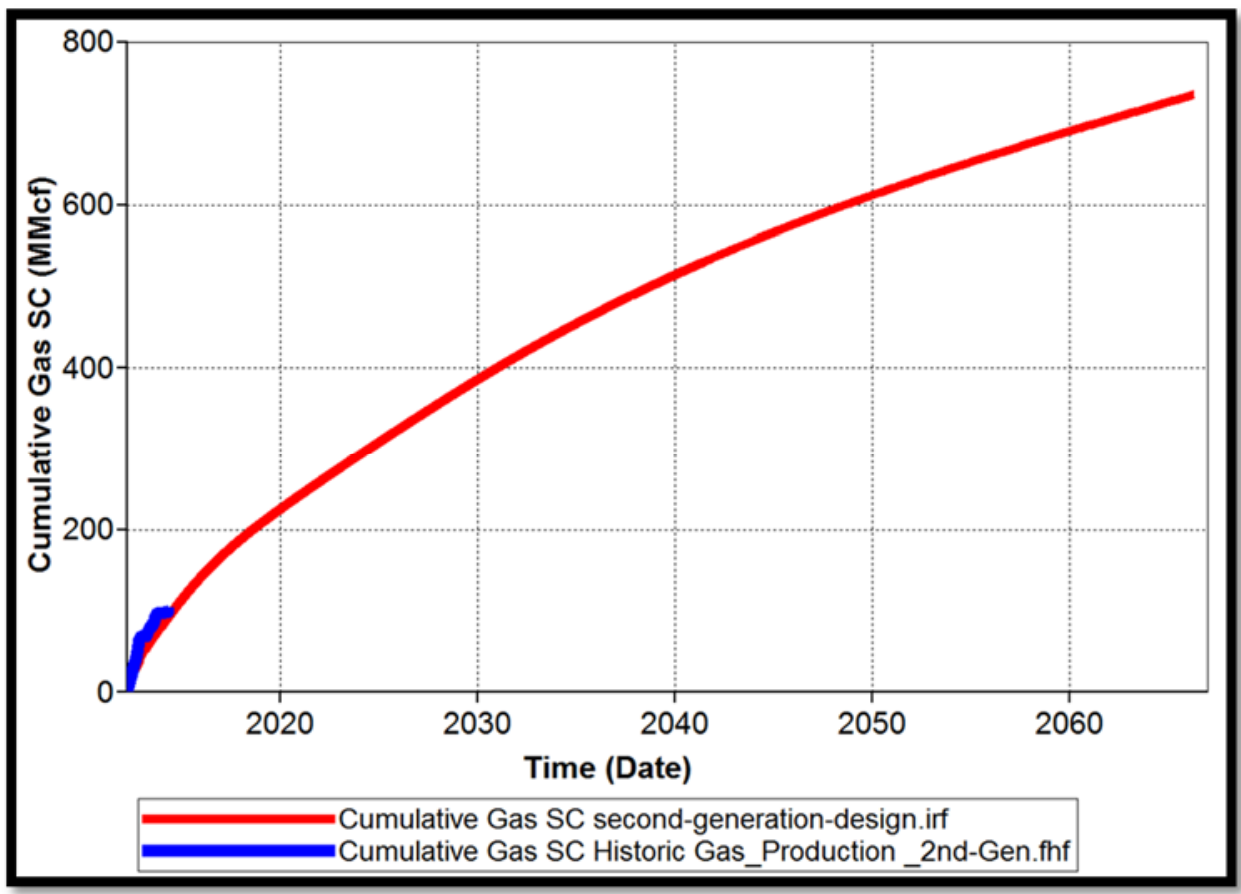

Figure 64: Second generation cumulative gas and history match 


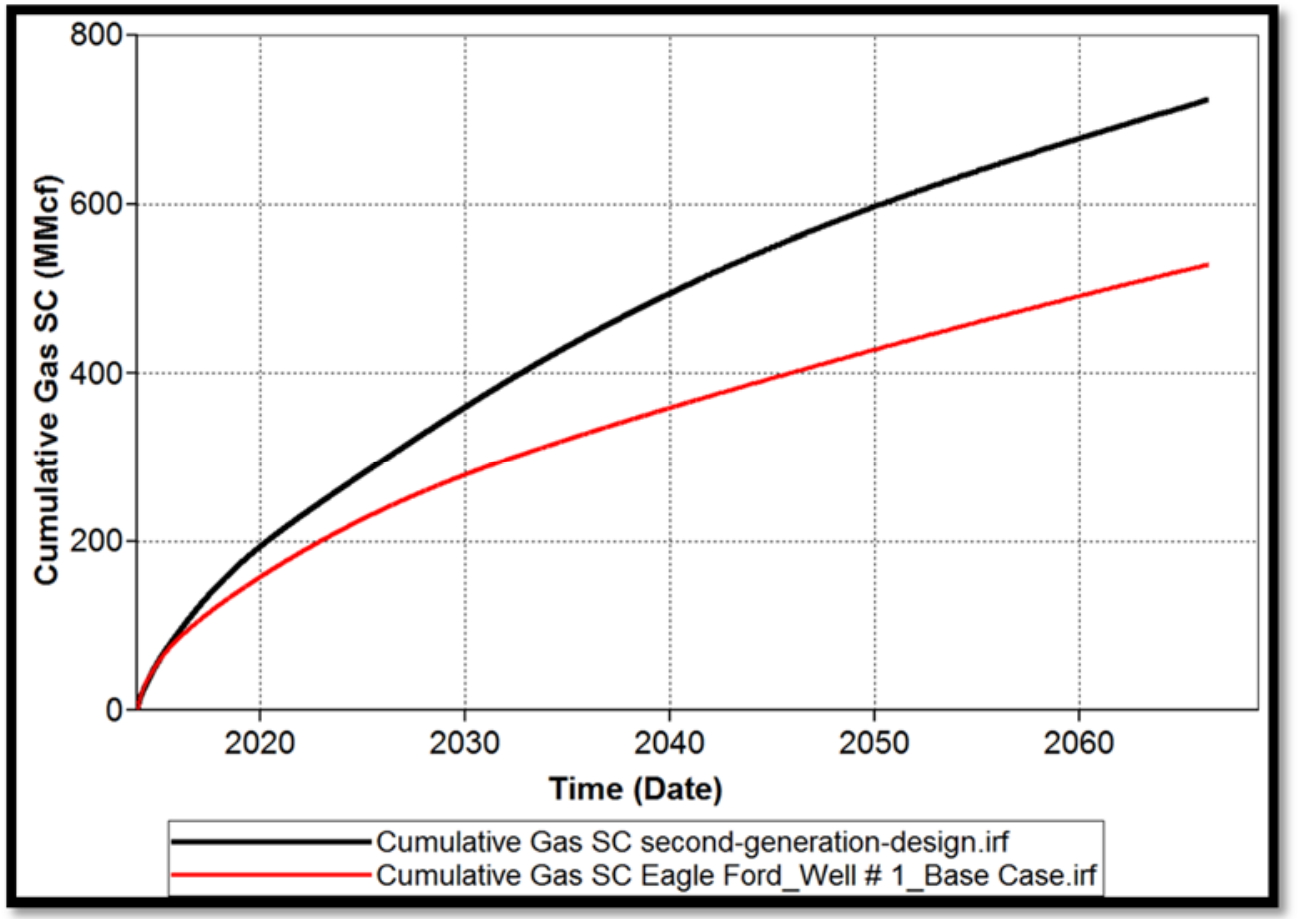

Figure 65: Cumulative gas production with First and Second generation designs

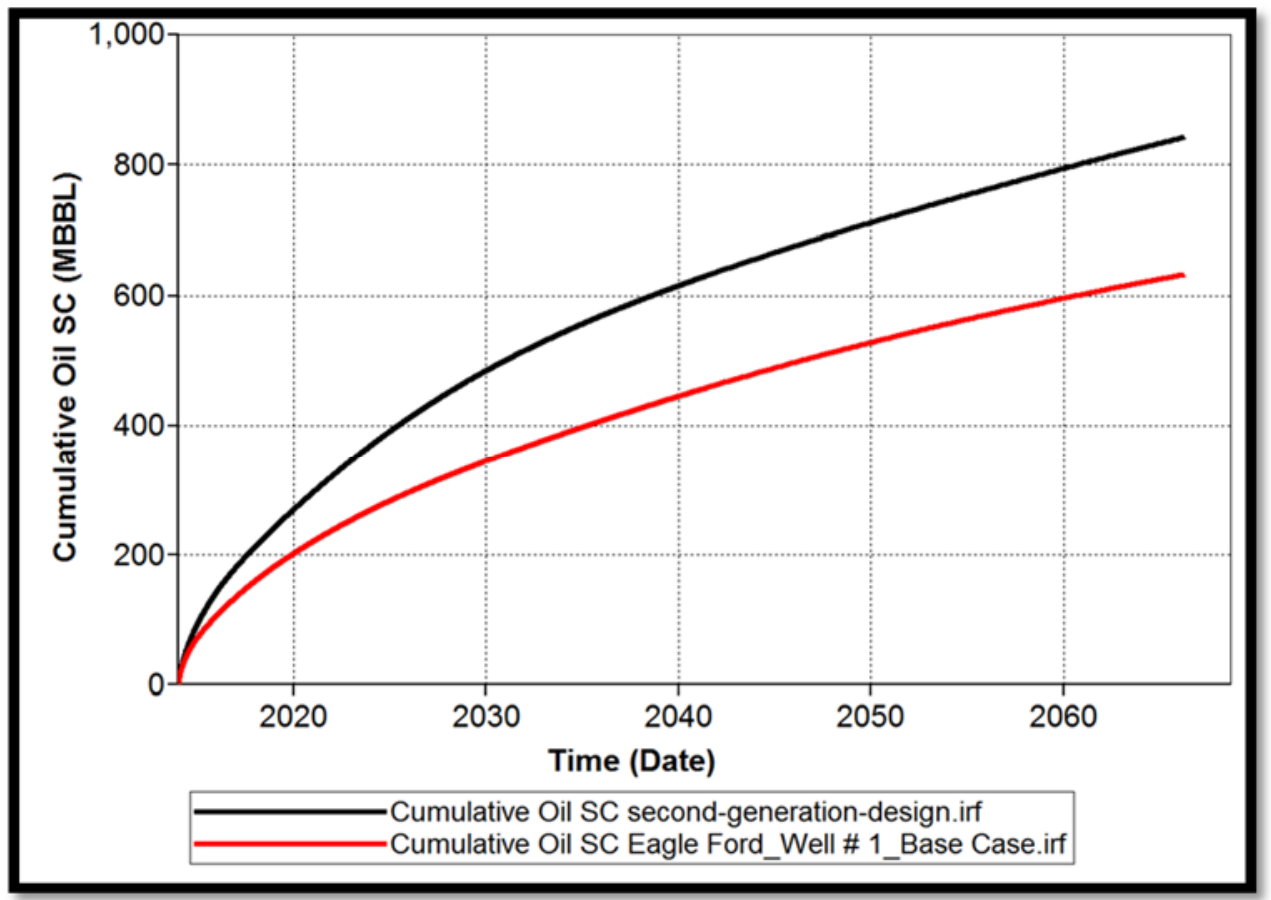

Figure 66: Cumulative oil production with First and Second generation designs 


\subsubsection{Eagle Ford Field Data Analysis}

A number of horizontal wells were drilled in the targeted Eagle Ford organic shale formation. The average lateral length was $4400 \mathrm{ft}$., with an average of 16 stages at 280 $\mathrm{ft}$. stage spacing. Hydraulic fracturing treatment was successfully completed. Each stage had 6 to 9 perforation clusters that are $1 \mathrm{ft}$. wide and 5 shoot per foot. There were 42 to 50 perforation per stage fired at an average rate of $80 \mathrm{bpm}$.

Two different design procedures were conducted in 10 Eagle Ford wells. Each procedure was designed for a specific objective for the target formation and its special rock characteristics such as pay thickness, reservoir fluids, lithology, rock stress and other characteristics to optimize development of unconventional reservoir. First treatment design implemented a crosslink fluid system with high proppant concentration in order to provide sufficient conductivity into primary fracture and to lower proppant embedment. Second treatment design was utilized with a hybrid fluid system, high fluid volume, lower proppant concentration, and higher 100 mesh volume in order to generate large surface area and to connect natural and induced fractured in the near and far field. Table 33 presents completion parameters of first and second generation treatment designs.

The first generation treatment schedule was pumped with a more aggressive proppant ramp to help generate conductivity, knowing that the location was a liquid-rich condensate area, and that multiphase flow would require greater conductivity to adequately and effectively drain the reservoir. Table 34 below shows the summary of the first generation treatment design. The job consisted of $10 \mathrm{lb}$. of linear gel followed by linear Pad, with main proppant stages ranging from $0.5 \mathrm{ppa}$ to $5 \mathrm{ppa}$. The plug-and-perf completion was used. Each stage consisted of $285,000 \mathrm{lbs}$ total prop $(28,000 \mathrm{lb}$ of 100 mesh and $256,000 \mathrm{lb}$ of $30 / 50$ resin coated sand). $2 \% \mathrm{KCL}$ substitute treated water was applied to all stages ranging from $0.5 \mathrm{ppa}$ to $5 \mathrm{ppa}$, crosslink fluid system. 


\begin{tabular}{|c|c|c|c|c|c|c|}
\hline Well \# & \#Stages & Lateral (ft.) & Stage Spacing & Fluid (bbl.) & Prop (Ibm) & $\% 100$ mesh \\
\hline \multicolumn{7}{|c|}{ First Generation Treatment Design } \\
\hline 1 & 20 & 5,853 & 293 & 111,000 & $5,760,000$ & $9 \%$ \\
\hline 2 & 15 & 4,119 & 275 & 88,995 & $4,509,000$ & $9 \%$ \\
\hline 3 & 15 & 4,152 & 277 & 88,005 & $3,534,000$ & $10 \%$ \\
\hline 4 & 12 & 3,192 & 266 & 69,000 & $3,570,000$ & $8 \%$ \\
\hline 5 & 15 & 4,250 & 283 & 90,000 & $4,549,005$ & $9 \%$ \\
\hline \multicolumn{7}{|c|}{ Second Generation Treatment Design } \\
\hline 6 & 14 & 4,131 & 295 & 121,996 & $4,913,006$ & $25 \%$ \\
\hline 7 & 13 & 3,686 & 284 & 118,001 & $3,872,999$ & $26 \%$ \\
\hline 8 & 19 & 5,334 & 281 & 172,007 & $6,295,004$ & $26 \%$ \\
\hline 9 & 18 & 5,033 & 280 & 169,002 & $5,448,996$ & $26 \%$ \\
\hline 10 & 15 & 4,094 & 273 & 121,995 & $4,905,000$ & $25 \%$ \\
\hline
\end{tabular}

Table 33: Generation One and Two Completion Designs

\begin{tabular}{|c|c|c|c|c|c|c|}
\hline Fluid Name & Voluid Vol & Slurry Volume & Rate & Prop Conc. & Stage Prop & Prop Type \\
\hline & $\mathrm{bbl}$ & $\mathrm{bbl}$ & $(\mathrm{bpm})$ & $(\mathrm{ppg})$ & $(\mathrm{lbs})$ & \\
\hline Slickwater & $\mathbf{1 0 0}$ & 100 & $\mathbf{5}$ & $\mathbf{0}$ & & \\
\hline AquaVis 10G & $\mathbf{5 0 0}$ & 500 & $\mathbf{8 0}$ & $\mathbf{0}$ & & \\
\hline AquaVis 10G & $\mathbf{3 0 0}$ & 307 & $\mathbf{8 0}$ & $\mathbf{0 . 5}$ & 6,300 & $\mathbf{1 0 0}$ mesh \\
\hline AquaVis 10G & $\mathbf{3 0 0}$ & 314 & $\mathbf{8 0}$ & $\mathbf{1}$ & 12,600 & $\mathbf{1 0 0}$ mesh \\
\hline AquaVis 10G & $\mathbf{4 9 4}$ & 528 & $\mathbf{8 0}$ & $\mathbf{1 . 5}$ & 31,122 & $\mathbf{1 0 0}$ mesh \\
\hline AquaVis 20G & $\mathbf{7 5 0}$ & $\mathbf{7 5 0}$ & $\mathbf{8 0}$ & $\mathbf{0}$ & $\mathbf{0}$ & \\
\hline 20\# XL Fluid & $\mathbf{3 0 0}$ & 300 & $\mathbf{8 0}$ & $\mathbf{0}$ & 0 & \\
\hline 20\# XL Fluid & $\mathbf{2 5 0}$ & 256 & $\mathbf{8 0}$ & $\mathbf{0 . 5}$ & 5,250 & $\mathbf{3 0 / 5 0}$ Prime Plus \\
\hline 20\# XL Fluid & $\mathbf{2 5 0}$ & 262 & $\mathbf{8 0}$ & $\mathbf{1}$ & 10,500 & $\mathbf{3 0 / 5 0}$ Prime Plus \\
\hline 20\# XL Fluid & $\mathbf{2 5 0}$ & 267 & $\mathbf{8 0}$ & $\mathbf{1 . 5}$ & 15,750 & $\mathbf{3 0 / 5 0}$ Prime Plus \\
\hline 20\# XL Fluid & $\mathbf{3 5 0}$ & 383 & $\mathbf{8 0}$ & $\mathbf{2}$ & 29,400 & $\mathbf{3 0 / 5 0}$ Prime Plus \\
\hline 20\# XL Fluid & $\mathbf{3 5 0}$ & 391 & $\mathbf{8 0}$ & $\mathbf{2 . 5}$ & 36,750 & $\mathbf{3 0 / 5 0}$ Prime Plus \\
\hline 20\# XL Fluid & $\mathbf{3 5 0}$ & 399 & $\mathbf{8 0}$ & $\mathbf{3}$ & 44,100 & $\mathbf{3 0 / 5 0}$ Prime Plus \\
\hline 20\# XL Fluid & $\mathbf{3 5 0}$ & 415 & $\mathbf{8 0}$ & $\mathbf{4}$ & 58,800 & $\mathbf{3 0 / 5 0}$ Prime Plus \\
\hline 20\# XL Fluid & $\mathbf{1 2 5}$ & $\mathbf{1 5 4}$ & $\mathbf{8 0}$ & $\mathbf{5}$ & 26,250 & $\mathbf{3 0 / 5 0}$ Prime Plus \\
\hline AquaVis 20G & $\mathbf{2 5 0}$ & $\mathbf{2 5 0}$ & $\mathbf{8 0}$ & $\mathbf{0}$ & & \\
\hline Totals & $\mathbf{5 , 2 6 9}$ & $\mathbf{5 , 5 7 4}$ & & & $\mathbf{2 7 6 , 8 2 2}$ & \\
\hline
\end{tabular}

Table 34: Generation One Pump Schedule 
The second generation job design consisted of sweep stage with $10 \mathrm{lb}$. of linear gel followed by linear Pad and main proppant stages ranging from 0.25 PPA to 3 PPA. The "plug-and-perf" completion was used. An average proppant per stage consisted of $318,000 \mathrm{lbs}$ total prop $(80,000 \mathrm{lb}$. of 100 mesh and $238,000 \mathrm{lb}$ of $40 / 70$ resin coated sand). All staged with 0.5 ppa to 3 ppa, and a hybrid system with $2 \% \mathrm{KCL}$ substitute treated water. The pump schedule was designed to create a large surface area. Large volume of water was injected with smaller proppant concentration to enhance efficiency of primary fracture and far field conductivity. Table 35 shows the summary of the pump schedule for second generation treatment design.

\begin{tabular}{|c|c|c|c|c|c|c|c|}
\hline Rate bpm & Fluid \# & Fluid Name & vuliud Vol. & Prop \# & Prop Con PPA & Slurry Vol (bbls) & Prop Mass (lb) \\
\hline 5 & 1 & Slickwater & 15 & 0 & 0 & 16 & $\mathbf{0}$ \\
\hline 10 & 2 & Diesel & 12 & 0 & 0 & 12 & 0 \\
\hline 80 & 1 & Slickwater & 476 & 0 & 0 & 476 & 0 \\
\hline 80 & 3 & WF110 Linear Gel & 476 & 100 mesh & 0.5 & 487 & 10000 \\
\hline 80 & 3 & WF110 Linear Gel & 595 & 100 mesh & 1.0 & 622 & 25000 \\
\hline 80 & 3 & WF110 Linear Gel & 714 & 100 mesh & 1.5 & 763 & 45000 \\
\hline 80 & 4 & WF120 Linear Gel-2 & 595 & $\mathbf{0}$ & 0 & 595 & 0 \\
\hline 80 & 4 & WF120 Linear Gel-2 & 357 & 40/70 Prime PI. & 0.25 & 361 & 3750 \\
\hline 80 & 4 & WF120 Linear Gel-2 & 476 & 40/70 Prime PI. & 0.5 & 488 & 10000 \\
\hline 80 & 4 & WF120 Linear Gel-2 & 595 & 40/70 Prime PI. & 0.75 & 616 & 18750 \\
\hline 80 & 4 & WF120 Linear Gel-2 & 595 & 40/70 Prime PI. & 1.0 & 623 & 25000 \\
\hline 80 & 4 & WF120 Linear Gel-2 & 595 & 40/70 Prime PI. & 1.25 & 631 & 31250 \\
\hline 80 & 5 & $20 \#$ XL Fluid & 476 & 40/70 Prime PI. & 1.5 & 510 & 30000 \\
\hline 80 & 5 & 20\# XL Fluid & 476 & 40/70 Prime PI. & 2.0 & 521 & 40000 \\
\hline 80 & 5 & 20\# XL Fluid & 238 & 40/70 Prime PI. & 2.25 & 264 & 22500 \\
\hline 80 & 5 & $20 \#$ XL Fluid & 238 & 40/70 Prime PI. & 2.5 & 266 & 25000 \\
\hline 80 & 5 & 20\# XL Fluid & 117 & 40/70 Prime PI. & 3.0 & 133 & 14700 \\
\hline 80 & 4 & WF120 & 129 & 0 & 0 & 129 & 0 \\
\hline & & & 7,049 & & & 7,514 & 300,950 \\
\hline
\end{tabular}

Table 35: Generation Two Pump Schedule 


\subsubsection{Completion and Production Analysis}

It is recognized that shale reservoir production is driven by a number of factors such as geology, petrophysics, geomechanics, completion, landing and placement of laterals. This study focused on the preliminary effect on completions, particularly in a hydraulic fracturing treatment. Completion strategy was divided in two treatment designs. Staging and perforating a job was done to accommodate variations of stress and minerology along a lateral. Table 36 shows normalized treatment fluid and proppant volume used in hydraulic fracture treatments per stage. Average fluid volume per stage varied from 5,550 to $9389 \mathrm{bbl}$. Average total proppant per stage ranged from 230,600 to 350,929 $\mathrm{lbm}$ and average 100 mesh ratio per stage ranged from $9 \%$ to $26 \%$. Lateral length from the deepest perforation hole to the shallowest one in a well was analyzed. The value ranged between $3192 \mathrm{ft}$. to $5853 \mathrm{ft}$.

\begin{tabular}{|c|c|c|c|c|c|}
\hline Well \# & Lateral Length (ft.) & BBL/ stg & $\mathrm{lbm} / \mathrm{stg}$ & $\% 100$ mesh & 300 Day (BBL/ stg) \\
\hline \multicolumn{6}{|c|}{ First Generation Treatment Design } \\
\hline 1 & 5,853 & 5,550 & 288,000 & $9 \%$ & 2,844 \\
\hline 2 & 4,119 & 5,933 & 300,600 & $9 \%$ & 2,553 \\
\hline 3 & 4,152 & 5,867 & 235,600 & $10 \%$ & 1,627 \\
\hline 4 & 3,192 & 5,750 & 297,500 & $9 \%$ & 2,900 \\
\hline 5 & 4,250 & 6,000 & 303,267 & $9 \%$ & 2,681 \\
\hline \multicolumn{6}{|c|}{ Second Generation Treatment Design } \\
\hline 6 & 4,131 & 8,714 & 350,929 & $25 \%$ & 6,193 \\
\hline 7 & 3,686 & 9,077 & 297,923 & $26 \%$ & 3,923 \\
\hline 8 & 5,334 & 9,053 & 331,316 & $26 \%$ & 4,059 \\
\hline 9 & 5,033 & 9,389 & 302,722 & $26 \%$ & 4,299 \\
\hline 10 & 4,094 & 8,133 & 327,000 & $25 \%$ & 3,481 \\
\hline
\end{tabular}

Table 36: Normalized Completion Data

Cumulative oil production of 10 producing wells were gathered and compared with treatment design data in order to show the parameters that help or hinder optimization of the completion process. A more rigorous approach was conducted in examining relationship between numerous treatment parameters and production. Total of 10 wells ( 5 wells with $1^{\text {st }}$ generation design and 5 wells with $2^{\text {nd }}$ generation design) with completion parameters including but not limited to lateral length, fluid and proppant 
volumes were analyzed. As illustrated in Figures 67 through 69, well performance was influenced by treatment fluid volume.

It is observed that second generation wells produced higher cumulative oil, due to the fact that it was pumped with a higher fluid volume. Examining the same figure gives us a basic understanding that proppant volume had little influence in well performance.

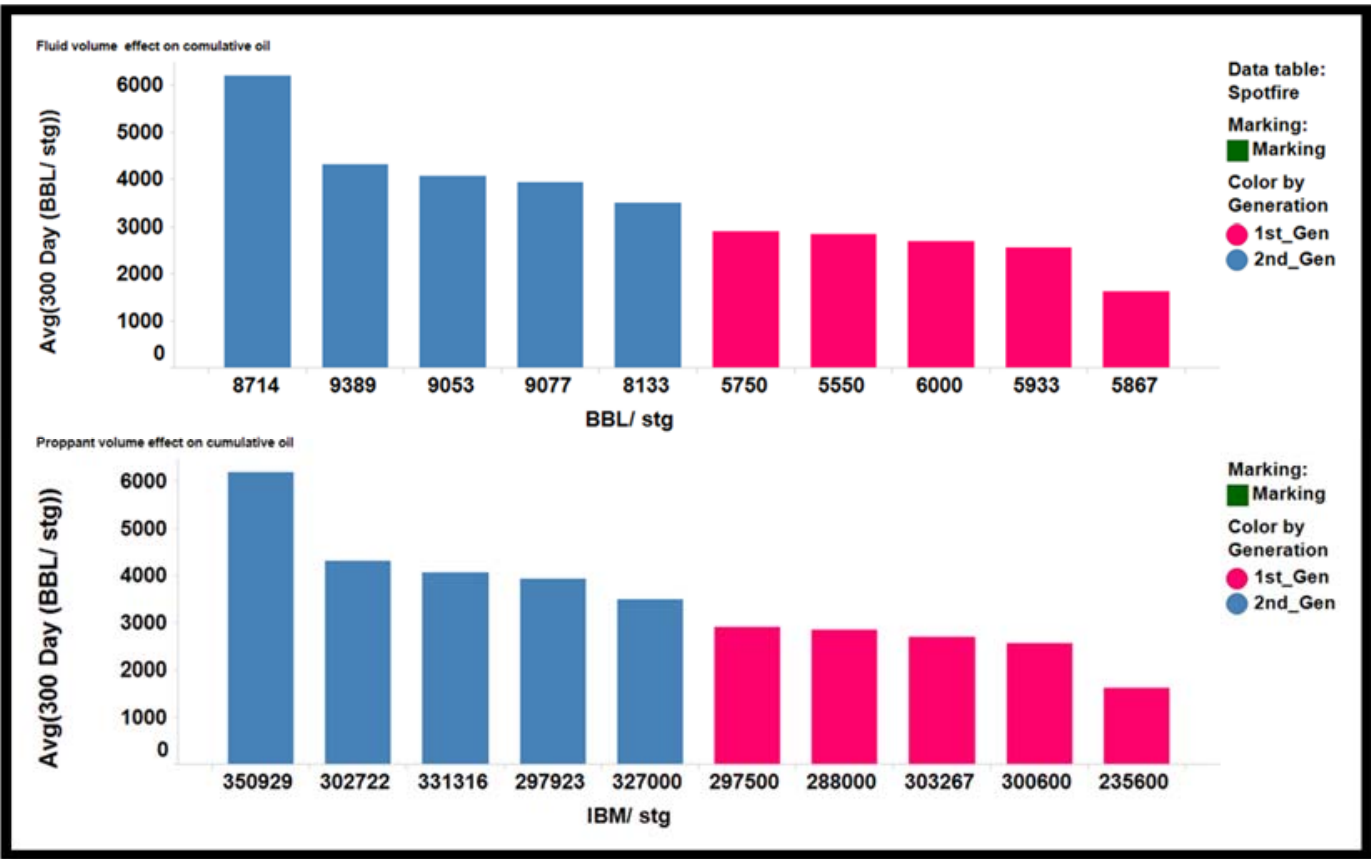

Figure 67: Effect on fluid and proppant volume into Cumulative Oil 


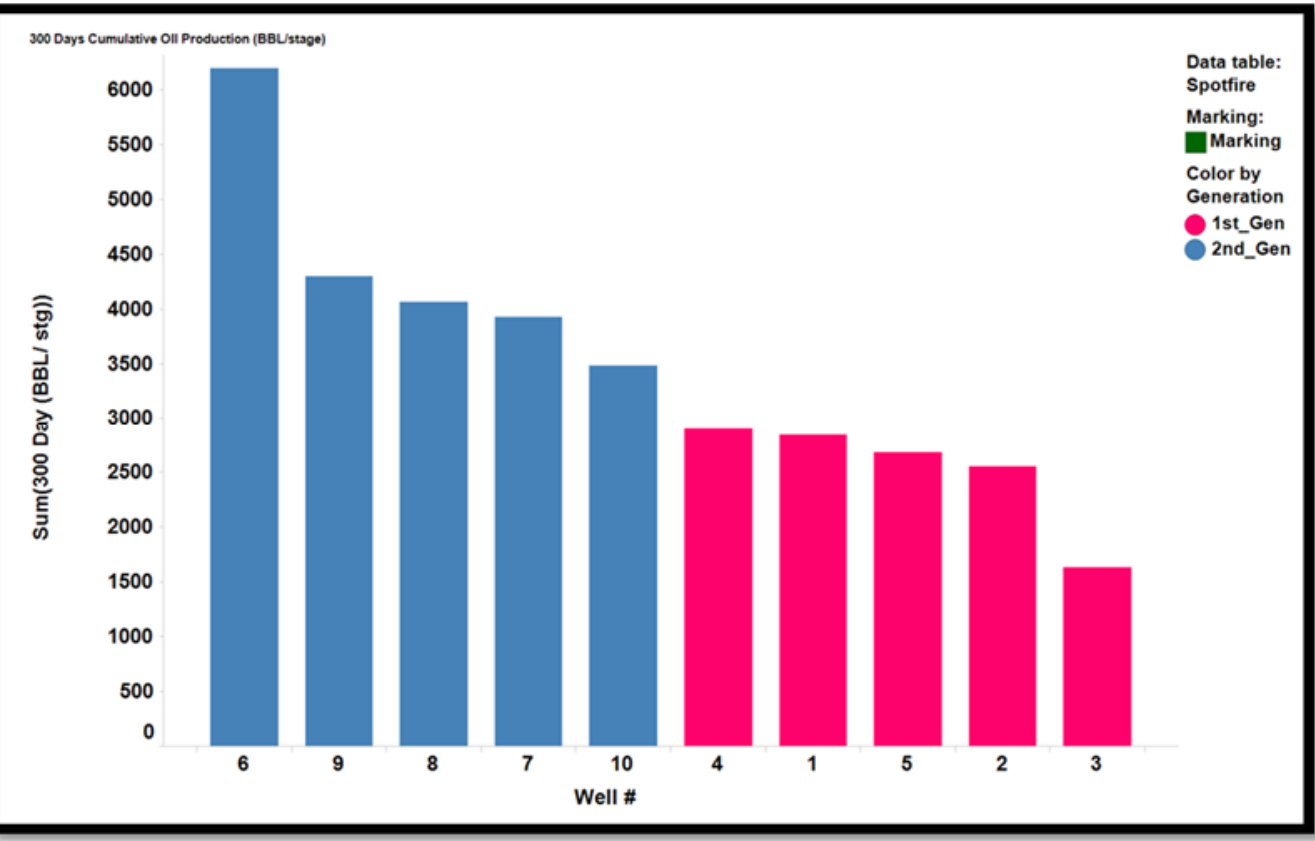

Figure 68: First Generation and Second Generation Production comparison

It was also observed that the total proppant volume may not influence well productivity but increasing ratio of 100 mesh will have a positive effect on well performance. Figure 69 shows the best producing well was injected with the highest ratio of 100 mesh. In addition to identifying high fluid volume and high ratio of 100 mesh, a hybrid fluid system with a low concentration proppant and 40/70 mesh was utilized among best producing wells or second generation treatment design and results are presented in Figure 67. 40/70 mesh proppant ( 0.0124 mean diameter) was expected to prop into primary fracture which had a width of approximately $0.12 \mathrm{in}$. It was harder to place proppant into secondary fracture due to the risk of screen-out. Placement of smaller 100 mesh (0.006 in mean diameter) proppant into the secondary and natural fractures was achievable. The ability to transport 100 mesh in slick water fluid was easier than 40/70. Therefore, making 100 mesh the best solution to prop secondary fracture. 


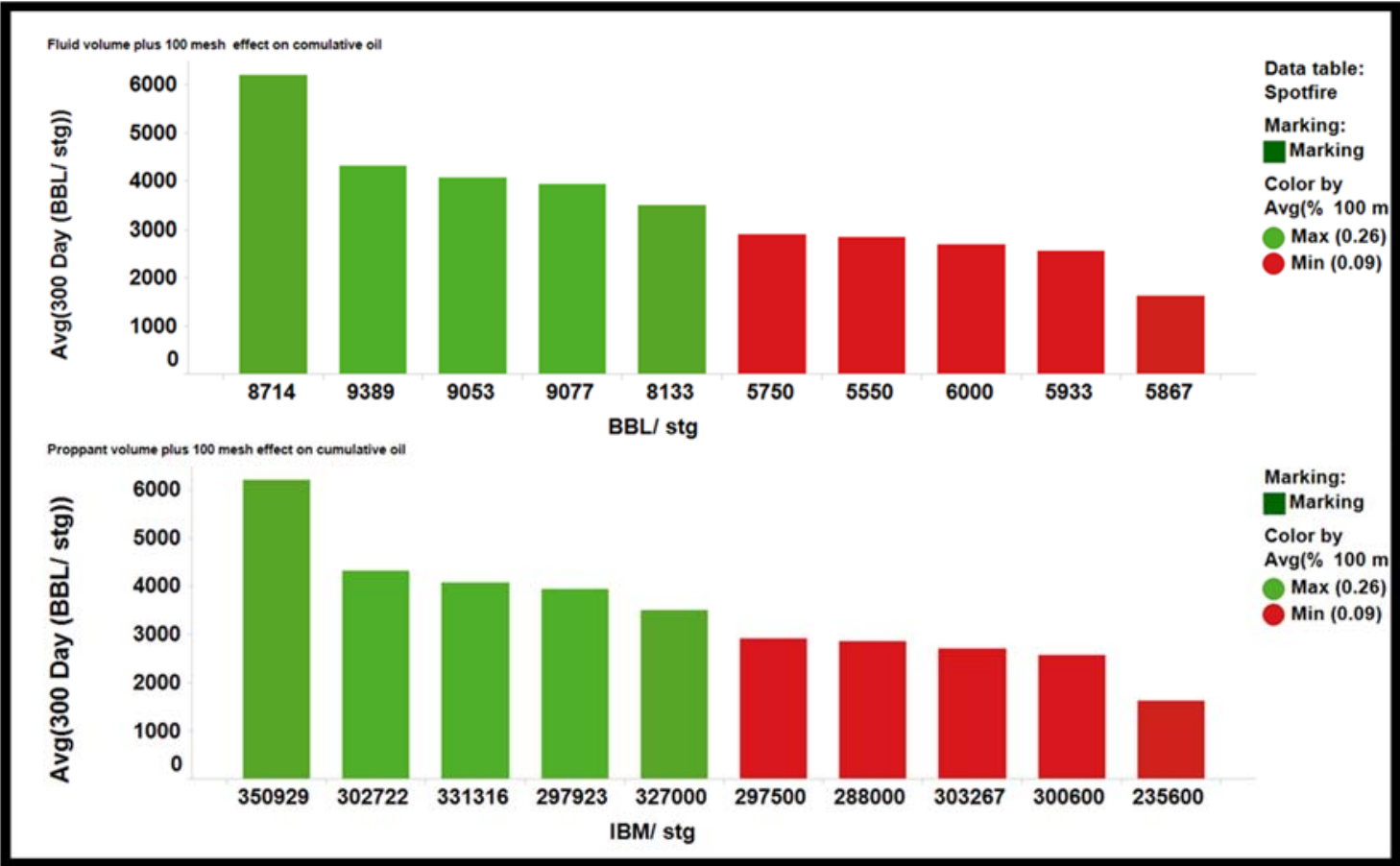

Figure 69: Effect of 100 mesh ratio in cumulative oil production

The objective of this secondary treatment design was to maximize liquid production by improving surface area and proppant placement in the secondary fracture. It was observed that late time productivity in the second generation was higher than in the first generation because design was more effectively connected to the secondary fractures and natural fracture to the wellbore. Table 37 shows production volumes of each well after 180 days. Second generation wells produced $11 \mathrm{bbl}$. /stages on average and fist generation produced $6 \mathrm{bbl}$. /stage on average. Figure 70 compares average cumulative oil production between first and second generation treatment designs. Detailed examinations of Eagle Ford completion were conducted to identify parameters that influence well performance and they are outlined below. 


\begin{tabular}{|c|c|c|c|c|c|}
\hline Time (Days) & Well \# 1_bbl/stg & Well \# 2_bbl/stg & Well \# 3_bbl/stg & Well \# 4_bbl/stg & Well \# 5_bbl/stg \\
\hline \multicolumn{6}{|c|}{ First Generation Treatment Design } \\
\hline 180 & 8 & 8 & 6 & 14 & 10 \\
\hline 210 & 6 & 7 & 3 & 8 & 9 \\
\hline 240 & 6 & 6 & 3 & 6 & 8 \\
\hline 270 & 8 & 5 & 2 & 6 & 5 \\
\hline 300 & 5 & 4 & 2 & 5 & 5 \\
\hline 330 & 6 & 3 & 1 & 5 & 5 \\
\hline \multicolumn{6}{|c|}{ Second Generation Treatment Design } \\
\hline 180 & 19 & 14 & 15 & 11 & 9 \\
\hline 210 & 16 & 13 & 17 & 11 & 7 \\
\hline 240 & 13 & 12 & 9 & 12 & 10 \\
\hline 270 & 13 & 8 & 11 & 12 & 8 \\
\hline 300 & 15 & 5 & 10 & 7 & 6 \\
\hline 330 & 16 & 5 & 10 & 6 & 5 \\
\hline
\end{tabular}

Table 37: After 180 days First Generation and Second Generation Production comparison

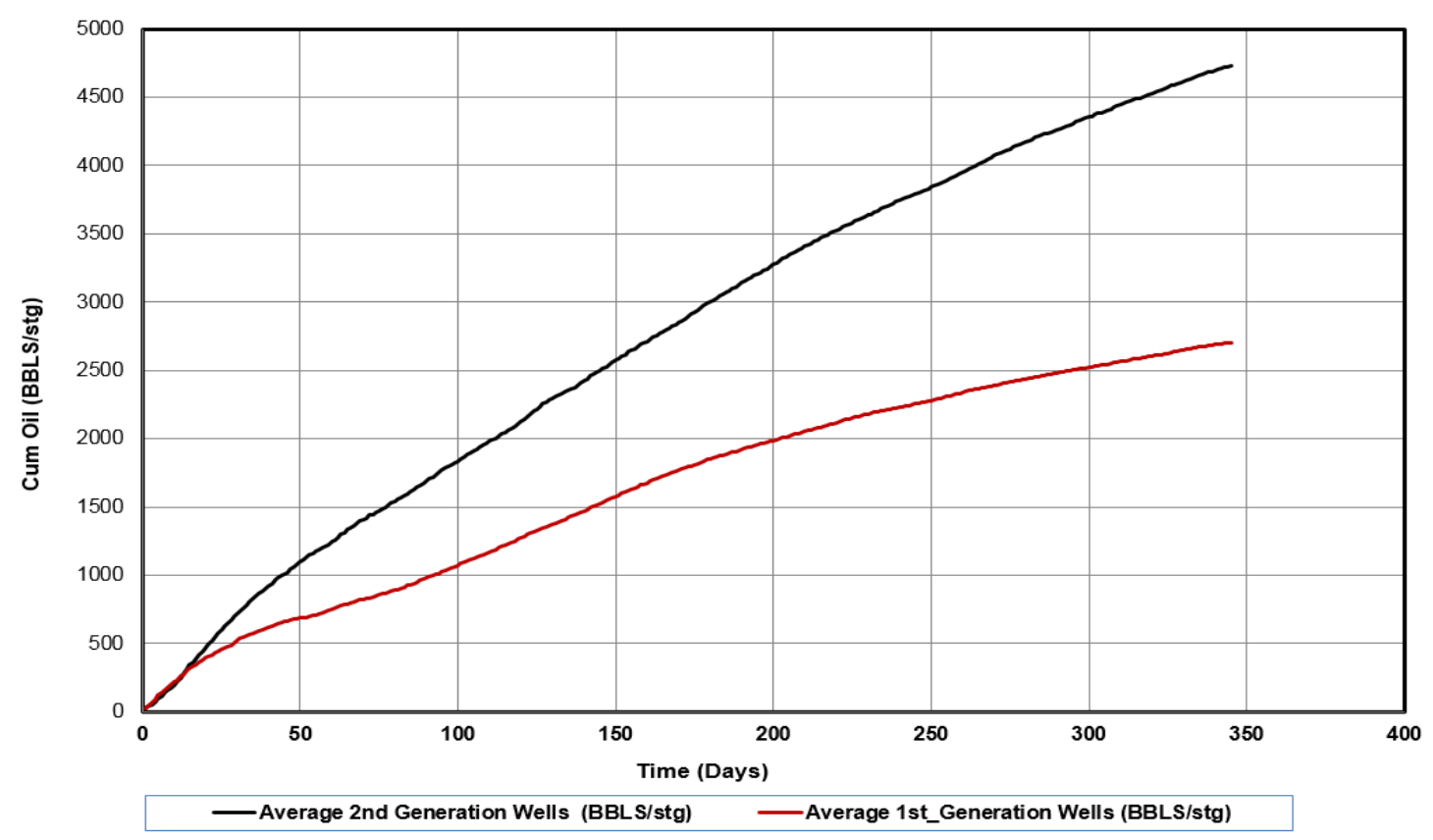

Figure 70: First and Second generation average cumulative oil (bbl. /stage) comparison

Work flow compared individual completion parameters to production, with the main goal of identifying trends. A more rigorous approach was conducted to examine the relationship between numerous completion parameters and hydrocarbon production. Two treatment procedures were examined for a total of 10 wells with completion parameters including but not limited to lateral length and fluid and proppant volumes. 
Examining provided a basic understanding about the trend: well performance was influenced by numerous interrelated completion parameters. The highest producing wells had the following characteristics for their treatment design:

1. Usage of high fluid volume:

- The objective was to increase surface area and to connect reservoir into wellbore.

2. Moderate percentage of 100 mesh sand

- Can be transport out into fracture and prop open natural fractures to retain production contribution during depletion.

- A size of 100 mesh proppant was more likely to enter and prop open natural fractures.

3. Low average proppant concentration

- Helped proppant distribution into primary fracture and enlarged field fractures.

Understanding relationship between rock properties, reservoir fluid, and fracturing fluid helped to achieve optimum design in localized stimulation treatment in Eagle ford. This approach can be a used in other parts of Eagle Ford particularly in oil and condensate window, where the rock is more brittle with higher YM, lower stress anisotropy, and low clay content. To fully apply this approach successfully in the neighboring counties such as Dimmit County, local rock and fluid property evaluations must be conducted.

\subsection{Optimum Well Spacing}

A development plan was selected to drill at least 6 horizontal wells in a section. On an average basis, 100 acre per well was used with one section equivalent to 640 acres. A total drainage area of 640 acres was kept constant throughout the duration of the study.

Down-spacing increases well density to improve productivity from the unpropped region of the Eagle Ford formation. It was observed that most of the productivity originated from the stimulated region. Based on the numerical model, the stimulated area in the 
base case (Generation \#1) was estimated to be 54 acres and the optimized case (Generation \#2) was estimated to be 80 acres. This indicated that there may still be hydrocarbons left in the section. The solution to this problem is that the wells should be spaced close enough to increase the total stimulated area and to drain entire section within a reasonable time frame. On the other hand, it is important to minimize the possibility of fracture interference by offset wells or overlapping drainage area of an adjacent well.

Fracture and reservoir simulation were performed for each case consisted of 80,64 , 49,40 , and 20 acres. All the cases were completed with a similar fluid system. Production profile for each case and number of wells per section were normalized to well type. After performing numerical modeling, total production was plotted against number of wells per section, which are illustrated in Figure 71. It's observed that there was a direct correlation between increasing numbers of wells per section and total productivity.

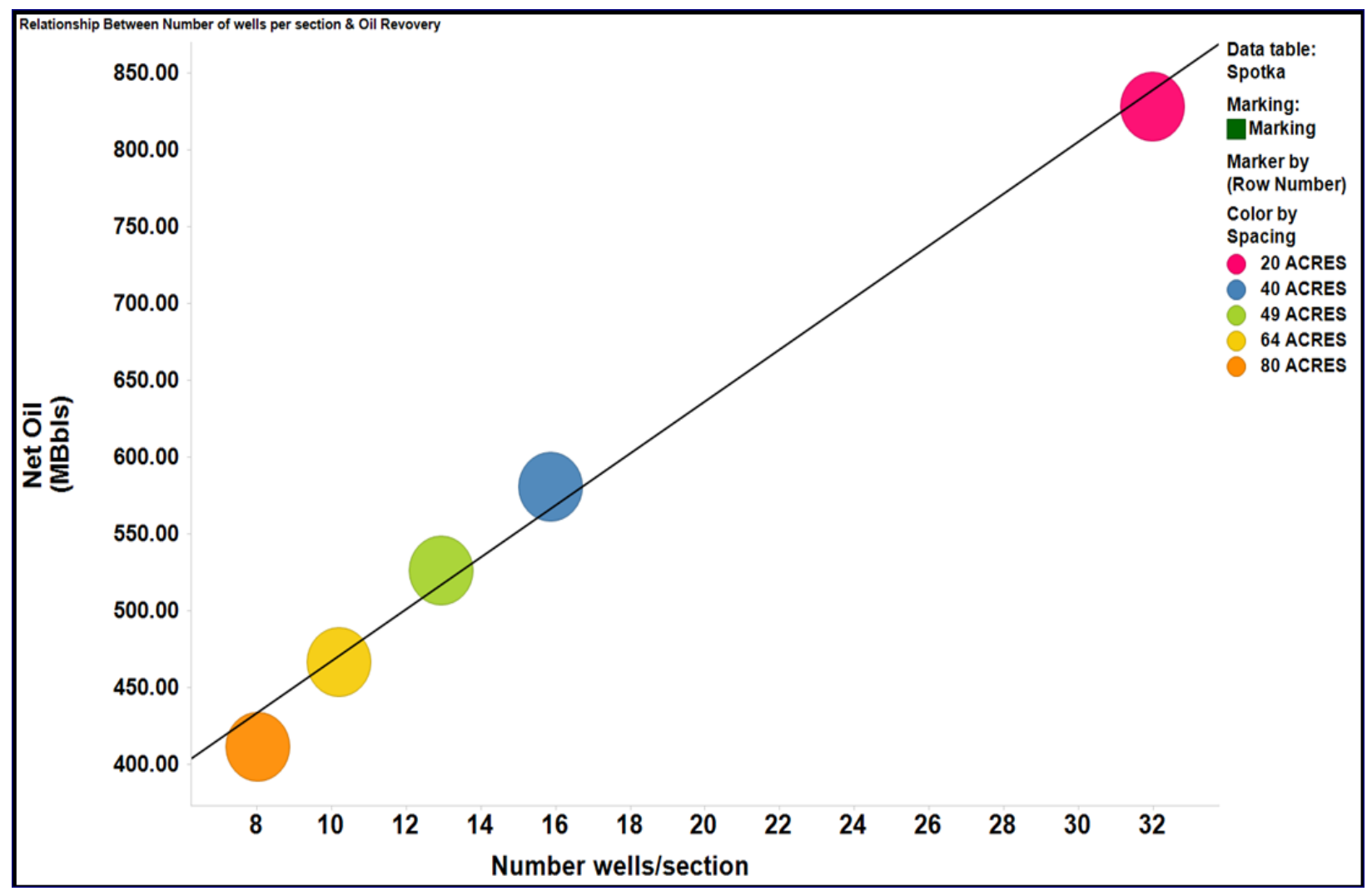

Figure 71: Number of wells per section vs cumulative oil production 


\subsubsection{Effect of Fixed Price on Well Spacing}

The price of oil fluctuates and the historic monthly trend is shown in Figure 72 for West Texas Intermediate (WTI) and Brent oil between 2006 and 2016. The minimum and maximum oil prices during this time interval was $\$ 31$ per bbl and $\$ 133$ per bbl, respectively. In order to understand the impact of oil price variation on the simulation treatment of Eagle Ford Shale, an economic study was conducted. Further, this investigation is designed to provide information regarding the total simulated reservoir volume for each case and it's associated cost. Crude oil price forecast by EIA was used in the economic analysis for net present value (NPV) determinations. Runs were conducted with a constant revoir volume but with different well spacing desings. Five well spacing options used in the model study was considered for the economic evaluation. Based on oil price estimates of 42,59 and $72 \$ /$ bbls for the first three years and $\$ 71 / \mathrm{bbl}$ for the remainder of the time, the net present values (NPV) were determined for five well spacing options. Results show that all spacing designs yield a positive NPV and the maximum NPV was when a 40-acre spacing (with 16 wells per section) was used. Table 38 shows that the optimum NPV and net oil (EUR) increased more than $40 \%$ when the well spacing is reduced from 80 to 40 acres. 


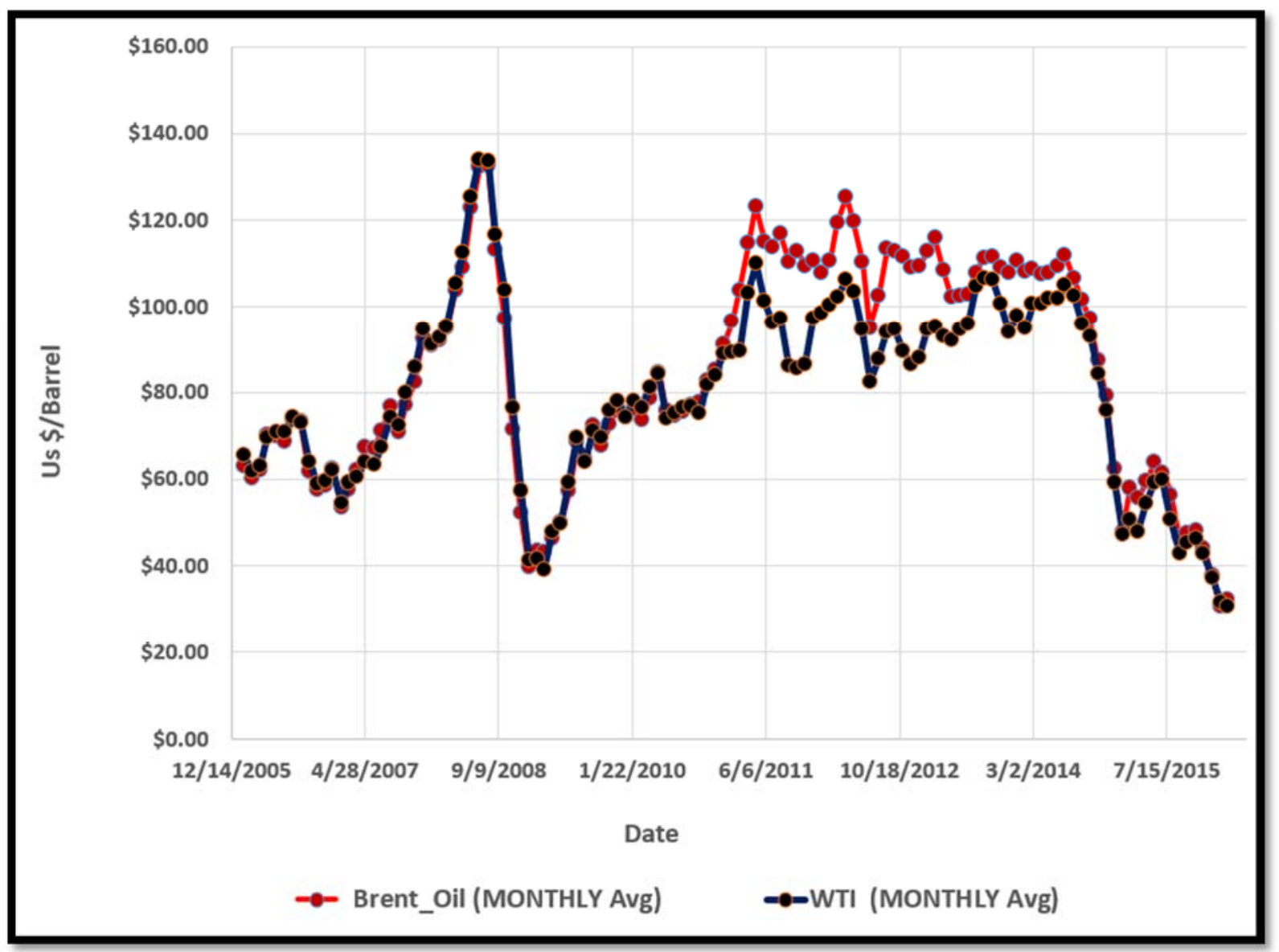

Figure 72: Historic Oil price from 2006 to 2016

\begin{tabular}{|c|c|c|c|c|c|}
\hline Spacing & wells & Net Reserves & \multicolumn{3}{|c|}{ Future Net Revenue } \\
\hline & Number of wells & Oil & Total & \multicolumn{2}{|c|}{ Present Worth at $\mathbf{1 0 \%}$} \\
\hline (Acre) & (well/section) & (MBBL) & (M\$) & \multicolumn{2}{|c|}{ (M\$) } \\
\hline 20 & 32 & 831 & 33,375 & \multicolumn{2}{|c|}{10,788} \\
\hline 40 & 16 & 584 & 32,777 & \multicolumn{2}{|c|}{17,184} \\
\hline 49 & 13 & 529 & 29,443 & \multicolumn{2}{|c|}{15,349} \\
\hline 64 & 10 & 470 & 26,204 & \multicolumn{2}{|c|}{13,676} \\
\hline 80 & 8 & 411 & 22,985 & \multicolumn{2}{|c|}{12,007} \\
\hline \multicolumn{6}{|c|}{ EIU Oil Prices Forecast } \\
\hline Year & & 2016 & 2017 & 2018 & 2019 \\
\hline Oil (US\$/b) & & 42 & 59 & 72 & 71 \\
\hline
\end{tabular}

Table 38: Results of optimum well spacing with EIA future oil price forecast

A second set of economic analysis was conducted using a reduction of $20 \%$ in the oil prices of the first analysis. Results are shown in Table 39 for the second analysis. All 
cases yielded positive NPV values with 40 acre well spacing design as the maximum. However, there was approximately $25 \%$ less NPV compared to the first study as a result of reduced prices.

\begin{tabular}{|c|c|c|c|c||}
\hline Spacing & wells & Net Reserves & \multicolumn{2}{c|}{ Future Net Revenue } \\
\hline \hline & Number of wells & Oil & Total & Present Worth at 10\% \\
\hline (Acre) & (well/section) & $\mathbf{( M B B L )}$ & $\mathbf{( M \$ )}$ & $\mathbf{( M \$ )}$ \\
\hline 20 & 32 & 831 & 23,416 & 5,605 \\
\hline $\mathbf{4 0}$ & $\mathbf{1 6}$ & $\mathbf{5 8 4}$ & $\mathbf{2 5 , 9 1 5}$ & $\mathbf{1 3 , 5 6 2}$ \\
\hline 49 & 13 & 529 & 23,235 & 12,072 \\
\hline 64 & 10 & 470 & 20,690 & 10,765 \\
\hline 80 & 8 & 411 & 18,157 & 9,459 \\
\hline \hline \multicolumn{7}{|l|}{ EIU Oil Prices Forecast } \\
\hline \hline Year & $\mathbf{2 0 1 6}$ & $\mathbf{2 0 1 7}$ & $\mathbf{2 0 1 8}$ & $\mathbf{2 0 1 9}$ \\
\hline Oil (US\$/b) & $\mathbf{3 4}$ & $\mathbf{4 7}$ & $\mathbf{5 8}$ & $\mathbf{5 7}$ \\
\hline
\end{tabular}

Table 39: Results of optimum well spacing with reduced EIA future oil price forecast In the final analysis, runs were conducted with four different constant oil prices of $\$ 20$, $\$ 40, \$ 60$ and $\$ 80$ per barrel were used with the same five well designs as the first and second economic analysis. The results are presented in Table 40 . When the four different oil prices and five different well spacing were considered, only one case with a $\$ 20$ per barrel oil price and 20 acre well spacing, had a negative NPV. For all oil prices used for this analysis, 40 acres spacing had the maximum NPV. Thus, the wells can be placed closer together by 40 acres per section (16 wells) to accelerate production and to ultimately increase net revenue.

\begin{tabular}{|c|c|c|c|r|c|c||}
\hline Spacing & Wells & Net reserve & \multicolumn{4}{|c|}{ Oil Prices } \\
\hline (Acre) & (wells/section) & Net Oil (MBbls) & $\mathbf{\$ 8 0}$ & $\mathbf{5 6 0}$ & $\mathbf{\$ 4 0}$ & $\mathbf{\$ 2 0}$ \\
\hline \hline & & & \multicolumn{4}{|c|}{ Present Worth at 10\% } \\
\hline 20 ACRES & 32 & 832 & 19,531 & 10,758 & 1,984 & $-6,789$ \\
\hline 40 ACRES & 16 & 585 & $\mathbf{2 4 , 1 1 8}$ & $\mathbf{1 7 , 7 6 7}$ & $\mathbf{1 1 , 4 1 6}$ & $\mathbf{5 , 0 6 4}$ \\
\hline 49 ACRES & 13 & 529 & 21,623 & 15,877 & 10,131 & 4,385 \\
\hline 64 ACRES & 10 & 470 & 19,248 & 14,145 & 9,041 & 3,938 \\
\hline 80 ACRES & 8 & 412 & 16,886 & 12,417 & 7,949 & 3,481 \\
\hline
\end{tabular}

Table 40: Effect on oil price for well spacing 


\section{Conclusion}

This study evaluated existing fracture treatment design and presented a new treatment procedure and workflow for liquids-rich window of the Eagle Ford Shale. Based on the result, the following conclusions are presented:

1. Eagle Ford Shale presents a great variability and a single technique or procedure for hydraulic fracturing that is universally adaptable is not used.

2. Each fracture treatment job must be designed for the target formation with special attributes to properties such as pay thickness, reservoir fluids, lithology, rock stress and other characteristics.

3. Methodology used in this study can be applied to other areas of Eagle Ford shale stimulation design.

4. Integrating local reservoir properties from DFITT, micro seismic, minerology, log, core data, production, and economic into hydraulic fracture treatment design can improve productivity of hydrocarbons and increases NPV.

5. The risk of clay swelling and proppant embedment can be neglected for more brittle (high YM) formations.

6. Hybrid stimulation treatment design provides optimum fracture geometry and increases contact between reservoirs and wellbore, while maintaining required conductivity for enhancing productivity.

7. Increased injection volume is essential to increase fracture length and surface area in order to sustain production in a Nano Darcy formation.

8. Lower mesh and lower concentration proppant placement can be conducted to stimulate and reach productive zones further away from the wellbore.

9. Use of 40/70 mesh proppant (0.0124-in. mean diameter) makes it relatively easy to place it into primary fracture. The ability to transport and distribute 100 mesh proppant in a clean fluid is easier than 40/70 mesh and 30/50 mesh proppant.

10. Using a 100 mesh sand is the most attractive solution to prop secondary fractures. 
11. Microseismic data together with fracture and reservoir modeling indicates that only about $50 \%$ of available drainage area is simulated using a conventional design.

12. Down spacing should be considered to increase productivity per section. More wells per section results in higher EUR values.

13. Economics of the fracture operation dictates the number of required wells per section for Eagle Ford Shale. For the cases studied, 40 acre spacing yields the maximum NPV. 


\section{Reference}

Anderson, D. M., \& Thompson, J. M. (2014, April 1). How Reliable is Production Data Analysis? Society of Petroleum Engineers. doi:10.2118/169013-MS

Barree, R. D., Ramurthy, M., Kundert, D. P., Petre, J. E., \& Mullen, M. J. (2011, January 1). Surface Area vs Conductivity Type Fracture Treatments in Shale Reservoirs. Society of Petroleum Engineers. doi:10.2118/140169-MS

Bazan, L. W., Larkin, S. D., Lattibeaudiere, M. G., \& Palisch, T. T. (2010, January 1). Improving Production in the Eagle Ford Shale with Fracture Modeling, Increased Fracture Conductivity, and Optimized Stage and Cluster Spacing Along the Horizontal Wellbore. Society of Petroleum Engineers. doi:10.2118/138425-MS

Bilgesu, H.I. and A. Yusuf, (2011) "The Impact of stress and formation properties on the outcome of fracture operations in horizontal shale wells", Paper SPE 149512 presented at the SPE Eastern Regional Meeting, Columbus, OH, 17-19 August, 2011

Chaudhary, A. S., Ehlig-Economides, C. A., \& Wattenbarger, R. A. (2011, January 1). Shale Oil Production Performance from a Stimulated Reservoir Volume. Society of Petroleum Engineers. doi:10.2118/147596-MS

Chong, K. K., Grieser, W. V., Passman, A., Tamayo, H. C., Modeland, N., \& Burke, B. E. (2010, January 1). A Completions Guide Book to Shale-Play Development: A Review of Successful Approaches toward Shale-Play Stimulation in the Last Two Decades. Society of Petroleum Engineers. doi:10.2118/133874-MS

Cipolla, C.L., N.R. Warpinski, M.J Mayerhofer and E.P Lolon, (2004) "The relationship between fracture complexity, reservoir properties, and fracture treatment design", Paper SPE 115769 
presented at the SPE annual Technical conference and exhibition, Denver, Colorado, USA, 21-24 September

CMG, Computer Modeling Group Ltd.;" Advanced Oil/Gas Reservoir Simulator" Version 2015, Imex, User's Guide.

Condon, S.M. and Dyman, T.S., 2006, 2003 Geologic Assessment of Undiscovered Conventional Oil and Gas Resources in the Upper Cretaceous Navarro and Taylor Groups, Western Gulf Province, Texas, U.S. in Chapter 2 of Petroleum Systems and Geologic Assessment of Undiscovered Oil and Gas, Navarro and Taylor Groups, Western Gulf Province, Texas: Geological Survey Digital Data Series DDS-69-H.

Craft, B., Hawkins, M. and Terry, R. (1991), Applied petroleum reservoir engineering, Old Tappan, NY (USA); Prentice Hall Inc.

Denney, D. (2012, March 1). Evaluating Production-Log Data from Horizontal Organic-Shale Wells. Society of Petroleum Engineers. doi:10.2118/0312-0077-JPT

Drillinginfo. 2008-2014. DI Desktop, http://www.hpdi.com/

Driskill, B., Suurmeyer, N., Rilling-Hall, S., Govert, A. M., \& Garbowicz, A. (2012, January 1). Reservoir Description of the Subsurface Eagle Ford Formation, Maverick Basin Area, South Texas, USA. Society of Petroleum Engineers. doi:10.2118/154528-MS

Hentz, T.F., and Ruppel, 2011, Regional Stratigraphic and Rock Characteristics of Eagle Ford Shale in Its Play Area: Maverick Basin to East Texas Basin, Search and Discovery Article \#10325, based on oral presentation at AAPG Annual Convention and Exhibition, Houston, Texas, USA, April 10-13, 2011.

IHS Energy Eagle Ford Regional Play Assessment 2015. 
IHS-Fekete Software Manual, 2016.

Mattar, L., \& Stalgorova, E. (2013, November 5). Analytical Modeling for Geomechanical Changes in Multi-Frac Completions. Society of Petroleum Engineers. doi:10.2118/167191-MS

Mayerhofer, M.J., E.P. Lolon, N.R. Warpiniski, C.L. Cipolla, D. Walser and C.M. Rightmire, (2004) "What is Stimulated reservoir volume?", Paper SPE 119890 presented at the SPE shale gas production conference, Fort Worth, Texas, USA 16-18 November 2004.

McKinney, P.D., Rushing, J.A., and Sanders, L.A. 2002. Applied Reservoir Characterization for Maximizing Reserve Growth and Profitability in Tight Gas Sands: A Paradigm Shift in Development Strategies for Low-Permeability Gas Reservoirs. Paper presented at the SPE Gas Technology Symposium, Calgary, Alberta, Canada. Copyright 2002, Society of Petroleum Engineers Inc. 00075708. DOI: 10.2118/75708-ms.

Meyer, B.R. and L.W. Bazan, (2011) “A Discrete Fracture Network Model for Hydraulically Induced Fracture: Theory, Parametric and Case Studies", Paper SPE 140514 presented at the SPE hydraulic fracturing Technology and Exhibition, Woodlands, TX, 24-26 January

Meyers \& Associate, Inc.: Meyers Fracture Simulators User's Guide, Eleventh Edition, 2014 Mullen, J. (2010, January 1). Petrophysical Characterization of the Eagle Ford Shale in South Texas. Society of Petroleum Engineers. doi:10.2118/138145-MS

Orangi, A., Nagarajan, N. R., Honarpour, M. M., \& Rosenzweig, J. J. (2011, January 1). Unconventional Shale Oil and Gas-Condensate Reservoir Production, Impact of Rock, Fluid, and Hydraulic Fractures. Society of Petroleum Engineers. doi:10.2118/140536-MS

Parra, P.A., Rubio, N., Ramirez, C., Guerra, V.A., Campos, I.R., Trejo, M.D., Olguin, J. Vargas, C.H., Valbuena, R., Soler, D.F., Weimann, M.I., Lujan, V., Bonningue, P., Reyes, P.G., Martinez, R., Munoz, R., Rodriquez, E., and Garcia, M., 2013, Unconventional Reservoir Development in Mexico: 
Lessons Learned From the Frist Exploratory Wells, Society of Petroleum Engineers, Unconventional Resources Conference- USA held in The Woodlands, Texas, USA, 10-12 April 2013, SPE 164545

Railroad Commission of Texas (http://www.rrc.state.tx.us/oil-gas/)

Rickman, R., Mullen, M. J., Petre, J. E., Grieser, W. V., \& Kundert, D. (2008, January 1). A Practical Use of Shale Petrophysics for Stimulation Design Optimization: All Shale Plays Are Not Clones of the Barnett Shale. Society of Petroleum Engineers. doi:10.2118/115258-MS

Sayers, C. M., Fisher, K., \& Walsh, J. J. (2015, August 4). Rock Physics Model of the Eagle Ford Shale. Society of Petroleum Engineers. doi:10.15530/urtec-2015-2151459

Schlumberger oil Field Taring Course, petroleum Geology material 2007)

Sondhi, N., 2011, Petrophysical Characterization of the Eagle Ford Shale. Master's Thesis, University of Oklahoma, Norman, OK. 197 pp. S

Stalgorova, E., \& Mattar, L. (2012, January 1). Practical Analytical Model to Simulate Production of Horizontal Wells with Branch Fractures. Society of Petroleum Engineers. doi:10.2118/162515-MS

Stegent, N. A (2011, July 21). Let's put Engineering back into Fracture Stimulation. Oklahoma Geological Society.

Stegent, N. A., Wagner, A. L., Mullen, J., \& Borstmayer, R. E. (2010, January 1). Engineering a Successful Fracture-Stimulation Treatment in the Eagle Ford Shale. Society of Petroleum Engineers. doi:10.2118/136183-MS

Theilen, F. (1982, January 1). Anelastic Properties of Sediments. Society of Exploration Geophysicists.

U.S. Energy Information Administration (EIA). 
Wan, J., Barnum, R. S., Digloria, D. C., Leahy-Dios, A., Missman, R., \& Hemphill, J. (2013, March 26). Factors Controlling Recovery in Liquids Rich Unconventional Systems. International Petroleum Technology Conference. doi:10.2523/17103-MS

Whitson, C.H. and Sunjerga, S. (2012). PVT in Liquid-Rich Shale Reservoirs. SPE 155499, paper presented at the 2012 SPE ATCE, San Antonio, TX, October 8-10, 2012.

Za Za Energy Company Corporation, Presentation, 2013, Investor Presentation December 2014, p. 14., http://www.zazaenergy.com/ 


\section{Appendix A: A Discrete Fracture Network Model}

The discrete fracture network (DFN) design discussed in section 2.8 uses a set of equations that satisfy continuity, mass conservation, constitutive relationship and momentum equations. This appendix lists the main equations used in DFN growth modeling including stimulated reservoir volume and proppant transport distribution. All equations below are documented in Meyers Fracture Simulators User's Guide, Eleventh Edition, 2014.

\section{Mass Conservation}

The mass conservation equations state that the injected fluid volume minus the leak-off loss and spurt loss must equal the fracture volume as shown in the equation below:

$$
\int_{0}^{t} q(\tau) d \tau-V_{l}(t)-V_{s p}(t)=V_{f}(t)
$$

The leak-off loss and spurt loss for $\mathrm{N}$ discrete fractures can be calculated using the following relationship:

$$
V_{l}(t)=\sum_{i=1}^{N} 2 \int_{0}^{t} \int_{0}^{A} v \gamma_{c} d a d \tau+\sum_{i=1}^{N} 2 \int_{0}^{A} s_{p} \gamma_{c} d a
$$

Where the fluid loss $Y\llcorner$ multiplier and the total discrete fracture area can be calculated with the following expression:

$$
\begin{gathered}
\gamma_{l}=\left(A / A_{D F N}-1\right) \Phi_{l}+1 \\
A_{D F N}=\sum_{i=1}^{N} A_{i} .
\end{gathered}
$$

The DFN geometric properties such as length, width, volume and area can be estimated based on the following equations: 


$$
\begin{aligned}
& L_{D F N}=\sum_{\zeta=x, y, z}\left\lfloor\sum_{j=1}^{N_{\zeta}} L_{\zeta}(j)\right\rfloor \\
& A_{D F N}=\sum_{\zeta=x, y, z}\left[\sum_{j=1}^{N_{\zeta}} A_{\zeta}(j)\right] \\
& V_{D F N}=\sum_{\zeta=x, y, z}\left[\sum_{j=1}^{N_{\zeta}} V_{\zeta}(j)\right] \\
& \bar{w}_{D F N}=V_{D F N} / A_{D F N}
\end{aligned}
$$

The stimulated reservoir volume is defined as:

$$
V_{S R}=\int_{A} h(\xi) d \xi=\pi \alpha b \bar{h}
$$

The major or dominant fracture half-length ( $x$ direction) is a network extension in the $y$ direction or minor axis $(b)$. The stimulated projected area is the area in the $x-y$ plane as observed in the z-direction (note: $\pi a b=\pi \lambda a^{2}$ where $\lambda$ is the ellipsoidal DFN aspect ratio).

\section{Continuity equation with flow rate Interaction}

The fracture flow rate for $\mathrm{i}^{\text {th }}$ discrete fracture is given by the following equation:

$$
q_{i}=\frac{\partial V_{f i}}{\partial t}+\frac{\partial V_{l i}}{\partial t}+\sum_{j=1}^{N} \frac{\partial V_{j i}}{\partial t}
$$

\section{DFN Momentum equations}

The fluid loss in terms of Darcy friction factor based on the cross-sectional average velocity can be calculated as follows:

$$
\frac{d p}{d \zeta}=-\frac{f}{2} \frac{\rho\langle\bar{v}\rangle^{2}}{d_{h}}
$$


The proppant distribution allocation is defined as:

$$
\chi_{p}=M_{f} / M_{D F N}=M_{f} / M_{t}
$$

Where $M_{f}$ is the mass of proppant the primary fracture and $M_{t}$ is the total proppant mass injected (or mass in DFN system).

The proppant distribution allocation for a uniform distribution is:

$$
\chi_{p}=M_{f} / M_{D F N} \cong V_{f} / V_{D F N}
$$

DFN system efficiency $\left(\eta_{D F N}\right)$ is a representative value that can be used throughout the fracture network for proppant transport and proppant concentration in the fracture network and dominant fracture.

The proppant distribution allocation for a uniform distribution is:

$$
\chi_{p}=M_{f} / M_{D F N} \cong{ }^{V_{f}} / V_{D F N}
$$

The uniform proppant distribution efficiency is calculated with the following equation:

$$
\eta_{D F N}=V_{D F N} / \int_{0}^{t} q(\tau) d \tau
$$

\section{Dominant Fracture Proppant Distribution}

The Dominant Fracture Proppant Distribution option assumes that all the proppant remains in the primary fracture and no proppant enters the secondary DFN.

The proppant distribution allocation for all the proppant in the primary or dominant fracture is defined by:

$$
\chi_{p}=M_{f} / M_{D F N}={ }^{M_{f}} / M_{t}=1
$$


The dominant fracture efficiency, $\eta$, for all proppant remaining in the primary fracture is given as:

$$
\eta=V_{f} / \int_{0}^{t} q(\tau) d \tau=\eta_{D F N} \cdot V_{f} / V_{D F N}
$$

\section{User Specified Proppant Distribution}

The User Specified Proppant Distribution option allows the user to specify the minimum proppant allocation that remains in the primary fracture. The minimum allocation will be set to the primary fracture to DFN volume ratio as:

$$
\chi_{p \mid \min } \geq V_{f} / V_{D F N}
$$

The proppant distribution allocation is defined with the following:

$$
\chi_{p}=M_{f} / M_{D F N}=M_{f} / M_{t}
$$

The mass in the secondary fractures, $M_{s}$, is given as:

$$
M_{s}=M_{t}-M_{f}=M_{t}\left(1-\chi_{p}\right)
$$

The average slurry concentration in the primary fracture and secondary network system is defined with:

$$
\begin{aligned}
& \bar{c}_{f}=M_{f} / V_{f}=\chi_{p} M_{t} / V_{f} \\
& \text { And } \\
& \bar{c}_{s}=M_{s} / V_{s}=\left(1-\chi_{p}\right) M_{t} /\left(V_{D F N}-V_{f}\right)
\end{aligned}
$$




\section{Appendix B: Analytical Method}

Equations presented are based on the assumption of a constant flowing pressure at the well. This is a reasonable simplification for tight gas and shale production, in which wells are typically produced under high drawdown. [IHS-Fekete Software Manual, 2016]

Based on the straight-line behavior of the square root time plot, the simplest form of the linear flow equation is:

$$
\frac{1}{q}=m \sqrt{t}+b^{\prime}
$$

The intercept captures a number of near well effects such as skin and finite fracture conductivity, and the slope is given by:

For oil:

$$
m=\frac{31.3 B}{h x_{f} \sqrt{k}} \sqrt{\frac{\mu}{\phi C_{t}}} * \frac{1}{p_{i}-p_{w f}}
$$

For gas:

$$
m=\frac{315.4 T}{h \sqrt{\left(\phi \mu_{g} C_{t}\right)_{i}}} * \frac{1}{p_{p i}-p_{p w f}} * \frac{1}{x_{f} \sqrt{k}}
$$

From the slope fracture half-length and permeability are determined as a single product. To determine either explicitly, the other parameter must be known.

The intercept of the line determined the skin and Fracture conductivity:

For oil: $\quad s^{\prime}=\frac{b^{\prime}\left(p_{i}-p_{w f}\right) k\left(2 x_{f}\right)}{141.2 B \mu} \quad F_{C D}^{\prime}=\frac{141.2 B \mu}{b^{\prime}\left(p_{i}-p_{w f}\right) k h n_{f}} *\left(1+\frac{h}{x_{f}}\left(\ln \left(\frac{h}{2 r_{w}}\right)-\frac{\pi}{2}\right)\right)$

For gas: $\quad s^{\prime}=\frac{b^{\prime}\left(p_{p i}-p_{p w f}\right) k\left(2 x_{f}\right)}{1.417 * 10^{6} T} \quad F_{C D}^{\prime}=\frac{1.417 * 10^{6} T}{b^{\prime}\left(p_{p i}-p_{p w f}\right) k h n_{f}} *\left(1+\frac{h}{x_{f}}\left(\ln \left(\frac{h}{2 r_{w}}\right)-\frac{\pi}{2}\right)\right)$ 
The distance of investigation can be obtained from the following equation (With Reservoir geometry)

$$
\frac{Y_{e}}{2}=0.159 \sqrt{\frac{k t_{e l f}}{\left(\phi \mu c_{t}\right)_{i}}}
$$

The permeability is tied into the $\left(x_{f} \sqrt{ } / k\right)$ term and reservoir width is related to the drainage area $(A)$; however, both of these are related to fracture half-length $\left(X_{f}\right)$. Using the definition of drainage area $\left(A=2{ }^{*} X_{f}{ }^{*} Y_{e}\right)$.

$\mathrm{X}_{\mathrm{f}} \sqrt{ } \mathrm{k}$ can be determined by using following equations:

For oil:

$$
x_{f} \sqrt{k}=\frac{31.3 B}{m h} x \frac{1}{p_{i}-p_{w f}} x \sqrt{\frac{\mu}{\varphi c_{t}}}
$$

For gas:

$$
x_{f} \sqrt{k}=f_{c p} \frac{315.4 T}{m h\left(p_{p i}-p_{p w f}\right)} \sqrt{\frac{1}{\left(\phi \mu c_{t}\right)_{i}}}
$$

The duration of linear flow (and hence the beginning of boundary-dominated flow) is determined using the following equation:

For oil:

For gas:

$$
t_{e l f}=\left[\frac{A h\left(\varphi c_{t}\right) m\left(p_{i}-p_{w f}\right)}{19.9 B}\right]^{2}
$$

$$
t_{e l f}=\left[\frac{A h\left(\varphi C_{t}\right)_{i} m\left(p_{p i}-p_{p w f}\right)}{200.6 T}\right]^{2}
$$




\section{Boundary-Dominated Flow}

Given the geometry of the reservoir considered, linear flow is followed directly by boundarydominated flow. In the interest of keeping the method simple and practical, the hyperbolic decline method is used. Hyperbolic decline is defined in the following equation.

$$
q=\frac{q_{i}}{\left[1+b a_{i} t\right]^{1 / b}}
$$

Since the hyperbolic decline forecast starts at the end of linear flow, the flow rate, the decline rate, and time will be with respect to time at the end of linear flow $\left(t_{\text {eff }}\right)$. The decline exponent (b) is selected to be between 0 and 0.5 .

$$
q=\frac{q_{e l f}}{\left[1+b a_{e l f}\left(t-t_{e l f}\right)\right]^{1 / b}}
$$

